\title{
Multivalent carbohydrate inhibitors against bacterial toxins
}

Diksha Bansi Haksar

2021 
Cover design by T. Heise \& D. Haksar

Still frames taken and modified from "Glycoscience: illuminating the secret world of your glycans", produced by Sensu on behalf of Utrecht University.

https://www.youtube.com/watch?v=sT1qghJZdW8

(C) 2021 D. Haksar

All rights reserved. No part of this publication may be reproduced or transmitted in any form or by any means without written permission form the author.

DOI: https://doi.org/10.33540/655 


\section{Multivalent carbohydrate inhibitors against bacterial toxins}

Multivalente koolhydraat inhibitoren van bacteriële toxines

(met een samenvatting in het Nederlands)

\section{Proefschrift}

ter verkrijging van de graad van doctor aan de Universiteit Utrecht op gezag van de

rector magnificus, prof.dr. H.R.B.M. Kummeling, ingevolge het besluit van het college voor promoties in het openbaar te verdedigen op

maandag 22 november 2021 des middags te 12.15 uur

door

\section{Diksha Bansi Haksar}

geboren op 15 maart 1987

te Jammu, India 
Promotor:

Prof. dr. R.J. Pieters 
Table of contents

Chapter 1

Introduction \& thesis outline

Chapter 2

Strong inhibition of cholera toxin B subunit by affordable, polymer-based multivalent inhibitors

Chapter 3

A hybrid polymer to target blood group dependence of cholera toxin

Chapter 4

Fighting Shigella by blocking its disease-causing toxin

Chapter 5

Summary \& Perspectives

\section{Appendices}

Nederlandse Samenvatting

List of Publications

Curriculum Vitae

Acknowledgements 


\section{List of abbreviations}

\begin{tabular}{|c|c|}
\hline$\mu \mathrm{M}$ & micromolar \\
\hline $4 \AA \mathrm{MS}$ & 4 angstrom molecular sieves \\
\hline$\AA$ & angstrom \\
\hline Ac & acetyl \\
\hline $\mathrm{ADP}$ & adenosine diphosphate \\
\hline AOS & alginate oligosaccharide \\
\hline Asn & asparagine \\
\hline AUC & analytical ultra centrifugation \\
\hline BGAs & histo-blood group antigens \\
\hline $\mathrm{Bn}$ & benzyl \\
\hline BSA & bovine serum albumin \\
\hline $\mathrm{Bz}$ & benzoyl \\
\hline cAMP & 3',5'-cyclic adenosine monophosphate \\
\hline cCT & classical cholera toxin \\
\hline Cer & ceramide \\
\hline $\cos$ & chitosan oligosaccharide \\
\hline CT & cholera toxin \\
\hline CTB & cholera toxin b subunit \\
\hline CuAAC & copper catalyzed alkyne azide cycloaddition \\
\hline $\mathrm{Da}$ & dalton \\
\hline DCM & dichloromethane \\
\hline DLS & dynamic light scattering \\
\hline DMAP & 2,6-di-tert-butyl-4-methylpyridine \\
\hline DMF & dimethylformamide \\
\hline EDC & 1-ethyl-3-(3-dimethylaminopropyl)carbodiimide \\
\hline EDTA & ethylene diamine tetra-acetic acid \\
\hline EHEC & enterohemorrhagic E. coli \\
\hline ELISA & enzyme-linked immunosorbent assay \\
\hline ELLA & enzyme-linked lectin assay \\
\hline ESI & electrospray ionization \\
\hline ET CT & El Tor cholera toxin \\
\hline Et3N & triethylamine \\
\hline Et3SiH & triethylsilane \\
\hline FOS & fructo oligosaccharide \\
\hline fuc & fucose \\
\hline Gal & galactose \\
\hline GalNAc & $\mathrm{N}$-acetylgalactosamine \\
\hline Gb3 & globotriaosylceramide \\
\hline Glc & glucose \\
\hline GlcNAc & $\mathrm{N}$-acetylglucosamine \\
\hline GM1 & monosialotetrahexosylganglioside \\
\hline GM1os & GM1 oligosaccharide \\
\hline GOS & galacto oligosaccharide \\
\hline $\mathrm{H}_{2} \mathrm{O}_{2}$ & hydrogen peroxide \\
\hline hPG & hyperbranched polyglycerol \\
\hline HPLC & high performance liquid chromatography \\
\hline HRMS & high resolution mass spectrometry \\
\hline HRP & horseradish peroxidase \\
\hline HUS & hemolytic uremic syndrome \\
\hline $\mathrm{IC}_{50}$ & half maximal inhibitory concentration \\
\hline IR & infrared \\
\hline ITC & isothermal titration calorimetry \\
\hline $\mathrm{K}_{\mathrm{d}}$ & dissociation constant \\
\hline $\mathrm{kDa}$ & kilodalton \\
\hline Lac & lactose \\
\hline LCST & lower critical solution temperature \\
\hline
\end{tabular}


Lex

LeY

LT1-B

MALDI-TOF

$\mathrm{MeOH}$

$\mathrm{MIC}_{50}$

$\mathrm{mM}$

$\mathrm{Mn}$

MNPG

MS

MTT

Mw

Nap

Neu5Ac

nM

NMR

PAA-fucose

PBS

PDB

PEG

$\mathrm{Ph}$

pM

PNAM

RAFT

SDS-PAGE

SEM

Ser

SPR

STEC

Stx

Stx1B

TEER

TFA

$\mathrm{TfOH}$

THF

Thr

TLC

TMSOTf

USFDA

WHO
Lewis X glycan

Lewis $Y$ antigen

heat-labile enterotoxin

matrix-assisted laser desorption/ionization time of flight

methanol

minimum inhibitory concentration required to

inhibit the growth of $50 \%$ of organisms

millimolar

number average molecular weight

meta-nitrophenyl $\alpha$-galactoside

mass spectrometry

3-(4,5-dimethylthiazol-2-yl)-2,5-

diphenyltetrazolium bromide

molecular weight

2-naphthyl

$\mathrm{N}$-acetylneuraminic acid

nanomolar

nuclear magnetic resonance

polyacrylamide-conjugated L- fucose

phosphate buffered saline

protein data bank

polyethylene glycol

phenyl

picomolar

poly(n-acryloylmorpholine)

reversible addition-fragmentation chain transfer sodium dodecyl sulfate - polyacrylamide gel

electrophoresis

standard error of the mean

serine

surface plasmon resonance

shiga toxin producing $E$. coli

shiga toxin

shiga toxin B subunit

transepithelial electrical resistance

trifluoroacetic acid

triflic acid

tetrahydrofuran

threonine

thin layer chromatography

trimethylsilyl trifluoromethanesulfonate

United States Food and Drug Administration

World Health Organization 

Chapter 1

\section{Introduction \& thesis outline}





\subsection{Carbohydrate- Protein interactions}

Carbohydrates are ubiquitous by way of the "glycocalyx" which is a 10-100 nm layer of complex carbohydrates or glycans that coat all cells. ${ }^{1}$ Carbohydrates are an important class of biomacromolecules together with DNA, proteins and lipids. However, glycans are not encoded directly in the genome and are the result of post-translational modifications. Glycans have multiple crucial roles in cellular responses to environmental stimuli as well as cellular growth and differentiation; specific changes in glycan composition are directly linked to many diseases. Glycosylation of protein molecules is one of the most important post-translational modifications, mainly $\mathrm{N}$ - and $\mathrm{O}$ - linked glycosylation. N-linked glycosylation refers to the modification of proteins due to the attachment of $\mathrm{N}$-acetylglucosamine (GlcNAc) to the nitrogen atom of an asparagine (Asn) side chain by a $\beta-1 \mathrm{~N}$ linkage. O-glycosylation refers to glycosylation that can occur on amino acids with functional hydroxyl groups, which are most often serine (Ser) and threonine (Thr). In humans, the most common sugars linked to Ser or Thr are GlcNAc and Nacetylgalactosamine (GalNAc). ${ }^{2}$

Proteins that bind to carbohydrate moieties are broadly termed "lectins". Lectins are noncovalent glycan-binding proteins mediating cellular interactions. These can be further classified into R-type lectins, L-type lectins, C-type lectins, P-type lectins, C-type lectins, I-type lectins, galectins, microbial lectins (toxins, adhesins and hemagglutinins). ${ }^{3}$ Carbohydrate-protein interactions are the intermolecular and intramolecular interactions between protein and carbohydrate moieties. ${ }^{4}$ These interactions are central to a number of important biological processes including physiological as well as pathological functions in the cell. ${ }^{5}$ Carbohydrateprotein interactions play a key role in the binding of bacteria, viruses and toxins to the cell surfaces. This interaction between the carbohydrate and the protein is usually the first step in a series of events and interactions leading to a complex signalling cascade.

\subsection{Carbohydrate-derived drugs}

Despite the crucial role carbohydrates play in a number of biological processes, only a handful of carbohydrate-derived drugs are available as commercial therapeutic interventions. These include but are not limited to antidiabetics which are $\alpha$-glucosidase inhibitors: miglitol, voglibose and acarbose; anticoagulants: heparins and fondaparinux; inhibitors of viral neuraminidases: oseltamivir and zanamivir; anti-epileptic: topiramate; treatment for Gaucher's disease: miglustat (Figure 1). 1 


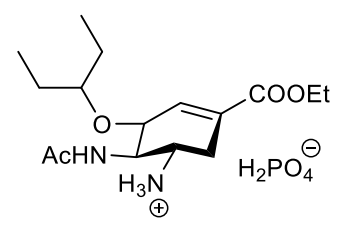

Oseltamivir phosphate

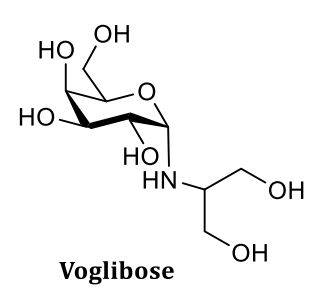

Voglibose

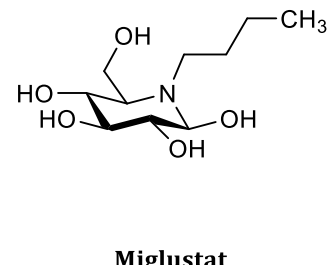

Miglustat

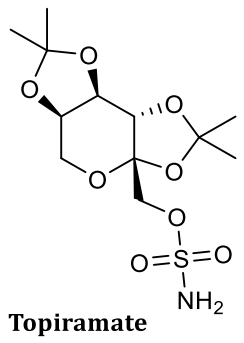

Topiramate

Figure 1. Carbohydrate-derived drugs.

Many pathophysiologically important carbohydrate-protein interactions have yet to be exploited as a source of new drug targets. Carbohydrates are inherently polar that make them poor candidates for drug development for oral use owing to their poor pharmacokinetic profile. Further, parenterally administered carbohydrates are excreted quickly by the kidneys. ${ }^{6}$ Thus, there is ample scope to explore carbohydrate-protein interactions as novel drug targets.

\subsection{Multivalency in Carbohydrate- Protein Recognition}

An interaction is termed "multivalent" when it occurs between an $m$-valent receptor and an $n$ valent ligand (wherein $m, n>1$ ). ${ }^{7}$ Multivalent interactions are employesd in nature for biologically relevant events, notably the binding of multiple hemagglutinin proteins on the surface of an influenza virus to sialic acids on the host cells that leads to its adhesion. Since, carbohydrates bind weakly to their complementary proteins, multivalency as a design principle can be beneficial in converting inhibitors with low affinity to ones with high avidity relative to a monovalent candidate. ${ }^{8}$ The current therapeutic approach in medicine is to employ monovalent drugs.

Chelation is the process where the protein (aggregate) allows simultaneous binding of more than one (sub)ligand of a multivalent system to more than one binding site of the protein target, the binding of the second (sub)ligand should be enhanced, since translational and rotational entropic penalties were already paid by the first binding event and need to only be paid once (Fig. 2a). Chelation can also occur by two non-identical ligands to two non-identical binding sites. Some of the largest multivalency effects observed are attributed to chelation, especially for the inhibition of $\mathrm{AB}_{5}$ toxins. Enhancements as high as $10^{3}-10^{6}$ have been observed for both carbohydrate-based systems and non-carbohydrate systems.

Another type of mechanism that must be operative in cases where the tether between the carbohydrate (sub)ligands is too short to allow chelation or where the protein contains only a 
single binding site, but where multivalency enhancements are observed nonetheless. One such mechanism has been named statistical rebinding and the effects have been called proximity/statistical effects. The effect is caused by the slower off-rate of the multivalent carbohydrate in comparison with a monovalent ligand, due to the close proximity of additional (sub)ligands that can take the place of the first after it releases, resulting in a net increased affinity (Fig 2b).

The design of a multivalent structure is based on a wide range of parameters. The valency can vary from two to higher numbers. Another factor is the geometrical distribution of the ligands, it can be a linear, a circular or a multibranched structure. The results obtained are analyzed to rationalize a possible mechanism behind the recognition process. Even though good results have been obtained, predicting the effect of using a multivalent system still remains a challenge. ${ }^{9}$

By using polymers that display multiple kinds of ligands as side-chains, multivalency can convert a surface having one set of properties into one with different properties. ${ }^{8}$

a)

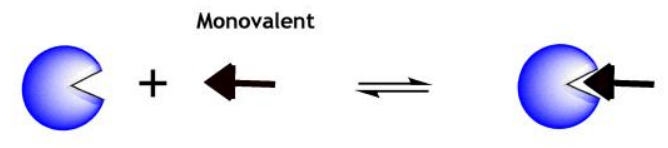

b)

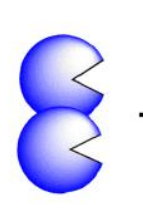

$$
\text { Divalent }
$$
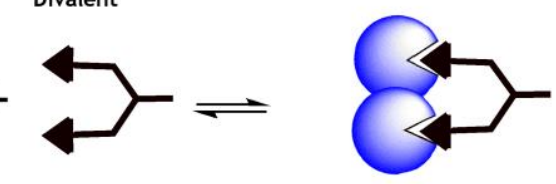

c)

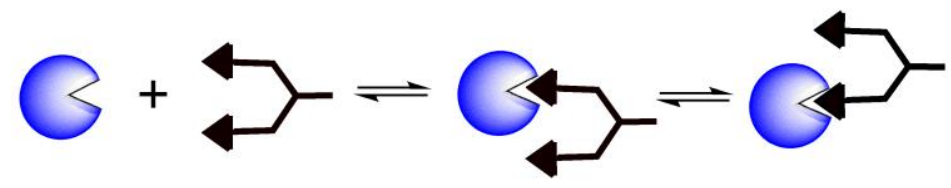

Figure 2. a) monovalent binding b) a divalent ligand binding via a chelation mechanism, c) a divalent ligand binding via a statistical rebinding mechanism. ${ }^{9}$

\subsection{Cholera toxin}

Cholera is caused by the cholera toxin (CT) which is an $\mathrm{AB}_{5}$ toxin secreted by the Vibrio cholera bacterium. The core of the toxin consists of the A subunit which is responsible for the toxicity, surrounded by the pentameric B subunit. The B subunit (CTB) enables the attachment of the toxin to GM1 ganglioside molecules on the intestinal cell surface which leads to endocytosis where the 
A subunit catalyses ADP ribosylation of G-proteins leading to increased adenylate cyclase activity. ${ }^{10}$

a)

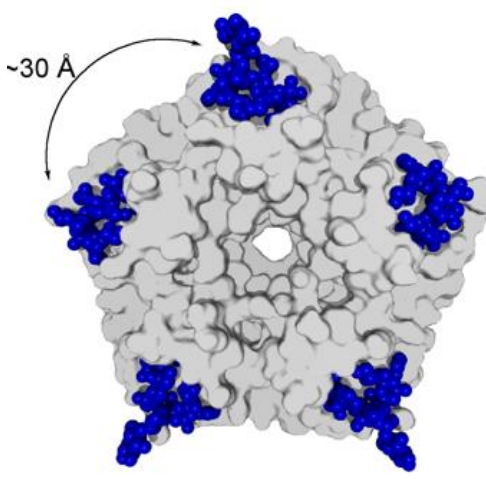

c)
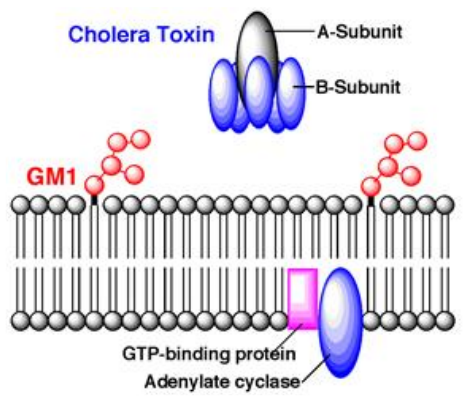

b)

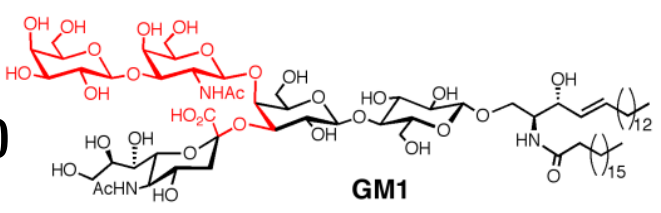

Figure 3. a) X-ray structure of the cholera toxin $B$-subunit bound to GM1os ${ }^{11}$ b) GM1 ganglioside c) Schematic of CT intoxication.

This leads to increased intracellular cAMP which results in a chloride outflow leading to water secretion and diarrhea. ${ }^{12}$

Another closely related $A_{5}$ toxin is heat-labile enterotoxin (LT1-B) that shares $80 \%$ sequence homology with CTB and causes traveler's diarrhea. ${ }^{13}$ Millions of people are affected by cholera every year and it is endemic to places with poor sanitation and limited access to potable water. Cholera is usually treated using oral rehydration therapy and concomitant antibiotic use. Antibiotics are increasingly facing the threat of resistance worldwide and currently no prophylactic for cholera is available. Therefore, preventing the entry of the toxin into the cell by blocking its attachment to the GM1 ganglioside is thought to be a good target for development of prophylactic drugs. ${ }^{14}$ The high-affinity binding interaction of GM1-CTB $\left(K_{d}=43 \mathrm{nM}\right)$ has been demonstrated using Isothermal titration calorimetry (ITC). ${ }^{15}$ 


\subsubsection{Mono- and bi-valent inhibitors of CTB}

One of the earliest inhibitors of CTB is a GM1 mimic that was designed using molecular modelling wherein the 3,4-disubstituted galactose unit, was substituted with a conformationally locked dicarboxy cyclohexanediol (Figure 4a). ${ }^{16}$ A second generation of GM1 mimics was synthesized wherein the sialic acid moiety was replaced by simple hydroxy acids (Figure $4 \mathbf{b}$ ). Amongst the various molecules tested the (R)-lactic acid derivative showed the highest affinity with a $K_{d}=190$ $\mu \mathrm{M} .{ }^{17}$

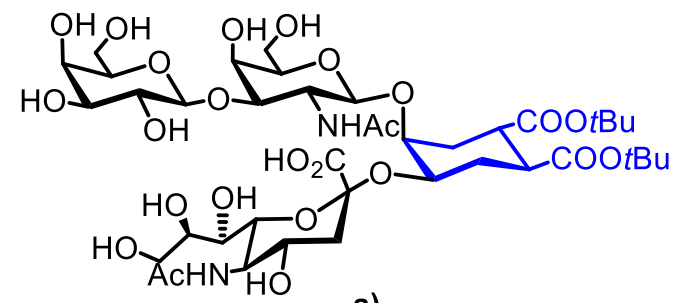

a)

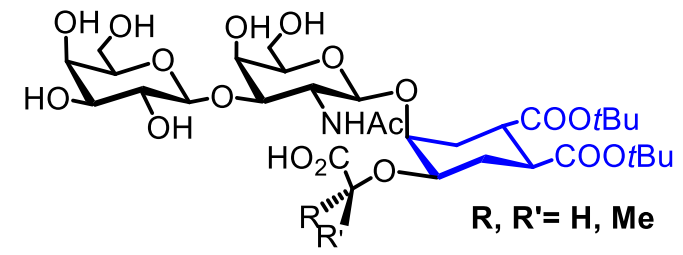

b)

Figure 4. a) First generation GM1 mimic with conformationally locked dicarboxy cyclohexanediol (highlighted in blue) b) Second generation GM1 mimic

In our group, the second generation mimic was used to synthesize multivalent compounds while using simple dendrimers based on the 3,5-di-(2-aminoethoxy)-benzoic acid branching unit as scaffolds. A clear enhancement in potency was observed and the tetravalent compound in comparison to lactose was almost 19000 -fold more active. ${ }^{18}$ The second generation GM1 mimic was further conjugated to a calixarene diacid to yield a divalent compound that demonstrated a slightly higher activity $\left(\mathrm{IC}_{50}=48 \mathrm{nM}\right)$ in comparison to $\mathrm{GM} 1 \mathrm{os}\left(\mathrm{IC}_{50}=219 \mathrm{nM}\right)$ in a fluorescence assay . ${ }^{19}$

A structure-based exploration of the GM1 binding sites of the Escherichia coli heat-labile enterotoxin (LT) and cholera toxin led to the discovery of meta-nitrophenyl $\alpha$-galactoside (MNPG) (Figure 5a). With an IC $\mathrm{C}_{50}$ of $0.6 \mathrm{mM}$ in the LT ELISA and $0.72 \mathrm{mM}$ in the CT assay, it was 100 times more potent than free galactose. ${ }^{20}$ After this discovery, a number of MNPG-based monovalent compounds were synthesized by Fan and co-workers, most of which were poorly soluble. Out of the total 15 synthesized compounds, two morpholine-based compounds showed better solubility, so the $K_{d}$ of $12 \mu \mathrm{M}$ could be determined in the ITC assay using LT1-B. The potency gain of MNPG over galactose was explained using X-ray crystallography. Within the binding site, 
a new hydrogen bond is formed with the nitro group liberating a conserved water molecule, in addition to increasing the surface of the ligand that can interact with the protein (Figure $\mathbf{5 b}$ ). ${ }^{21}$

A number of 3,5-substituted phenylgalactosides were synthesised by Hol and co-workers which were only slightly better than the parent MNPG. ${ }^{22}$ MNPG-based bivalent ligands with spacers that were too short to bridge the binding sites were then synthesised by Fan and co-workers with $\mathrm{IC}_{50}$ 's that showed 10-100 fold improved potency, presumably due to additional interactions with the spacer and steric blocking of non-occupied binding sites by the appended tail. ${ }^{23}$ In an attempt to overcome the solubility issues of the previously synthesised compounds, guanidine-bridged PEG's were used in a pentacyclen core to synthesize a multivalent molecule $\left(\mathrm{IC}_{50}=6 \mathrm{nM}\right)$, the conjugate was not stable, and the result of a long and expensive synthesis. ${ }^{24}$

a)

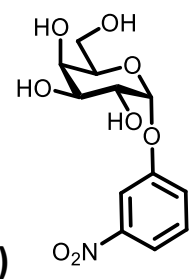

b)

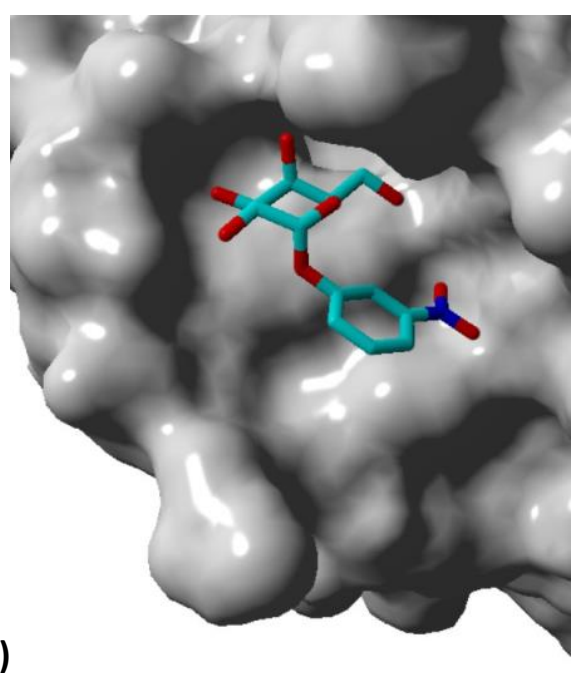

Figure 5. a) Structure of MNPG b) MNPG bound to CTB5; MNPG is in blue (PDB: 1EEI). ${ }^{25}$

A series of bivalent 1,2,3-triazole linked galactopyranosides as potential inhibitors of cholera toxin (CT) were synthesized by Leaver et al. The design comprised of a piperazine core, a polyethylene glycol (PEG) linker and pendant galactotriazole units. The inhibitory activity of the bivalent series was examined and the series showed low inhibitory activity (millimolar $\mathrm{IC}_{50}$ 's). Conversely, the monomeric galactotriazole analogues were strong inhibitors of cholera toxin $\left(\mathrm{IC}_{50}=71-75 \mu \mathrm{M}\right){ }^{26}$ These results were surprising and it was suggested that the triazole could be used as an isosteric substitute for MNPG in the monovalent compounds. The authors hypothesized that the PEG chains could be coiling around the sugar groups in solution thereby preventing the desired extended conformation in the inhibition assay explaining the low potency of the divalent compounds. 


\subsubsection{Multivalent inhibitors of CTB}

A pentavalent inhibitor was first explored by Fan et al. for the inhibition of LTB where a pentacyclen core was used as the scaffold on which amidated galactose was conjugated by long flexible linkers. ${ }^{27}$ Significant potency gains over galactose were achieved $\left(\mathrm{IC}_{50}=0.56 \mu \mathrm{M}\right)$ and this was followed up by crystallographic studies of their compounds inhibited by forming $1: 1$ or 1:2 complexes with the toxin. ${ }^{28,29}$

Pukin et al. synthesized GM1os-based multivalent inhibitors by using "click" chemistry on dendritic scaffolds (Figure 6). Between the tested mono-, di- tetra- and octavalent compounds, a clear enhancement in potency was observed based on the valency. The octavalent version revealed the strongest multivalent inhibitor to CTB $\left(\mathrm{IC}_{50}=50 \mathrm{pM}\right)$, with 380,000 -fold stronger inhibition. ${ }^{30}$ Further studies with Analytical Ultra Centrifugation (AUC) and dynamic light scattering (DLS) were used to demonstrate that the multivalent inhibitors induced toxin aggregation. The aggregation was attributed to the valency mismatch of the ligand and the toxin. 31

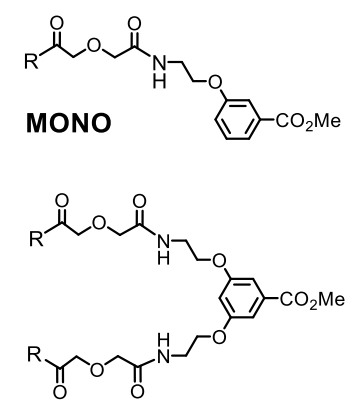

Di

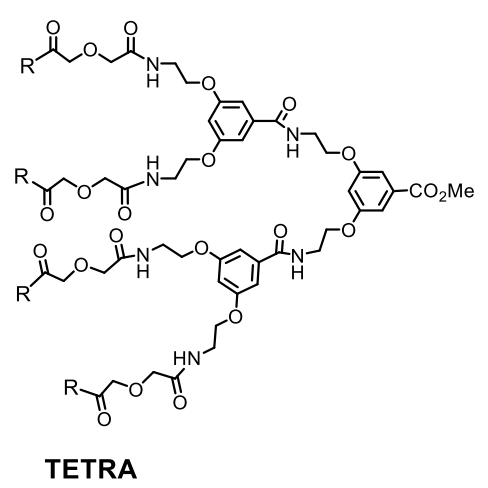

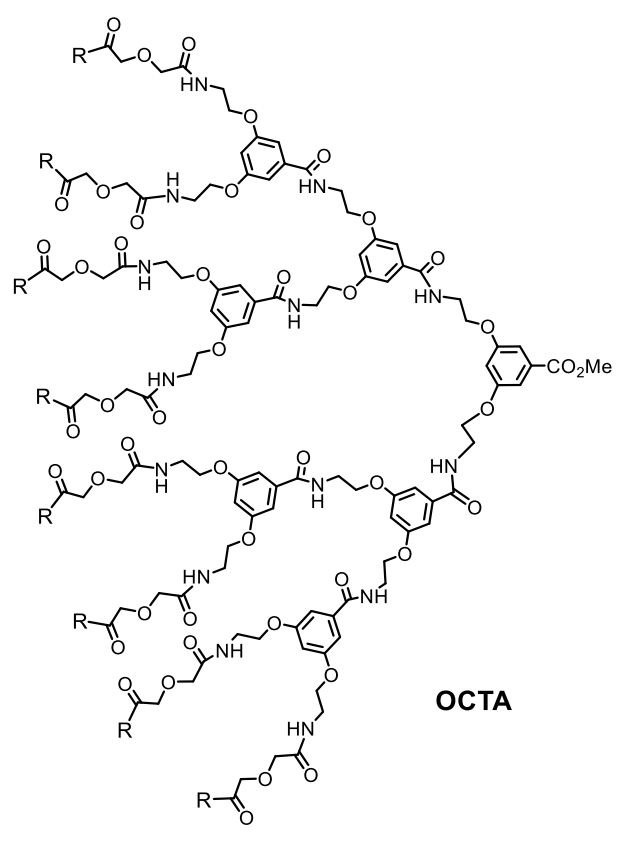

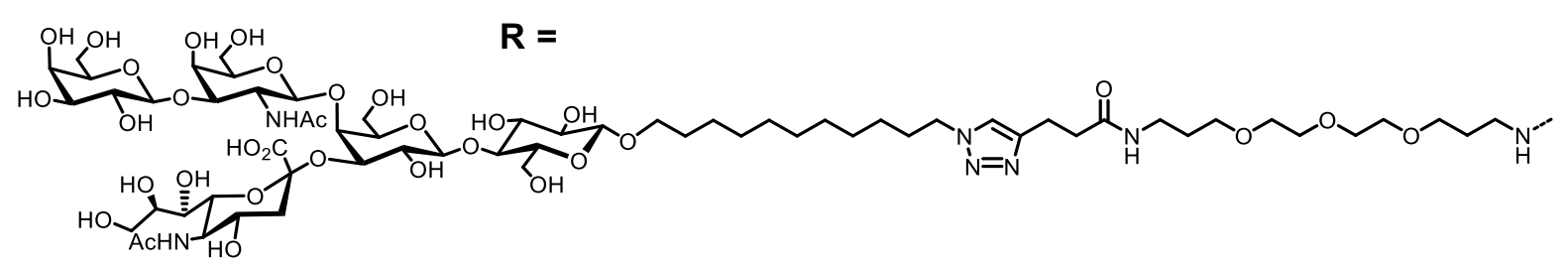

Figure 6 Mono-, di- , tetra- and octavalent compounds by Pukin et al. 
The first GM1os-based pentavalent inhibitor was synthesized using a calix[5] arene scaffold and was significantly potent with an $\mathrm{IC}_{50}=450 \mathrm{pM}$ (Figure 7a). ${ }^{32}$ GM1 was also conjugated to a corannulene unit and afforded inhibition in the nanomolar range $\left(\mathrm{IC}_{50}=5 \mathrm{nM}\right.$ ) (Figure 7b). ${ }^{33}$

a)

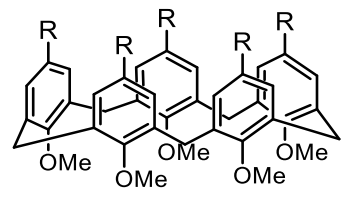<smiles>[R]O[R]=O</smiles>

b)<smiles></smiles><smiles>[R]OCCCCCCCCCCn1cc(COCCOCCOCCn2cc(COCCOCCOCCn3cc(CCC)nn3)nn2)nn1</smiles>

Figure 7 a) GM1os conjugated to a calix[5]arene scaffold, b) GM1os conjugated to a corannulene scaffold

In our group, $\mathrm{Fu}$ et al. have synthesised and evaluated a pentavalent inhibitor analogous to the tetravalent compound based on the same scaffold (Figure 8). ${ }^{11}$ Surprisingly, the pentavalent inhibitor was slightly less potent $\left(\mathrm{IC}_{50}=260 \mathrm{pM}\right)$ than the tetravalent compound $\left(\mathrm{IC}_{50}=160 \mathrm{pM}\right)$ and the toxin aggregation mechanism was supported using AUC technique. These compounds were further tested for the first time using intestinal organoids where the aforementioned results were further substantiated. ${ }^{34}$

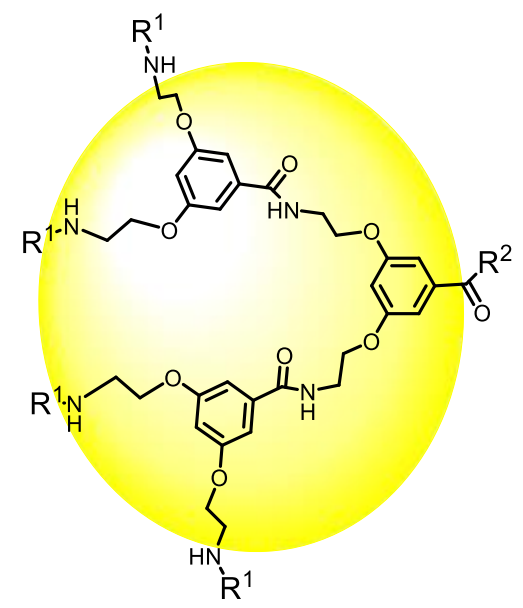

Pentavalent scaffold

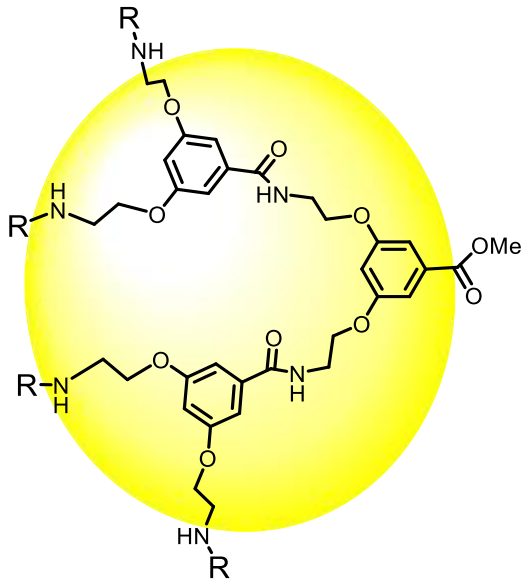

Tetravalent scaffold 

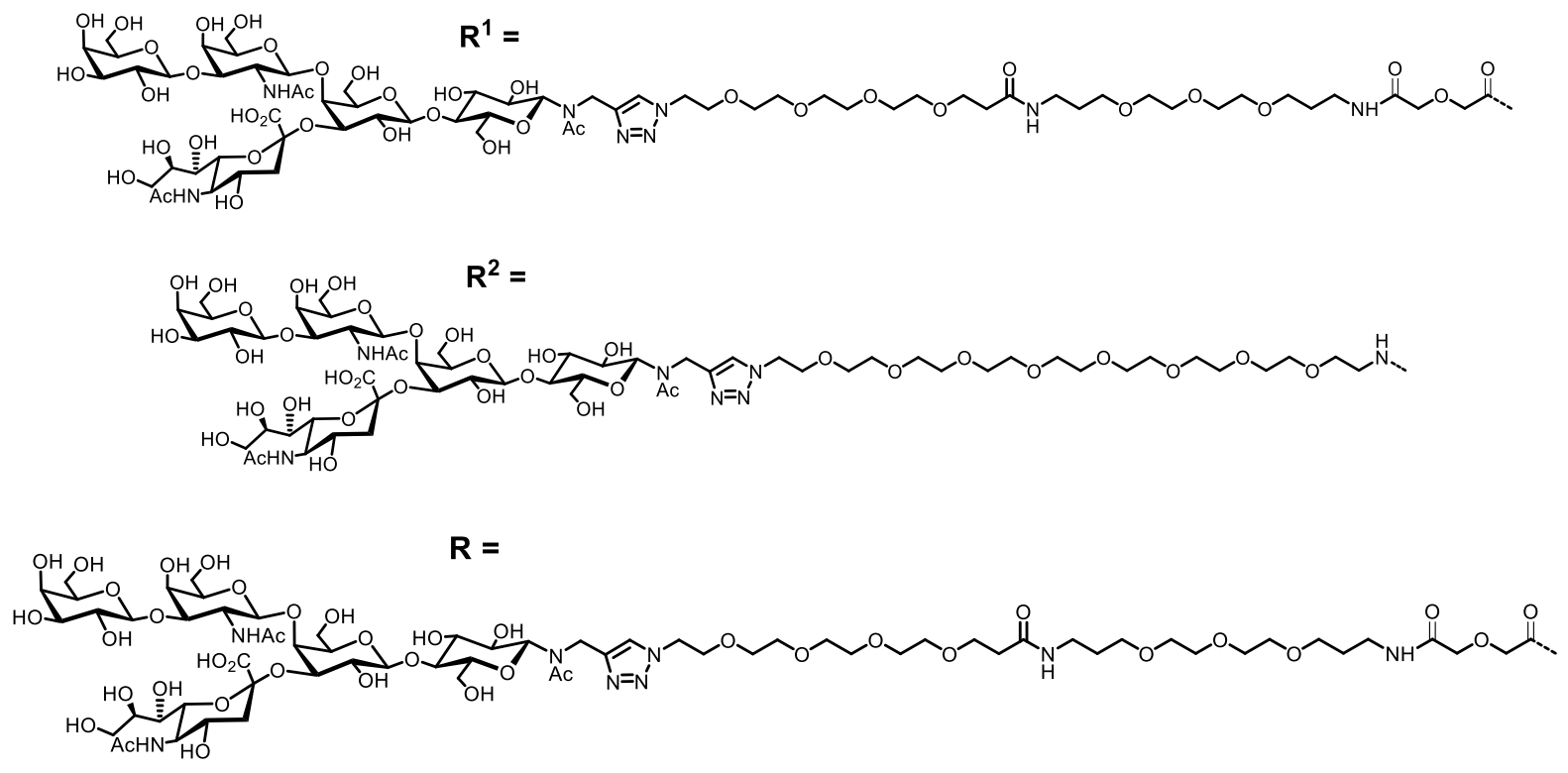

Figure 8. Structure of the Pentavalent inhibitor

Turnbull and co-workers came up with the idea of using CTB itself (albeit a non-binding mutant) in order to conjugate it to a GM1 ligand which was called a neoglycoprotein inhibitor (Figure 9). The pentavalent molecule as expected was extremely potent $\left(\mathrm{IC}_{50}=104 \mathrm{pM}\right)$ and formed a protein heterodimer with CTB in a 1:1 ratio (as observed with Dynamic light scattering and Analytical Ultracentrifugation). ${ }^{35}$
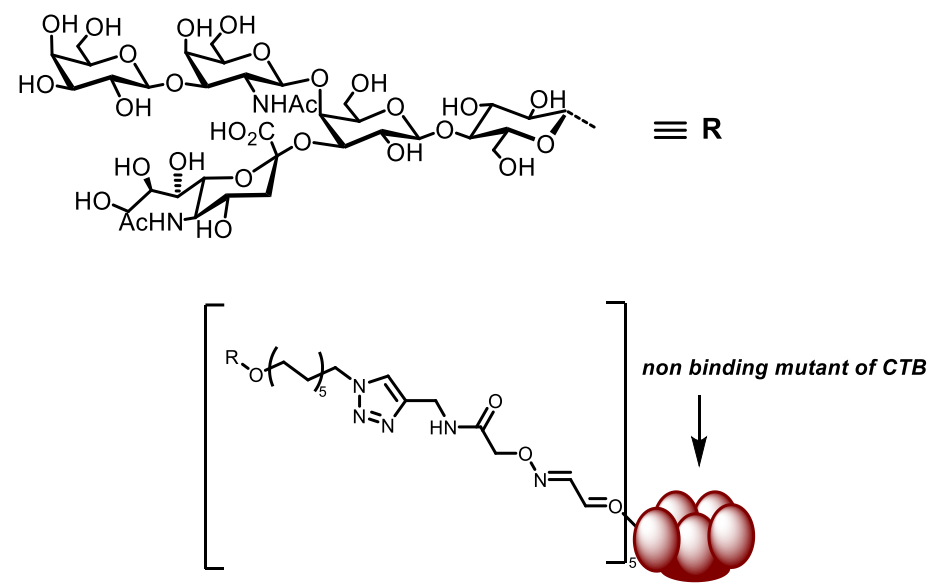

Figure 9. Neoglycoprotein inhibitor based on a non-binding mutant of CTB.13,35

\subsubsection{Polymer-based inhibitors of CTB}

Polizzotti and Kiick synthesized a series of galactose-functionalized polymers with a poly(Lglutamic acid) backbone, wherein the density and linker length of the carbohydrate moiety was varied. A comparison was made between two sets of glycopolymers, derivatized with either 
$\beta$-D-galactosylamine or $\mathrm{N}$-( $\varepsilon$-aminocaproyl)- $\beta$-D-galactosylamine. The polymers were evaluated in an enzyme-linked assay alongwith a fluorescence titration assay. They observed, that an increase in the sugar density led to a decrease in toxin inhibition for both sets of glycopolymers. Thus, an improvement in inhibition with decreasing sugar density was due to the improvements in the accessibility of the sugar moieties in the binding event. Additionally, glycopolymers derivatized with $\mathrm{N}$-( $\varepsilon$-aminocaproyl)- $\beta$-D-galactosylamine $\left(\mathrm{IC}_{50}=50 \mu \mathrm{M}\right.$ for the most potent molecule) showed greater potency relative to the ones with $\beta$-D-galactosylamine $\left(\mathrm{IC}_{50}=158 \mu \mathrm{M}\right.$ for the most potent molecule). These results pointed towards the effect of the linker length in effective inhibition, possibly due to the improvements in the accessibility of the terminal galactopyranoside provided by the 6-aminohexanoic acid linker arm.(Figure 10). ${ }^{36}$

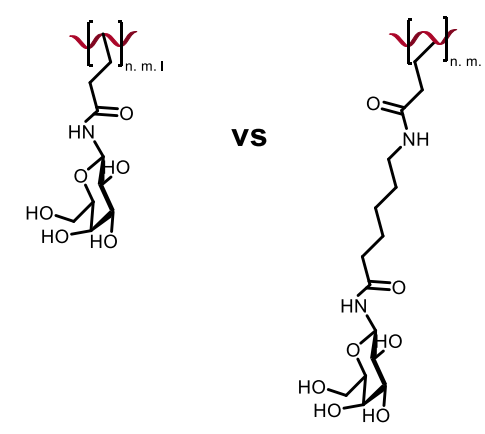

Figure 10. Schematic for the synthesis of galactose-functionalized polymers with a poly(Lglutamic acid) backbone. 36

Continuing from this work, and in order to gain a better control over the backbone, Liu and Kiick explored glycopolypeptides for the inhibition of СТB. Broadly, two families of $\alpha$-helical glycopolypeptides were designed to display galactopyranosides at a distance of 35 and $17 \AA$ between two adjacent pendant sugar ligands (the distance between two adjacent sugarrecognizing binding sites on $\mathrm{CTB}_{5}$ is $\sim 30 \AA \AA$ ). CTB inhibition was better for the glycopeptide with a functional group spacing of $35 \AA$ ( $\mathrm{IC}_{50}=160 \mu \mathrm{M}, \mathrm{Mw}=16 \mathrm{kDa}, 6$ sugars) over the one with $17 \AA$ $\left(\mathrm{IC}_{50}=725 \mu \mathrm{M}, \mathrm{Mw}=17.8 \mathrm{kDa}, \sim 12\right.$ sugars$)$. The overall inhibition was attributed to both multivalent and statistical rebinding effects (Figure 11). ${ }^{37}$

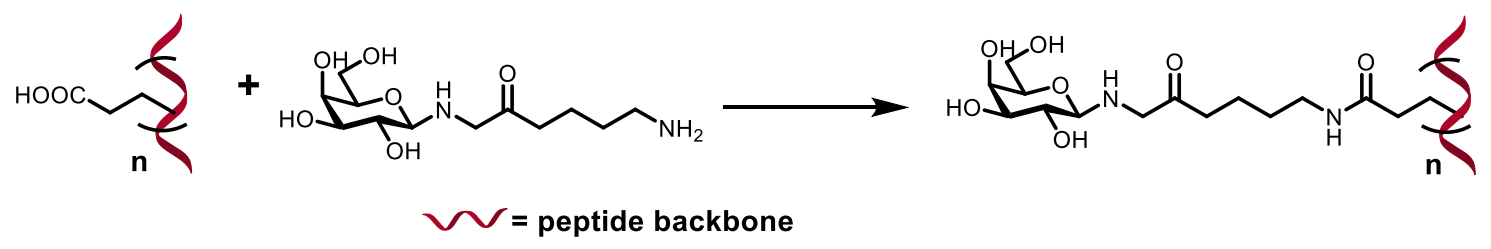

Figure 11. Schematic for the synthesis of glycopolypeptides. 
As an alternative to GM1, Bundle and co-workers have described the synthesis of a library of hetero-bifunctional compounds wherein a polyacrylamide or dextran scaffold was used to tether an $\alpha$ or a $\beta$ galactose moiety and a non-sugar fragment (Figure 12). ${ }^{38}$ Although this led to the generation of some potent CTB inhibitors further optimization of the molecules was not carried out.
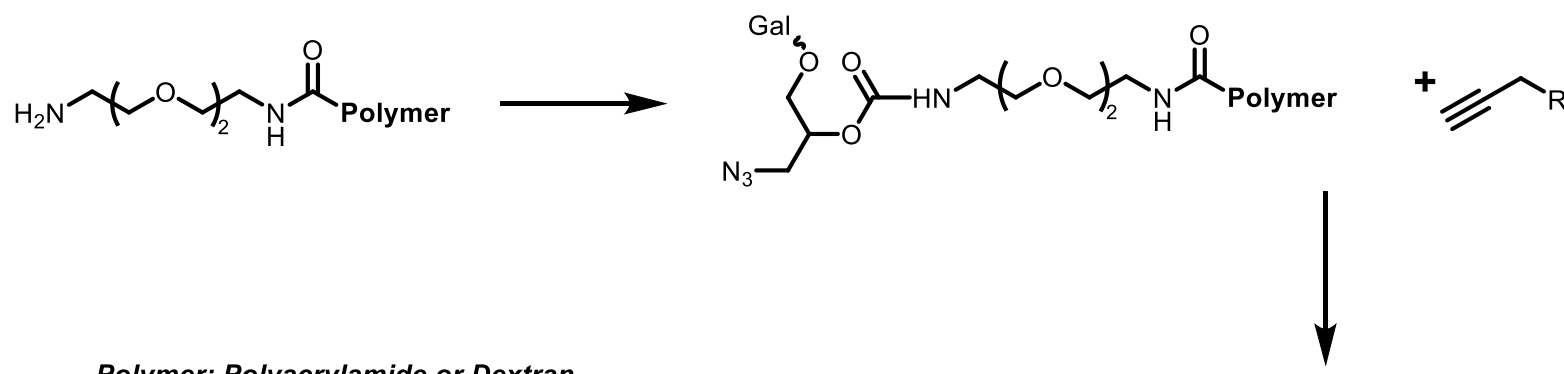

Polymer: Polyacrylamide or Dextran

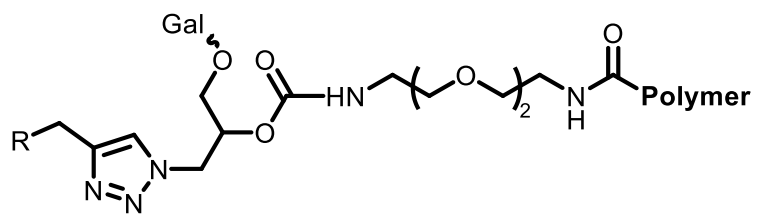

Figure 12. General scheme for the synthesis of hetero-bifunctional compounds by Bundle and coworkers.

A series of glycopolymers with varying sugar density, linker length, and chain length were synthesized by tandem post-polymerization modification by Richards et al. (Figure 13). The polymers were evaluated in terms of the minimum concentration required to inhibit $50 \%$ binding of the lectin $\left(\mathrm{MIC}_{50}\right)$. The longer linkers were shown to result in increased inhibition of the CTB due to the depth of the binding pocket. A nonlinear relationship was observed between the density and the activity of the polymers. The highest and lowest density polymers tested $(100 \%$ and $10 \%$ ) were the most active, on a per-sugar basis with $\mathrm{MIC}_{50}$ of $\sim 2 \mu \mathrm{g} / \mathrm{mL}$ and $\sim 5$ $\mu \mathrm{g} /$ mLrespectively. ${ }^{39}$ Following up on this, a secondary binding (branched) motif was introduced onto the linker with the aim of increasing the specificity and affinity towards CTB. The secondary motif proved useful and was found to improve both the affinity and the selectivity (up to 20-fold) of the glycopolymers towards CTB. 40 

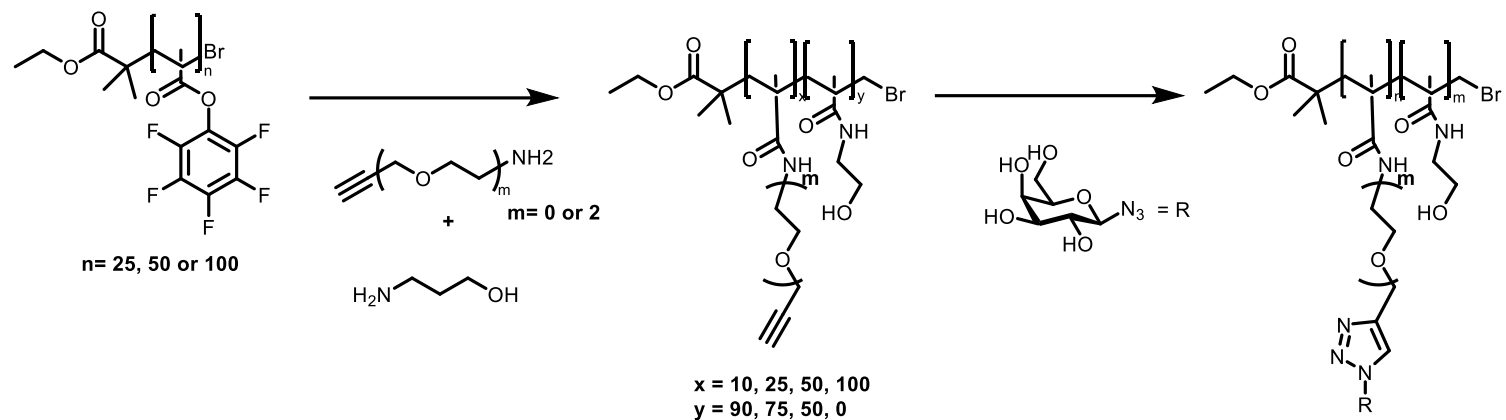

Figure 13. General scheme for the synthesis of glycopolymer libraries.

Poly(N-acryloylmorpholine) (PNAM) polymers using Reversible Addition-Fragmentation chain Transfer (RAFT) technology have been synthesized as bivalent inhibitors of CTB (18-28 kDa). This work was built upon the previously mentioned 1,2,3-triazole linked galactopyranosides 26 also by Leaver et al., with the aim to find a better linker in order to bridge the CTB binding sites. These bivalent RAFT polymers had a piperazine core and a PNAM linker coupled with a terminal thio-galactose moiety. The polymers showed only modest inhibition with millimolar IC ${ }_{50}{ }^{\text {'s. }}{ }^{41}$

More recently, stimuli-responsive receptors for the recognition unit of the cholera toxin (CTB) were prepared by attaching multiple copies of GM1 oligosaccharide to a thermoresponsive polymer scaffold to afford compound P2-GM1os (Figure 14). P2-GM1os was evaluated in an enzyme-linked lectin assay (ELLA) as well as the organoid assay with impressive inhibitory potencies $\left(\mathrm{IC}_{50}=3.8 \mathrm{nM}\right.$ and $\left.\mathrm{IC}_{50}=5.7 \mathrm{nM}\right)$. Addditionally, it was demonstrated that below their lower critical solution temperature (LCST), the polymers complexed CTB with nanomolar affinity. When heated above their LCST, polymers underwent a reversible coil to globule transition which render a proportion of the carbohydrate recognition motifs inaccessible to CTB. This temperature-mediated 'catch-and-release' behaviour was used to isolate CTB from bacterial growth medium and could contribute to the development of diagnostics for cholera. ${ }^{42}$ 


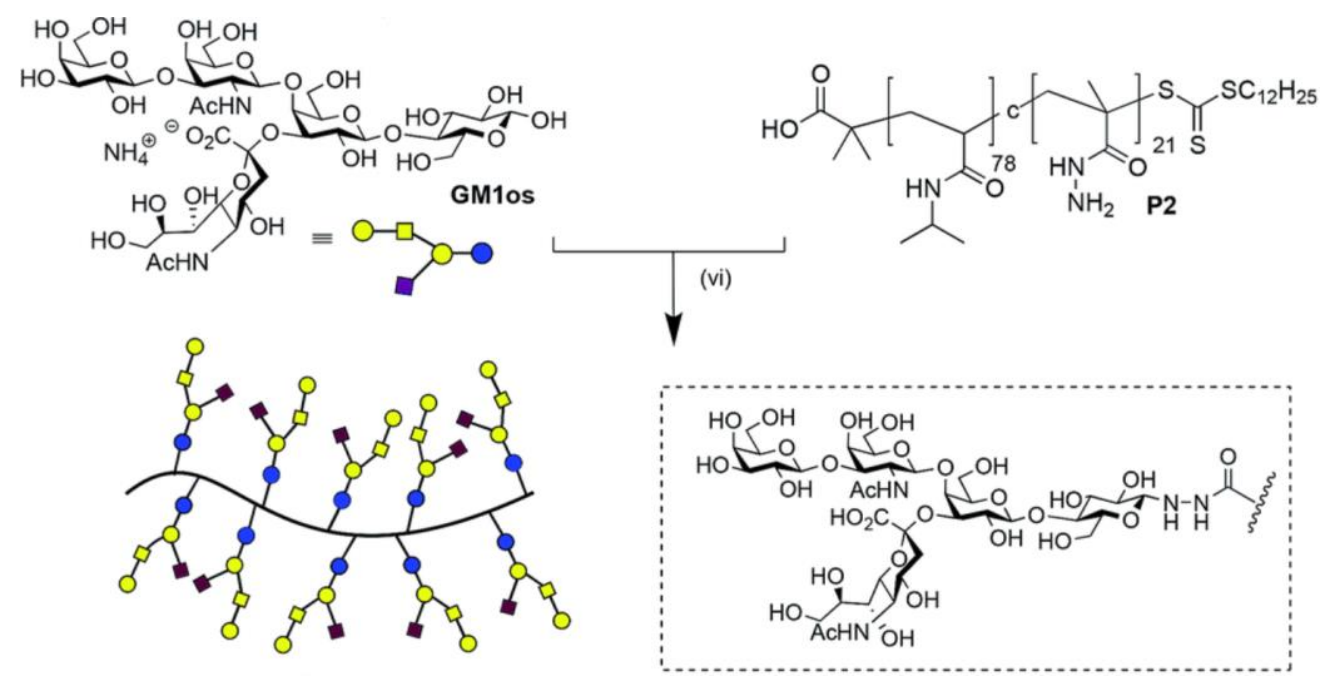

\section{P2-GM1os}

Figure 14. Scheme for the synthesis of P2-GM1os (Reproduced from Faraday Discuss. 2019, $219,112-127$ with permission from the Royal Society of Chemistry)

A novel secondary binding site has been recently identified that binds to fucosylated molecules including fucosylated blood group antigens although the binding is weaker than the nanomolar GM1 binding site, with a $\mathrm{K}_{\mathrm{d}}$ of $1.4 \mathrm{mM}$ for the LeY-CTB binding (Figure 15).43,44 Despite it's much lower affinity, the binding site has emerged as a key recognition determinant for CT binding to two human intestinal epithelial cell lines (T84 and Colo205).44,45 Also, inhibition of fucosylation was shown to reduce CTB binding to cells, thereby reducing the ability of CT to raise intracellular cAMP levels. Therefore, the secondary binding site could be a viable target for novel cholera therapeutics.
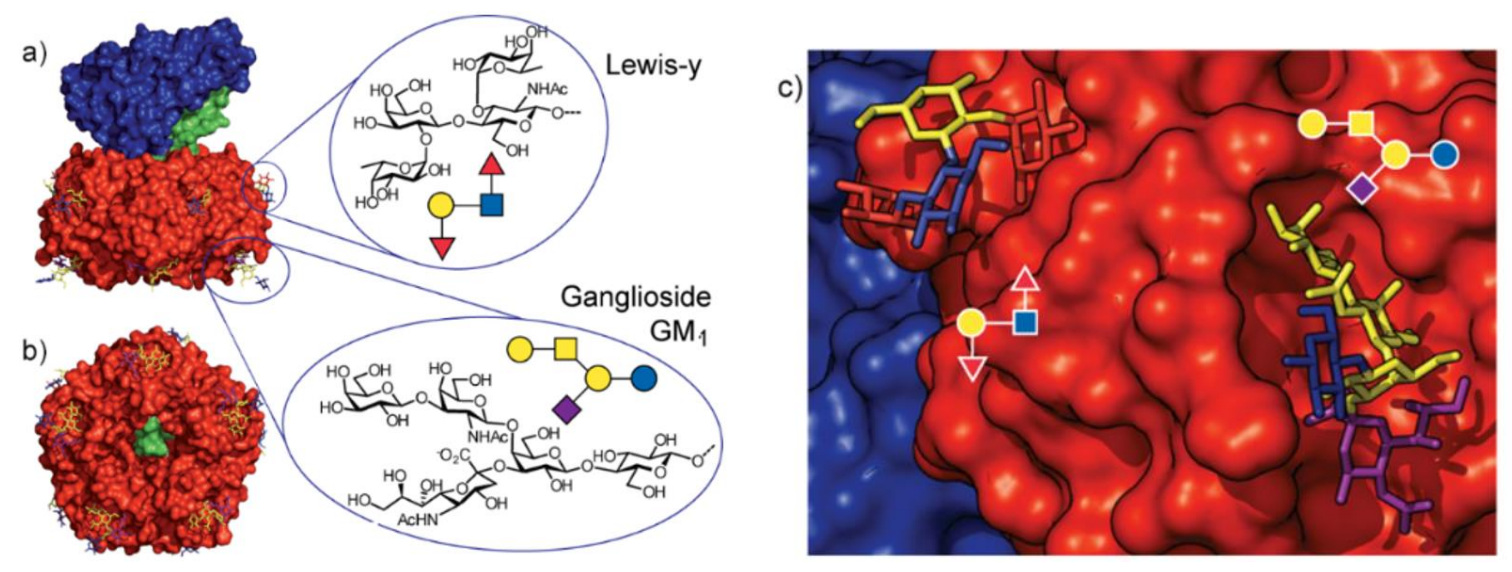
Figure 15. a) Structure of the cholera toxin showing the location of its carbohydrate binding sites and the structures of the Lewis-y and GM1 ligand; A-subunit (blue), B-subunit (red) and the A2 peptide linker (green). b) Bottom face of the toxin showing the symmetry of the B-subunit and the A2 peptide linker emerging through the central channel. c) Close-up view of the two sugar binding sites. (Figure taken from, Kumar, V. et al., Beilstein J. Org. Chem. 2018, 14, 484-498., Licensed under CC BY 4.0)

\subsection{Shiga toxin}

Bacterial dysentery or shigellosis has been identified as one of the major causes of mortality in children under 5 years of age. ${ }^{46}$ Shigellosis is caused by gram negative bacteria of four species of Shigella: S. dysenteriae, S. flexneri, S. boydii, and S. sonnei through the fecal-oral route. The pathology can include bloody diarrhea (hemorraghic colitis) followed by the often fatal hemolytic uremic syndrome (HUS). HUS can occur if the pathogen is also producing the Shiga toxin. Shiga toxin was described in 1898 by Kiyoshi Shiga and thereby named after him. ${ }^{47}$ The toxin is produced by $S$. dysenteriae serotype 1 but closely related toxins Stx1 and Stx 2 are also produced by Shiga toxin producing E. coli (STEC) or enterohemorrhagic E. coli (EHEC), where Stx2 has been reported to cause the more severe infections. ${ }^{48} \mathrm{~A}$ number of STEC outbreaks have been reported and are mostly food-borne with the largest ever reported in Germany (2011), linked to sprout consumption. ${ }^{49}$

The Shiga toxin is an $\mathrm{AB}_{5}$ toxin composed of the toxic $\mathrm{A}$ subunit and a pentameric $\mathrm{B}$ subunit that is responsible for the binding of the toxin to its cell surface receptor globotriaosylceramide $(\mathrm{Gb} 3$; Gal $\alpha 1-4 G a l \beta 1-4 G l c \beta 1-c e r a m i d e$, also known as CD77 or the Pk blood group antigen) (Figure 16a). ${ }^{50}$ Each B subunit can bind to fifteen Gb3 molecules simultaneously (Figure 16b). ${ }^{51,52,53}$ After the initial bloody diarrhea the toxin enters the bloodstream by poorly understood mechanisms. ${ }^{54}$ The ample presence of Gb3 molecules in the kidney targets the toxin to this location. Once endocytosed, the toxin induces multiple signaling pathways leading to blockage of protein synthesis and induction of apoptosis 55,56 and HUS (Figure 17). STEC infections are treated with antibiotics although their use is controversial with respect to their ability to increase the risk of HUS. ${ }^{57}$ The recent emergence of toxin producing strains of S. flexneri and S. sonnei points towards increased future morbidity and mortality. $58,59,60,61,62,63,64,65,66,67$ 

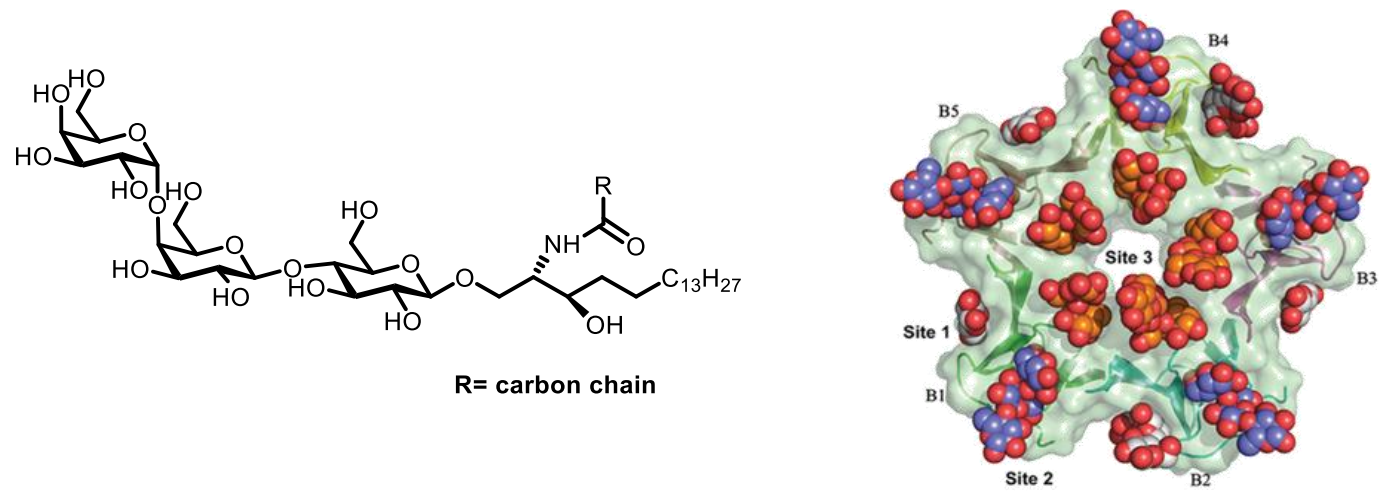

Figure 16. a) Gb3 structure, b) Shiga toxin B subunit bound to 15 GB3 molecules (Figure taken from Jacobson, J. M. et al., J. Biol. Chem. 2014, 289 (2), 885-894., Licensed under CC BY 4.0)

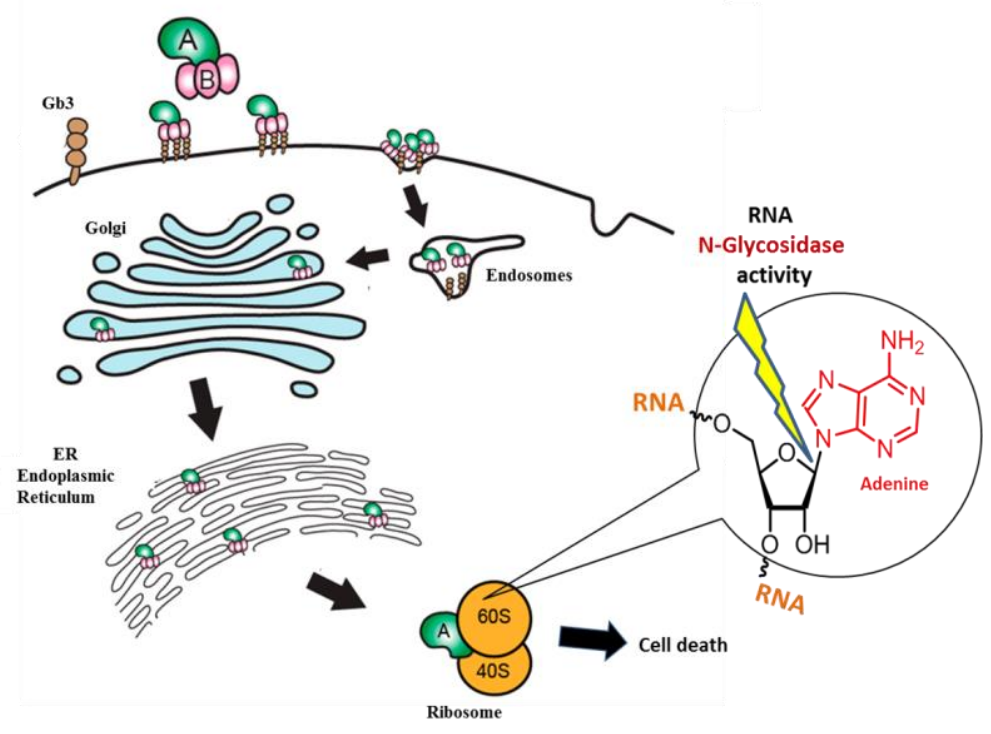

Figure 17. Schematic for the intracellular pathways involved in pathology of shiga toxin (Figure adapted from Hall, G. et al., Toxins. 2017 9(9)., Licensed under CC BY 4.0)

\subsubsection{Non-polymeric inhibitors of Stx}

As an alternative to antibiotics, synthetic molecules based on $\mathrm{Gb} 3$ have been explored as potential prophylactic treatment for STEC.68 The soluble STARFISH inhibitor with decametric display of $\mathrm{Gb} 3$ trisaccharide, reported by Bundle et al. exhibited subnanomolar inhibition $\left(\mathrm{IC}_{50}=0.21 \mathrm{nM}\right)$ 
of Stx1, with large potency gains (relative potency of 875000 per saccharide unit) over the divalent analogue and the Pk trisaccharide itself (Figure 18). ${ }^{69}$

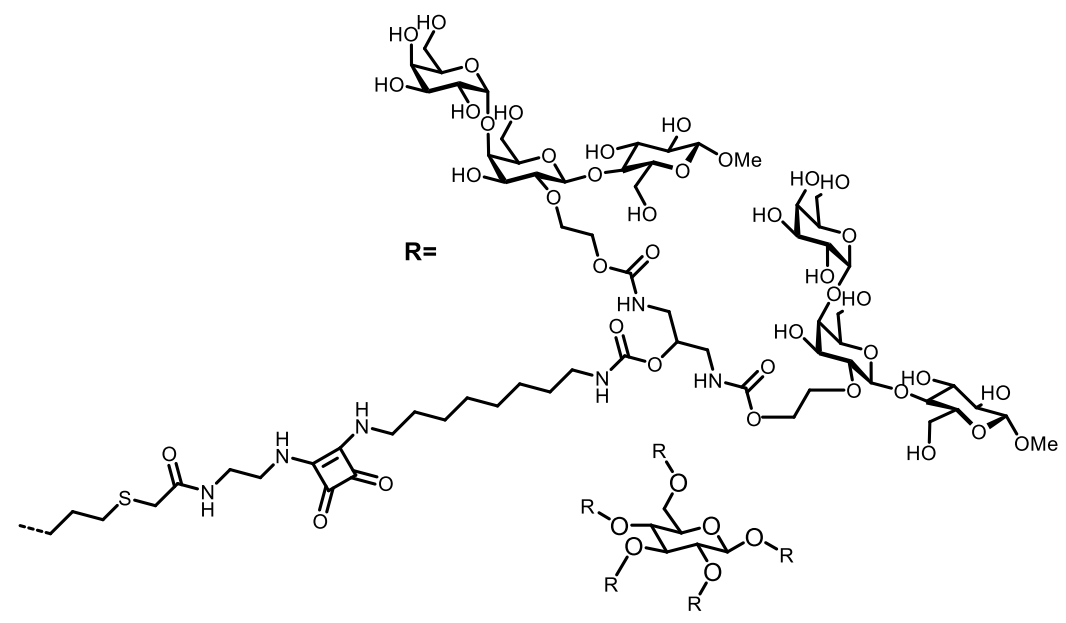

Figure 18. Dodeca version of STARFISH inhibitor

A modification of the STARFISH named DAISY was observed to be effective against both Stx1 and Stx2 with nanomolar inhibition and in vivo activity in EHEC orally infected mice by subcutaneous injection $24 \mathrm{~h}$ afterwards (Figure 19). ${ }^{70}$

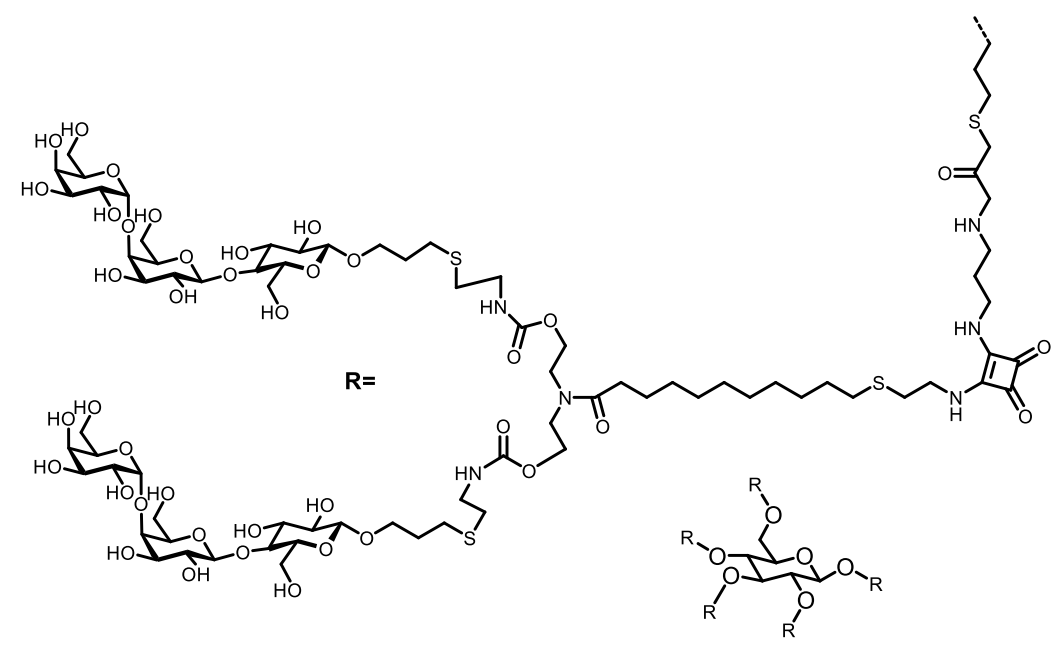

Figure 19. DAISY inhibitor

Synsorb Pk, silicon dioxide coupled to synthetic Pk showed promising results in the trapping of toxins and preventing toxic effects on renal cells (Figure 20). ${ }^{71}$ Synsorb Pk became a drug candidate but the clinical trials were suspended after it was unsuccessful at diminishing diarrheaassociated HUS possibly due to late administration of the drug to the GI tract while the toxin was already active systemically. ${ }^{72}$ 


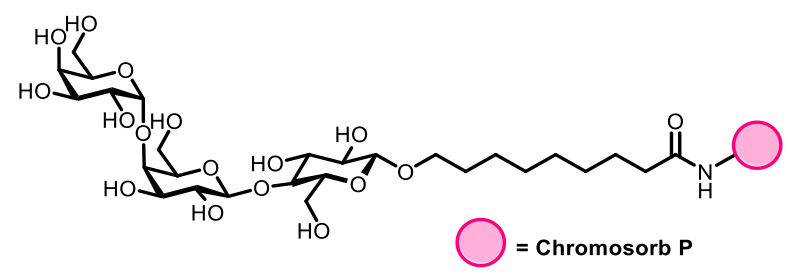

Figure 20. Synsorb Pk

To counter this problem, antibodies, nanobodies as well as smaller dendritic molecules were explored which have been recently summarized. ${ }^{73}$

Nishikawa et al. developed carbosilane dendrimers the termini of which were conjugated to the Gb3 trisaccharide ( 6 and 12 Gb3 units) and called it SUPER TWIG. They found that the SUPER TWIG with six trisaccharides bound to Stx with high affinity $\left(K_{d}=1.1 \times 10^{-6} \mathrm{M}\right)$ and were functional in the circulation. ${ }^{74}$ Further optimization of the SUPER TWIGs led to the synthesis of SUPER TWIG (2)18 with 18 trisaccharides $\left(\mathrm{IC}_{50}=0.21 \mu \mathrm{mol} / \mathrm{L}\right.$ and $2.1 \mu \mathrm{mol} / \mathrm{L}$ for Stx1 and Stx2 respectively) (Figure 21). The dumbbell shape was found to be required for formation of a complex with the toxin that facilitated the efficient uptake and degradation of the toxin by macrophages and, subsequently for potent toxin neutralization in the circulation. ${ }^{75}$

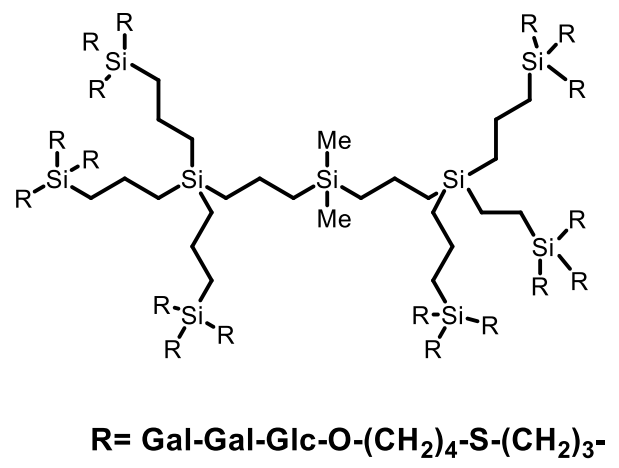

Figure 21. SUPER TWIG 2(18)

\subsubsection{Polymer-based inhibitors of Stx}

Glycoconjugate polymers carrying lactose and globotriose residues were synthesized by Miyagawa et al. For this purpose, firstly the carbohydrate derivatives with n-pentenyl as the polymerizable group at the aglycon was synthesized which was further elongated with an acrylamide group (Figure 22). ${ }^{76}$ Polymers of varying ratios of carbohydrate-conjugated (X) and carbohydrate-free acrylamide units $(\mathrm{Y})$ were synthesized. The polymers were tested against both Stx 1 and Stx 2 and the most potent compound in the series was identified as the Gb3 polymer with 
the $\mathrm{X}: \mathrm{Y}$ ratio of 1:0 $\left(\mathrm{Mw}=36 \mathrm{kDa}\right.$ with $\sim 50$ trisaccharides; $\mathrm{IC}_{50}=0.33$ and $0.34 \mu \mathrm{mol} / \mathrm{L}$ for Stx1 and Stx2 respectively). Detailed in vivo studies in mice were also done to demonstrate the efficacy of the Gb3 polymer as a useful oral therapeutic. In the model used, the infection was detected in stool on day 2 and in serum on day 3 after intragastric injection of $E$. coli 0157:H7. The polymer was administered twice a day for 3 consecutive days (days $3-5) .77$

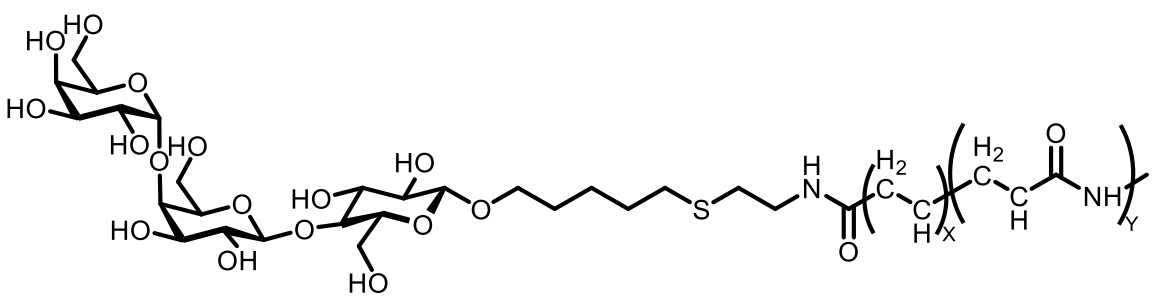

Figure 22. General structure of the globotriose and lactose glycopolymer by Miyagawa et al.

Following up on this, the same group shortened the spacer tethering the trisaccharide to the core to synthesize a Gb3 polymer with the X:Y ratio of 1:17. They observed that shortening the spacer length markedly reduced the binding affinity for Stx2 $\left(\mathrm{IC}_{50}=0.08 \mu \mathrm{M}\right)$ but not $\operatorname{Stx} 1\left(\mathrm{IC}_{50}=0.17\right.$ $\mu M)$. Moreover, mutational analysis revealed that the essential binding sites of the terminal trisaccharides were completely different between Stx1 and Stx2 . 68

Chitosan conjugates bearing globotriose with varying degrees of substitution were synthesized by Li et al. (Figure 23). The synthesis was accomplished by conjugating a globotriose derivative containing an aldehyde-functionalized aglycone to chitosan amino groups. The conjugate with the highest degree of substitution i.e. 59\% emerged as the most potent of the series $\left(\mathrm{IC}_{50}=0.02 \mu\right.$ $\mathrm{g} / \mathrm{mL}$ and $0.09 \mu \mathrm{g} / \mathrm{mL}$ for Stx1 and Stx2 respectively). In vivo studies with mice showed that the Stx levels in the gut of infected mice receiving oral doses of the conjugate were reduced and survived the fatal STEC challenge. ${ }^{78}$
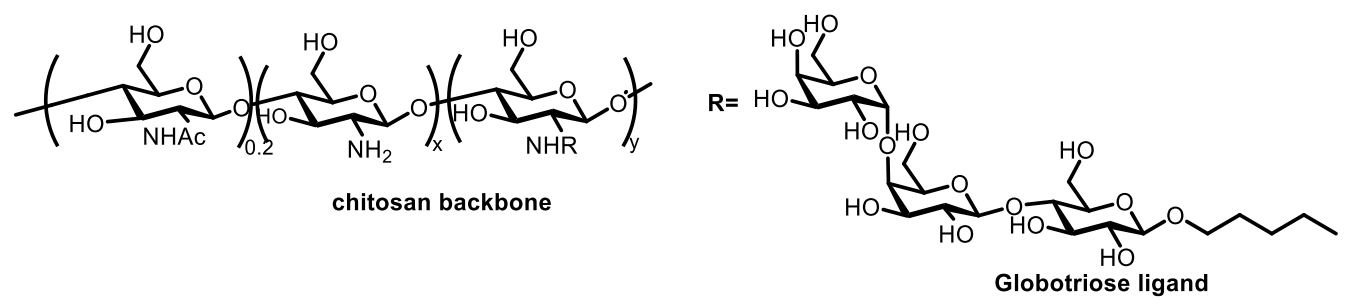

Figure 23. General structure of the chitosan-globotriose conjugate 


\subsection{Thesis Outline}

Chapter 1 provides a brief introduction to the phenomena of multivalency in carbohydrateprotein recognition. The thesis focuses on $\mathrm{AB}_{5}$ toxins (cholera and shiga toxin) and their inhibition and therefore an introduction to these toxins is provided along with some of the most important multivalent inhibitors synthesized and tested thus far.

Chapter 2 describes present the synthesis of meta-nitrophenyl $\alpha$-galactoside (MNPG) in greatly improved yields and its use while linked to a multivalent scaffold. We used economical polymers as multivalent scaffolds, namely polyacrylamide, dextran and hyperbranched polyglycerols (hPGs). Copper catalyzed alkyne azide cycloaddition reaction (CuAAC) produced the inhibitors that were tested in an ELISA-type assay and an intestinal organoid swelling inhibition assay. The inhibitory properties varied widely depending on the type of polymer and the most potent conjugates showed $\mathrm{IC}_{50}$ values in the nanomolar range

Chapter 3 explores heteromultivalency as a concept to deal with the increasing evidence that is pointing towards the role of the secondary binding site. This aim was achieved by designing and synthesizing a "hybrid" molecule, capable of blocking both modes of toxin attachment. In order to further simplify the testing of such inhibitors, a novel assay was utilized circumventing the use of cell lines for inhibition testing.

Chapter 4 describes different approaches to tackle the shiga toxin. The aim was to provide a simple yet effective toxin inhibitor. We did this by comparing three classes of carbohydrate based inhibitors: glycodendrimers, glycopolymers and oligosaccharides. We observed a clear enhancement in potency for the multivalent inhibitors, with the divalent and tetravalent compounds inhibiting in the millimolar and micromolar range respectively. However, the polymeric inhibitor based on galabiose was the most potent in the series exhibiting nanomolar inhibition. 


\subsection{References}

(1) Williams, S. J.; Davies, G. J. Protein-Carbohydrate Interactions: Learning Lessons from Nature. TRENDS Biotechnol. 2001, 19 (9).

(2) Reily, C.; Stewart, T. J.; Renfrow, M. B.; Novak, J. Glycosylation in Health and Disease. Nature Reviews Nephrology. 2019, pp 346-366.

(3) Varki, A.; Cummings, R. D.; Esko, J. D.; Stanley, P.; Hart, G. W.; Aebi, M.; Darvill, A. G.; Kinoshita, T.; Packer, N. H.; Prestegard, J. H.; Schnaar, R. L.; Seeberger, P. H. Essentials of Glycobiology; Cold Spring Harbor Laboratory Press, 2017.

(4) Lee, Y. C.; Lee, R. T. Carbohydrate-Protein Interactions: Basis of Glycobiology. Acc. Chem. Res. 1995, 28 (8), 321-327.

(5) De Schutter, K.; Van Damme, E. J. M. Protein-Carbohydrate Interactions, and Beyond. Molecules 2015, 20 (8), 15202-15205.

(6) Ernst, B.; Magnani, J. L. From Carbohydrate Leads to Glycomimetic Drugs. Nature Reviews Drug Discovery. 2009, pp 661-677.

(7) Fasting, C.; Schalley, C. A.; Weber, M.; Seitz, O.; Hecht, S.; Koksch, B.; Dernedde, J.; Graf, C.; Knapp, E. W.; Haag, R. Multivalency as a Chemical Organization and Action Principle. Angew. Chemie - Int. Ed. 2012, 51 (42), 10472-10498.

(8) Krishnamurthy, V. M.; Estroff, L. A.; Whitesides, G. M. Multivalency in Ligand Design. In Fragmentbased Approaches in Drug Discovery; 2006; Vol. 34, pp 11-53.

(9) Pieters, R. J. Maximising Multivalency Effects in Protein-Carbohydrate Interactions. Org. Biomol. Chem. 2009, 7, 2013-2025.

(10) Hayes, E. D.; Turnbull, W. B. CHAPTER 5 Monovalent and Multivalent Inhibitors of Bacterial Toxins. In Synthesis and Biological Applications of Glycoconjugates,; 2011; pp 78-91.

(11) Fu, O.; Pukin, A. V.; van Ufford, H. C. Q.; Branson, T. R.; Thies-Weesie, D. M. E.; Turnbull, W. B.; Visser, G. M.; Pieters, R. J. Tetra- versus Pentavalent Inhibitors of Cholera Toxin. ChemistryOpen 2015, 4 (4), 471-477.

(12) Baldauf, K. J.; Royal, J. M.; Hamorsky, K. T.; Matoba, N. Cholera Toxin B: One Subunit with Many Pharmaceutical Applications. Toxins (Basel). 2015, 7, 974-996.

(13) Kumar, V.; Turnbull, W. B. Carbohydrate Inhibitors of Cholera Toxin. Beilstein J. Org. Chem. 2018, $14,484-498$.

(14) Zuilhof, H. Fighting Cholera One-on-One: The Development and E Ffi Cacy of Multivalent CholeraToxin-Binding Molecules. Acc. Chem. Res. 2016, 49, 274-285.

(15) Turnbull, W. B.; Precious, B. L.; Homans, S. W. Dissecting the Cholera Toxin-Ganglioside GM1 Interaction by Isothermal Titration Calorimetry. J. Am. Chem. Soc. 2004, 126 (4), 1047-1054.

(16) Bernardi, A.; Checchia, A.; Brocca, P.; Sonnino, S.; Zuccotto, F. Sugar Mimics: An Artificial Receptor for Cholera Toxin. J. Am. Chem. Soc. 1999, 121 (10), 2032-2036.

(17) Bernardi, A.; Carrettoni, L.; Ciponte, A. G.; Monti, D.; Sonnino, S. Second Generation Mimics of Ganglioside GM1 as Artificial Receptors for Cholera Toxin: Replacement of the Sialic Acid Moiety. Bioorganic Med. Chem. Lett. 2000, 10 (19), 2197-2200.

(18) Arosio, D.; Vrasidas, I.; Valentini, P.; Liskamp, R. M. J.; Pieters, R. J.; Bernardi, A. Synthesis and Cholera Toxin Binding Properties of Multivalent GM1 Mimics. Org. Biomol. Chem. 2004, 2, 21132124.

(19) Arosio, D.; Fontanella, M.; Baldini, L.; Mauri, L.; Bernardi, A.; Casnati, A.; Sansone, F.; Ungaro, R. A Synthetic Divalent Cholera Toxin Glycocalix[4]Arene Ligand Having Higher Affinity than Natural GM1 Oligosaccharide. J. Am. Chem. Soc. 2005, 127, 3660-3661.

(20) Minke, W. E.; Roach, C.; Hol, W. G. J.; Verlinde, C. L. M. J. Structure-Based Exploration of the Ganglioside GM1 Binding Sites of Escherichia Coli Heat-Labile Enterotoxin and Cholera Toxin for the Discovery of Receptor Antagonists †. Biochemistry 1999, 38 (18), 5684-5692.

(21) Pickens, J. C.; Merritt, E. a; Ahn, M.; Verlinde, C. L. M. J.; Hol, W. G. J.; Fan, E. Anchor-Based Design of Improved Cholera Toxin and E. Coli Heat-Labile Enterotoxin Receptor Binding Antagonists That Display Multiple Binding Modes. Chem. Biol. 2002, 9 (02), 215-224.

(22) Mitchell, D. D.; Pickens, J. C.; Korotkov, K.; Fan, E.; Hol, W. G. . 3,5-Substituted Phenyl Galactosides as Leads in Designing Effective Cholera Toxin Antagonists: Synthesis and Crystallographic Studies. Bioorg. Med. Chem. 2004, 12 (5), 907-920.

(23) Pickens, J. C.; Mitchell, D. D.; Liu, J.; Tan, X.; Zhang, Z.; Verlinde, C. L. M. J.; Hol, W. G. J.; Fan, E. Nonspanning Bivalent Ligands as Improved Surface Receptor Binding Inhibitors of the Cholera Toxin B Pentamer. Chem. Biol. 2004, 11 (9), 1205-1215. 
(24) Zhang, Z.; Pickens, J. C.; Hol, W. G. J.; Fan, E. Solution- and Solid-Phase Syntheses of GuanidineBridged, Water-Soluble Linkers for Multivalent Ligand Design. Org. Lett. 2004, 6 (9), 1377-1380.

(25) Fan, E.; Merritt, E. A.; Zhang, Z.; Pickens, J. C.; Roach, C.; Ahn, M.; Hol, W. G. J. Exploration of the GM1 Receptor-Binding Site of Heat-Labile Enterotoxin and Cholera Toxin by Phenyl-RingContaining Galactose Derivatives. Acta Crystallogr. Sect. D Biol. Crystallogr. 2001, 57 (2), 201-212.

(26) Leaver, D. J.; Dawson, R. M.; White, J. M.; Polyzos, A.; Hughes, A. B. Synthesis of 1,2,3-Triazole Linked Galactopyranosides and Evaluation of Cholera Toxin Inhibition. Org. Biomol. Chem. 2011, 9 (24), 8465.

(27) Fan, E. K.; Zhang, Z. S.; Minke, W. E.; Hou, Z.; Verlinde, C. L. M. J.; Hol, W. G. J.; Uni, V. High-Affinity Pentavalent Ligands of Escherichia Coli Heat-Labile Enterotoxin by Modular Structure-Based Design. J. Am. Chem. Soc. 2000, 122 (9), 2663-2664.

(28) Zhang, Z.; Merritt, E. a.; Ahn, M.; Roach, C.; Hou, Z.; Verlinde, C. L. M. J.; Hol, W. G. J.; Fan, E. Solution and Crystallographic Studies of Branched Multivalent Ligands That Inhibit the Receptor-Binding of Cholera Toxin. J. Am. Chem. Soc. 2002, 124 (44), 12991-12998.

(29) Merritt, E. A.; Zhang, Z.; Pickens, J. C.; Ahn, M.; Hol, W. G. J.; Fan, E. Characterization and Crystal Structure of a High-Affinity Pentavalent Receptor-Binding Inhibitor for Cholera Toxin and E. Coli Heat-Labile Enterotoxin. J. Am. Chem. Soc. 2002, 124 (30), 8818-8824.

(30) Pukin, A. V; Branderhorst, H. M.; Sisu, C.; Weijers, C. A. G. M.; Gilbert, M.; Liskamp, R. M. J.; Visser, G. M.; Zuilhof, H.; Pieters, R. J. Strong Inhibition of Cholera Toxin by Multivalent GM1 Derivatives. ChemBioChem 2007, 8 (13), 1500-1503.

(31) Sisu, C.; Baron, A. J.; Branderhorst, H. M.; Connel, S. D.; Weijers, C. C. A. G. M.; de Vries, R.; Hayes, E. D.; Pukin, A. V.; Gilbert, M.; Pieters, R. J.; Zuilhof, H.; Visser, G. M.; Turnbull, W. B.; Connell, S. D. The Influence of Ligand Valency on Aggregation Mechanisms for Inhibiting Bacterial Toxins. ChemBioChem 2009, 10 (2), 329-337.

(32) Garcia-Hartjes, J.; Bernardi, S.; Weijers, C. A. G. M.; Wennekes, T.; Gilbert, M.; Sansone, F.; Casnati, A.; Zuilhof, H. Picomolar Inhibition of Cholera Toxin by a Pentavalent Ganglioside GM1osCalix[5]Arene. Org. Biomol. Chem. 2013, 11 (26), 4340-4349.

(33) Mattarella, M.; Garcia-Hartjes, J.; Wennekes, T.; Zuilhof, H.; Siegel, J. S. Nanomolar Cholera Toxin Inhibitors Based on Symmetrical Pentavalent Ganglioside GM1os-Sym-Corannulenes. Org. Biomol. Chem. 2013, 11 (26), 4333-4339.

(34) Zomer-Van Ommen, D. D.; Pukin, A. V.; Fu, O.; Quarles Van Ufford, L. H. C.; Janssens, H. M.; Beekman, J. M.; Pieters, R. J. Functional Characterization of Cholera Toxin Inhibitors Using Human Intestinal Organoids. J. Med. Chem. 2016, 59 (14), 6968-6972.

(35) Branson, T. R.; McAllister, T. E.; Garcia-Hartjes, J.; Fascione, M. a.; Ross, J. F.; Warriner, S. L.; Wennekes, T.; Zuilhof, H.; Turnbull, W. B. A Protein-Based Pentavalent Inhibitor of the Cholera Toxin B-Subunit. Angew. Chemie - Int. Ed. 2014, 53, 8323-8327.

(36) Polizzotti, B. D.; Kiick, K. L. Effects of Polymer Structure on the Inhibition of Cholera Toxin by Linear Polypeptide-Based Glycopolymers. Biomacromolecules 2006, 7 (2), 483-490.

(37) Liu, S.; Kiick, K. L. Architecture Effects on the Binding of Cholera Toxin by Helical Glycopolypeptides. Macromolecules 2008, 41 (3), 764-772.

(38) Tran, H.-A.; Kitov, P. I.; Paszkiewicz, E.; Sadowska, J. M.; Bundle, D. R. Multifunctional Multivalency: A Focused Library of Polymeric Cholera Toxin Antagonists. Org. Biomol. Chem. 2011, 9 (10), 36583671.

(39) Richards, S.-J.; Jones, M. W.; Hunaban, M.; Haddleton, D. M.; Gibson, M. I. Probing Bacterial-Toxin Inhibition with Synthetic Glycopolymers Prepared by Tandem Post-Polymerization Modification: Role of Linker Length and Carbohydrate Density. Angew. Chemie Int. Ed. 2012, 51 (31), $7812-$ 7816.

(40) Jones, M. W.; Otten, L.; Richards, S. J.; Lowery, R.; Phillips, D. J.; Haddleton, D. M.; Gibson, M. I. Glycopolymers with Secondary Binding Motifs Mimic Glycan Branching and Display Bacterial Lectin Selectivity in Addition to Affinity. Chem. Sci. 2014, 5 (4), 1611-1616.

(41) Leaver, D. J.; Hughes, A. B.; Dawson, R. M.; Postma, A.; Malic, N.; Polyzos, A. Synthesis of RAFT Polymers as Bivalent Inhibitors of Cholera Toxin. RSC Adv. 2014, 4 (29), 14868-14871.

(42) Mahon, C. S.; Wildsmith, G. C.; Haksar, D.; de Poel, E.; Beekman, J. M.; Pieters, R. J.; Webb, M. E.; Turnbull, W. B. A 'Catch-and-Release' Receptor for the Cholera Toxin. Faraday Discuss. 2019, 219 , 112-127.

(43) Wands, A. M.; Cervin, J.; Huang, H.; Zhang, Y.; Youn, G.; Brautigam, C. A.; Matson Dzebo, M.; Björklund, P.; Wallenius, V.; Bright, D. K.; Bennett, C. S.; Wittung-Stafshede, P.; Sampson, N. S.; Yrlid, U.; Kohler, J. J. Fucosylated Molecules Competitively Interfere with Cholera Toxin Binding to Host Cells. ACS Infect. Dis. 2018, 4 (5), 758-770. 
(44) Wands, A. M.; Fujita, A.; McCombs, J. E.; Cervin, J.; Dedic, B.; Rodriguez, A. C.; Nischan, N.; Bond, M. R.; Mettlen, M.; Trudgian, D. C.; Lemoff, A.; Quiding-Jarbrink, M.; Gustavsson, B.; Steentoft, C.; Clausen, H.; Mirzaei, H.; Teneberg, S.; Yrlid, U.; Kohler, J. J. Fucosylation and Protein Glycosylation Create Functional Receptors for Cholera Toxin. Elife 2015, 4, e09545.

(45) Sethi, A.; Wands, A. M.; Mettlen, M.; Krishnamurthy, S.; Wu, H.; Kohler, J. J. Cell Type and Receptor Identity Regulate Cholera Toxin Subunit B (CTB) Internalization. Interface Focus 2019, 9 (2), 20180076.

(46) Liu, J.; Platts-Mills, J. A.; Juma, J.; Kabir, F.; Nkeze, J.; Okoi, C.; Operario, D. J.; Uddin, J.; Ahmed, S.; Alonso, P. L.; Antonio, M.; Becker, S. M.; Blackwelder, W. C.; Breiman, R. F.; Faruque, A. S. G.; Fields, B.; Gratz, J.; Haque, R.; Hossain, A.; Hossain, M. J.; Jarju, S.; Qamar, F.; Iqbal, N. T.; Kwambana, B.; Mandomando, I.; McMurry, T. L.; Ochieng, C.; Ochieng, J. B.; Ochieng, M.; Onyango, C.;

Panchalingam, S.; Kalam, A.; Aziz, F.; Qureshi, S.; Ramamurthy, T.; Roberts, J. H.; Saha, D.; Sow, S. O.; Stroup, S. E.; Sur, D.; Tamboura, B.; Taniuchi, M.; Tennant, S. M.; Toema, D.; Wu, Y.; Zaidi, A.; Nataro, J. P.; Kotloff, K. L.; Levine, M. M.; Houpt, E. R. Use of Quantitative Molecular Diagnostic Methods to Identify Causes of Diarrhoea in Children: A Reanalysis of the GEMS Case-Control Study. Lancet 2016, 388 (10051), 1291-1301.

(47) Shiga, K. Weitere Studien Fiber Den Dysenteriebacillus. 1898, 24, 913-918.

(48) Tesh, V. L.; Burris, J. A.; Owens, J. W.; Gordon, V. M.; Wadolkowski, E. A.; O’Brien, A. D.; Samuel, J. E. Comparison of the Relative Toxicities of Shiga-like Toxins Type I and Type II for Mice. Infect. Immun. 1993, 61 (8), 3392-3402.

(49) Muniesa, M.; Hammerl, J. A.; Hertwig, S.; Appel, B.; Brüssow, H. Shiga Toxin-Producing Escherichia Coli 0104:H4: A New Challenge for Microbiology. Appl. Environ. Microbiol. 2012, 78 (12), 40654073.

(50) Lee, M. S.; Koo, S.; Jeong, D. G.; Tesh, V. L. Shiga Toxins as Multi-Functional Proteins: Induction of Host Cellular Stress Responses, Role in Pathogenesis and Therapeutic Applications. Toxins. 2016, pp 1-23.

(51) Bergan, J.; Dyve Lingelem, A. B.; Simm, R.; Skotland, T.; Sandvig, K. Shiga Toxins. Toxicon 2012, 60 (6), 1085-1107.

(52) Ling, H.; Boodhoo, A.; Hazes, B.; Cummings, M. D.; Armstrong, G. D.; Brunton, J. L.; Read, R. J. Structure of the Shiga-like Toxin I B-Pentamer Complexed with an Analogue of Its Receptor Gb3. Biochemistry 1998, 37 (7), 1777-1788.

(53) Jacobson, J. M.; Yin, J.; Kitov, P. I.; Mulvey, G.; Griener, T. P.; James, M. N. G.; Armstrong, G.; Bundle, D. R. The Crystal Structure of Shiga Toxin Type 2 with Bound Disaccharide Guides the Design of a Heterobifunctional Toxin Inhibitor. J. Biol. Chem. 2014, 289 (2), 885-894.

(54) Lingwood, C. Verotoxin Receptor-Based Pathology and Therapies. Front. Cell. Infect. Microbiol. 2020, 10 (March), 1-10.

(55) Paletta, A. C. C.; Castro, V. S.; Conte-Junior, C. A. Shiga Toxin-Producing and Enteroaggregative Escherichia Coli in Animal, Foods, and Humans: Pathogenicity Mechanisms, Detection Methods, and Epidemiology. Current Microbiology. 2020, pp 612-620.

(56) Hall, G.; Kurosawa, S.; Stearns-Kurosawa, D. J. Shiga Toxin Therapeutics: Beyond Neutralization. Toxins. 2017.

(57) Wong, C. S.; Jelacic, S.; Hareeb, R. L.; Watkins, S. L.; Tarr, P. I. The Risk of the Hemolytic-Uremic Syndrome after Antibiotic Treatment of Escherichia Coli 0157:H7 Infections. N. Engl. J. Med. 2000, 342, 1930-1936.

(58) Fogolari, M.; Mavian, C.; Angeletti, S.; Salemi, M.; Lampel, K. A.; Maurelli, A. T. Distribution and Characterization of Shiga Toxin Converting Temperate Phages Carried by Shigella Flexneri in Hispaniola. Infect. Genet. Evol. 2018, 65 (April), 321-328.

(59) Carter, C. C.; Fierer, J.; Chiu, W. W.; Looney, D. J.; Strain, M.; Mehta, S. R. A Novel Shiga Toxin 1aConverting Bacteriophage of Shigella Sonnei With Close Relationship to Shiga Toxin 2-Converting Pages of Escherichia Coli. Open Forum Infect. Dis. 2016, 3 (2), ofw079.

(60) Nyholm, O.; Lienemann, T.; Halkilahti, J.; Mero, S.; Rimhanen-Finne, R.; Lehtinen, V.; Salmenlinna, S.; Siitonen, A. Characterization of Shigella Sonnei Isolate Carrying Shiga Toxin 2-Producing Gene. Emerg. Infect. Dis. 2015, 21 (May), 891-892.

(61) Tóth, I.; Sváb, D.; Bálint, B.; Brown-Jaque, M.; Maróti, G. Comparative Analysis of the Shiga Toxin Converting Bacteriophage First Detected in Shigella Sonnei. Infect. Genet. Evol. 2016, 37 (2016), 150-157.

(62) Gray, M. D.; Lampel, K. A.; Strockbine, N. A.; Fernandez, R. E.; Melton-Celsa, A. R.; Maurelli, A. T. Clinical Isolates of Shiga Toxin 1a-Producing Shigella Flexneri with an Epidemiological Link to Recent Travel to Hispaniola. Emerg. Infect. Dis. 2014, 20 (10), 1669-1677. 
(63) Gupta, S. K.; Strockbine, N.; Omondi, M.; Hise, K.; Fair, M. A.; Mintz, E. Short Report: Emergence of Shiga Toxin 1 Genes within Shigella Dysenteriae Type 4 Isolates from Travelers Returning from the Island of Hispanola. Am. J. Trop. Med. Hyg. 2007, 76 (6), 1163-1165.

(64) Sváb, D.; Bálint, B.; Vásárhelyi, B.; Maróti, G.; Tóth, I. Comparative Genomic and Phylogenetic Analysis of a Shiga Toxin Producing Shigella Sonnei (STSS) Strain. Front. Cell. Infect. Microbiol. 2017, 7 (May), 1-10.

(65) Bekal, S.; Pilon, P. A.; Cloutier, N.; Doualla-bell, F.; Longtin, J. Identification of Shigella Flexneri Isolates Carrying the Shiga Toxin 1-Producing Gene in Quebec , Canada, Linked to Travel to Haiti. Can. J. Microbiol. 2015, 61 (September), 995-996.

(66) Beutin, L.; Strauch, E.; Fischer, I. Isolation of Shigella Sonnei l y s o g e n i c for a Bacteriophage Encoding Gene for Production of Shiga Toxin. Lancet 1999, 353, 1498.

(67) Lamba, K.; Nelson, J. A.; Kimura, A. C.; Poe, A.; Collins, J.; Kao, A. S.; Cruz, L.; Inami, G.; Vaishampayan, J.; Garza, A.; Chaturvedi, V.; Vugia, D. J. Shiga Toxin 1 - Producing Shigella Sonnei Infections, California, United States, 2014-2015. Emerg. Infect. Dis. 2016, 22, 679-686.

(68) Watanabe, M.; Igai, K.; Matsuoka, K.; Watanabe, T.; Yanoshita, R.; Terunuma, D.; Natori, Y.; Miyagawa, A.; Samejima, Y. Structural Analysis of the Interaction between Shiga Toxin B Subunits and Linear Polymers Bearing Clustered Globotriose Residues Structural Analysis of the Interaction between Shiga Toxin B Subunits and Linear Polymers Bearing Clustered Globotriose Residu. Infect. Immun. 2006, 74 (3), 1984-1988.

(69) Kitov, P. I.; Sadowska, J. M.; Mulvey, G.; Armstrong, G. D.; Ling, H.; Pannu, N. S.; Read, R. J.; Bundle, D. R. Shiga-like Toxins Are Neutralized by Tailored Multivalent Carbohydrate Ligands. Nature 2000, 403 (6770), 669-672.

(70) Mulvey, G. L.; Marcato, P.; Kitov, P. I.; Sadowska, J.; Bundle, D. R.; Armstrong, G. D. Assessment in Mice of the Therapeutic Potential of Tailored, Multivalent Shiga Toxin Carbohydrate Ligands. J. Infect. Dis. 2003, 187 (4), 640-649.

(71) Takeda, T.; Yoshino, K. I.; Adachi, E.; Sato, Y.; Yamagata, K. In Vitro Assessment of a Chemically Synthesized Shiga Toxin Receptor Analog Attached to Chromosorb P (Synsorb Pk) as a Specific Absorbing Agent of Shiga Toxin 1 and 2. Microbiol. Immunol. 1999, 43 (4), 331-337.

(72) Trachtman, H.; Cnaan, A.; Christen, E.; Gibbs, K.; Zhao, S.; DWK, A.; Weiss, R.; FJ, K.; Spitzer, A.; GH, H. Effect of an Oral Shiga Toxin-Binding Agent on Diarrhea-Associated Hemolytic Uremic Syndrome in Children: A Randomized Controlled Trial. JAMA J. Am. Med. Assoc. 2003, 290 (10), 1337-1344.

(73) Ganji, A.; Islami, M.; Ejtehadifar, M.; Zarei-Mehrvarz, E.; Darvish, M. Nanobody and Aptamer as Targeting Moiety against Bacterial Toxins: Therapeutic and Diagnostic Applications. Rev. Med. Microbiol. 2019, 30 (3), 183-190.

(74) Nishikawa, K.; Matsuoka, K.; Kita, E.; Okabe, N.; Mizuguchi, M.; Hino, K.; Miyazawa, S.; Yamasaki, C.; Aoki, J.; Takashima, S.; Yamakawa, Y.; Nishijima, M.; Terunuma, D.; Kuzuhara, H.; Natori, Y. A Therapeutic Agent with Oriented Carbohydrates for Treatment of Infections by Shiga ToxinProducing Escherichia Coli 0157:H7. Proc. Natl. Acad. Sci. U. S. A. 2002, 99 (11), 7669-7674.

(75) Nishikawa, K.; Matsuoka, K.; Watanabe, M.; Igai, K.; Hino, K.; Hatano, K.; Yamada, A.; Abe, N.; Terunuma, D.; Kuzuhara, H.; Natori, Y. Identification of the Optimal Structure Required for a Shiga Toxin Neutralizer with Oriented Carbohydrates to Function in the Circulation. J. Infect. Dis. 2005, 191 (12), 2097-2105.

(76) Miyagawa, A.; Kurosawa, H.; Watanabe, T.; Koyama, T.; Terunuma, D.; Matsuoka, K. Synthesis of Glycoconjugate Polymer Carrying Globotriaose as Artificial Multivalent Ligand for Shiga ToxinProducing Escherichia Coli 0157: H7. Carbohydr. Polym. 2004, 57 (4), 441-450.

(77) Watanabe, M.; Matsuoka, K.; Kita, E.; Igai, K.; Higashi, N.; Miyagawa, A.; Watanabe, T.; Yanoshita, R.; Samejima, Y.; Terunuma, D.; Natori, Y.; Nishikawa, K. Oral Therapeutic Agents with Highly Clustered Globotriose for Treatment of Shiga Toxigenic Escherichia Coli Infections. J. Infect. Dis. 2004, 189 (3), 360-368.

(78) Li, X.; Wu, P.; Cheng, S.; Lv, X. Synthesis and Assessment of Globotriose-Chitosan Conjugate, a Novel Inhibitor of Shiga Toxins Produced by Escherichia Coli. J. Med. Chem. Chem. 2012, 55, 2702. 

Chapter 2

\section{Strong inhibition of cholera toxin B subunit by affordable, polymer-based multivalent inhibitors}

This chapter is published in :

D. Haksar, E. de Poel, L. Q. van Ufford, S. Bhatia, R. Haag, J. Beekman and R. J. Pieters, Bioconjug. Chem., 2019, 30, 785-792. 



\subsection{Introduction}

Cholera is a disease that affects a large number of people in the developing countries due to limited access to safe drinking water and adequate sanitation. It is characterized by watery diarrhea which can rapidly be fatal when left untreated. ${ }^{1}$ The annual burden of cholera has been estimated at 1.3 to 4.0 million cases and 21,000 to 143,000 deaths worldwide. ${ }^{2}$ The recent cholera outbreak in Yemen has been called the world's worst cholera epidemic and has claimed 2200 lives in the year 2017 with more than a million suspected cases. ${ }^{3}$ Treatment for cholera involves the use of oral rehydration therapy and antibiotics. There are three oral cholera vaccines: Dukoral ${ }^{\circledR}$, Shanchol ${ }^{\mathrm{TM}}$, and Euvichol-Plus ${ }^{\circledR} /$ Euvichol ${ }^{\circledR}$ which are WHO pre-qualified and widely used but not very effective for children under five years of age. ${ }^{4}$ Vaxchora ${ }^{\circledR}$ has recently been approved by the USFDA as a vaccine for adults who travel to an area of active cholera transmission. ${ }^{5}$

GM1 mimics, as monovalent inhibitors of $\mathrm{CTB}^{6,7}$ and divalent ${ }^{8,9,10,11}$ inhibitors based on different scaffolds have been developed. Multivalent inhibitors based on different scaffolds such as dendrimers, ${ }^{12}$ calix[5]arene, ${ }^{8}$ polymers, ${ }^{13,14}$ and glycopeptides ${ }^{15}$ have been synthesized. The most potent inhibitors are multivalent in nature and based on the GM1 oligosaccharide s(GM1os).16,17,18,19,20 These systems are all very potent and inhibit in the nano- and picomolar range. Unfortunately, the structural complexity of GM1 and therefore the costs involved in preparing it does not make it an ideal candidate for drug development. The oligosaccharide of GM1 is very costly with hundreds of dollars for milligram amounts. Affordability is key, especially considering that the therapeutic needs to be repeatedly administered due to the natural flow of the intestinal tract, in order to maintain protection during epidemics. Thus, there is an urgent need for potent and economical inhibitors of CTB.

To this end, researchers have conjugated galactose ligands to polymers and evaluated their potencies. ${ }^{21}$ Among the best examples are Poly(L-glutamic)acid that was used and inhibitors reached $\mathrm{IC}_{50}$ 's in the 40-50 micromolar range, a 600-fold enhancement over monovalent galactose. ${ }^{14}$ Similar results were reported with polyacrylamide linked galactoside, but a comparison with monovalent galactosides was not made. ${ }^{13}$ Tran et al.22 described a compound search of galactoside derivatives that were screened while linked to polyacrylamide, and yielded potent conjugates, although the monovalent compound itself was of similar potency to MNPG used in our study (vide infra). Jones et al. ${ }^{23}$ used a similar approach. Based on these results we aimed to make a polymeric CTB antagonist of sufficient potency that is readily made and consists of affordable components. Within these constraints, this should include an optimal monovalent ligand combined with an optimal polymeric pharmaceutically benign backbone. The word 
sufficient potency is based on the concentration of cholera toxin present during cholera attacks in the intestinal tract which may reach close to $1 \mu \mathrm{M}$ of B-subunits. ${ }^{24,25}$ Submicromolar Kd's are therefore sufficient while picomolar inhibitors provide little advantage, as they still need to be present in micromolar inhibitor concentration to neutralize all the toxin.

Meta-nitrophenyl $\alpha$-galactoside (MNPG) was the main candidate for our monovalent compound, which was discovered by Minke et al. almost two decades ago as a promising monovalent inhibitor in a screening assay where it exhibited a 100 -fold increase in potency over D-galactose. ${ }^{26}$ Its potency increase over galactose was thought to be entropy driven. This was explained by a new hydrogen bond formed with the nitro group liberating a conserved water molecule, in addition to increasing the surface of the ligand that can interact with the protein. ${ }^{27}$ Further optimization of MNPG did not yield satisfactory results. ${ }^{28,29} \mathrm{~A}$ multivalent version was potent when linked to a pentacyclen core $\left(\mathrm{IC}_{50}=6 \mathrm{nM}\right)$ however, the conjugate was not stable, 30 and the result of a long and expensive synthesis. A major barrier was also the synthesis of MNPG and even more so for a version amenable to conjugation. Single digit yields combined with the need for an enzyme to separate the anomeric mixtures precluded the use of MNPG for applications. ${ }^{28}$

In the present study, we focused on the synthesis of MNPG and a version suitable for conjugation and subsequently presenting it in a polymeric multivalent system. For this purpose, we have used the linear polyacrylamide and dextran with periodic branching, typically less than $10 \%$, readily available and economical (Figure 1). The third polymer was considerably more branched: a hyperbranched polyglycerol (hPG) and known to be biocompatible and the $10 \mathrm{kDa}$ variant is known to have a more globular nanoparticle shape with a diameter of 5-6 nm, substituted or not. $31,32,33,34,35$ All three polymers were used as a scaffold by introducing azido functions and linking MNPG by Copper catalyzed alkyne azide cycloaddition (CuAAC) conjugation. The resulting glycopolymers were potent cholera toxin inhibitors, but the activity varied widely with the type of polymeric scaffold. Compounds were evaluated using an ELISA assasy, but some compounds were also tested in our recently reported organoid assay. ${ }^{36}$ Traditionally, rabbit ileal loop assay has been used to study enterotoxins including CT. However, the assay is not widely used to evaluate CT inhibitors as it is extremely stressful to the animals, time-consuming and not easy to standardize. The organoid assay overcomes these issues and could serve as a precursor to the animal model studies. 


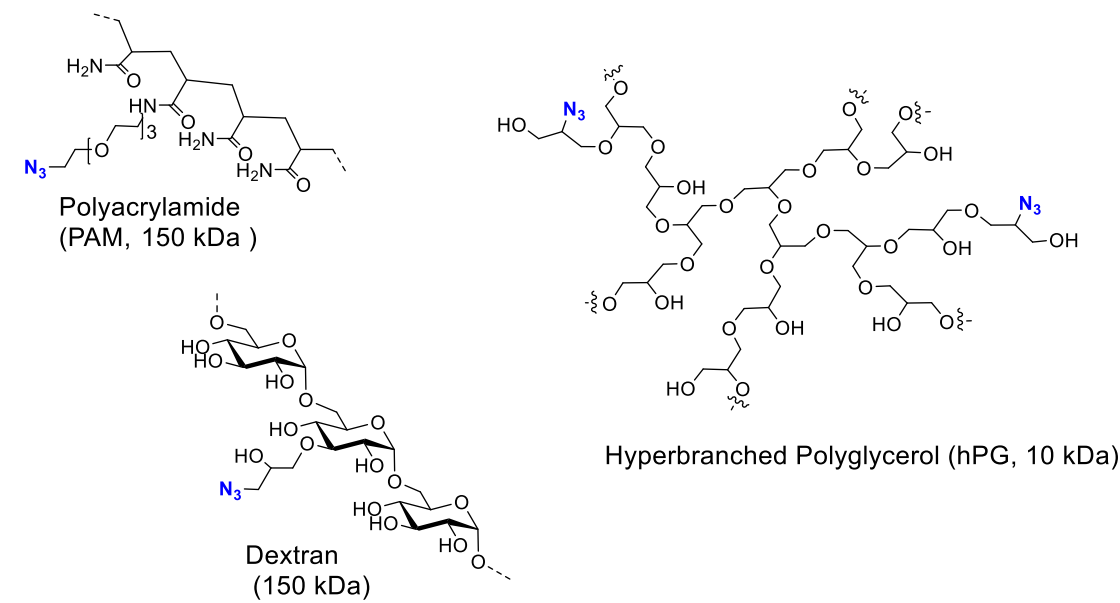

Figure 1. Polymers used for the multivalent presentation of Cholera toxin ligands

\subsection{Results}

\subsubsection{Synthesis}

A major limitation of the use of MNPG as a ligand suitable for conjugation, was its difficult, poorly described and extremely low yielding synthesis. ${ }^{28}$ In our hands eventually an imidate-based, TfOH catalyzed glycosylation proved to yield the desired $\alpha$-isomer with reasonable yields. 3-hydroxy5-nitrobenzoic acid was used as the starting point for the synthesis in which the acidic group was converted to a propargyl amide $\mathbf{2}$ (Scheme 1). Galactose imidate $\mathbf{1}^{37}$ was used as the glycosyl donor and a glycosylation reaction was performed using triflic acid as the promoter wherein phenol (2), obtained from 3-hydroxy-5-nitrobenzoic acid, served as the acceptor. The glycosylation product (3) was obtained in $40-44 \%$. It was then deprotected to give the MNPG ligand 4 that was used for the 'click' reaction with the different polymeric scaffolds. We have synthesized unsubstituted MNPG using 3-nitrophenol as the glycosyl acceptor and galactose imidate as the donor in the triflic acid promoted glycosylation to give the $\alpha$-isomer $\mathbf{5}$ in $58 \%$ yield, which was deprotected to give MNPG 6. Besides compounds 4 and 6, a third MNPG-based and more soluble monovalent compound was synthesized using 11-azido-3,6,9-trioxundecan-1amine by first converting the amine to amide $\mathbf{7}$ and then conjugating it to $\mathbf{3}$ to give $\mathbf{8}$ which was deprotected to give $\mathbf{9}$.

11-azido-3,6,9-trioxundecan-1-amine was also used for the conjugation of an azide moiety to polyacrylamide (Mn: $150 \mathrm{kDa})$ and dextran $(\mathrm{Mn}: 150 \mathrm{kDa})$ according to reported procedures ${ }^{38,22}$ to give polymers $\mathbf{1 0}$ and $\mathbf{1 1}$ respectively (Scheme 2). The incorporation of the azide group was confirmed by the appearance of the azide stretching peak at $2110 \mathrm{~cm}^{-1}$ in the infrared spectroscopy (IR) spectra. The molecular weights and the percent azide functionalization of $\mathbf{1 0}$ 
and 11 (1.7\% and $0.6 \%$ respectively) were calculated by integrating relevant peaks in the proton NMR spectra. ${ }^{38} \mathrm{~A}$ shorter azide containing appendage was also used to functionalize dextran. ${ }^{39}$ To this end 1-azido-2,3-epoxypropane was used which was synthesized in two steps from epichlorohydrin Polymer 12 was obtained with a 6\% azide functionalization, as determined by proton NMR and was conjugated to the MNPG ligand 4 and prop-2-ynyl $\beta$-galactoside using CuAAC to give 15 and 17 respectively. The complete disappearance of the azide stretching peak in each of the reactions confirmed that all of the polymer azide was consumed. hPG (Mn: 10,000) with a $10 \%$ azide functionalization was prepared as before ${ }^{35}$ and used for conjugation to 4 to give glycopolymer 18. 


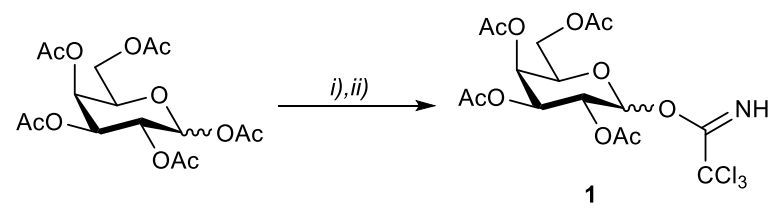<smiles>C#CCNC(=O)c1cc(O)cc([N+](=O)[O-])c1</smiles>

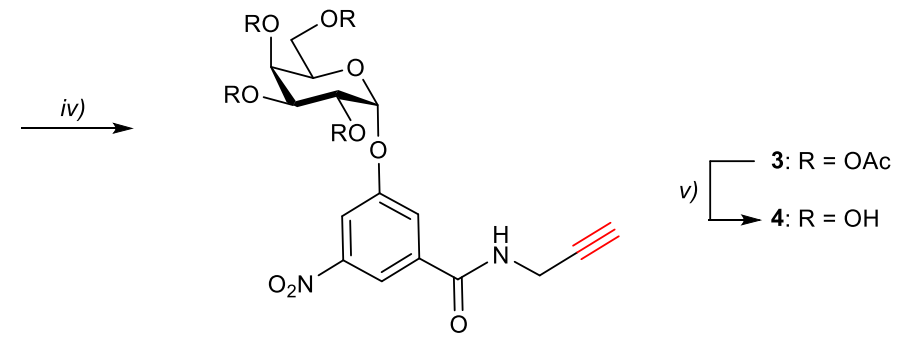
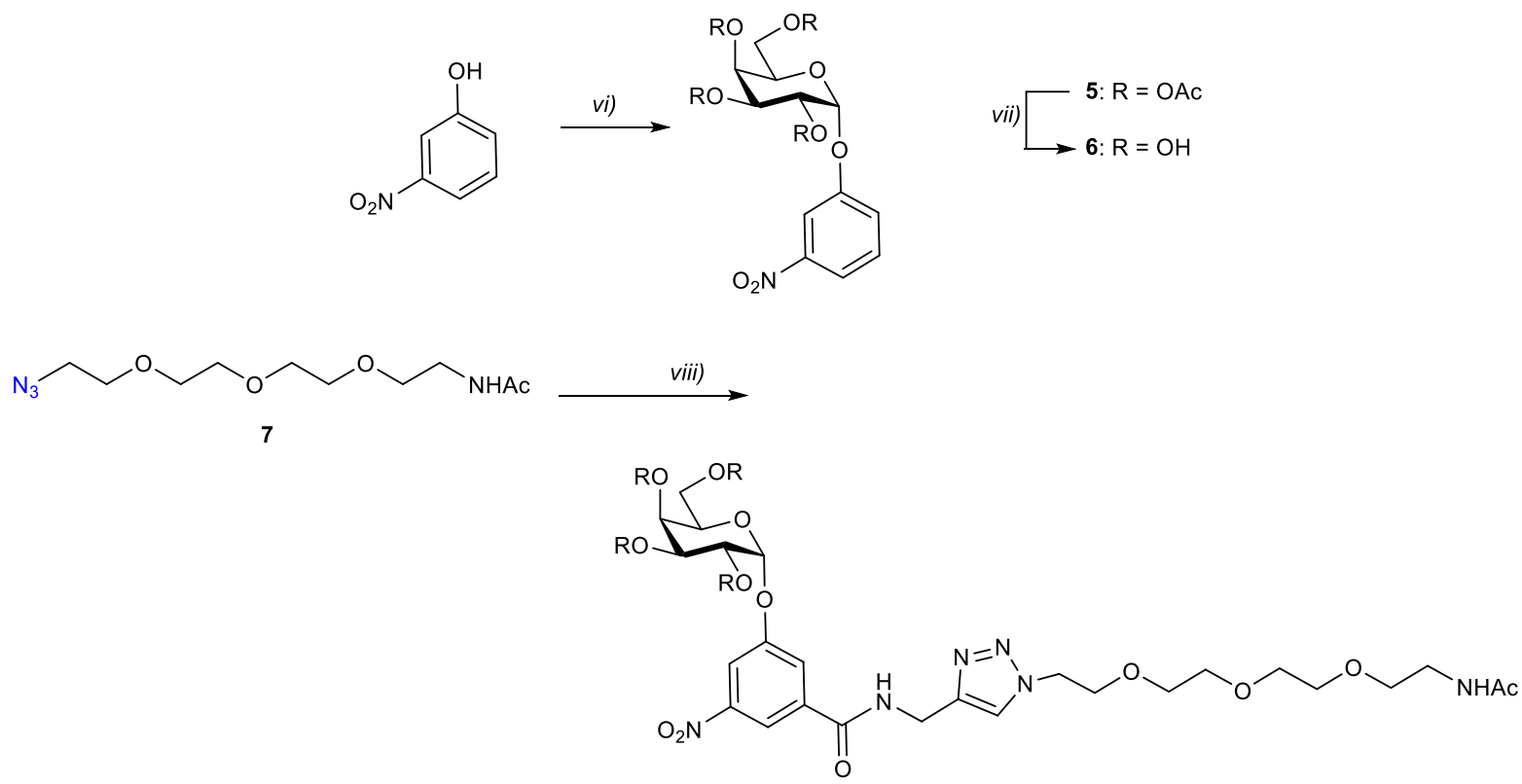

ix) $\longrightarrow$ 8: $\mathrm{R}=\mathrm{OAC}$

Scheme 1. Synthesis of MNPG and derivatives

Reagents and conditions: (i) $\mathrm{BnNH}_{2}, \mathrm{DMF}$, r.t., quantitative, (ii) Trichloroacetonitrile, $\mathrm{K}_{2} \mathrm{CO}_{3}, \mathrm{CH}_{2} \mathrm{Cl}_{2}, 96 \%$, (iii) Propargylamine, EDCI, DMAP,76\%, (iv) 1, TfOH, $-35^{\circ} \mathrm{C}$-r.t. 40-44\%, (v) $\mathrm{NaOH}, \mathrm{MeOH}, 85 \%$, (vi) 1, $\mathrm{TfOH},-35^{\circ} \mathrm{C}$-r.t. $58 \%$, (vii) $\mathrm{NaOH}, \mathrm{MeOH}, 83 \%$, (viii) 3, $\mathrm{CuSO}_{4}, \mathrm{Na}$. ascorbate, microwave, 75\%, (ix) $\mathrm{NaOH}, \mathrm{MeOH}, 73 \%$. 

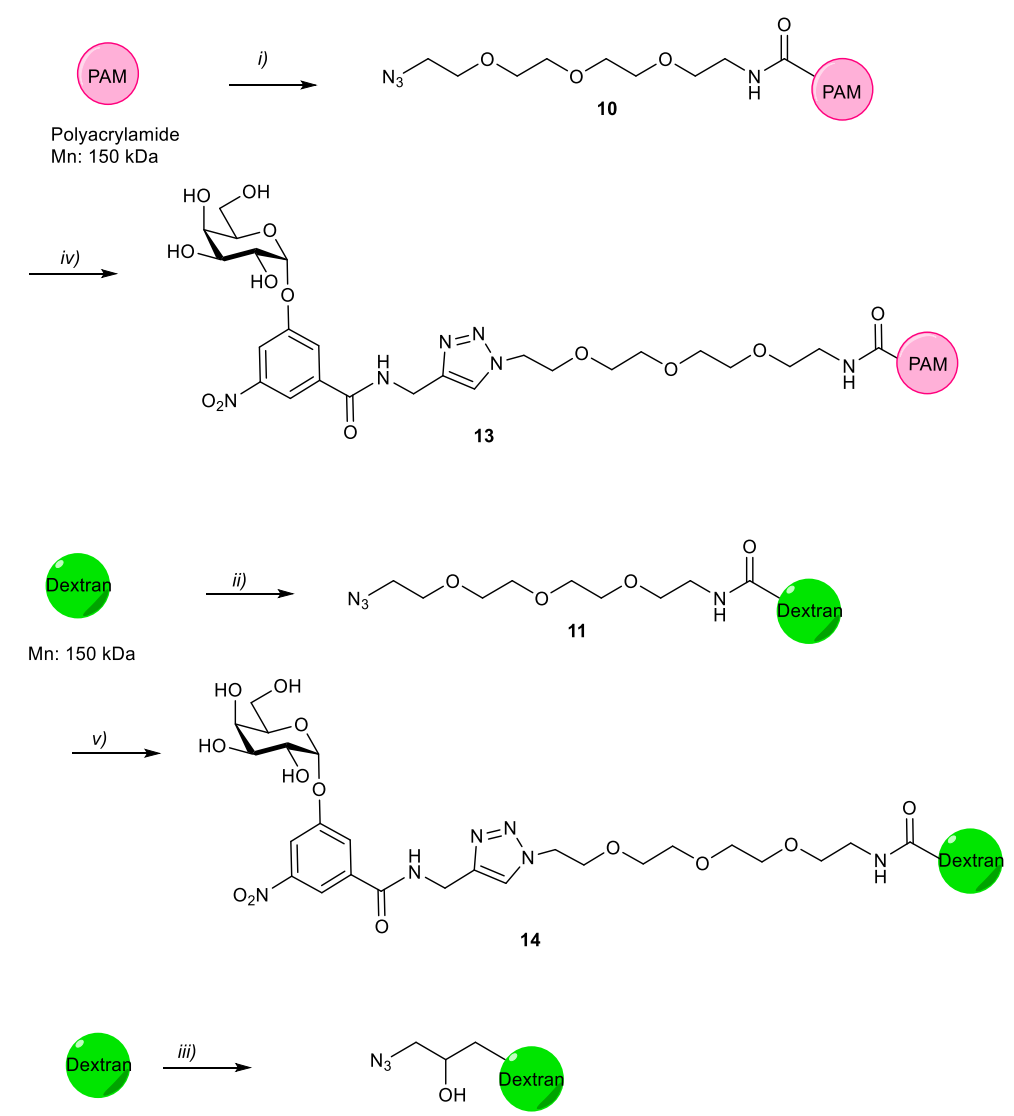

$\mathrm{Mn}: 150 \mathrm{kDa}$

12
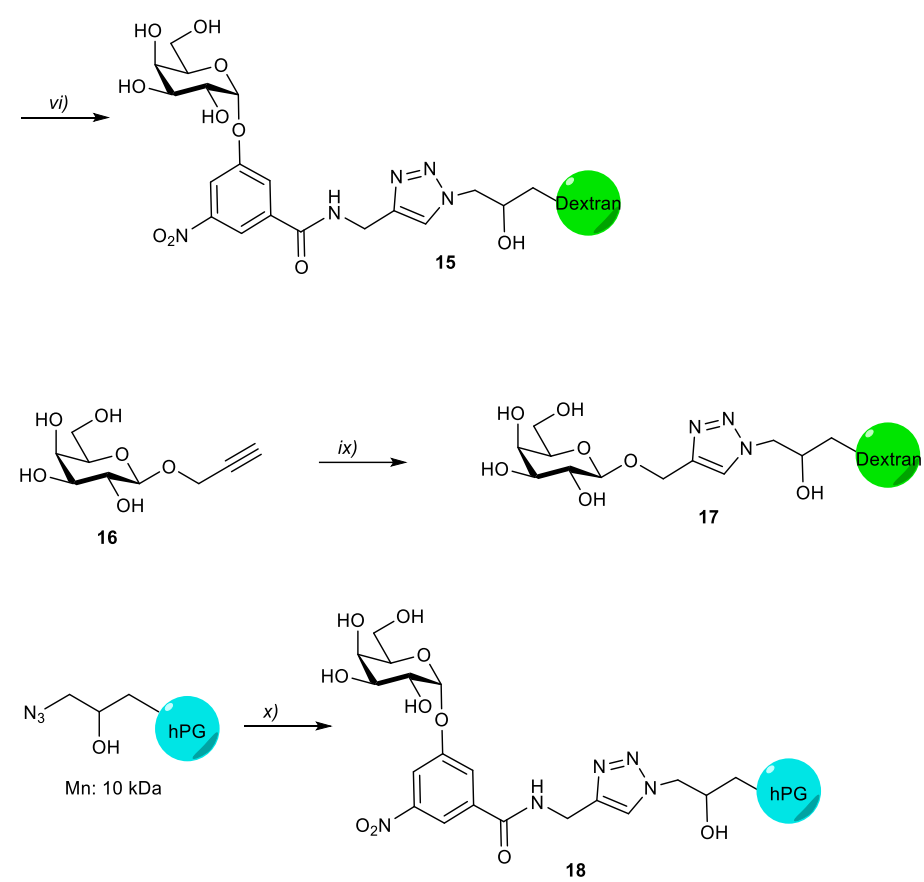

Scheme 2. Synthesis of MNPG- and galactose-based polymers

Reagents and conditions: i) 11-Azido-3,6,9-trioxaundecan-1-amine, $80^{\circ} \mathrm{C}, 60 \mathrm{~min} .95 \%$, ii) 11-Azido-3,6,9trioxaundecan-1-amine, CDI, DMAP, DMSO, r.t., 48h, iii) a) iPrOH, AcOH, NaN3, Epichlorohydrin, 5M NaOH, b) 5M NaOH, iv) $4, \mathrm{CuSO}_{4}$, Na. ascorbate, $100^{\circ} \mathrm{C}, 78 \%$, v) $4, \mathrm{CuSO}_{4}, \mathrm{Na}$. ascorbate, $100^{\circ} \mathrm{C}, 83 \%$, vi) $4, \mathrm{CuSO}_{4}$, Na. ascorbate, $100^{\circ} \mathrm{C}, 51-$ $58 \%$, ix) $12, \mathrm{CuSO}_{4}, \mathrm{Na}$ ascorbate, $\left.100^{\circ} \mathrm{C}, 35 \%, \mathrm{x}\right) 4, \mathrm{CuSO}_{4}$, Na. ascorbate, $100^{\circ} \mathrm{C}, 62 \%$. 


\subsubsection{Cholera toxin inhibition}

The synthesized compounds were tested for their ability to inhibit the cholera toxin B-subunit by making use of the well-established GM1-based ELISA assay. Galactose was used as a reference inhibitor and was the least potent molecule with an $\mathrm{IC}_{50}$ of $111 \mathrm{mM}$ (Table 1). Monovalent inhibitors MNPG (6) and its derivative 9 showed inhibition in the low millimolar range. MNPG emerged as the best monovalent ligand with a 58-fold potency increase over galactose (IC $\mathrm{I}_{50} 1.9$ $\mathrm{mM}$ ) which is comparable to the reported enhancement values. Compound 9 showed 27 -fold potency gain over galactose $\left(\mathrm{IC}_{50}=4 \mathrm{mM}\right)$. All of the multivalent compounds showed at least inhibition in the low micromoler range. Dextran-based Compound 15 and hPG- based compound 18 emerged as the most potent with comparable $\mathrm{IC}_{50}$ values in the nanomolar range (390 and 530 $\mathrm{nM}$ respectively). Dextran-MNPG conjugate $\mathbf{1 5}$ was more potent than the dextran-galactose conjugate 17 despite the same number of azides on the dextran thereby confirming the inhibitory potential of MNPG. Polyacrylamide-MNPG conjugate 13 and dextran conjugate 14 also showed significant inhibition (IC $\mathrm{I}_{50}$ 's $5.6 \mu \mathrm{M}$ and $8.4 \mu \mathrm{M}$ ).

Table 1. Results of inhibition by multivalent carbohydrates in CTB-HRP ELISA assay. ${ }^{a}$

$\begin{array}{ccccccc}\text { construct } & \text { ligand } & \begin{array}{c}\text { Valency (\% } \\ \text { functionalization of } \\ \text { polymer) }\end{array} & \text { IC } 50(\mu \mathrm{M}) & \text { rel.pot.b } & \begin{array}{c}\text { rel. pot. } \\ \text { per sugarc }\end{array} & \begin{array}{c}\mathrm{IC}_{50} \\ (\mu \mathrm{g} / \mathrm{mL})\end{array} \\ \text { galactose } & \text { gal } & 1 & \begin{array}{c}111,500 \\ \pm 10,000\end{array} & 1 & 1 & 20,087 \\ \mathbf{6} & \text { MNPG } & 1 & 1,907 \pm & 58 & 58 & 574 \\ \mathbf{9} & \text { MNPG } & 1 & 420 & & & \\ \mathbf{1 7} & & & 4095 \pm & 27 & 27 & 2,628 \\ \mathbf{1 3} & \text { gal } & 55(6 \%) & 6.6 \pm 1 & 16,870 & 304 & 1,108 \\ \mathbf{1 5} & \text { MNPG } & 36(1.7 \%) & 5.6 \pm 0.5 & 731 & 20 & 961 \\ \mathbf{1 4} & \text { MNPG } & 65(6 \%) & 0.39 \pm 1 & 10,500 & 191 & 69 \\ \mathbf{1 8} & \text { MNPG } & 13(10 \%) & 0.53 \pm 2 & 7,726 & 594 & 8\end{array}$

${ }^{a}$ determined in an ELISA-like assay with CTB5-HRP $(40 \mathrm{ng} / \mathrm{mL})$ and wells coated with GM1, ${ }^{b}$ relative to the potency of galactose for $\mathbf{6}, \mathbf{9}$ and $\mathbf{1 7}$, and to $\mathbf{9}$ for the rest, crelative potency divided by the valency. 
Besides the ELISA assay, the best multivalent glycopolymers $(\mathbf{1 3 , 1 5 , 1 8 )}$ along with all the monovalent compounds were evaluated for their inhibitory potential in our recently reported organoid assay. ${ }^{36}$ To apply the organoid assay, intestinal organoids ${ }^{40}$ were stimulated dose dependently with cholera toxin to select a non-saturating concentration for inhibitor testing while retaining maximal assay sensitivity. $3 \mu \mathrm{g} / \mathrm{mL}$ of cholera toxin was required to induce sufficient swelling of these patient derived organoids which is 30 times higher than was needed for previously used organoids derived from a different patient. ${ }^{36}$ We next assessed dosedependent inhibition of cholera toxin-mediated swelling of the inhibitors for binding cholera toxin B subunit. Galactose was measured as a reference inhibitor. Organoids were stimulated with cholera toxin, with or without inhibitors. We found that all the polymer-based compounds were potent inhibitors of cholera toxin-induced swelling, with $\mathrm{IC}_{50}$ 's in the low micromolar range Table 2). hPG-based inhibitor (18) was the most potent (6.9 $\mu \mathrm{M})$ with $\mathbf{1 3}$ and $\mathbf{1 5}$ showing comparable inhibition ( $\mathrm{IC}_{50}=15 \mu \mathrm{M}$ and $12 \mu \mathrm{M}$ ). Galactose was the least potent $\left(\mathrm{IC}_{50} 100 \mathrm{mM}\right.$ ) with MNPG 6 and 9 inhibiting in the low millimolar concentration ( $\mathrm{IC}_{50} 13 \mathrm{mM}$ and $9.9 \mathrm{mM}$ respectively).

Table 2. Results of inhibition of CT induced swelling of intestinal organoids by multivalent carbohydrates $^{a}$

$\begin{array}{ccccccc}\text { construct } & \text { ligand } & \begin{array}{c}\text { Valency }(\% \\ \text { functionalization of } \\ \text { polymer) }\end{array} & \mathrm{IC}_{50}(\mu \mathrm{M}) & \text { rel.pot.b } & \begin{array}{c}\text { rel. pot. } \\ \text { per sugar }\end{array} & \begin{array}{c}\mathrm{IC}_{50} \\ (\mu \mathrm{g} / \mathrm{mL})\end{array} \\ \text { galactose } & \text { gal } & 1 & \begin{array}{c}100,000 \\ \pm 10,000\end{array} & 1 & 1 & 18,015 \\ \mathbf{6} & \text { MNPG } & 1 & 13,380 \pm & 7 & 7 & 4269 \\ \mathbf{9} & \text { MNPG } & 1 & 1844 & & & \\ \mathbf{1 3} & \text { MNPG } & 36(1.7 \%) & 15.5 \pm 5 & 644 & 18 & 2583 \\ \mathbf{1 5} & \text { MNPG } & 55(6 \%) & 12 \pm 4 & 832 & 10 & 2121 \\ \mathbf{1 8} & \text { MNPG } & 13(10 \%) & 6.9 \pm 2 & 1,448 & 111 & 110\end{array}$

${ }^{a}$ determined in an assay observing the swelling of intestinal organoids by CT as a function of inhibitor concentration, ${ }^{b}$ relative to the potency of galactose for $\mathbf{6}$ and $\mathbf{9}$, and to $\mathbf{9}$ for the rest, ${ }^{c}$ relative potency divided by the valency. 


\subsubsection{Discussion and Conclusion}

We have synthesized and evaluated glycoconjugates as inhibitors of the cholera toxin. Our previous dendrimers containing GM1os were very potent, but not economically practical for application. ${ }^{19,36}$ To put this into perspective, the GM1 sugar that was used for the synthesis currently costs ca. 400 USD per miligram whereas the polymers used by us only cost a fraction i.e. just a dollar or so per gram, which is also the case for 3-hydroxy-5-nitrobenzoic acid, while bulk prices are much lower. For the first time, we described a step-by-step synthesis of MNPG whereby it can be easily synthesised and purified in good quantities. The fact that only the $\alpha-$ isomer of MNPG and derivatives was obtained may be due to the anomeric effect providing enhanced stability for the $\alpha$-isomer caused by the electron withdrawing nitrophenyl group. TfOH likely catalyzes the anomerization to the $\alpha$-isomer even if the $\alpha$-isomer was formed also. Similar observations were made previously. ${ }^{41}$ We also developed a reaction strategy to incorporate it in a multivalent system by synthesizing compound 4. Following this, we have successfully incorporated it into the polymeric scaffolds (i.e. polyacrylamide, dextran and hPG) of varying azide functionalization for the synthesis of the final multivalent compounds. The inhibitory potential of the synthesized compounds was evaluated using the GM1 ELISA protocol. Additionally, an intestinal organoid swelling inhibition assay was performed which is a more biorelevant in vitro assay to confirm the inhibitory potential of the synthesized compounds.

The most important measure for the potency enhancement imparted by the scaffold on which the ligands are presented is the potency per ligand. If a divalent ligand is twice as potent compared to the monovalent ligand it essentially provides no benefit, the relative potency per ligand is 1 . The highest number observed here is 594-fold for $\mathbf{1 8}$. This is a big number and clearly shows the large benefit of the hPG nanoparticle/polymer. The second best was galactose based-dextran conjugate 17 with a 304-fold potency enhancement over galactose. The same scaffold also yielded a high potency enhancement for MNPG linked to the same scaffold, but here the number was 191-fold per sugar. Interestingly, the most effective polymeric backbone seems to be the hPG especially when expressing its activity in terms of $\mu \mathrm{g} / \mathrm{mL}$ of the whole polymeric construct. Its geometry is considered a nanoparticle with a ca. 5-6 nm diameter, ${ }^{35}$ which matches the toxin diameter size (6-7 $\mathrm{nm}$ diameter) quite well. This is a feature that was recently shown to be favorable and of importance for strong inhibition, based on computational studies. ${ }^{42}$

Our previous multivalent dendritic non-polymeric inhibitors, including a pentavalent one, were shown to aggregate the toxin by analytical ultracentrifuge measurements, which may have contributed to their potency. ${ }^{17,43}$ One-on-one complexes have also been reported by DLS for a well-defined $\mathrm{CTB}_{5}$-based inhibitor, ${ }^{16}$ as well as 2:1 complexes for a decavalent system. ${ }^{44}$ Based on this it is likely that the polymeric and nanoparticle inhibitors described here, that are of higher 
valency than our mentioned dendritic inhibitors, also bind to multiple toxins and induce aggregation that way. We here observed a distinct advantage of the nanoparticle $h P G$ as the ligand scaffold over the linear polyacrylamide and the sporadically crosslinked dextran. A possible explanation is that a high number of ligands in a small area is beneficial as they can occupy several of the toxin binding sites simultaneously. The hPG also had the highest ligand density of $10 \%$, and for dextran the higher ligand density of $\mathbf{1 5}$ was beneficial in comparison to the 10 times lower functionalized of 14. The hPG seemed to be the most potent due to a combination of the particle shape of suitable size and a relatively high functionalization. Even though the polyacrylamide and dextran backbones were previously shown ${ }^{22}$ to be highly effective ligand scaffold, the hPG is clearly superior. This is particularly clear when expressing the potency in terms of $\mu \mathrm{g} / \mathrm{mL}$, where the weight of the polymer and the ligand density also play a role.

The cholera toxin inhibition observed here is of sufficient practical potency, that should be able to neutralize the up to micromolar quantities of the toxin B-subunits present in an active infection by repeated administration. The polyacrylamide backbone was the least effective in our study, and is suspect with respect to toxicity. 45 The dextran polymeric backbone is biodegradable, which is considered an advantage for our application, ${ }^{22}$ and has also used by others in the intestinal tract. 46 The hPG nanoparticles have been studied in detail for their behavior in biological systems and found to be non-toxic. ${ }^{47}$

We have prepared a new potent conjugate between MNPG and the pharmaceutically benign hPG nanoparticle platform. The new synthesis makes MNPG readily accessible and the conjugate showed good potency against the cholera toxin B-subunit in two assays, with potential as a prophylactic drug in cholera epidemics. 


\subsection{Experimental Section}

\subsubsection{General information}

Chemicals were obtained from commercial sources and were used without further purification unless noted otherwise. Solvents were purchased from Biosolve (Valkenswaard, The Netherlands). All the other solvents were dried over molecular sieves $4 \AA$ or $3 \AA$ A TLC was performed on Merck precoated Silica 60 plates. Spots were visualized by UV light and $10 \% \mathrm{H}_{2} \mathrm{SO}_{4}$ in $\mathrm{MeOH}$. Microwave reactions were carried out in a Biotage microwave Initiator (Uppsala, Sweden). The microwave power was limited by temperature control once the desired temperature was reached. Sealed vessels of 2-5 mL and 10-20 mL were used. 1H NMR, HSQC, COSY $(400 \mathrm{MHz}, 500 \mathrm{MHz})$ and 13C (100 MHz, $162 \mathrm{MHz})$ were performed on a Varian G-300 spectrometer. Electrospray Mass experiments were performed in a Shimadzu LCMS QP-8000. High resolution mass spectrometry (HRMS) analysis was performed using an ESI-QTOF II spectrometer (Bruker, Billerica, USA) and Applied Biosystems 4700 MALDI TOF/TOF instrument. Infrared (IR) spectroscopy was performed using Universal Attenuated Total Reflectance (UATR) accessory of Perkin Elmer Spectrum Two FT-IR. Polyacrylamide (749222 Aldrich, Avg Mn:: 150000) and Dextran (D-4876 Sigma, Avg Mn:: 150000) was purchased from Sigma-Aldrich.

Note: hPG(10kDa) was synthesized by Sumati Bhatia in the lab of professor R. Haag. The organoid assay was performed by Eyleen de Poel in the lab of professor J. Beekman.

\subsubsection{CTB5 inhibition assay (GM1 ELISA)}

A 96-well plate was coated with a solution of GM1 $(100 \mu \mathrm{L}, 2 \mu \mathrm{g} / \mathrm{mL})$ in phosphate buffered saline (PBS) overnight. Unattached ganglioside was removed by washing with PBS and the remaining binding sites of the surface were blocked with BSA (1\%) which was followed by washing with PBS. Samples of toxin-peroxidase conjugate (CTB5-HRP; Sigma, 40ng/ml) and inhibitor in PBS with BSA $(0.1 \%)$ and Tween-20 (0.05\%) were incubated at room temperature for $2 \mathrm{~h}$ and were then transferred to the GM1-coated plate. After $30 \mathrm{~min}$ of incubation the solution was removed and the wells were washed with BSA $(0.1 \%) /$ Tween-20 $(0.05 \%)$ in PBS. To identify toxin binding to surface-bound GM1, the wells were treated with a freshly prepared solution of ophenylenediamine $/ \mathrm{H}_{2} \mathrm{O}_{2}$ in citrate buffer $(100 \mu \mathrm{L})$ for $15 \mathrm{~min}$. After being quenched with $\mathrm{H}_{2} \mathrm{SO}_{4}$, the absorbance in each well was measured at $490 \mathrm{~nm}$. Inhibition data from at least two independent experiments were averaged and fitted in GraphPad Prism 5.0 


\subsubsection{Organoid assay}

\section{Human Rectal Biopsies}

Rectal biopsies were collected from a healthy human subject after acquiring approval of this study by the Ethics Committee of the University Medical Center Utrecht (UMCU) and after obtaining informed consent of this individual.

\section{Generating and Culturing organoids}

The generation and biobanking of the intestinal organoids differed slightly from previously described protocols ${ }^{40,48}$. After washing rectal biopsies with PBS, crypts were isolated by 60-90 min incubation in $10 \mathrm{mM}$ Ethylenediaminetetraacetic acid (EDTA) solution at $4^{\circ} \mathrm{C}$ on a rocking platform. Crypts were collected, centrifuged at $130 \mathrm{~g}$ for $5 \mathrm{~min}$ at $4{ }^{\circ} \mathrm{C}$, and supernatant was removed. The pellet containing the crypts was resuspended in 50\% matrigel (Corning, diluted in complete culture medium, see below), and matrigel droplets harbouring crypts were plated in pre-warmed 24-well plates. After polymerization of the matrigel $\left( \pm 15 \mathrm{~min}\right.$ at $37^{\circ} \mathrm{C} / 5 \% \mathrm{CO}_{2}$ ), droplets were immersed in complete culture medium (advanced DMEM/F12 supplemented with HEPES, GlutaMAX, penicillin and streptomycin, B-27 (2\%), mEGF (50 ng/ml, Life Technologies), $\mathrm{N}$-acetylcysteine (1,25 mM), nicotinamide (10 mM), SB202190 (10 $\mu$ M, Sigma), A83-01 (500 nM, Tocris),, prymocin (100 $\mathrm{mg} / \mathrm{ml}$, Invivogen), and 50\% Wnt3a-, 20\% Rspo-1-, and 10\% Nogginconditioned media). In 5-9 days, crypts grew out into fully grown organoids, which were subsequently passaged 1:4 via mechanical disruption of the organoids. Culture medium was refreshed every 2-3 days, and organoids were passaged at least two times before assays were performed.

\section{Organoid swelling assay}

CFTR function measurements in intestinal organoids was performed slightly different when compared to previously described procedures.54,48,36 Organoid cultures of 6-8 days old were mechanically disrupted, seeded into flat-bottom 96 -well plates in 50\% matrigel and incubated overnight at $37^{\circ} \mathrm{C} / 5 \% \mathrm{CO}_{2}$. The next day, cholera toxin $(3 \mu \mathrm{g} / \mathrm{mL})$ was incubated together with cholera toxin inhibitors (titration range) for $4 \mathrm{~h}$ at room temperature, followed by staining of the organoids with $3 \mu \mathrm{M}$ calcein AM (Invitrogen) for 15-30 min prior to organoid stimulation. Swelling of organoids was monitored over time using the Zeiss LSM 800 confocal microscope (images were taken every 15 min during cholera/inhibitor stimulation and every 10 min during forskolin stimulation) while the organoids were kept at $37^{\circ} \mathrm{C} / 5 \% \mathrm{CO}_{2}$. Organoid area increase (2D) was analyzed using Zen Blue 2.0 analysis software, and area under the curve (AUC) calculations (of the total area increase measured in $4 \mathrm{~h}$ ) were conducted with GraphPad Prism 5.0. 


\section{Cholera toxin and inhibitors}

Cholera toxin from Vibrio cholerae (Sigma C8052) was used to stimulate organoid fluid secretion. Cholera toxin inhibitors were preincubated for $4 \mathrm{~h}$ with cholera toxin prior to organoid stimulation. The multivalent structures of the inhibitors are based on polyacrylamide, dextran and hPG. The monovalent inhibitors are MNPG-based and free galactose serves as a reference compound. 


\subsubsection{Inhibition curves for GM1 ELISA}

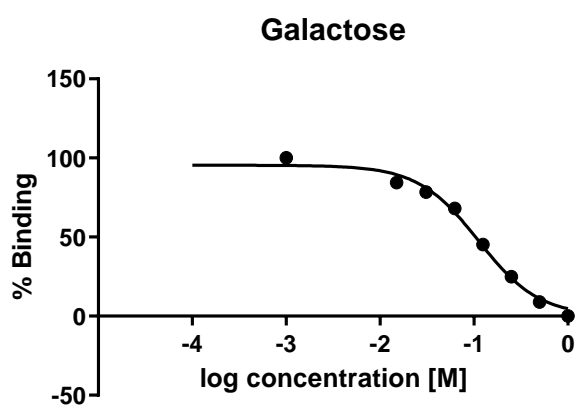

$\mathrm{IC}_{50}(\mu \mathrm{M}): 111,500 \pm 10,000$

Compound 9

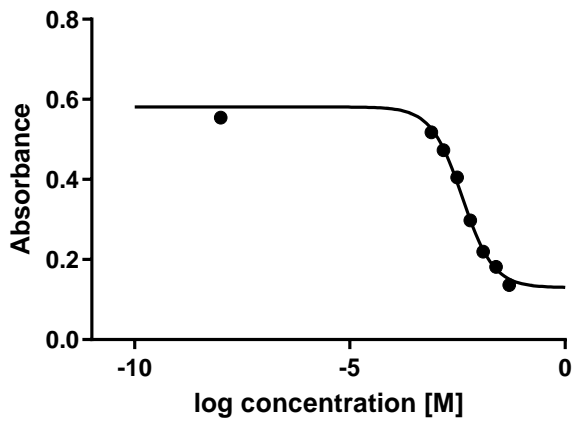

IC $50(\mu \mathrm{M}): 4095 \pm 230$

Compound 14

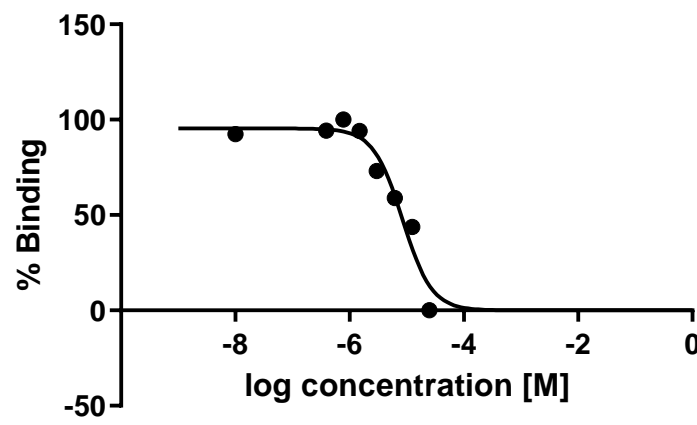

$\mathrm{IC}_{50}(\mu \mathrm{M}): 8.4 \pm 1$

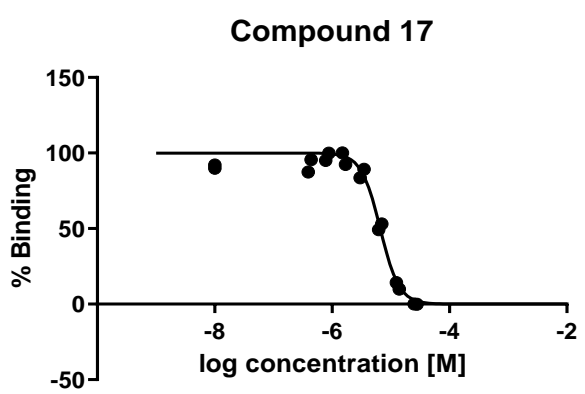

IC $50(\mu \mathrm{M}): 6.6 \pm 1$
Compound 6

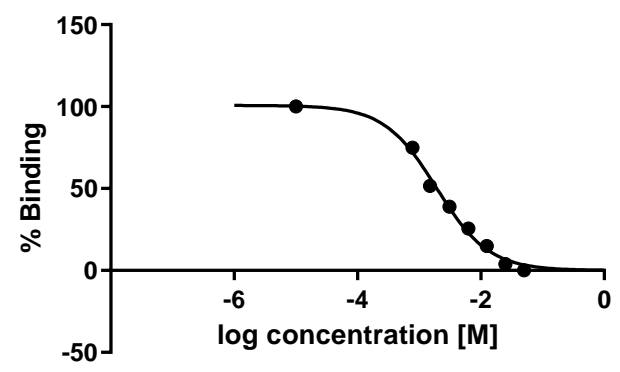

$\mathrm{IC}_{50}(\mu \mathrm{M}): 1,907 \pm 420$

Compound 13

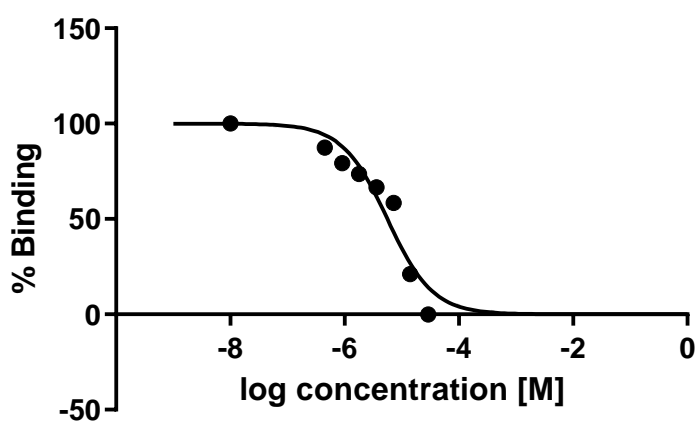

IC $50(\mu \mathrm{M}): 5.6 \pm 0.5$

Compound 15

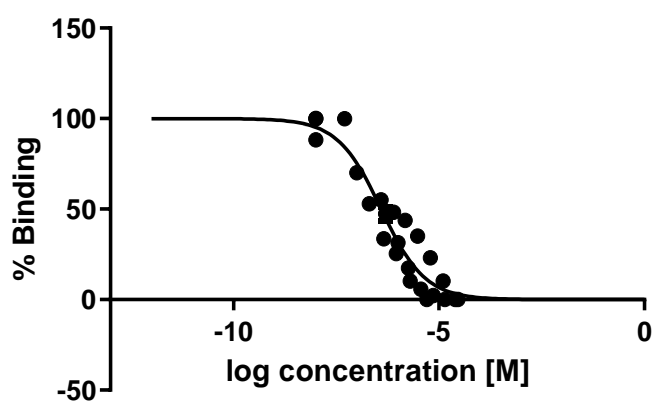

IC $_{50}(\mu \mathrm{M}): 0.39 \pm 1$

Compound 18

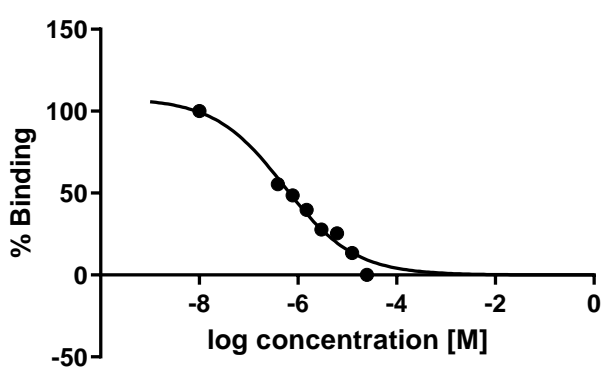

$\mathrm{IC}_{50}(\mu \mathrm{M}): 0.53 \pm 2$ 


\subsubsection{Inhibition curves for Organoid assay}

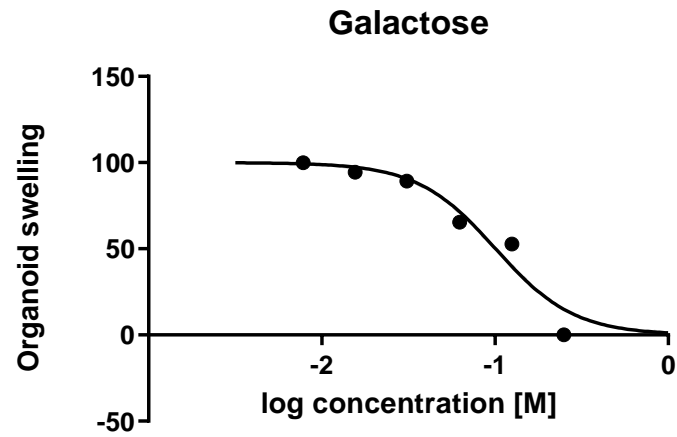

$\mathrm{IC}_{50}(\mu \mathrm{M}): 100,000 \pm 10,000$

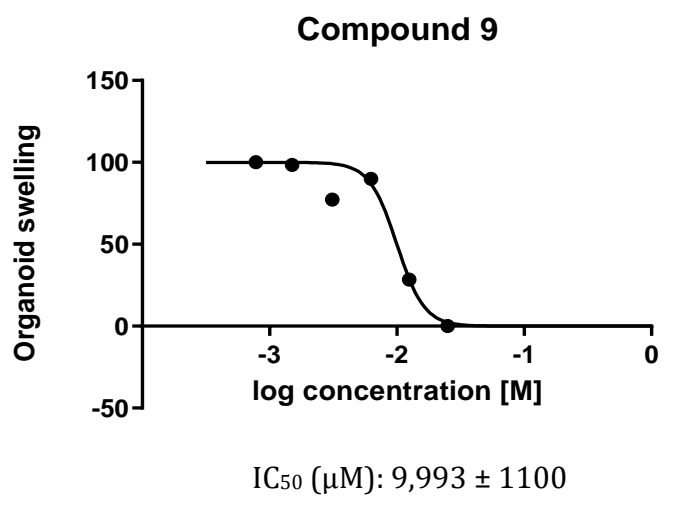

Compound 15

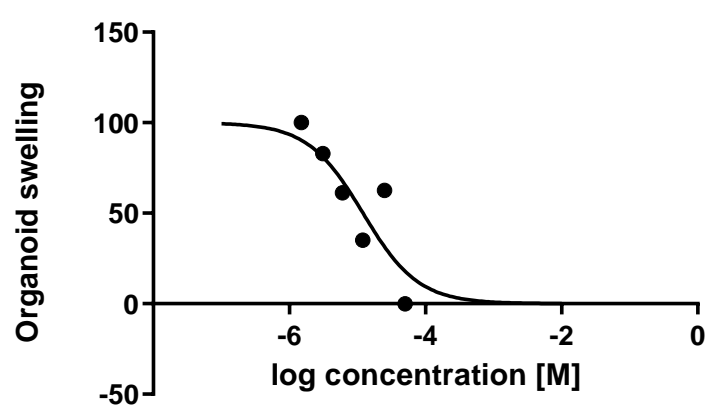

$\mathrm{IC}_{50}(\mu \mathrm{M}): 12 \pm 4$
Compound 6

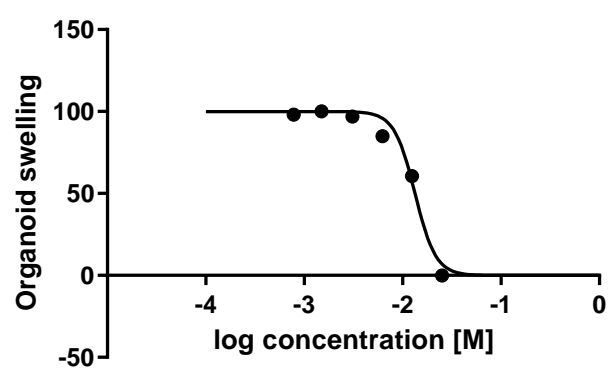

$\mathrm{IC}_{50}(\mu \mathrm{M}): 13,380 \pm 1844$

Compound 13

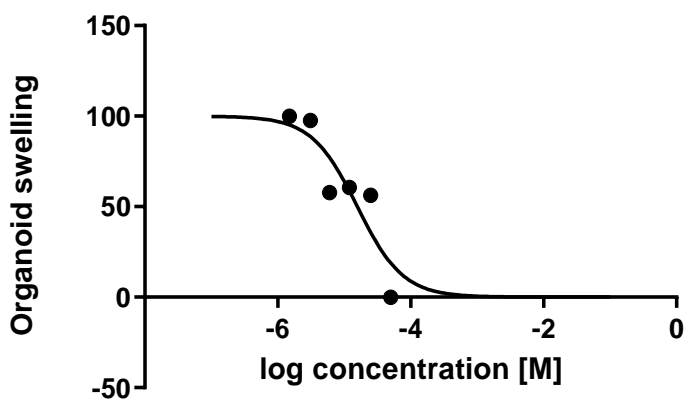

IC50 $(\mu \mathrm{M}): 15.5 \pm 5$

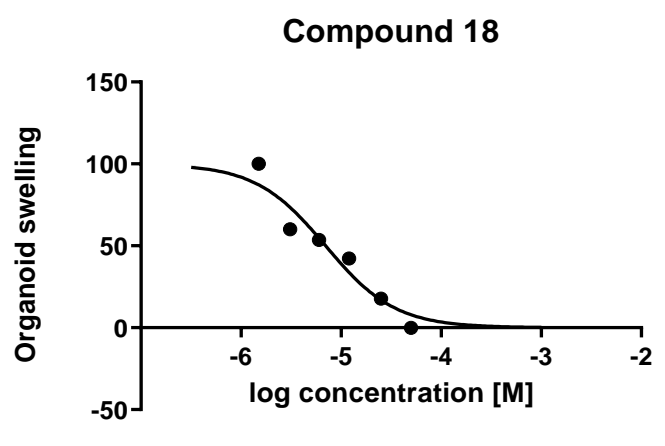

$\mathrm{IC}_{50}(\mu \mathrm{M}): 6.9 \pm 2$ 


\subsubsection{Detailed Synthesis}

\section{General procedure for the deacetylation reaction}

The protected compound is dissolved in anhydrous methanol, followed by addition of a catalytic amount of aqueous $1 \mathrm{M} \mathrm{NaOH}$ solution and stirred at room temperature. The reaction is monitored by TLC. Upon the completion of the reaction, if required, the reaction mixture is neutralized by the addition of Dowex marathon resin. The solvent is evaporated and the crude mixture is purified by column chromatography (EtOAc: $\mathrm{MeOH}: \mathrm{H}_{2} \mathrm{O}-4: 2: 1$ ) to get the pure compound.

\section{General procedure for the click reaction}

The azido polymer is dissolved in water followed by the addition of the ligand (1.3 equiv.). 0.1 equiv. of copper sulphate pentahydrate is dissolved in water separately and added to the reaction mixture. $0.3 \mathrm{Eq}$. of sodium ascorbate is also dissolved in water separately and added to the reaction mixture. The reaction is carried out at $100^{\circ} \mathrm{C}$ in the microwave for $60 \mathrm{~min}$. The solvent is evaporated and the crude reaction mixture is purified by dialysis using a cellulose based dialysis cassette (MWCO: 2K) against deionized water for 3-4 days and freeze dried.

\subsubsection{Synthesis of intermediates and MNPG monovalent compounds}

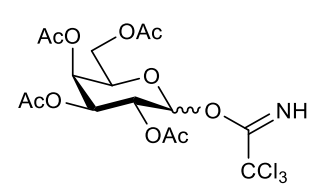

1,2,3,4,6-penta-o-acetyl- $\beta$-D-galactopyranoside ( $10 \mathrm{~g}, 25.64 \mathrm{mmol}$ ) was dissolved in DMF ( $100 \mathrm{~mL}$ ). To this solution, benzylamine $\left(3.76 \mathrm{~mL}, 43.58 \mathrm{mmol}\right.$ ) was added and stirred at $60{ }^{\circ} \mathrm{C}$ till the completion of the reaction. The solvent was removed and the mixture was dissolved in $\mathrm{CH}_{2} \mathrm{Cl}_{2}$ and then washed with saturated sodium bicarbonate, water, and brine. The combined organic layers were dried over $\mathrm{Na}_{2} \mathrm{SO}_{4}$, filtered and concentrated under reduced pressure. The residue was purified by column chromatography on silica gel to afford the anomeric deacetylation product as a yellow solid in quantitative yield. The NMR data was consistent with that reported in the literature. 49

To a solution of the above compound (6.26 g, $16.30 \mathrm{mmol})$ in anhydrous $\mathrm{CH}_{2} \mathrm{Cl}_{2}(90 \mathrm{~mL})$, potassium carbonate (11.25 g, $81.5 \mathrm{mmol})$ and trichloroacetonitrile $(16.3 \mathrm{~mL}, 163 \mathrm{mmol})$ was added and stirred at room temperature overnight. Upon completion of the reaction, potassium carbonate was filtered off and the solvent was evaporated. The residue was purified by column chromatography on silica gel to afford $\mathbf{1}$ as a yellow solid $(96 \%, \alpha: \beta=60: 40)$. The NMR data was consistent with that reported in the literature. ${ }^{37}$ 


\section{Compound 2}<smiles>C#CCNC(=O)c1cc(O)cc([N+](=O)[O-])c1</smiles>

3-hydroxy-5-nitrobenzoic acid (5 g, $27.32 \mathrm{mmol}$ ) is dissolved in anhydrous $\mathrm{CH}_{2} \mathrm{Cl}_{2}$ (100 mL) and pyridine (30 mL). To this mixture, 1-Ethyl-3-(3-dimethylaminopropyl)carbodiimide (6.26 g, $32.78 \mathrm{mmol}$ ), 4-Dimethylaminopyridine (3.99 g, $32.78 \mathrm{mmol}$ ) and propargylamine (6.98 $\mathrm{mL}, 109.28$ $\mathrm{mmol}$ ) is added and stirred at room temperature overnight. The reaction mixture is diluted with ethyl acetate and extracted using $\mathrm{KHSO}_{4}$, saturated $\mathrm{NaHCO}_{3}$, water, and brine. The combined organic layers are dried over anhydrous $\mathrm{Na}_{2} \mathrm{SO}_{4}$, filtered and concentrated under reduced pressure to give $\mathbf{2}$ as a fairly pure off-white solid in $76 \%$ yield which was used without further purification. HRMS: calcd for $\mathrm{C}_{10} \mathrm{H}_{8} \mathrm{~N}_{2} \mathrm{O}_{4}$ $(\mathrm{M}+\mathrm{H})+221.0562$, found 221.0559. ${ }^{1} \mathrm{H}$ NMR $(400 \mathrm{MHz}$, DMSO-d $) \delta(\mathrm{ppm}): 10.75(\mathrm{~s}, 1 \mathrm{H}, \mathrm{OH}), 9.24(\mathrm{t}, J=5.5$ $\mathrm{Hz}, 1 \mathrm{H}, \mathrm{NH}$ ), 8.16 (dd, J = 2.1, $1.5 \mathrm{~Hz}, 1 \mathrm{H}, \mathrm{H}-6$ ), $7.70-7.67$ (m, 2H, H-2, H-4), 4.06 (dd, J = 5.5, $2.5 \mathrm{~Hz}, 2 \mathrm{H}, \mathrm{H}-$ 8), 3.15 (t, 1H, H-10). ${ }^{13} \mathrm{C}$ NMR (100 MHz, DMSO- $d_{6}$ ) $\delta(\mathrm{ppm}): 163.84$ (C-7) 158.30 (C-3), 148.65 (C-5), 136.16 (C-1), 120.94 (C-2), 112.48 (C-4), 112.30(C-6), 80.83 (C-9), 73.12 (C-10), 28.71 (C-8).

\section{Compound 3}

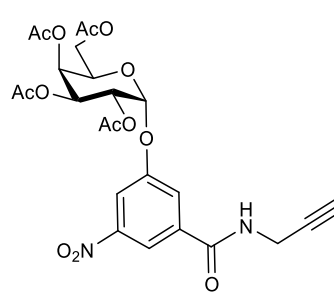

Compound 1 (3.35g, $6.81 \mathrm{mmol})$ was dissolved in anhydrous $\mathrm{CH}_{2} \mathrm{Cl}_{2}(20 \mathrm{~mL})$, followed by addition of compound 2 ( $1 \mathrm{~g}, 4.54 \mathrm{mmol}$ ) in anhydrous acetonitrile $(20 \mathrm{~mL})$. The reaction mixture was cooled to $-35^{\circ} \mathrm{C}$ and trifluoromethanesulfonic acid $(0.3 \mathrm{~mL}, 3.4 \mathrm{mmol})$ was added and stirred at room temperature overnight. The reaction mixture was diluted with $\mathrm{CH}_{2} \mathrm{Cl}_{2}$ and extracted using sodium bicarbonate $(200 \mathrm{~mL}, 2 \mathrm{X})$, water $(100 \mathrm{~mL}, 2 \mathrm{X})$, and brine water $(100 \mathrm{~mL}, 1 \mathrm{X})$. The combined organic layers were dried over anhydrous $\mathrm{Na}_{2} \mathrm{SO}_{4}$, filtered and concentrated under reduced pressure. The residue was purified by column chromatography on silica gel (5\% Acetone in $\left.\mathrm{CH}_{2} \mathrm{Cl}_{2}\right)$ to afford $\mathbf{3}$ as an off-white solid (40-44\%). HRMS m/z calcd for $\mathrm{C}_{24} \mathrm{H}_{26} \mathrm{~N}_{2} \mathrm{O}_{13}(\mathrm{M}+\mathrm{H})+551.1513$, found 551.1507. ${ }^{1} \mathrm{H}$ NMR (400 MHz, $\mathrm{CDCl}_{3}-$ d) $\delta(\mathrm{ppm}): 8.32\left(\mathrm{dd}, \mathrm{J}=2.0,1.4 \mathrm{~Hz}, 1 \mathrm{H}, \mathrm{H}-4^{\prime}\right), 8.09$ (t, J = 2.2 Hz, 1H, H-2'), 7.89 (dd, J = 2.4, $1.5 \mathrm{~Hz}, 1 \mathrm{H}, \mathrm{H}-6^{\prime}$ ), $6.66(\mathrm{t}, 1 \mathrm{H}, \mathrm{NH}), 5.89$ (d, J = 3.6 Hz, 1H, H-1), $5.58-5.50(\mathrm{~m}, 2 \mathrm{H}, \mathrm{H}-3$ and H-4 ), $5.36-5.29$ (m, 1H, H-2), 4.34 - 4.25 (m, 3H, H-8'and H-5), 4.18 - 4.03 (m, 2H, H-6), 2.32 (t, J = 2.6 Hz, 1H, H-10'), 2.21 - 1.91 (m, 12H, 4 X $\left.\mathrm{CH}_{3}\right)$.

${ }^{13} \mathrm{C}$ NMR $\left(100 \mathrm{MHz}, \mathrm{CDCl}_{3}-d\right) \delta(\mathrm{ppm}): 170.67,170.39,170.18,170.10$ (4× C=0), 164.32(C-7'), 156.83(C-1'), 149.08(C-3'), 136.66(C-5'), 122.37(C-6'), 116.29(C-2'), 114.63(C-4'), 95.49(C-1), 79.10(C-9'), 72.11(C-10'), 67.90(C-5), 67.69(C-2), 67.39(C-3), 67.25(C-4), 61.60(C-6), 29.97(C-8'), 20.72, 20.66, 20.62, 20.52 (4× $\mathrm{C}(\mathrm{O}) \mathrm{CH} 3)$. 


\section{Compound 4}

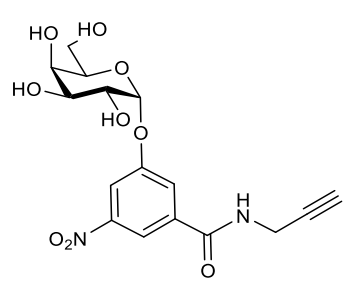

${ }^{1} \mathrm{H}$ NMR (400 MHz, $\left.\mathrm{D}_{2} \mathrm{O}-d\right) \delta 8.19\left(\mathrm{t}, \mathrm{J}=1.7 \mathrm{~Hz}, 1 \mathrm{H}, \mathrm{H}-4^{\prime}\right), 8.12\left(\mathrm{t}, \mathrm{J}=2.2 \mathrm{~Hz}, 1 \mathrm{H}, \mathrm{H}-2^{\prime}\right)$, 7.83 (t, J = 1.9 Hz, 1H, H-6'), 5.80 (d, J = 3.5 Hz, 1H, H-1), 4.20 - 3.96 (m, 6H, H-8', H-2, H-3, H-4, H-5), 3.81 3.66 (m, 2H, H-6), 2.69 (t, 1H, H-10'). ${ }^{13} \mathrm{C}$ NMR (101 MHz, D2O-d) $\delta 166.97\left(\mathrm{C}-7^{\prime}\right), 156.73\left(\mathrm{C}-1^{\prime}\right), 148.53\left(\mathrm{C}-3^{\prime}\right)$, 135.44(C-5'), 121.97(C-6'), 116.10(C-4'), 115.07(C-2'), 97.58(C-1), 79.16, 72.24, 72.06, 69.24, 68.98, 67.78, 60.91(C-6), 29.37(C-8').Yield: 85\% (calculated for sodium acetate impurity), HRMS m/z calcd for $\mathrm{C}_{16} \mathrm{H}_{18} \mathrm{~N}_{2} \mathrm{O} 9(\mathrm{M}+\mathrm{H})^{+} 383.1090$, found 383.1086.

\section{Compound 5}

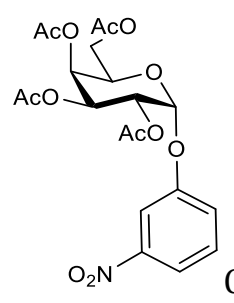

Compound $\mathbf{1}$ ( $1.32 \mathrm{~g}, 2.69 \mathrm{mmol}$ ) was dissolved in anhydrous $\mathrm{CH}_{2} \mathrm{Cl}_{2}(13 \mathrm{~mL})$, followed by addition of 3-nitrophenol $(0.25 \mathrm{~g}, 1.79 \mathrm{mmol})$. The reaction mixture was cooled to $-35^{\circ} \mathrm{C}$ and trifluoromethanesulfonic acid $(0.12 \mathrm{~mL}, 1.34 \mathrm{mmol})$ was added and stirred at room temperature. The reaction mixture was diluted with $\mathrm{CH}_{2} \mathrm{Cl}_{2}$ and extracted using sodium bicarbonate $(100 \mathrm{~mL}, 2 \mathrm{X})$, water $(100$ $\mathrm{mL}, 2 \mathrm{X})$, and brine water $(100 \mathrm{~mL}, 1 \mathrm{X})$. The combined organic layers were dried over anhydrous $\mathrm{Na}_{2} \mathrm{SO}_{4}$, filtered and concentrated under reduced pressure. The residue was purified by column chromatography on silica gel to afford 5 as a yellow colored solid (58\%). HRMS: calcd for $\mathrm{C}_{20} \mathrm{H}_{23} \mathrm{NO}_{12}\left(\mathrm{M}+\mathrm{NH}_{4}\right)^{+}$487.1564, found 487.1559. ${ }^{1} \mathrm{H}$ NMR (400 MHz, $\left.\mathrm{CDCl}_{3}-d\right) \delta(\mathrm{ppm}): 7.98-7.93\left(\mathrm{~m}, 2 \mathrm{H}, \mathrm{H}-2\right.$ ' and $\mathrm{H}-4{ }^{\prime}$ aryl), $7.49(\mathrm{t}, 1 \mathrm{H}, \mathrm{H}-$ 5' aryl), 7.40 (ddd, J = 8.3, 2.4, 1.1 Hz, 1H, H-6' aryl), 5.85 (d, J = 3.6 Hz, 1H, H-1), $5.58-5.53$ (m, 2H, H-4 and H-3), 5.32 (dd, J = 10.6, 3.6 Hz, 1H, H-2), 4.31 (t, 1H, H-5), $4.13-4.08$ (m, 2H, H-6), $2.20-1.92$ (m, 12H, 4 X $\left.\mathrm{CH}_{3}\right)$.

${ }^{13} \mathrm{C}$ NMR (100 MHz, $\mathrm{CDCl}_{3}-d$ ) $\delta(\mathrm{ppm}): 170.45,170.43,170.20,170.10$ (4× C=0), 156.86 (C-1'), 149.37 (C3'), 130.42 (C-5'), 123.24 (C-6'), 118.13 (C-4'), 112.06 (C-2'), 95.53 (C-1), 67.87(C-5), 67.83(C-4), 67.68(C3), 67.43(C-2), 61.66 (C-6), 20.85, 20.78, 20.74, 20.62 (4× C(O)CH3).

\section{Compound 6}

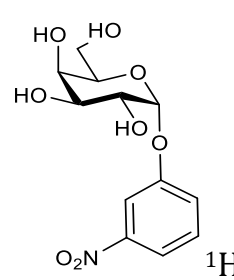

${ }^{1} \mathrm{H}$ NMR (400 MHz, $\left.\mathrm{D}_{2} \mathrm{O}-d\right) \delta 8.05-8.01(\mathrm{~m}, 1 \mathrm{H}, \mathrm{H}-2$ ' aryl), 8.00 - $7.94(\mathrm{~m}, 1 \mathrm{H}, \mathrm{H}-4$ ' aryl), 7.61 - 7.54 (m, 2H, H-5' aryl, H-6' aryl), 5.78 (d, J = 3.7 Hz, 1H, H-1), 4.13 - 3.99 (m, 4H, H-2, H-3, H-4, H-5), 3.76 - 3.65 (m, 2H, H-6). ${ }^{13}$ C NMR (101 MHz, D2O-d) $\delta 156.43$ (C-1'), 148.66 (C-3'), 130.45 (C-5'), 124.05 (C-6'), 
117.79 (C-4'), 112.06 (C-2'), 97.41 (C-1), 72.02 (C-5), 69.35 (C-3), 69.06 (C-2), 67.91 (C-4), 60.94 (C6).Yield: $83 \%$ (calculated for sodium acetate impurity) HRMS: calcd for $\mathrm{C}_{12} \mathrm{H}_{15} \mathrm{NO}_{8}(\mathrm{M}+\mathrm{Na})+324.0695$, found 324.0687.

\section{Compound 7}

$\mathrm{N}_{3} \bigcirc \sim_{\mathrm{O}} \Upsilon_{\mathrm{NHAC}}$

$\mathrm{N}$-acetylation of 11-Azido-3,6,9-trioxaundecan-1-amine $(1.009 \mathrm{mmol})$ was performed using acetic anhydride $(1.26 \mathrm{mmol})$ and pyridine $(0.12 \mathrm{~mL})$ at room temperature overnight. After completion of the reaction solvent was co-evaporated with toluene to give a light yellow colored viscous compound which

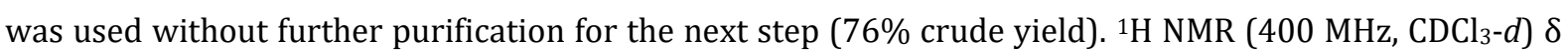
6.35 (s, 1H, NH), 3.68 - 3.54 (m, 10H, H-4, H-5, H-7, H-8, H-10), 3.50 (t, 2H, H-2), 3.38 (q, 2H, H-11), 3.32 (t, 2H, H-1), 1.93 (s, 3H, $\mathrm{CH}_{3}$ ). ${ }^{13} \mathrm{C} \mathrm{NMR} \mathrm{(101} \mathrm{MHz,} \mathrm{CDCl}_{3}-d$ ) $\delta 170.06$ (C=0), 70.49, 70.43, 70.38, 70.06, 69.85 (C-4, C-8, C-10, C-5, C-7), 69.58 (C-2), 50.50 (C-1), 39.18 (C-11), 22.93 (C(O)CH3).

\section{Compound 8}

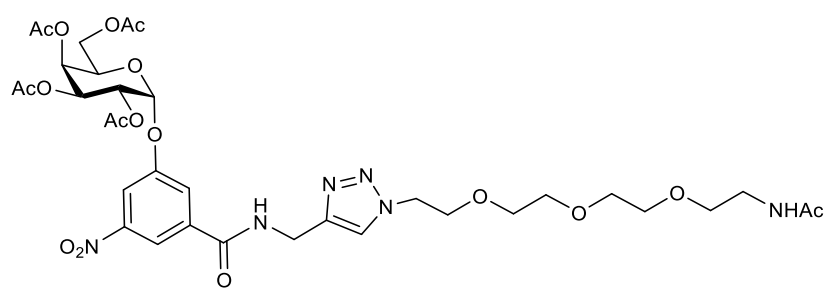

${ }^{1} \mathrm{H}$ NMR $\left(400 \mathrm{MHz}, \mathrm{CDCl}_{3}-d\right) \delta 8.42(\mathrm{~s}, 1 \mathrm{H}, \mathrm{CONH}-$ $\mathrm{CH}_{2}$ ), 8.08 - 7.94 (m, 3H, H-4', H-2', triazole), 7.81 (s, 1H, H-6'), 6.38 (s, 1H, CONH-CH 3 ), 5.89 (d, J = $3.6 \mathrm{~Hz}$, 1H, H-1), 5.57-5.52 (m, 2H, H-3 and H-4), 5.33-5.50 (dd, J = 10.2, $3.8 \mathrm{~Hz}, 1 \mathrm{H}, \mathrm{H}-2$ ), 4.73 (d, J = 5.4 Hz, 2H, H$\left.8^{\prime}\right), 4.54\left(\mathrm{t}, \mathrm{J}=5.0 \mathrm{~Hz}, 2 \mathrm{H}, \mathrm{H}-11^{\prime}\right), 4.29(\mathrm{t}, \mathrm{J}=6.5 \mathrm{~Hz}, 1 \mathrm{H}, \mathrm{H}-5), 4.13-4.02(\mathrm{~m}, 2 \mathrm{H}, \mathrm{H}-6), 3.89(\mathrm{t}, \mathrm{J}=5.0 \mathrm{~Hz}, 2 \mathrm{H}$, H-12'), 3.69 - 3.48 (m, 10H, H-13', H-14', H-15', H-16', H-17'), 3.40 (q, J = 5.3 Hz, 2H, H-18'), 2.06 (m, J = 56.6, $35.0 \mathrm{~Hz}, 15 \mathrm{H}, 5 \mathrm{X} \mathrm{CH}_{3}$ ).Yield: $75 \%$.

\section{Compound 9}

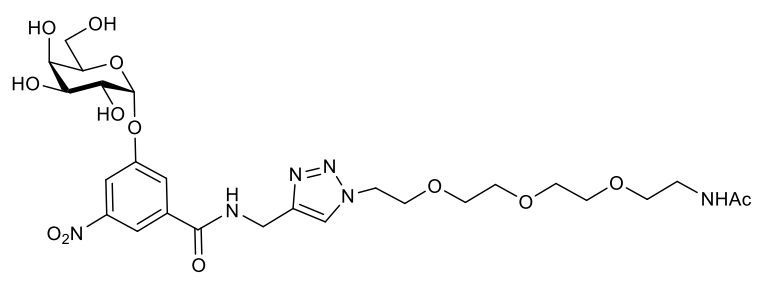

${ }^{1} \mathrm{H}$ NMR $\left(400 \mathrm{MHz}, \mathrm{D}_{2} \mathrm{O}-d\right) \delta 8.34(\mathrm{~d}, \mathrm{~J}=1.7 \mathrm{~Hz}, 1 \mathrm{H}, \mathrm{H}-$

2'), 8.21 (s, 1H, H-4'), 8.05 (s, 1H, H-10'), 7.93 (dd, J = 2.6, 1.3 Hz, 1H, H-6'), 5.86 (d, J = 3.6 Hz, 1H, H-1), 4.73 - 4.55 (m, 4H, H-8', H-11'), 4.18 - 3.92 (m, 7H, H-2, H5, H-3, H-4), 3.82 - 3.39 (m, 15H, H-6, ), 3.31 (t, J = 5.4 $\mathrm{Hz}, 2 \mathrm{H}, \mathrm{H}-18$ '), $1.98-1.90$ (m, 3H, $\left.\mathrm{CH}_{3}\right)$.

${ }^{13} \mathrm{C}$ NMR (101 MHz, D2O- $d$ ) $\delta 173.99$ (C(O)CH3), 167.32 (C(O)NH), 156.76 (C-1'), 148.65 (C-3'), 135.75 (C5'), 124.35 (C-10'), 121.99 (C-6'), 116.13 (C-2'), 115.02 (C-4'), 97.50 (C-1), 72.25 (C-5), 69.54, 69.40, 69.35 (C-3), 69.22, 68.95, 68.62, 68.57 (C-12'), 67.75 (C-2), 60.89 (C-6), 49.95 (C-8'), 38.84 (C-18'), 34.96 (C-11'), 
21.66 (C(O)CH3). Yield: 73\% (calculated for sodium acetate impurity). HRMS: calcd for $\mathrm{C}_{26} \mathrm{H}_{38} \mathrm{~N}_{6} \mathrm{O}_{13}$ $(\mathrm{M}+\mathrm{Na})^{+} 665.2394$, found 665.2411

\section{Compound 16}<smiles>C#CCOC(O)C(O)C1C(CO)OCC(O)C1O</smiles>

1,2,3,4,6-penta-o-acetyl- $\beta$-D-galactopyranoside $(7.69 \mathrm{mmol})$ was dissolved in anhydrous $\mathrm{CH}_{2} \mathrm{Cl}_{2}(20 \mathrm{~mL})$, which was followed by the addition of iodine (4.61 mmol) and triethylsilane ( $4.65 \mathrm{mmol}$ ). The mixture was stirred at r.t. for 60 mins. Upon the complete disappearance of the starting material, the reaction was diluted with $\mathrm{CH}_{2} \mathrm{Cl}_{2}(20 \mathrm{~mL})$ and quenched by the addition of $10 \% \mathrm{NaS}_{2} \mathrm{O}_{3}(20$ $\mathrm{mL})$. The organic phase was separated and washed with sat. $\mathrm{NaHCO}_{3}(20 \mathrm{~mL})$. The collected organic layer was dried over $\mathrm{Na}_{2} \mathrm{SO}_{4}$, filtered and concentrated in vacuo. The obtained white foam was used directly without further purification. The crude iodo-compound in anhydrous $\mathrm{CH}_{2} \mathrm{Cl}_{2}(20 \mathrm{~mL})$ was then treated with propargyl alcohol (13.43 mmol) and $\mathrm{Ag}_{2} \mathrm{CO}_{3}(3.1 \mathrm{~g}, 11.24 \mathrm{mmol}$ ) and stirred at r.t. overnight. The mixture was filtered over celite, the filtrate was concentrated under reduced pressure and the residue was purified by silica gel chromatography, to get the compound (1.16 g, 63\% over two steps) as a colorless oil. The spectroscopic data was consistent with that of the literature. ${ }^{50}$ The deprotection was done according to the general procedure for deacetylation. The final compound $\mathbf{1 6}$ was obtained in quantitative yield and its spectroscopic data was consistent with that of the literature. ${ }^{51}$

\subsubsection{Synthesis of polymers and polymer conjugates}

\section{Compound 10}

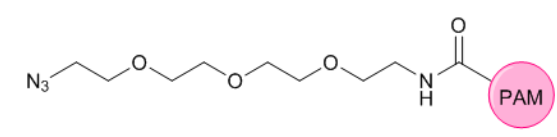

To a solution of polyacrylamide (Mn: 150,000, $40 \mathrm{mg}$ ) in water, 11Azido-3,6,9-trioxaundecan-1-amine $(0.4 \mathrm{~mL})$ was added and the reaction mixture was stirred at $80^{\circ} \mathrm{C}$ for 60 min. ${ }^{22}$ The mixture was dialyzed against distilled water for 3-4 days and freeze-dried to give a white powder. The incorporation of the azide group was confirmed by the characteristic azide stretching at 2111 $\mathrm{cm}^{-1}$ in the IR spectra. The degree of functionalization was calculated from the NMR spectra of the conjugated compound. 38 Yield: $95 \%$

${ }^{1} \mathrm{H}$ NMR (400 MHz, $\mathrm{D}_{2} \mathrm{O}-\mathrm{d}$ ) $\delta: \delta 3.86-3.68(\mathrm{~m}), 3.52(\mathrm{t}), 3.34(\mathrm{t}), 3.24(\mathrm{ddd}, \mathrm{J}=6.7,4.9,1.9 \mathrm{~Hz}), 1-1.9(\mathrm{~m}, \mathrm{CH}$, $\mathrm{J}=48.4 \mathrm{~Hz}), 2-2.42(\mathrm{~m}, \mathrm{CH}, \mathrm{J}=43.1 \mathrm{~Hz})$.

Mw calculation:

Ligand proton integration by ${ }^{1} \mathrm{H}$ NMR (a) $=10.1$

Total number of protons on the ligand $(\mathrm{b})=16 ; \mathrm{a} / \mathrm{b}=0.63$

Polyacrylamide integration ${ }^{1} \mathrm{H}$ NMR (c) $=34 ; 0.63 / \mathrm{c}=0.018=1.8 \%$

Total number of monomers $=$ Mol. Wt. of polymer $/$ Mol. Wt. of monomer; 
$150000 / 71.08=2110.3$ monomers

Number of functionalized monomers $=$ Total number of monomers $* 1.8 / 100=38$ monomers

Mw of Compound 9: $150000+\left(38 * \mathrm{C}_{8} \mathrm{H}_{16} \mathrm{O}_{3} \mathrm{~N}_{3}\right) ; 150000+(38 * 202.11)=157680$

Mw of Compound 10: 157680+ $(38 * 382)=172196$

\section{Compound 11}<smiles></smiles>

Compound $\mathbf{1 0}$ was clicked to Compound $\mathbf{4}$ under described standard conditions. The IR spectra of the final compound no longer showed the azide stretching peak which confirmed that all of the azido polymer was consumed. The conjugated compound showed the anomeric proton of the sugar ligand at 5.85 ppm. Yield: $78 \%$

${ }^{1} \mathrm{H}$ NMR (400 MHz, D $20-d$ ) 8: 8.6-7.86 (H-2', H-4', H-6', H-10'), 5.85 (H-1), 3.13-4.13 (H-2, H-3, H-4, H-5, H6, H-9', H-11', H-12', H-13', H-14', H-15', H-16', H-17', H-18'), 1-1.9 (polymer CH), 2-2.42 (polymer $\mathrm{CH}_{2}$ )

\section{Compound 12}<smiles>NCCOCCOCCOCCNC(=O)[O+]1[CH][CH][CH][CH]1</smiles>

The azidation of dextran was carried out according to a reported procedure. ${ }^{38}$ The incorporation of the azide group was confirmed by the characteristic azide stretching at $2109 \mathrm{~cm}^{-1}$ in the IR spectra. The degree of functionalization was calculated from the NMR spectra of the conjugated compound.

Azide Dextran integrals-Native Dextran integrals $=7.0-6.52=0.8$

Azide ligand has 16 protons $; 0.8 / 16=0.05$ and $0.05 /$ Dextran integration $=0.05 / 6.52=0.0076=0.76 \%$ Number of functionalized monomers $=150000 / \mathrm{C}_{6} \mathrm{H}_{10} \mathrm{O}_{5}=150000 / 162.05=925.64$ glucose

$0.76 \%$ of $925.6=7.1$ monomers

Mw of Compound $\mathrm{c}=150000+7.1 * 100=150710$

Mw of Compound $13=150710+7.1 * 382=153422$

\section{Compound 13}<smiles>O=C(NCCOCCOCCOCCn1cc(CNC(=O)C2CCCCC2)nn1)c1cc(OCC2COC(O)C(CO)OC2)cc([N+](=O)[O-])c1</smiles>

Azide-Dextran 12 was clicked to Compound 4 under described standard conditions. The disappearance of the azide stretching peak in the IR spectra of the final compound confirmed that all of the azido polymer 
was consumed. The conjugated compound showed the anomeric proton of the sugar ligand at $5.85 \mathrm{ppm}$. Yield: $80 \%$

${ }^{1} \mathrm{H}$ NMR (400 MHz, $\mathrm{D}_{2} \mathrm{O}-d$ ) $\delta: 8.38,8.24,8.08,7.95$ (4xs, 3x aromartic, triazole), 5.03-4.96 (d, dextran H-1, $1 \mathrm{H}), 4.11-3.40$ (m, Dextran [5H], MNPG [7H]).

\section{Compound 14}

The azidation of dextran was carried out according to a reported procedure ${ }^{39}$ by first synthesizing 1-azido-2,3-epoxypropane which was then used for conjugation to dextran. The incorporation of the azide group was confirmed by the characteristic azide stretching at $2105 \mathrm{~cm}^{-1}$ in the IR spectra. The degree of functionalization was calculated from the NMR spectra of the conjugated compound.

${ }^{13} \mathrm{C}$ NMR (101 MHz, $\left.\mathrm{D}_{2} \mathrm{O}-d\right)$ ) $\delta: 97.69,73.39,71.38,70.60,70.17,69.53,65.56,62.78,52.95$.

Azide Dextran integrals-Native Dextran integrals $=8.53-6.52=2.01$

Azide ligand has 5 protons ; $2.01 / 5=0.402$ and 0.402 /Dextran integrals $=0.402 / 6.52=0.061=6 \%$ Number of functionalized monomers $=150000 / \mathrm{C}_{6} \mathrm{H}_{10} \mathrm{O}_{5}=150000 / 162.05=925.64$ glucose

$6 \%$ of $925.6=55.53$ monomers

Mw of Compound $b=150000+55.53 * 100=155553.84$

Mw of Compound $11=155553.84+55.53 * 382=176766.3$

Mw of Compound $12=155553.84+55.53 * 218=167652$

\section{Compound 15}

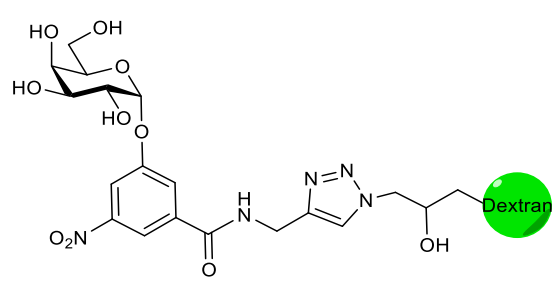

Compound $\mathbf{1 4}$ was clicked to Compound $\mathbf{4}$ under described standard conditions. The disappearance of the azide stretching peak in the IR spectra of the final compound confirmed that all of the azido polymer was consumed. The conjugated compound showed the anomeric proton of the sugar ligand at $5.85 \mathrm{ppm}$. Yield: $51-58 \%$

${ }^{1} \mathrm{H}$ NMR (400 MHz, $\mathrm{D}_{2} \mathrm{O}-d$ ) $8: 8.40-7.84$ (4xs, 3x aromatic, triazole), 5.04-4.95 (d, dextran $\mathrm{H}-1,1 \mathrm{H}$ ), 4.09-2.72 (m, Dextran [5H], MNPG [7H]). 


\section{Compound 17}

$\mathrm{OH}$
$\mathrm{O}$ reaction to give a white solid compound. The disappearance of the azide stretching peak in the IR spectra of the final compound confirmed that all of the azido polymer was consumed. The triazole peak was seen at 8.17 ppm. Yield: $35 \%$

${ }^{1} \mathrm{H}$ NMR (400 MHz, D $20-d$ ) $8: 8.17$ (triazole), 5.04-4.95 (d, dextran H-1, 1H), 4.07-3.40 (m, Dextran [5H], MNPG [7H]).

\section{Compound 18}

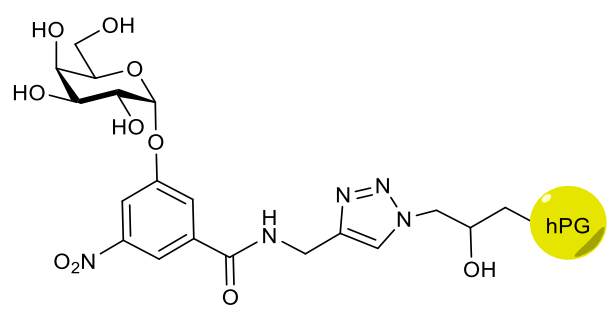

The hyperbranched polyglycerol $(10 \%$ azide functionalization, $10 \mathrm{kDa}{ }^{35}$ was conjugated to 4 using described conditions for the click reaction. The disappearance of the azide stretching peak in the IR spectra of the final compound confirmed that all of the azido polymer was consumed. The conjugated compound showed the anomeric proton of the sugar ligand at $5.77 \mathrm{ppm}$. Yield: $62 \%$

${ }^{1} \mathrm{H}$ NMR (400 MHz, $\mathrm{D}_{2} \mathrm{O}-d$ ) $8:$ 8.39-7.73 (3x aromatic, triazole), 5.77(H-1), 4.70-2.97 (m, hPG, MNPG [7H]).

Mol. Wt. of hPG: 10000

No. of surface hydroxy groups $=10000 / 74=135$

$\% \mathrm{~N} 3$ groups $=10 \%$

No of azide groups $=135(10 \%)=13.5$

No sugar ligands $=13.5$

Mw of Compound $14=10000+(14 \times 382+14 \times 42)=15.9 \mathrm{kDa} \sim 16 \mathrm{kDa}$ 


\subsubsection{NMR spectra}

\section{Compound 4}
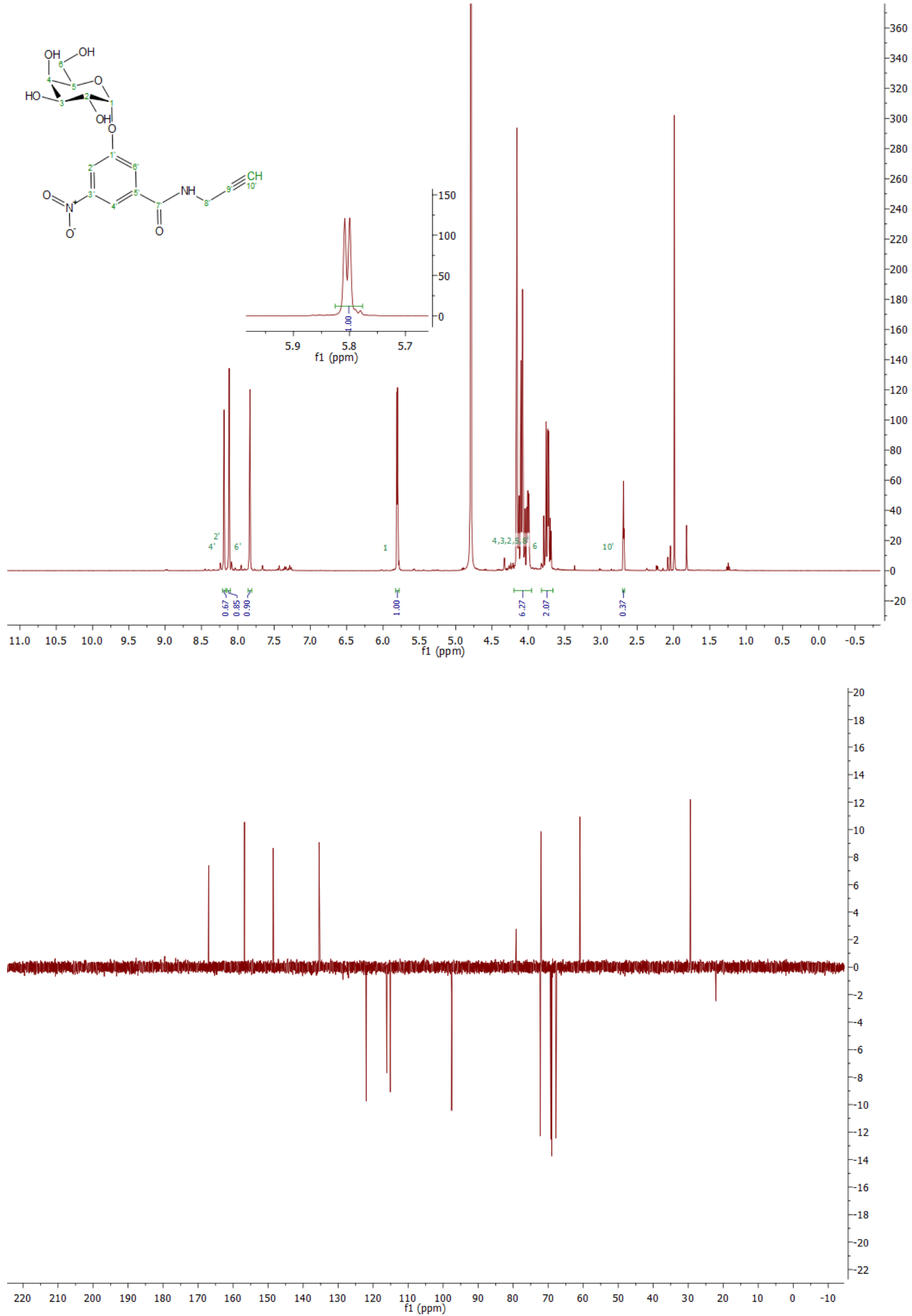


\section{Compound 11}

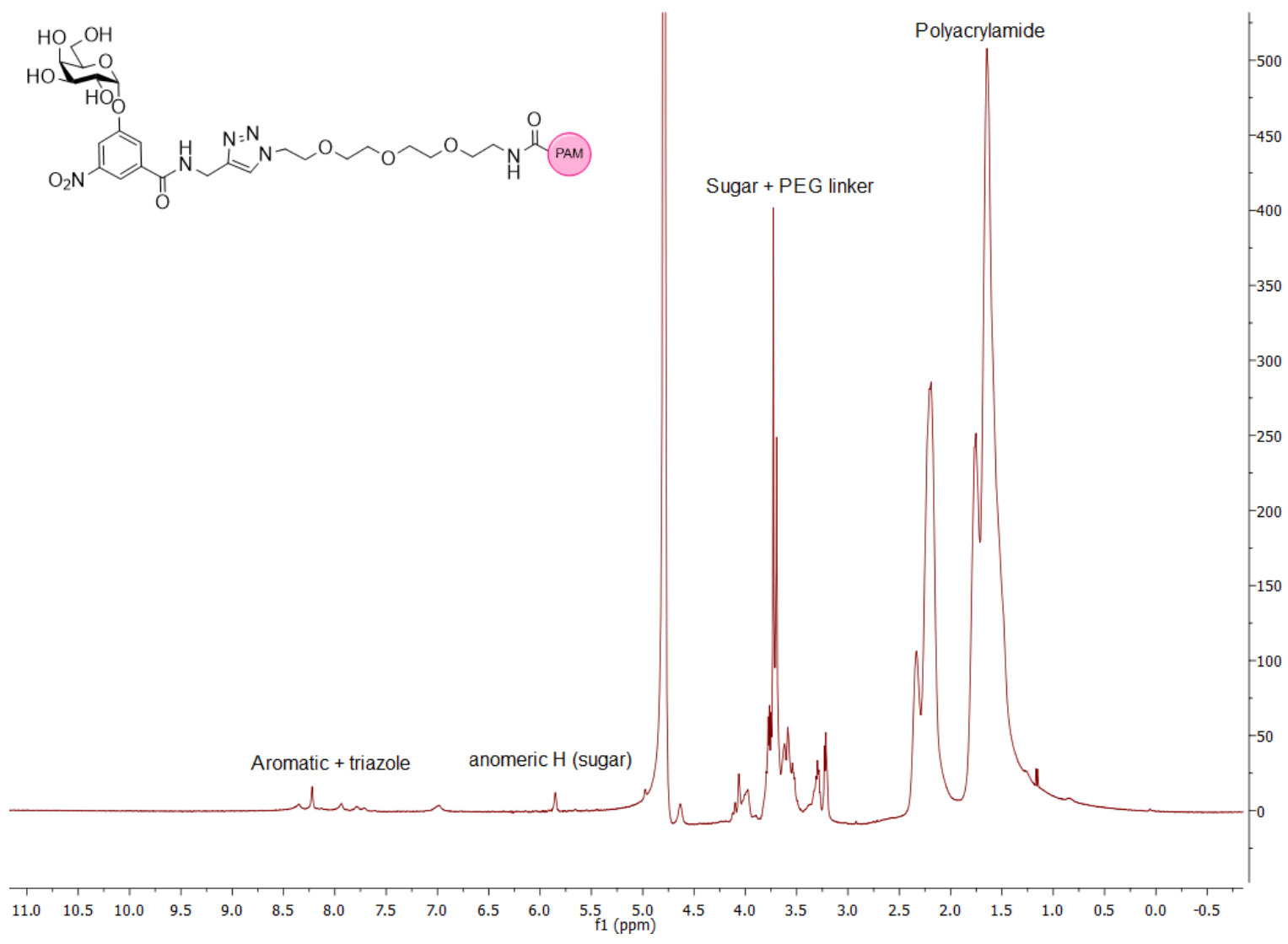

Compound 13

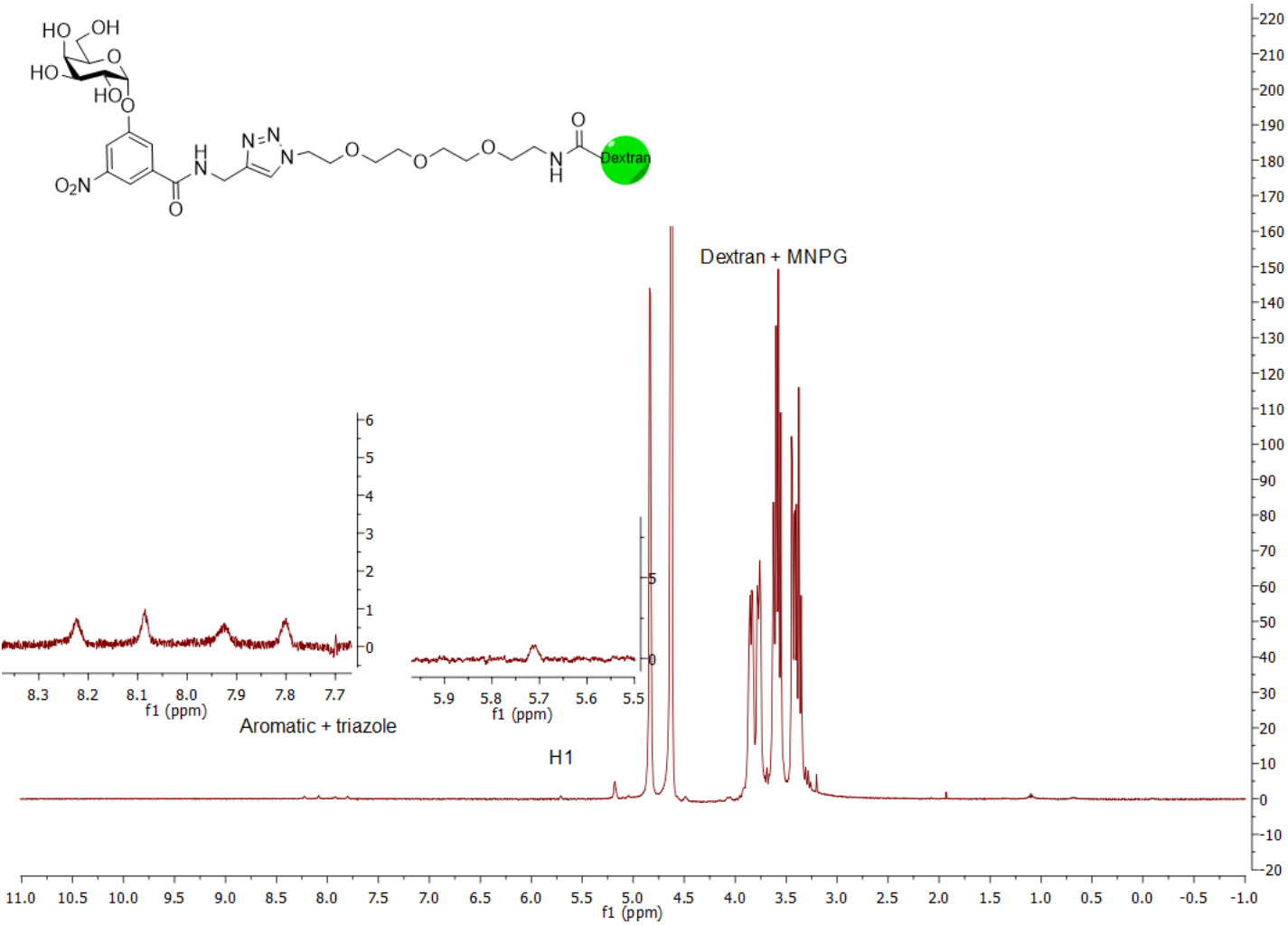




\section{Compound 15}

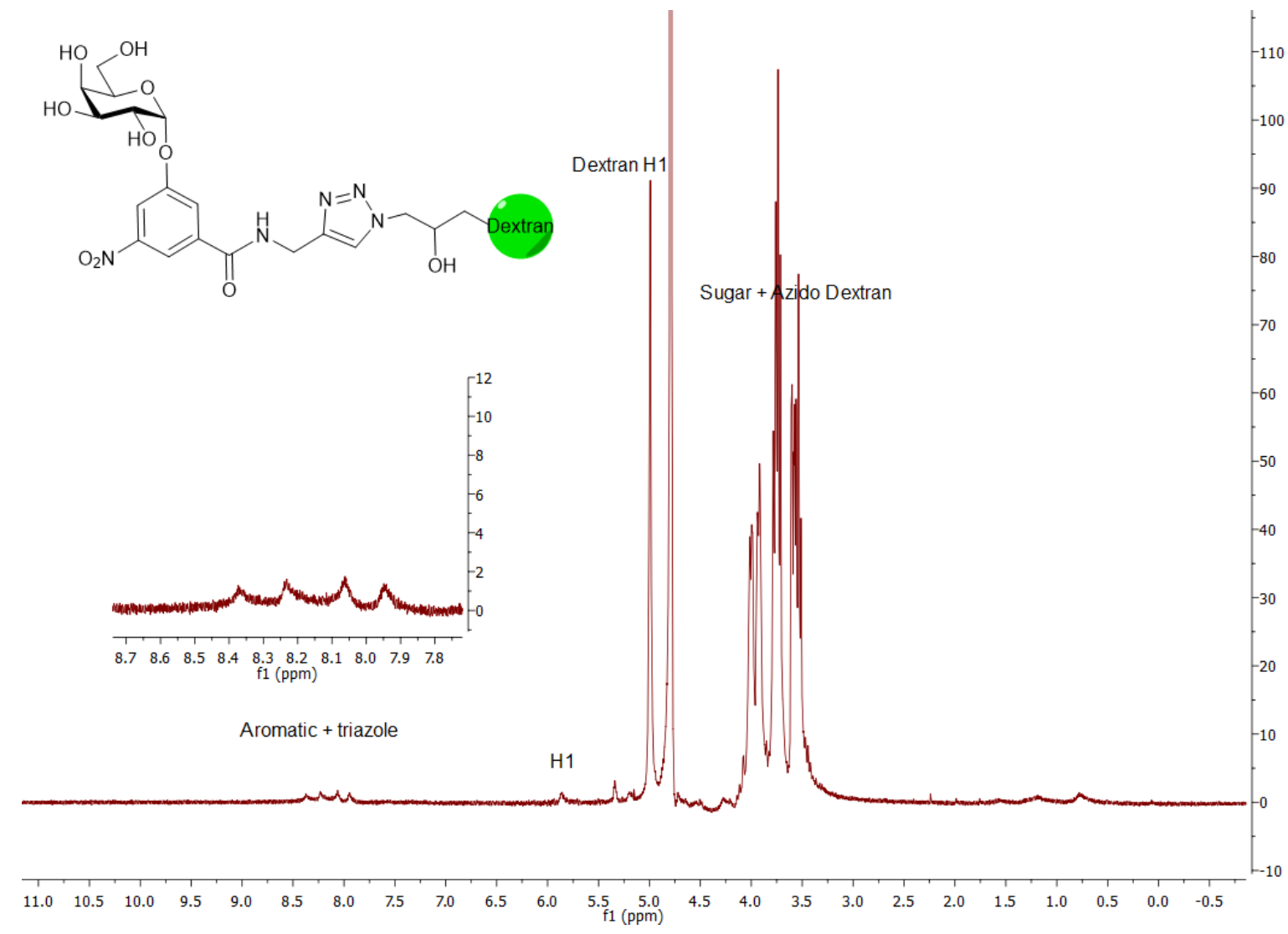

\section{Compound 18}

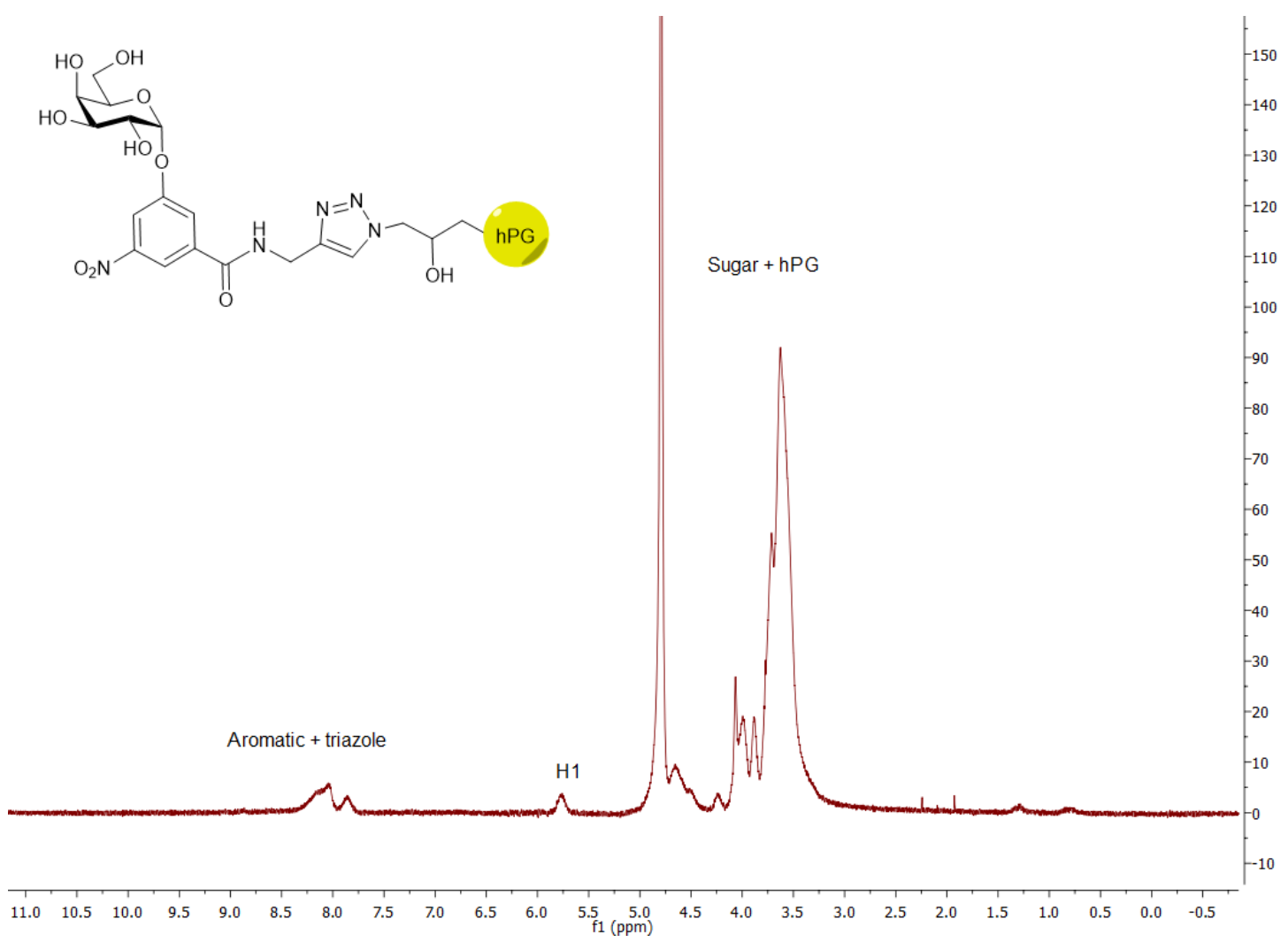




\subsubsection{IR spectra}

Hyperbranched polyglycerol (10\% azide functionalization, 10kDa)

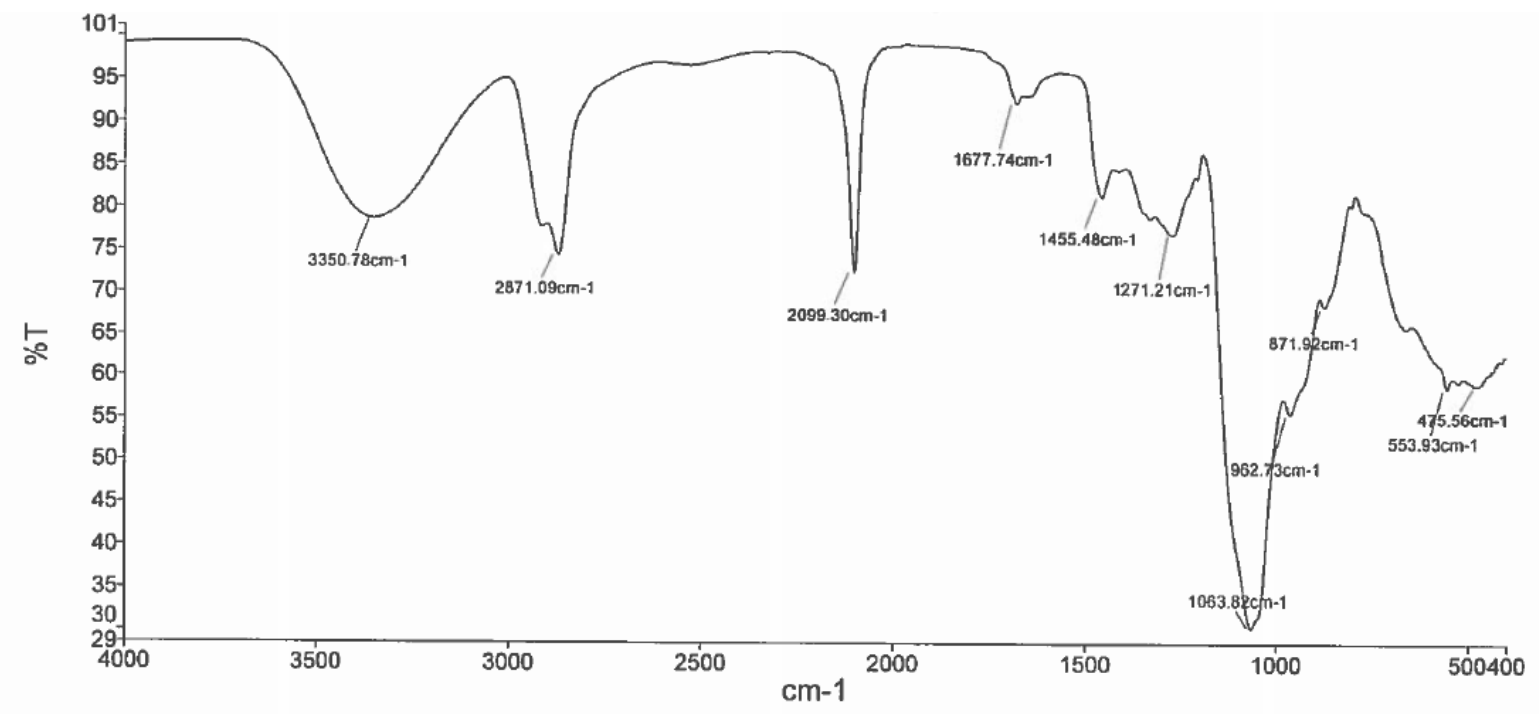

\section{Compound 18}
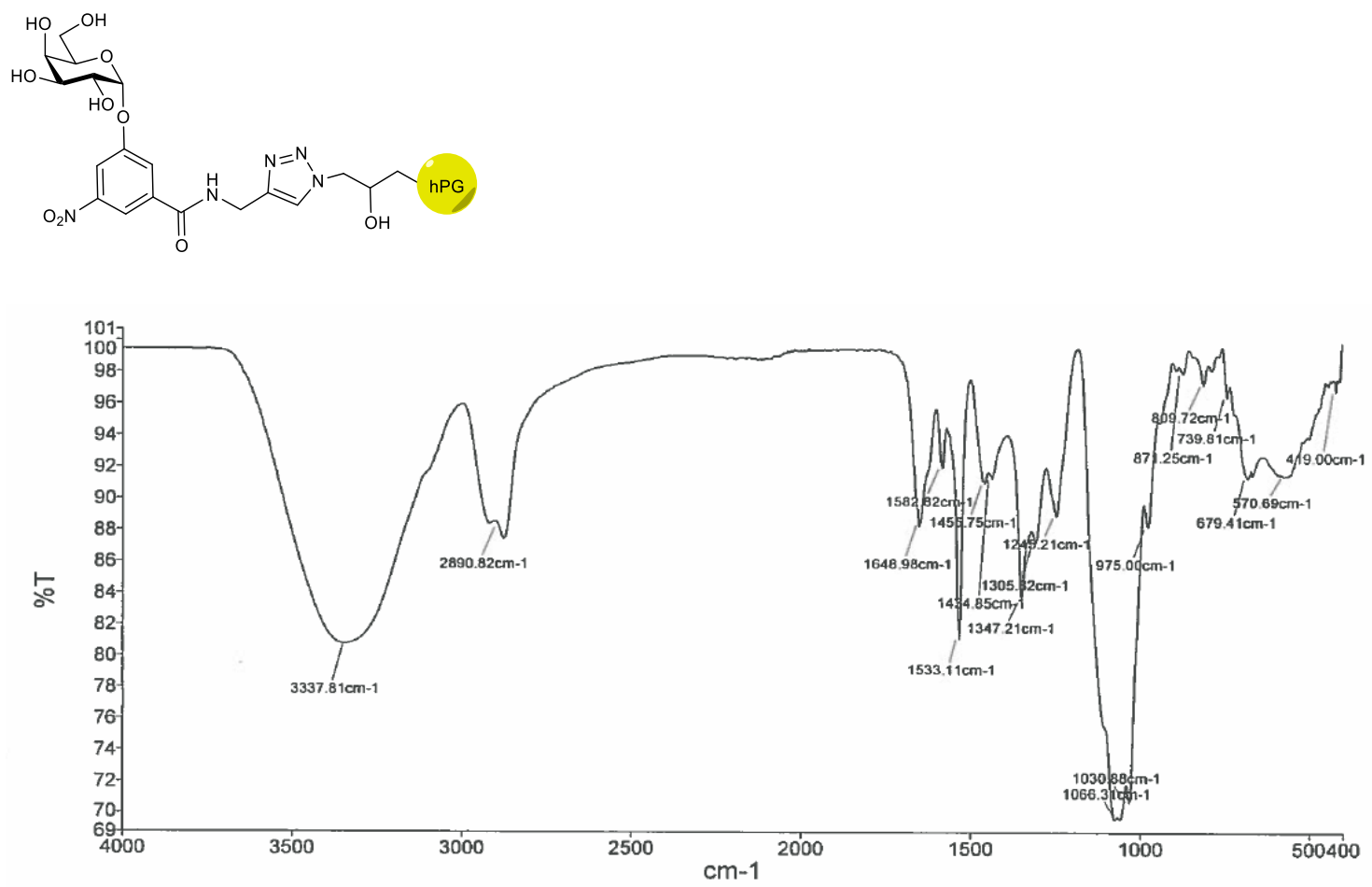


\subsection{References}

(1) WHO.2018. Cholera Factsheet, Feb 2018.

http://www.who.int/immunization/diseases/cholera/en/ (accessed 2018 -06-12).

(2) Ali, M.; Nelson, A. R.; Lopez, A. L.; Sack, D. A. Updated Global Burden of Cholera in Endemic Countries. PLoS Negl. Trop. Dis. 2015, 9 (6), e0003832.

(3) Zagaria, N. WHO Annual Report 2017 Yemen. Cairo: WHO Regional Office for the Eastern Mediterranean; 2018.

(4) Chowdhury, F. R.; Nur, Z.; Hassan, N.; von Seidlein, L.; Dunachie, S. Pandemics, Pathogenicity and Changing Molecular Epidemiology of Cholera in the Era of Global Warming. Ann. Clin. Microbiol. Antimicrob. 2017, 16 (1), 10.

(5) Mosley, J. F.; Smith, L. L.; Brantley, P.; Locke, D.; Como, M.; Como, M. Vaxchora: The First FDAApproved Cholera Vaccination in the United States. P T 2017, 42 (10), 638-640.

(6) Bernardi, A.; Checchia, A.; Brocca, P.; Sonnino, S.; Zuccotto, F. Sugar Mimics: An Artificial Receptor for Cholera Toxin. J. Am. Chem. Soc. 1999, 121 (10), 2032-2036.

(7) Bernardi, A.; Carrettoni, L.; Ciponte, A. G.; Monti, D.; Sonnino, S. Second Generation Mimics of Ganglioside GM1 as Artificial Receptors for Cholera Toxin: Replacement of the Sialic Acid Moiety. Bioorganic Med. Chem. Lett. 2000, 10 (19), 2197-2200.

(8) Arosio, D.; Fontanella, M.; Baldini, L.; Mauri, L.; Bernardi, A.; Casnati, A.; Sansone, F.; Ungaro, R. A Synthetic Divalent Cholera Toxin Glycocalix[4]Arene Ligand Having Higher Affinity than Natural GM1 Oligosaccharide. J. Am. Chem. Soc. 2005, 127, 3660-3661.

(9) Cheshev, P.; Morelli, L.; Marchesi, M.; Podlipnik, Č.; Bergström, M.; Bernardi, A. Synthesis and Affinity Evaluation of a Small Library of Bidentate Cholera Toxin Ligands: Towards Nonhydrolyzable Ganglioside Mimics. Chem. Eur. J. 2010, 16, 1951-1967.

(10) Leaver, D. J.; Hughes, A. B.; Dawson, R. M.; Postma, A.; Malic, N.; Polyzos, A. Synthesis of RAFT Polymers as Bivalent Inhibitors of Cholera Toxin; 2014.

(11) Leaver, D. J.; Dawson, R. M.; White, J. M.; Polyzos, A.; Hughes, A. B. Synthesis of 1,2,3-Triazole Linked Galactopyranosides and Evaluation of Cholera Toxin Inhibition; 2011.

(12) Arosio, D.; Vrasidas, I.; Valentini, P.; Liskamp, R. M. J.; Pieters, R. J.; Bernardi, A. Synthesis and Cholera Toxin Binding Properties of Multivalent GM1 Mimics. Org. Biomol. Chem. 2004, 2 (14), 2113-2124.

(13) Richards, S.-J.; Jones, M. W.; Hunaban, M.; Haddleton, D. M.; Gibson, M. I. Probing Bacterial-Toxin Inhibition with Synthetic Glycopolymers Prepared by Tandem Post-Polymerization Modification: Role of Linker Length and Carbohydrate Density. Angew. Chemie Int. Ed. 2012, 51 (31), 78127816.

(14) Polizzotti, B. D.; Kiick, K. L. Effects of Polymer Structure on the Inhibition of Cholera Toxin by Linear Polypeptide-Based Glycopolymers. Biomacromolecules 2006, 7 (2), 483-490.

(15) Kumar, V.; Yadav, N.; Kartha, K. P. R. Synthetic Multivalent Ligands for Cholera \& Cholera-like Toxins: Protected Cyclic Neoglycopeptides. Carbohydr. Res. 2016, 431, 47-55.

(16) Branson, T. R.; McAllister, T. E.; Garcia-Hartjes, J.; Fascione, M. a.; Ross, J. F.; Warriner, S. L.; Wennekes, T.; Zuilhof, H.; Turnbull, W. B. A Protein-Based Pentavalent Inhibitor of the Cholera Toxin B-Subunit. Angew. Chemie - Int. Ed. 2014, 53, 8323-8327.

(17) Fu, O.; Pukin, A. V.; van Ufford, H. C. Q.; Branson, T. R.; Thies-Weesie, D. M. E.; Turnbull, W. B.; Visser, G. M.; Pieters, R. J. Tetra- versus Pentavalent Inhibitors of Cholera Toxin. ChemistryOpen 2015, 4 (4), 471-477.

(18) Garcia-Hartjes, J.; Bernardi, S.; Weijers, C. A. G. M.; Wennekes, T.; Gilbert, M.; Sansone, F.; Casnati, A.; Zuilhof, H. Picomolar Inhibition of Cholera Toxin by a Pentavalent Ganglioside GM1osCalix[5]Arene. Org. Biomol. Chem 2013, 11.

(19) Pukin, A. V; Branderhorst, H. M.; Sisu, C.; Weijers, C. A. G. M.; Gilbert, M.; Liskamp, R. M. J.; Visser, G. M.; Zuilhof, H.; Pieters, R. J. Strong Inhibition of Cholera Toxin by Multivalent GM1 Derivatives. ChemBioChem 2007, 8 (13), 1500-1503.

(20) Das, S.; Angsantikul, P.; Le, C.; Bao, D.; Miyamoto, Y.; Gao, W.; Zhang, L.; Eckmann, L. Neutralization of Cholera Toxin with Nanoparticle Decoys for Treatment of Cholera. PLoS Negl. Trop. Dis. 2018, 12, 1-17.

(21) Weisman, A.; Chou, B.; O’Brien, J.; Shea, K. J. Polymer Antidotes for Toxin Sequestration. Adv. Drug Deliv. Rev. 2015, 90, 81-100.

(22) Tran, H.-A.; Kitov, P. I.; Paszkiewicz, E.; Sadowska, J. M.; Bundle, D. R. Multifunctional Multivalency: A Focused Library of Polymeric Cholera Toxin Antagonists. Org. Biomol. Chem. 2011, 9 (10), 3658- 
3671.

(23) Jones, M. W.; Otten, L.; Richards, S. J.; Lowery, R.; Phillips, D. J.; Haddleton, D. M.; Gibson, M. I. Glycopolymers with Secondary Binding Motifs Mimic Glycan Branching and Display Bacterial Lectin Selectivity in Addition to Affinity. Chem. Sci. 2014, 5 (4), 1611-1616.

(24) Turnbull, P. C. B.; Lee, J. V.; Miliotis, M. D.; Still, C. S.; Isaacson, M.; Ahmad, Q. S. In Vitro and In Vivo Cholera Toxin Production by Classical and El Tor Isolates of Vibrio Cholerae. J. Clin. Microbiol. 1985, 21 (6), 884-890.

(25) Zuilhof, H. Fighting Cholera One-on-One: The Development and E Ffi Cacy of Multivalent CholeraToxin-Binding Molecules. Acc. Chem. Res. 2016, 49, 274-285.

(26) Minke, W. E.; Roach, C.; Hol, W. G. J.; Verlinde, C. L. M. J. Structure-Based Exploration of the Ganglioside GM1 Binding Sites of Escherichia Coli Heat-Labile Enterotoxin and Cholera Toxin for the Discovery of Receptor Antagonists †. Biochemistry 1999, 38 (18), 5684-5692.

(27) Minke, W. E.; Roach, C.; Hol, W. G. J.; Verlinde, C. L. M. J. Structure-Based Exploration of the Ganglioside GM1 Binding Sites of Escherichia Coli Heat-Labile Enterotoxin and Cholera Toxin for the Discovery of Receptor Antagonists. Biochemistry 1999, 38, 5684-5692.

(28) Pickens, J. C.; Merritt, E. a; Ahn, M.; Verlinde, C. L. M. J.; Hol, W. G. J.; Fan, E. Anchor-Based Design of Improved Cholera Toxin and E. Coli Heat-Labile Enterotoxin Receptor Binding Antagonists That Display Multiple Binding Modes. Chem. Biol. 2002, 9 (02), 215-224.

(29) Mitchell, D. D.; Pickens, J. C.; Korotkov, K.; Fan, E.; Hol, W. G. . 3,5-Substituted Phenyl Galactosides as Leads in Designing Effective Cholera Toxin Antagonists: Synthesis and Crystallographic Studies. Bioorg. Med. Chem. 2004, 12 (5), 907-920.

(30) Zhang, Z.; Pickens, J. C.; Hol, W. G. J.; Fan, E. Solution- and Solid-Phase Syntheses of GuanidineBridged, Water-Soluble Linkers for Multivalent Ligand Design. Org. Lett. 2004, 6 (9), 1377-1380.

(31) Papp, I.; Dernedde, J.; Enders, S.; Haag, R. Modular Synthesis of Multivalent Glycoarchitectures and Their Unique Selectin Binding Behavior. Chem. Commun. 2008, 5851-5853.

(32) Calderón, M.; Quadir, M. A.; Sharma, S. K.; Haag, R. Dendritic Polyglycerols for Biomedical Applications. Advanced Materials. January 12, 2010, pp 190-218.

(33) Haag, R.; Sunder, A.; Stumbé, J. F. An Approach to Glycerol Dendrimers and Pseudo-Dendritic Polyglycerols [6]. J. Am. Chem. Soc. 2000, 122 (12), 2954-2955.

(34) Bhatia, S.; Lauster, D.; Bardua, M.; Ludwig, K.; Angioletti-Uberti, S.; Popp, N.; Hoffmann, U.; Paulus, F.; Budt, M.; Stadtmüller, M.; Wolff, T.; Hamann, A.; Böttcher, C.; Herrmann, A.; Haag, R. Linear Polysialoside Outperforms Dendritic Analogs for Inhibition of Influenza Virus Infection in Vitro and in Vivo. Biomaterials 2017, 138, 22-34.

(35) Sisson, A. L.; Steinhilber, D.; Rossow, T.; Welker, P.; Licha, K.; Haag, R. Biocompatible Functionalized Polyglycerol Microgels with Cell Penetrating Properties. Angew. Chemie Int. Ed. 2009, 48 (41), 7540-7545.

(36) Zomer-Van Ommen, D. D.; Pukin, A. V.; Fu, O.; Quarles Van Ufford, L. H. C.; Janssens, H. M.; Beekman, J. M.; Pieters, R. J. Functional Characterization of Cholera Toxin Inhibitors Using Human Intestinal Organoids. J. Med. Chem. 2016, 59 (14), 6968-6972.

(37) Amvam-Zollo, P.-H.; Sinaÿ, P. Streptococcus Pneumoniae Type XIV Polysaccharide: Synthesis of a Repeating Branched Tetrasaccharide with Dioxa-Type Spacer-Arms. Carbohydr. Res. 1986, 150 (1), 199-212.

(38) Heller, D. A.; Levi, Y.; Pelet, J. M.; Doloff, J. C.; Wallas, J.; Pratt, G. W.; Jiang, S.; Sahay, G.; Schroeder, A.; Schroeder, J. E.; Chyan, Y.; Zurenko, C.; Querbes, W.; Manzano, M.; Kohane, D. S.; Langer, R.; Anderson, D. G. Modular "click-in-Emulsion” Bone-Targeted Nanogels. Adv. Mater. 2013, 25 (10), 1449-1454.

(39) Pahimanolis, N.; Vesterinen, A.-H.; Rich, J.; Seppala, J. Modification of Dextran Using ClickChemistry Approach in Aqueous Media. Carbohydr. Polym. 2010, 82 (1), 78-82.

(40) Dekkers, J. F.; Wiegerinck, C. L.; de Jonge, H. R.; de Jong, N. W. M.; Bijvelds, M. J. C.; Nieuwenhuis, E. E. S.; van den Brink, S.; Clevers, H.; van der Ent, C. K.; Middendorp, S.; Beekman, J. M. A Functional CFTR Assay Using Primary Cystic Fibrosis Intestinal Organoids. Nat. Med. 2013, 19, 939-947.

(41) De Bruyne, C. K.; Carchon, H. The Acid Hydrolysis of Substituted Phenyl Alpha-DGalactopyranosides. Carbohydr. Res. 1974, 33, 117-125.

(42) Liese, S.; Netz, R. R. Quantitative Prediction of Multivalent Ligand-Receptor Binding Affinities for Influenza, Cholera, and Anthrax Inhibition. ACS Nano 2018, 12 (5), 4140-4147.

(43) Sisu, C.; Baron, A. J.; Branderhorst, H. M.; Connel, S. D.; Weijers, C. C. A. G. M.; de Vries, R.; Hayes, E. D.; Pukin, A. V.; Gilbert, M.; Pieters, R. J.; Zuilhof, H.; Visser, G. M.; Turnbull, W. B.; Connell, S. D. The Influence of Ligand Valency on Aggregation Mechanisms for Inhibiting Bacterial Toxins.

ChemBioChem 2009, 10 (2), 329-337. 
(44) Zhang, Z.; Merritt, E. a.; Ahn, M.; Roach, C.; Hou, Z.; Verlinde, C. L. M. J.; Hol, W. G. J.; Fan, E. Solution and Crystallographic Studies of Branched Multivalent Ligands That Inhibit the Receptor-Binding of Cholera Toxin. J. Am. Chem. Soc. 2002, 124 (44), 12991-12998.

(45) Mangan, D.; Snyder, I. S. The Effect of Acrylamide on Human Polymorphonuclear Neutrophils in Vitro. Br. J. Ind. Med. 1978, 35, 305-311.

(46) Kim, W.; Yang, Y.; Kim, D.; Jeong, S.; Yoo, J. W.; Yoon, J. H.; Jung, Y. Conjugation of Metronidazole with Dextran: A Potential Pharmaceutical Strategy to Control Colonic Distribution of the AntiAmebic Drug Susceptible to Metabolism by Colonic Microbes. Drug Des. Devel. Ther. 2017, 11, 419-429.

(47) Lauster, D.; Glanz, M.; Bardua, M.; Ludwig, K.; Hellmund, M.; Hoffmann, U.; Hamann, A.; Böttcher, C.; Haag, R.; Hackenberger, C. P. R.; Herrmann, A. Multivalente Peptid-Nanopartikel-Konjugate Zur Hemmung Des Influenzavirus. Angew. Chemie 2017, 129 (21), 6025-6030.

(48) Dekkers, J. F.; Berkers, G.; Kruisselbrink, E.; Vonk, A.; De Jonge, H. R.; Janssens, H. M.; Bronsveld, I.; Van De Graaf, E. A.; Nieuwenhuis, E. E. S.; Houwen, R. H. J.; Vleggaar, F. P.; Escher, J. C.; De Rijke, Y. B.; Majoor, C. J.; Heijerman, H. G. M.; De Winter-De Groot, K. M.; Clevers, H.; Van Der Ent, C. K.; Beekman, J. M. Characterizing Responses to CFTR-Modulating Drugs Using Rectal Organoids Derived from Subjects with Cystic Fibrosis. Sci. Transl. Med. 2016, 8 (344), 344ra84.

(49) Cai, T. B.; Lu, D.; Tang, X.; Zhang, Y.; Landerholm, M.; Wang, P. G. New Glycosidase Activated Nitric Oxide Donors: Glycose and 3-Morphorlinosydnonimine Conjugates. J. Org. Chem. 2005, 70 (9), 3518-3524.

(50) Mereyala, H. B.; Gurrala, S. R. A Highly Diastereoselective, Practical Synthesis of Allyl, Propargyl 2,3,4,6-Tetra-O-Acetyl- $\beta$-d-Gluco, $\beta$-d-Galactopyranosides and Allyl, Propargyl Heptaacetyl- $\beta$-dLactosides. Carbohydr. Res. 1998, 307 (3-4), 351-354.

(51) Lu, W.-Y.; Sun, X.-W.; Zhu, C.; Xu, J.-H.; Lin, G.-Q. Expanding the Application Scope of Glycosidases Using Click Chemistry. Tetrahedron 2010, 66 (3), 750-757. 


\section{Chapter 3}

\section{A hybrid polymer to target blood group dependence of cholera toxin}

This chapter is published in :

D. Haksar, L. Quarles Van Ufford and R. J. Pieters, Org. Biomol. Chem., 2019, $18,52-55$. 



\subsection{Introduction}

Cholera is an acute diarrheal infection that is caused by the ingestion of water or food contaminated with the Vibrio cholera bacterium. ${ }^{1}$ Cholera is endemic in countries with poor sanitation and inadequate drinking water facilities, with 3 to 5 million reported cases every year. ${ }^{1}$ The current cholera epidemic in Yemen that began in 2016 has so far resulted in more than 3500 fatalities. ${ }^{1}$ Cholera is caused by the cholera toxin (CT) which is an $\mathrm{AB}_{5}$ toxin secreted by the bacterium. The A subunit is the toxic portion whereas the B subunit attaches itself to GM1 gangliosides on the intestinal cell surface. This attachment is regarded as one of the strongest protein-carbohydrate interactions. ${ }^{2}$ Adhesion is followed by cellular endocytosis of the A subunit which catalyses the ADP ribosylation of G-proteins. The resulting stimulation of adenylate cyclase raises the intra-cellular cAMP levels followed by chloride outflow leading to water secretion and potentially fatal diarrhea. ${ }^{3}$ Many studies have focused on the inhibition of the toxin. $4,5,6,7,8$

CT has two major biotypes, classical (cCT) and El Tor (ET CT). Cholera has long been identified as a disease associated with a blood group-dependence. One of the first clinical findings of this dependence was noted in hospital settings in India and the Phillipines more than three decades ago, with an overrepresentation of blood group 0 patients.9,10 ABO blood groups are classified on the basis of the histo-blood group antigens (BGAs) present on red blood cells, with the $\mathrm{H}$ trisaccharide being the smallest determinant. Blood group $\mathrm{O}$ individuals carry the unmodified $\mathrm{H}$ antigen which has a terminal fucose residue while those with blood group A and B have terminal Gal and GalNAc residues, respectively. The BGAs are not only present in the blood but also in other body fluids such as mucus, saliva etc. in approximately $80 \%$ of the population termed as "secretors" while the rest are "non-secretors".11,12

Recently, a second binding site on the cholera toxin has been identified. It was shown to recognize BGAs and was first detect-ed for a chimeric toxin of CTB and the heat-labile enterotoxin of $E$. coli (LTB). ${ }^{13,14,15,16}$ Both cCT and ET CT were shown to bind BGAs with millimolar affinities at the second or secondary binding site on the lateral face of the toxin. ${ }^{16,17,18}$ Using surface plasmon resonance (SPR), it was observed that the $\mathrm{H}$ determinant binds more strongly than the $\mathrm{A}$ determinant, especially in the case of the ET CT variant. ${ }^{15}$ The enhanced binding of CT to displayed $\mathrm{H}$ trisaccharide thus may lead to increased toxin uptake and more severe symptoms for blood group 0 individuals. ${ }^{19}$

GM1-deficient cell lines i.e. T84 and Colo205 have been used to demonstrate that GM1 is not the sole receptor for CT.13 Additionally, it has been shown that besides these immortal cell lines, human intestinal epithelia also contain relatively little GM1.13,20 Furthermore, CTB binding to primary human jejunal epithelial cells was shown to correlate with the amount of displayed 
Lewis X (Lex) glycan. ${ }^{21}$ A direct binding interaction between CTB and the Le ${ }^{\mathrm{Y}}$ tetra-saccharide was studied by ITC and revealed $\mathrm{K}_{\mathrm{d}}$ of $1-2 \mathrm{mM} .{ }^{14}$ Crystal structures and SPR studies further show that Le ${ }^{\mathrm{x}}$ and also L-fucose bind exclusively to the secondary site with millimolar $\mathrm{K}_{\mathrm{d}}$ 's. ${ }^{20}$ Clearly, fucose is the common component of all glycans with affinity for the secondary CT binding site. Although GM1 is the primary receptor in cell lines with both receptors, fucosylated glycoconjugates also contribute to CTB binding and internalization. ${ }^{22}$
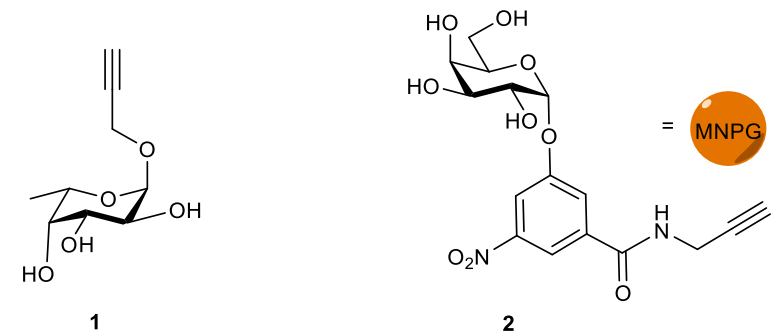

Figure 1: Monovalent ligands

So far only one fucose-based polymer has been reported with an $\mathrm{IC}_{50}$ of $1.5 \mu \mathrm{M}$ derived from a cell-based assay. ${ }^{14}$ We set out to create a molecule that could block both GM1-based and fucosebased intoxication, by constructing a "hybrid" polymeric ligand. This was done in anticipation of multivalency enhancements as we have seen for other multivalent platforms. ${ }^{23,24,25,26}$ For this purpose, we used a dextran based polymer to which fucose and a galactoside were conjugated. Meta-nitrophenyl $\alpha$-galactoside (MNPG) is an ideal candidate owing to its potency and we have demonstrated that when conjugated to polymers effective inhibition of cholera toxin is achieved in a GM1-based assay. ${ }^{27}$ In the present study, we have synthesized a fucosylated and a hybrid polymer. The synthesized compounds were tested for their ability to inhibit the cholera toxin Bsubunit by making use of the GM1-based ELISA assay along with the newly developed fucosebased version.

\subsection{Results}

\subsubsection{Synthesis}

Propargyl fucoside $\mathbf{1}$ and the MNPG derivative $\mathbf{2}$ were synthesized starting from L-fucose and galactose pentaacetate according to reported procedures. ${ }^{28,27}$ Azido-functionalized dextran $\left(\mathrm{M}_{\mathrm{w}}\right.$ $=155 \mathrm{kDa}$ ) with $6 \%$ azide functionalization was used as the polymeric scaffold. ${ }^{29}$ 
Copper-catalysed alkyne-azide cycloaddition (CuAAC) was used for the conjugation of the dextran polymer to the fucoside $\mathbf{1}$ in order to obtain the fucosylated polymer i.e. 3. The hybrid polymer $\mathbf{4}$ was obtained by conjugating both MNPG propargyl and $\mathbf{1}$ in equimolar quantities to the dextran azide. Final polymers $\mathbf{3}$ and $\mathbf{4}$ were characterized by NMR and infrared spectroscopy, the latter of which was useful to see the disappearance of the azide signal at $2110 \mathrm{~cm}^{-1}$.

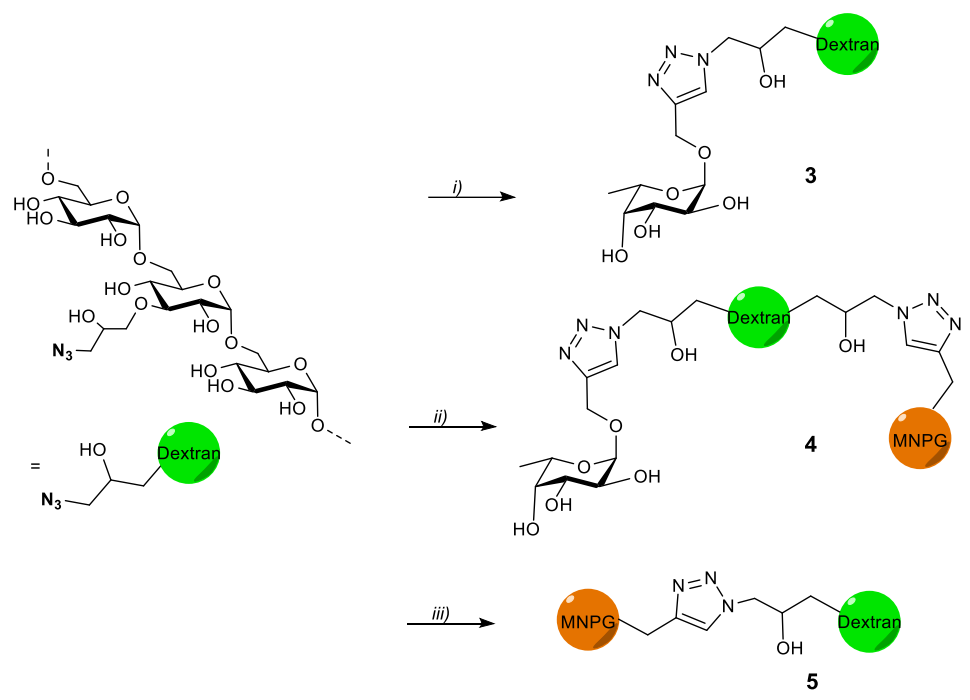

Scheme 1. Synthesis of fucose- and hybrid polymers ; Reagents and conditions i) Dextran azide, 1, $\mathrm{CuSO}_{4}, \mathrm{Na}$-ascorbate, $100^{\circ} \mathrm{C}, 75 \%$, ii) Dextran azide, 1,2, $\mathrm{CuSO}_{4}, \mathrm{Na}$ - ascorbate, $100^{\circ} \mathrm{C}, 81 \%$, iii) Dextran azide, $2, \mathrm{CuSO}_{4}$, Na-ascorbate, $100^{\circ} \mathrm{C}, 51-58 \%$.

\subsubsection{Cholera Toxin Inhibition}

The polymers were evaluated for CTB inhibition in an ELISA-type assay by immobilising the GM1 ganglioside and using a cholera toxin-biotin conjugate. Galactose was used as the monovalent reference compound and showed weak inhibition as before ${ }^{30,31}\left(\mathrm{IC}_{50}=195 \mathrm{mM}\right)$ whereas L-fucose was an extremely weak inhibitor with an $\mathrm{IC}_{50}$ of $1.6 \mathrm{M}$ (Table 1). Polymer 3 did not inhibit CTB in this assay up to $200 \mu \mathrm{M}$, while hybrid 4 showed inhibition with an $\mathrm{IC}_{50}$ of $26 \mu \mathrm{M}$. The dextran azide polymer was also tested and did not show any inhibition in the assay. 
Table 1: Results of inhibition by multivalent carbohydrates in CTB-biotin ELISA assay. ${ }^{a}$

\begin{tabular}{|c|c|c|c|c|c|}
\hline construct & ligand & $\begin{array}{l}\text { Valency (\% functionalization } \\
\text { of polymer) }\end{array}$ & $I C_{50}(\mu \mathrm{M})$ & rel.pot.b & $\begin{array}{l}\text { rel. pot. } \\
\text { per sugarc }\end{array}$ \\
\hline galactose & D-gal & 1 & $\begin{array}{l}195,000 \\
\pm 21,000\end{array}$ & 1 & 1 \\
\hline L-Fucose & L-fuc & 1 & $\begin{array}{l}1581000 \\
\pm 171000\end{array}$ & & \\
\hline 3 & L-fuc & $52(5.6 \%)$ & $\begin{array}{c}\text { No } \\
\text { inhibition }\end{array}$ & - & - \\
\hline 4 & $\begin{array}{l}\text { L-fuc }+ \text { MNPG } \\
(1: 1)\end{array}$ & $52(5.6 \%)$ & $26 \pm 10$ & 7500 & 288 \\
\hline 5 & MNPG & $55(6 \%)$ & $3.2 \pm 0.9$ & 61000 & 1108 \\
\hline
\end{tabular}

Previously a fucosylated polymer has been synthesized and tested for aggregation based inhibition in an ELISA with T84 cells, Colo 205 cells and primary human jejunal epithelial cells. ${ }^{14}$ These cells, notably T84, are not easy to culture, so as an alternative assay unambiguously focused on fucose-CT interactions, we utilized immobilized polyacrylamide-conjugated L- fucose (PAAfucose) and the same biotinylated toxin. PAA-fucose has been previously used to test fucosylated glycodendrimers. 32 


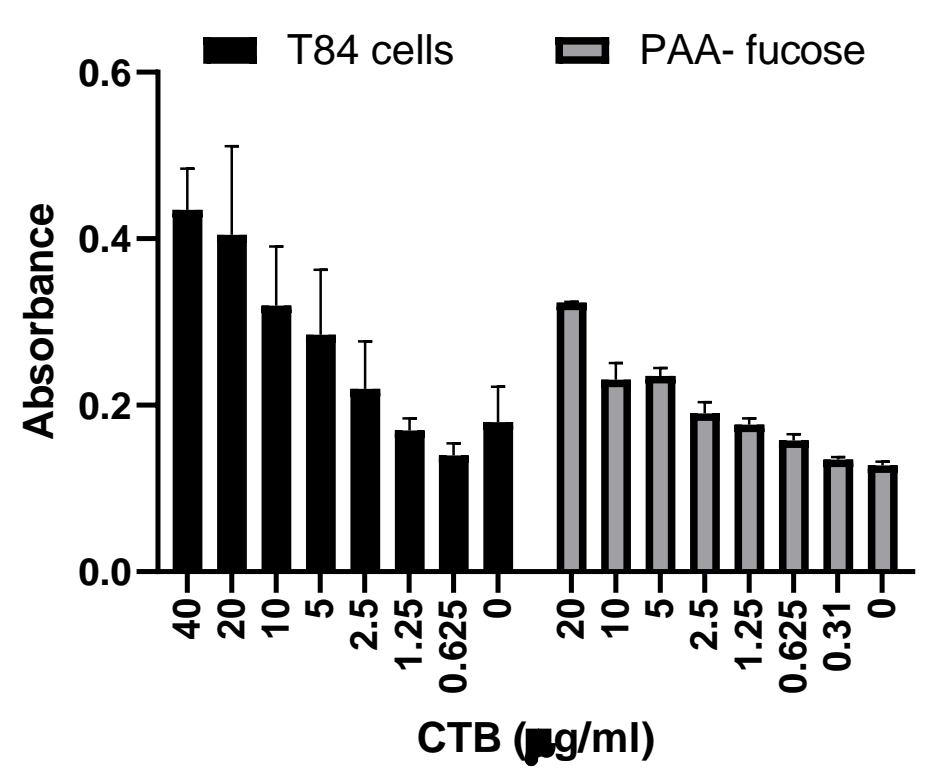

Figure 2: Comparison of T84 cell ELISA and PAA-fucose ELISA. Observed HRP-based signal as a function of toxin concentration.

We first compared the PAA-fucose assay with the T84 cell assay to evaluate for assay sensitivity and concluded that $15.3 \mu \mathrm{g} / \mathrm{mL}$ was an appropriate concentration for the toxin to be used for further inhibition assays (Figure 2). This is high in comparison to that required in the GM1 ELISA (40 ng/mL). L-fucose was used as a reference in the PAA-fucose ELISA and showed millimolar inhibition of the toxin with an $\mathrm{IC}_{50}$ of $12 \mathrm{mM}$ (Table 2). Both polymers 3 and $\mathbf{4}$ inhibited in the low micromolar range $(0.6 \mu \mathrm{M}$ and $1 \mu \mathrm{M}$ respectively) whereas polymer $\mathbf{5}$ did not inhibit the toxin. 
Table 2: Results of inhibition by multivalent carbohydrates in PAA-Fucose ELISA assay. ${ }^{a}$

\begin{tabular}{|c|c|c|c|c|c|}
\hline construct & ligand & $\begin{array}{c}\text { Valency }(\% \\
\text { functionalization of } \\
\text { polymer) }\end{array}$ & $I C_{50}(\mu \mathrm{M})$ & rel.pot. ${ }^{b}$ & $\begin{array}{l}\text { rel. pot. } \\
\text { per sugarc }\end{array}$ \\
\hline L-Fucose & L-Fuc & 1 & $11730 \pm 9000$ & 1 & 1 \\
\hline 3 & L-Fuc & $52(5.6 \%)$ & $0.63 \pm 0.2$ & 18619 & 358 \\
\hline 4 & $\begin{array}{c}\text { L-Fuc + } \\
\text { MNPG(1:1) }\end{array}$ & $52(5.6 \%)$ & $1.1 \pm 0.6$ & 10663 & 205 \\
\hline 5 & MNPG & $55(6 \%)$ & No inhibition & - & - \\
\hline
\end{tabular}

adetermined in an ELISA-like assay with CTB $_{5}$-biotin $(15.3 \mu \mathrm{g} / \mathrm{mL}$ final concentration) and wells coated with PAA-Fucose, brelative to the potency of L-fucose. crelative potency divided by the L-fucose valency

\subsection{Discussion and Conclusion}

We have synthesized a hybrid inhibitor for the cholera toxin that can inhibit both the GM1 based adhesion of the primary binding site and the fucose-based adhesion of the secondary binding site. Additionally, an ELISA using PAA-fucose made it possible to test the fucose-based adhesion in a short span of time. Although the hybrid is not quite as active as the homopolymers in either assay, the inhibition was still strong in the low micromolar range with large multivalency enhancements in either case. The fact that the hybrids were less active than the homopolymer was expected as the 'wrong' ligand may obstruct multivalent binding at times, but the reductions were only minor, especially for the fucose-based assay. Furthermore, the fucose polymer $\mathbf{3}$ did not show any inhibition in the GM1-based assay, and the MNPG based polymer was not active in the fucosebased assay. The hybrid glycopolymer is a practical approach to cover both intoxication scenario's with a single agent. The agent is easy to synthesize, in a likely scalable synthesis at relatively low costs and contains a pharmaceutically benign ${ }^{33,34}$ dextran backbone. 


\subsection{Experimental}

\subsubsection{General information}

Chemicals were obtained from commercial sources and were used without further purification unless noted otherwise. Solvents were purchased from Biosolve (Valkenswaard, The Netherlands). All the other solvents were dried over molecular sieves $4 \AA$ or $3 \AA$. TLC was performed on Merck precoated Silica plates. Spots were visualized by UV light and $10 \% \mathrm{H}_{2} \mathrm{SO}_{4}$ in $\mathrm{MeOH}$. Microwave reactions were carried out in a Biotage microwave Initiator (Uppsala, Sweden). The microwave power was limited by temperature control once the desired temperature was reached. Sealed vessels of $2-5 \mathrm{~mL}$ and 10-20 mL were used. 1H NMR, HSQC, $\operatorname{COSY}(600 \mathrm{MHz})$ and $13 \mathrm{C}(151 \mathrm{MHz})$ were performed on a Bruker 600 spectrometer. Infrared (IR) spectroscopy was performed using Universal Attenuated Total Reflectance (UATR) accessory of Perkin Elmer Spectrum Two FT-IR. Dextran (D-4876 Sigma, Avg Mn:: 150000) was purchased from Sigma-Aldrich.

\subsubsection{CTB5 inhibition assay (GM1 ELISA)}

A 96-well plate ( Nunc MaxiSorp ${ }^{\mathrm{TM}}$ ) was coated with a solution of GM1 (100 $\mu \mathrm{L}, 2 \mu \mathrm{g} / \mathrm{mL}$ ) in phosphate buffered saline (PBS) overnight. Unattached ganglioside was removed by washing with PBS and the remaining binding sites of the surface were blocked with BSA (1\%) which was followed by washing with PBS. Samples of toxin-biotin conjugate (CTB5-biotin; Sigma C9972, $40 \mathrm{ng} / \mathrm{ml})$ and inhibitor in PBS with BSA (0.1\%) and Tween-20 (0.05\%) were incubated at room temperature for $2 \mathrm{~h}$ and were then transferred to the GM1-coated plate. After $30 \mathrm{~min}$ of incubation the solution was removed and the wells were washed with BSA (0.1\%)/Tween-20 $(0.05 \%)$ in PBS. HRP-streptavidin conjugate (1:10 000) was incubated for $1 \mathrm{~h}$ to detect biotinylated toxin. HRP activity was measured by using a freshly prepared solution of ophenylenediamine $/ \mathrm{H}_{2} \mathrm{O}_{2}$ in citrate buffer $(100 \mu \mathrm{L})$ for a maximum of $15 \mathrm{~min}$. After quenching with $\mathrm{H}_{2} \mathrm{SO}_{4}$, the absorbance in each well was measured at $490 \mathrm{~nm}$. Inhibition data from at least two independent experiments with the exception of L-Fucose, were averaged and fitted in GraphPad Prism 8.0.

\subsubsection{Polyacrylamide-linked L-fucose assay (PAA-fucose ELISA)}

A 96-well plate ( Nunc MaxiSorp ${ }^{\mathrm{TM}}$ ) was coated with a solution of PAA-fucose (GlycoNZ Cat. No. $0027-\mathrm{PA} ; 100 \mu \mathrm{L}, 50 \mu \mathrm{g} / \mathrm{mL}$ ) in carbonate buffer for $1 \mathrm{~h}$ at $37^{\circ} \mathrm{C}$. Unattached PAA-fucose was removed by washing with PBS and then blocked with BSA (3\%) for 1h which was followed by 
washing with PBS. Samples of toxin-biotin conjugate (Thermo fischer C34779; Sigma C9972, 15.3 $\mu \mathrm{g} / \mathrm{mL}$ ) and inhibitor in PBS with Tween-20 (0.05\%) were incubated at room temperature for 2 $\mathrm{h}$ and then transferred to the PAA-fucose-coated plate. After $1 \mathrm{~h}$ of incubation, the solution was removed and the wells were washed with Tween-20 (0.05\%) in PBS. HRP-streptavidin conjugate (1:10 000) was incubated for $1 \mathrm{~h}$ to detect biotinylated toxin. HRP activity was measured by using a freshly prepared solution of o-phenylenediamine $/ \mathrm{H}_{2} \mathrm{O}_{2}$ in citrate buffer $(100 \mu \mathrm{L})$ for a maximum of 15 min. After quenching with $\mathrm{H}_{2} \mathrm{SO}_{4}$, the absorbance in each well was measured at $490 \mathrm{~nm}$. Ulex europeaus I lectin ( Sigma L8146) was used as a control for PAA-fucose binding to the plate. Inhibition data from at least two independent experiments were averaged and fitted in GraphPad Prism 8.0.

Cell culture: T84 cells (ATCC) were cultured in DMEM/Ham's F12 (1:1) + FCS (v/v) at $37{ }^{\circ} \mathrm{C}, 5 \%$ carbon dioxide. For collagen coating of 96 well plates, rat tail collagen (Corning 354236) was diluted in $0.1 \%$ acetic acid and coated on 96 well plates in a final concentration of $3.5 \mu \mathrm{g} / \mathrm{well}$ at $4{ }^{\circ} \mathrm{C}$ overnight.

T84 cell ELISA: T84 cells (25 000 cells/well) were cultured in DMEM/Ham's F12 + 5\% FCS on collagen coated 96 well plates for 3 days at $37^{\circ} \mathrm{C} / 5 \%$ carbon dioxide. Plates were then washed with $2 \mathrm{X}$ PBS and toxin-biotin conjugate was added and incubated on ice for $30 \mathrm{~min}$. Excess toxin was washed with 3X PBS. The cells were fixed with 4\% paraformaldehyde for $5 \mathrm{~min}$. on ice and 25 min. at room temperature and then washed with 3X PBS. The cells were blocked with $1 \%$ BSA/PBS for 1h. HRP activity was measured by using a freshly prepared solution of ophenylenediamine $/ \mathrm{H}_{2} \mathrm{O}_{2}$ in citrate buffer $(100 \mu \mathrm{L})$ for a maximum of $15 \mathrm{~min}$. After quenching with $\mathrm{H}_{2} \mathrm{SO}_{4}$, the absorbance in each well was measured at $490 \mathrm{~nm}$.

\subsubsection{Detailed Synthesis}

\section{General procedure for the deacetylation reaction}

The protected compound is dissolved in anhydrous methanol, followed by addition of a catalytic amount of aqueous $1 \mathrm{M} \mathrm{NaOH}$ solution and stirred at room temperature. The reaction is monitored by TLC. Upon the completion of the reaction, if required, the reaction mixture is neutralized by the addition of Dowex marathon resin. The solvent is evaporated and the crude mixture is purified by column chromatography (EtOAc: MeOH: H2O- 4:2:1) to get the pure compound. 


\section{General Procedure for the Click Reaction}

The azido polymer is dissolved in water followed by the addition of the alkyne ligand (1.3 equiv. or 0.65 equiv of each in case of the hybrid). 0.1 equiv. of copper sulphate pentahydrate is dissolved in water separately and added to the reaction mixture. 0.3 equiv. of sodium ascorbate is also dissolved in water separately and added to the reaction mixture. The reaction is carried out at $100^{\circ} \mathrm{C}$ in the microwave for 60 min. CupriSorb ${ }^{T M}$ (Seachem $\AA$ ) resin was added to the reaction mixture and stirred, followed by filtration of the resin. The solvent is evaporated and the crude reaction mixture is purified by dialysis using a cellulose based dialysis cassette (MWCO: 2K) against deionized water for 3-4 days and freeze dried.

Compound 1 was synthesized according to the reported glycosylation procedure ${ }^{35}$ and deprotected according to the above described deacetylation method, with the spectral data in agreement with the reported values. ${ }^{36}$

Compound 2 and Compound $\mathbf{5}$ were synthesized according to the previously reported procedure. 27

\section{Dextran Azide}

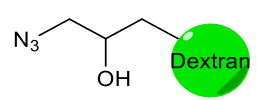

The azidation of dextran (Mn: 150000) was carried out according to a reported procedure ${ }^{29}$ by first synthesizing 1-azido-2,3-epoxypropane which was then used for conjugation to dextran. The incorporation of the azide group was confirmed by the appearance of the characteristic azide stretching at $2105 \mathrm{~cm}^{-1} \mathrm{in}$ the IR spectra. The degree of functionalization was calculated from the NMR spectra of the conjugated compound as described previously. ${ }^{27,37}$

Calculation for degree of functionalization:

Azide Dextran integrals-Native Dextran integrals $=8.36-6.53=1.83$

Azide ligand has 5 protons $; 1.83 \div 5=0.366 ; 0.366 \div$ Dextran integrals $=0.402 \div 6.53=0.056=5.6 \%$ Number of functionalized monomers $=5.6 \%$ of 925.6 glucose monomers $=52$ monomers

\section{Compound 3}

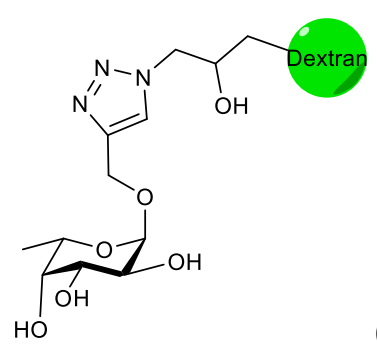

Compound 1 (1.3 equiv) was conjugated to the dextran azide (1 equiv) via the described click reaction to give a white solid compound. The disappearance of the azide stretching peak in the IR spectra of the final compound confirmed that all of the azido polymer was consumed. Yield: $75 \%$ 
${ }^{1} \mathrm{H}$ NMR (600 MHz, $\mathrm{D}_{2} \mathrm{O}-d$ ) $\delta:$ 8.08-8.01(triazole), 4.96 (d, dextran H-1, 1H), 4.01-3.41 (m, dextran [5H], Fuc $[4 \mathrm{H}]), 1.11$ (d, Fuc H-6, 3H)

\section{Compound 4}

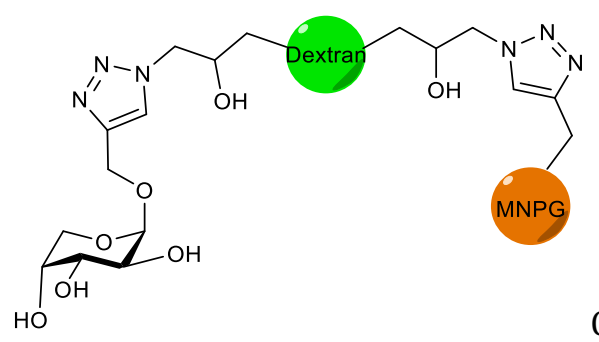

Compound 1 ( 0.65 equiv) and Compound 2 (0.65 equiv) was conjugated to the azido dextran via the described click reaction to give an off-white solid compound. The disappearance of the azide stretching peak in the IR spectra of the final compound confirmed that all of the azido polymer was consumed. Yield: $81 \%$

${ }^{1} \mathrm{H}$ NMR (600 MHz, D $20-d$ ) $\delta: 8.38-7.87$ (m, 3x aromatic [MNPG] , 2x triazole, 5H), 5.82 (MNPG. H-1, 1H), 4.96 (d, dextran H-1, 1H), 4.10-3.30 (m, dextran [5H], MNPG [7H], Fuc [4H] ), 1.02 (d, Fuc H-6, 3H). 


\subsubsection{NMR spectra}

\section{Compound 3}

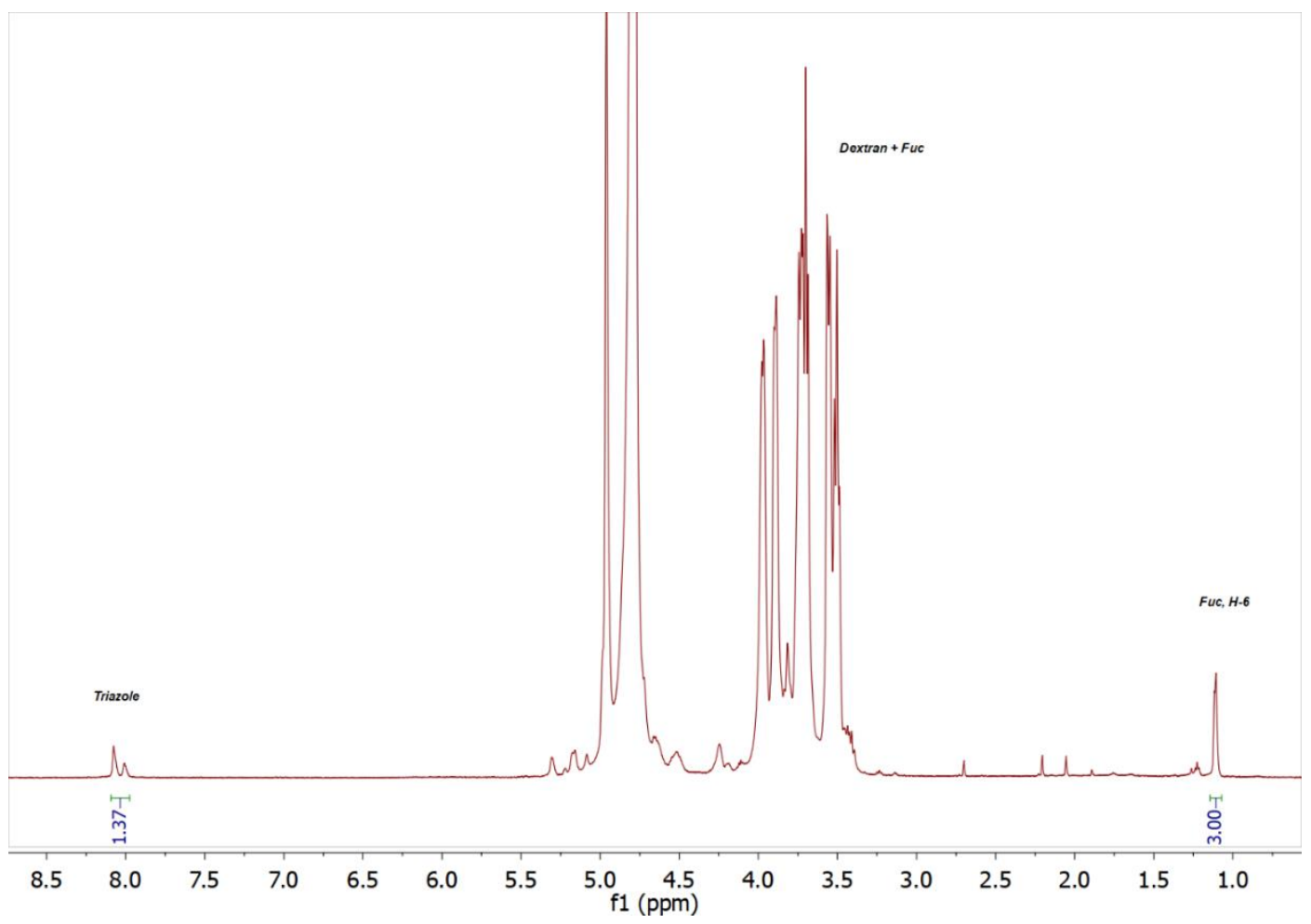

\section{Compound 4}
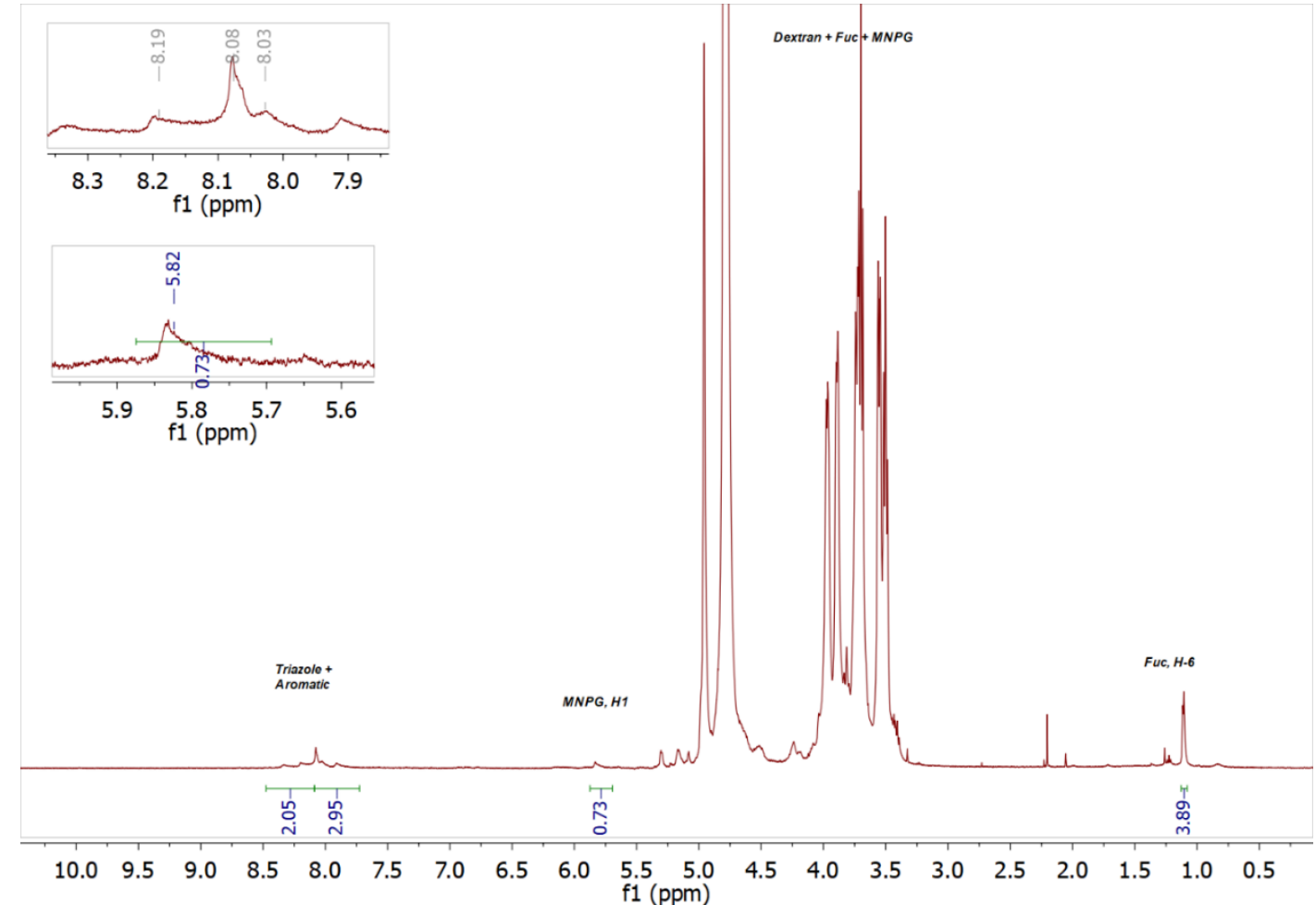


\subsubsection{IR spectra}

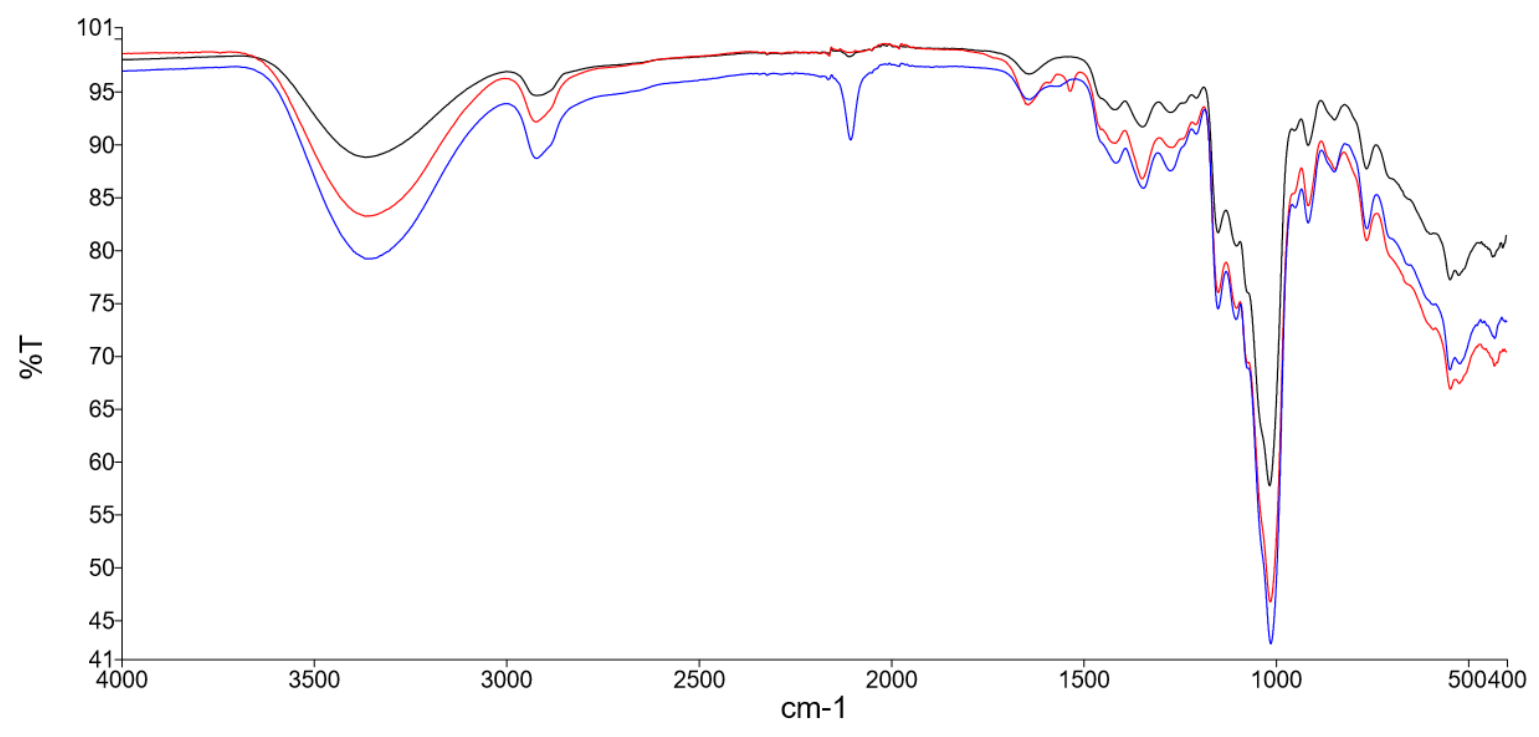

Dextran azide ; Compound 3; Compound 4. 


\subsection{References}

(1) World Health Organization. https://www.who.int/en/news- room/fact-sheets/detail/cholera (accessed Aug. 27, 2019).

(2) Kumar, V.; Turnbull, W. B. Carbohydrate Inhibitors of Cholera Toxin. Beilstein J. Org. Chem. 2018, $14,484-498$.

(3) Baldauf, K. J.; Royal, J. M.; Hamorsky, K. T.; Matoba, N. Cholera Toxin B: One Subunit with Many Pharmaceutical Applications. Toxins (Basel). 2015, 7, 974-996.

(4) Fan, E. K.; Merritt, E. A.; Verlinde, C.; Hol, W. G. J. AB(5) Toxins: Structures and Inhibitor Design. Curr. Opin. Struct. Biol. 2000, 10 (6), 680-686.

(5) Zuilhof, H. Fighting Cholera One-on-One: The Development and E Ffi Cacy of Multivalent CholeraToxin-Binding Molecules. Acc. Chem. Res. 2016, 49, 274-285.

(6) Branson, T. R.; Turnbull, W. B. Bacterial Toxin Inhibitors Based on Multivalent Scaffolds. Chem. Soc. Rev. 2013, 42 (11), 4613-4622.

(7) Bernardi, A.; Cheshev, P. Interfering with the Sugar Code: Design and Synthesis of Oligosaccharide Mimics. Chem. Eur. J. 2008, 14 (25), 7434-7441.

(8) Wittmann, V.; Pieters, R. J. Bridging Lectin Binding Sites by Multivalent Carbohydrates. Chem. Soc. Rev. 2013, 42 (10), 4492.

(9) Chaudhuri, A.; De, S. Cholera and Blood-Groups. Lancet 1977, 310, 404.

(10) Barua, D.; Paguio, A. S. ABO Blood Groups and Cholera. Ann. Hum. Biol. 1977, 4 (5), 489-492.

(11) Holmner, Å.; Mackenzie, A.; Krengel, U. Molecular Basis of Cholera Blood-Group Dependence and Implications for a World Characterized by Climate Change. FEBS Letters. 2010, pp 2548-2555.

(12) Heggelund, J. E.; Varrot, A.; Imberty, A.; Krengel, U. Histo-Blood Group Antigens as Mediators of Infections. Current Opinion in Structural Biology. 2017, pp 190-200.

(13) Wands, A. M.; Fujita, A.; McCombs, J. E.; Cervin, J.; Dedic, B.; Rodriguez, A. C.; Nischan, N.; Bond, M. R.; Mettlen, M.; Trudgian, D. C.; Lemoff, A.; Quiding-J?rbrink, M.; Gustavsson, B.; Steentoft, C.; Clausen, H.; Mirzaei, H.; Teneberg, S.; Yrlid, U.; Kohler, J. J. Fucosylation and Protein Glycosylation Create Functional Receptors for Cholera Toxin. Elife 2015, 4, e09545.

(14) Wands, A. M.; Cervin, J.; Huang, H.; Zhang, Y.; Youn, G.; Brautigam, C. A.; Matson Dzebo, M.; Björklund, P.; Wallenius, V.; Bright, D. K.; Bennett, C. S.; Wittung-Stafshede, P.; Sampson, N. S.; Yrlid, U.; Kohler, J. J. Fucosylated Molecules Competitively Interfere with Cholera Toxin Binding to Host Cells. ACS Infect. Dis. 2018, 4 (5), 758-770.

(15) Heggelund, J. E.; Burschowsky, D.; Bjornestad, V. A.; Hodnik, V.; Anderluh, G.; Krengel, U. HighResolution Crystal Structures Elucidate the Molecular Basis of Cholera Blood Group Dependence. PLoS Pathog. 2016, 12 (4), 1-19.

(16) Holmner, Â.; Lebens, M.; Teneberg, S.; Ångström, J.; Ökvist, M.; Krengel, U. Novel Binding Site Identified in a Hybrid between Cholera Toxin and Heat-Labile Enterotoxin. Structure 2004, 12 (9), 1655-1667.

(17) Heggelund, J. E.; Haugen, E.; Lygren, B.; Mackenzie, A.; Holmner, Å.; Vasile, F.; Reina, J. J.; Bernardi, A.; Krengel, U. Both El Tor and Classical Cholera Toxin Bind Blood Group Determinants. Biochem. Biophys. Res. Commun. 2012, 418, 731-735.

(18) Vasile, F.; Reina, J. J.; Potenza, D.; Heggelund, J. E.; Mackenzie, A.; Krengel, U.; Bernardi, A. Comprehensive Analysis of Blood Group Antigen Binding to Classical and El Tor Cholera Toxin BPentamers by NMR. Glycobiology 2014, 24, 766-778.

(19) Heim, J. B.; Hodnik, V.; Heggelund, J. E.; Anderluh, G.; Krengel, U. Crystal Structures of Cholera Toxin in Complex with Fucosylated Receptors Point to Importance of Secondary Binding Site. Sci. Rep. 2019, 9 (1), 1-14.

(20) Breimer, M. E.; Hansson, G. C.; Karlsson, K.-A.; Larson, G.; Leffler, H. Glycosphingolipid Composition of Epithelial Cells Isolated along the Villus Axis of Small Intestine of a Single Human Individual. Glycobiology 2012, 22 (12), 1721-1730.

(21) Cervin, J.; Wands, A. M.; Casselbrant, A.; Wu, H.; Krishnamurthy, S.; Cvjetkovic, A.; Estelius, J.; Dedic, B.; Sethi, A.; Wallom, K. L.; Riise, R.; Bäckström, M.; Wallenius, V.; Platt, F. M.; Lebens, M.; Teneberg, S.; Fändriks, L.; Kohler, J. J.; Yrlid, U. GM1 Ganglioside-Independent Intoxication by Cholera Toxin. PLoS Pathog. 2018, 14 (2), e1006862.

(22) Sethi, A.; Wands, A. M.; Mettlen, M.; Krishnamurthy, S.; Wu, H.; Kohler, J. J. Cell Type and Receptor Identity Regulate Cholera Toxin Subunit B (CTB) Internalization. Interface Focus 2019, 9 (2), 20180076.

(23) Zhang, H.; Laaf, D.; Elling, L.; Pieters, R. J. Thiodigalactoside-Bovine Serum Albumin Conjugates as 
High-Potency Inhibitors of Galectin-3: An Outstanding Example of Multivalent Presentation of Small Molecule Inhibitors. Bioconjug. Chem. 2018, 29 (4), 1266-1275.

(24) Pera, N. P. N. P.; Kouki, A.; Haataja, S.; Branderhorst, H. M.; Liskamp, R. M. J.; Visser, G. M.; Finne, J.; Pieters, R. J. Detection of Pathogenic Streptococcus Suis Bacteria Using Magnetic Glycoparticles. Org. Biomol. Chem. 2010, 8 (10), 2425-2429.

(25) Yu, G.; Vicini, A. C.; Pieters, R. J. Assembling of Divalent Ligands and Their Effect on Divalent Binding to Pseudomonas Aeruginosa Lectin LecA. J. Org. Chem. 2019, 84, 2470-2488.

(26) Ballell, L.; Scherpenzeel, M. Van; Buchalova, K.; Liskamp, R. M. J.; Pieters, R. J.; van Scherpenzeel, M. A New Chemical Probe for the Detection of the Cancer-Linked Galectin-3. Org. Biomol. Chem. 2006, 4 (23), 4387-4394.

(27) Haksar, D.; de Poel, E.; van Ufford, L. Q.; Bhatia, S.; Haag, R.; Beekman, J.; Pieters, R. J. Strong Inhibition of Cholera Toxin B Subunit by Affordable, Polymer-Based Multivalent Inhibitors. Bioconjug. Chem. 2019, 30 (3), 785-792.

(28) Fernandez-Megia, E.; Correa, J.; Rodriguez-Meizoso, I.; Riguera, R. A Click Approach to Unprotected Glycodendrimers. Macromolecules 2006, 39 (6), 2113-2120.

(29) Pahimanolis, N.; Vesterinen, A.-H.; Rich, J.; Seppala, J. Modification of Dextran Using ClickChemistry Approach in Aqueous Media. Carbohydr. Polym. 2010, 82 (1), 78-82.

(30) Branderhorst, H. M.; Liskamp, R. M. J.; Visser, G. M.; Pieters, R. J. Strong Inhibition of Cholera Toxin Binding by Galactose Dendrimers. Chem. Commun. 2007, No. 47, 5043-5045.

(31) Zomer-Van Ommen, D. D.; Pukin, A. V.; Fu, O.; Quarles Van Ufford, L. H. C.; Janssens, H. M.; Beekman, J. M.; Pieters, R. J. Functional Characterization of Cholera Toxin Inhibitors Using Human Intestinal Organoids. J. Med. Chem. 2016, 59 (14), 6968-6972.

(32) Thomas, B.; Berthet, N.; Garcia, J.; Dumy, P.; Renaudet, O. Electronic Supplementary Information Expanding the Scope of Oxime Ligation: Facile Synthesis of Large Cyclopeptide-Based Glycodendrimers.

(33) Varshosaz, J. Dextran Conjugates in Drug Delivery. Expert Opin. Drug Deliv. 2012, 9 (5), 509-523.

(34) Kim, W.; Yang, Y.; Kim, D.; Jeong, S.; Yoo, J. W.; Yoon, J. H.; Jung, Y. Conjugation of Metronidazole with Dextran: A Potential Pharmaceutical Strategy to Control Colonic Distribution of the AntiAmebic Drug Susceptible to Metabolism by Colonic Microbes. Drug Des. Devel. Ther. 2017, 11, 419-429.

(35) Nierengarten, J. F.; Iehl, J.; Oerthel, V.; Holler, M.; Illescas, B. M.; Muñoz, A.; Martín, N.; Rojo, J.; Sánchez-Navarro, M.; Cecioni, S.; Vidal, S.; Buffet, K.; Durka, M.; Vincent, S. P. Fullerene Sugar Balls. Chem. Commun. 2010, 46 (22), 3860-3862.

(36) Fernandez-Megia, E.; Correa, J.; Rodríguez-Meizoso, I.; Riguera, R. A Click Approach to Unprotected Glycodendrimers. Macromolecules 2006, 39 (6), 2113-2120.

(37) Heller, D. A.; Levi, Y.; Pelet, J. M.; Doloff, J. C.; Wallas, J.; Pratt, G. W.; Jiang, S.; Sahay, G.; Schroeder, A.; Schroeder, J. E.; Chyan, Y.; Zurenko, C.; Querbes, W.; Manzano, M.; Kohane, D. S.; Langer, R.; Anderson, D. G. Modular "click-in-Emulsion” Bone-Targeted Nanogels. Adv. Mater. 2013, 25 (10), 1449-1454. 


\section{Chapter 4}

\section{Fighting Shigella by blocking its disease- causing toxin}

This chapter is published in :

D. Haksar, M. Asadpoor, T. Heise, J. Shi, S. Braber, G. Folkerts, L. Ballell, J. Rodrigues and R. J. Pieters, J. Med. Chem., 2021, 64, 6059-6069. 



\subsection{Introduction}

Bacterial dysentery or shigellosis has been identified as one of the major causes of mortality in children under 5 years of age. ${ }^{1}$ Shigellosis is caused by gram negative bacterium of four species of Shigella: S. dysenteriae, S. flexneri, S. boydii, and S. sonnei through the fecal-oral route. The pathology can include bloody diarrhea (hemorraghic colitis) followed by the often fatal hemolytic uremic syndrome (HUS). HUS can occur if the pathogen is also producing the Shiga toxin. The toxin is produced by $S$. dysenteriae serotype 1 but closely related toxins Stx1 and Stx2 are also produced by Shiga toxin producing E. coli (STEC) or enterohemorrhagic E. coli (EHEC), where Stx2 has been reported to cause the more severe infections. ${ }^{2}$ STEC outbreaks are mostly foodborne with the largest ever reported in Germany (2011), linked to sprout consumption. ${ }^{3}$

The Shiga toxin is an $A_{5}$ toxin composed of the toxic $A$ subunit and a pentameric $B$ subunit that is responsible for the binding of the toxin to its cell surface receptor globotriaosylceramide $(\mathrm{Gb} 3$; Gal $\alpha 1-4$ Gal $\beta 1-4 G l c \beta 1$-ceramide, also known as CD77 or the Pk blood group antigen). ${ }^{4}$ Each B subunit can bind to fifteen Gb3 molecules simultaneously.5,6 After the initial bloody diarrhea the toxin enters the bloodstream by poorly understood mechanisms. ${ }^{7}$ The ample presence of Gb3 molecules in the kidney targets the toxin to this location. Once endocytosed, the toxin induces multiple signaling pathways leading to blockage of protein synthesis and induction of apoptosis ${ }^{8}$ and HUS. STEC infections are treated with antibiotics although their use is controversial with respect to their ability to increase the risk of HUS. ${ }^{9}$ The recent emergence of toxin producing strains of $S$. flexneri and $S$. sonnei points towards increased future morbidity and mortality. ${ }^{10,11,12,13,14,15,16,17,18,19}$ As an alternative to antibiotics, synthetic molecules based on Gb3 have been explored as potential prophylactic treatment for STEC. 20

Synsorb Pk, silicon dioxide coupled to synthetic Pk showed promising results in the trapping of toxins and preventing toxic effects on renal cells. ${ }^{21}$ However, a subsequent clinical trial was unsuccessful at diminishing diarrhea-associated HUS possibly due to late administration of the drug to the GI tract while the toxin was already active systemically. ${ }^{22}$ Recommendations were made for intervention in the circulation. This approach was explored in several cases with antibodies, and nanobodies as recently summarized. ${ }^{23}$ Smaller dendritic molecules were also explored in this respect. The soluble STARFISH inhibitor with decametric display of Gb3 trisaccharide, reported by Bundle et al. exhibited sub-nanomolar inhibition of Stx1, with large potency gains over the divalent analogue and the Pk trisaccharide itself. ${ }^{24}$ A modification of the STARFISH named DAISY was observed to be effective against both Stx1 and Stx2 with nanomolar inhibition and in vivo activity in EHEC orally infected mice by subcutaneous injection $24 \mathrm{~h}$ afterwards. ${ }^{25}$ Several related SUPERTWIG structures (based on Gb3 conjugated to carbosilane 
dendrimers), developed by Nishikawa et al. were also identified as effective neutralizers of Stx with a dependency on their valency and structure. ${ }^{26} \mathrm{~A}$ hexavalent structure provided protection after intravenous injections starting 3 days after oral infection.

In the present study, three types of potential inhibitors were investigated: dendritic synthesized multivalent inhibitors, glycopolymers and natural oligosaccharides. As the ligand we chose to explore the potential of the disaccharide (Gal $\alpha 1-4 \mathrm{Gal} \beta$; galabiose) as a possible monovalent alternative to $\mathrm{Gb} 3$ based inhibitors. The intention here was to explore what the minimal structural requirements for potent toxin inhibition would be, by minimizing the ligand and the multivalent scaffold. For the dendrimers, ease of preparation was central to the selection of diand tetravalent dendrimers utilized. Polymeric scaffolds were selected for potency comparison. For the polymer scaffold, hyperbranched polyglycerol (hPG) were used for their easy synthesis, high functionalization, biocompatibility and low in vivo toxicity. ${ }^{27} \mathrm{~A}$ polyalkyne and a polyazide variant of hPG was prepared for their conjugation by employing the copper-catalyzed alkyne azide cycloaddition (CuAAC) conjugations. In addition to the synthesized compounds, commercially available oligosaccharides: non-toxic food grade alginate, chitosan, fructo and galacto oligosaccharides (AOS, COS, GOS, FOS) were tested for Stx inhibition. These could serve as an even more viable practical alternative that could be part of a preventative food-based approach during outbreaks with a focus on the gastrointestinal phase of the toxin producing Shigella pathogenicity.

\subsection{Results}

\subsubsection{Synthesis}

For the synthesis of the monovalent galabiose reagent, galactose pentaacetate was used as the common precursor for the synthesis of the glycosyl donor and acceptor (Scheme 1). Glycosyl donor 1a was synthesized over three steps by thioglucoside preparation as the first step followed by silyl-protection of the sugar. Glycosyl donor $\mathbf{1 b}$ was synthesized by azidation using trimethylsilyl-azide and benzoyl protection. Trifluoromethanesulfonic anhydride-mediated glycosylation afforded the disaccharide $\mathbf{1 c}$ in moderate yields. Deprotection was performed over two steps without purification followed by acetylation to obtain 1d which was used for conjugation with various dendrimers. 

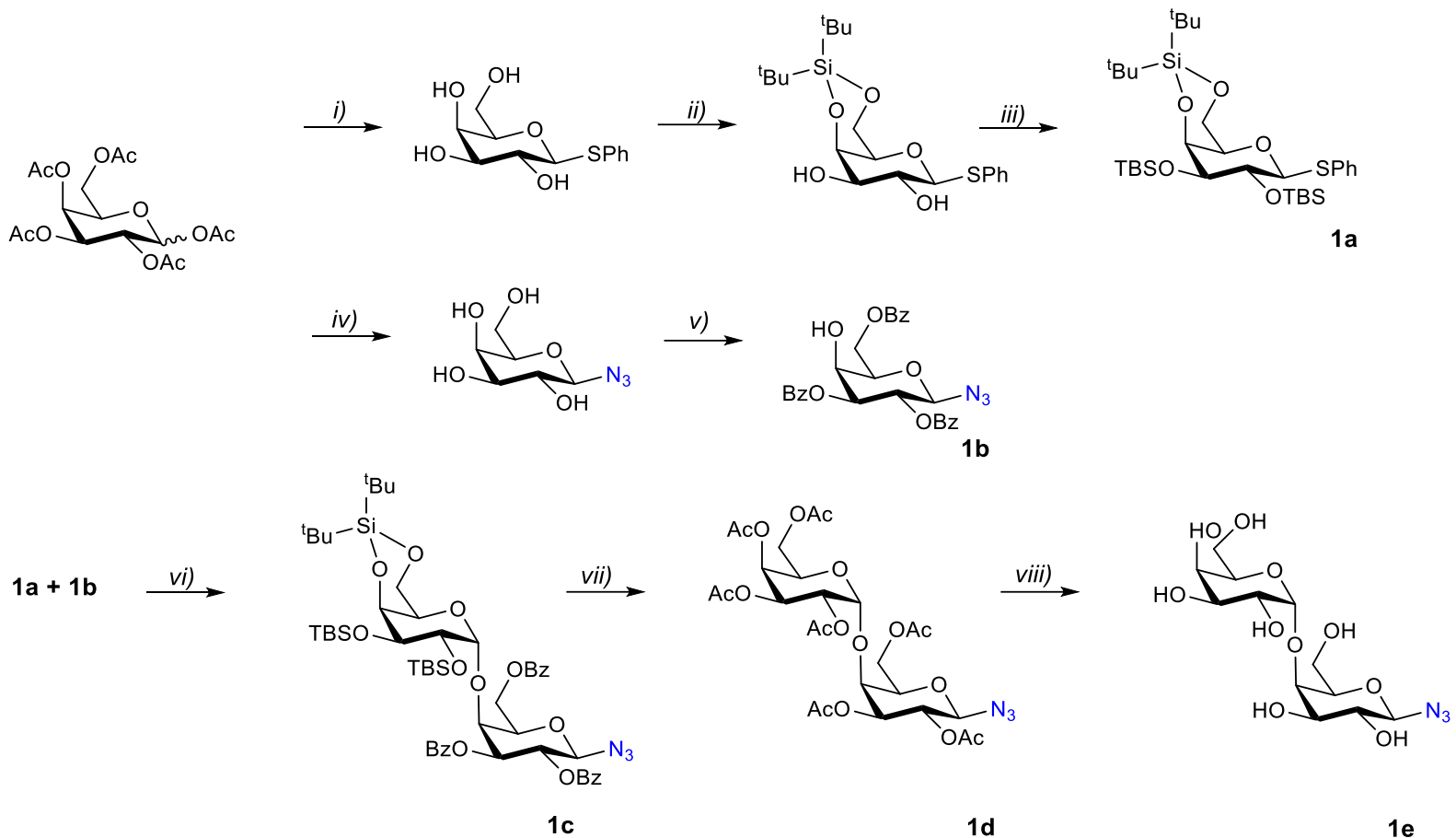

1c

1d

$1 \mathrm{e}$

Scheme 1. Synthesis of galabiose azide. ${ }^{a}$

${ }^{a}$ Reagents and conditions: i) $\mathrm{HSPh}_{3} \mathrm{BF}_{3} \cdot \mathrm{Et}_{2} \mathrm{O}, \mathrm{DCM}$, r.t., 16 h, 90\%; $\mathrm{NaOMe}, \mathrm{MeOH}$, r.t. $90 \%$ ii) $\mathrm{tBu}_{2} \mathrm{Si}(\mathrm{OTf})_{2}, \mathrm{Pyr}, \mathrm{DMF},-40^{\circ} \mathrm{C},>90 \%$ iii) TBDMSOTf, DMAP, Pyr, r.t. $70 \%$ iv) $\mathrm{TMSN}_{3}, \mathrm{SnCl}_{4}, \mathrm{DCM}$, $95 \%$; NaOMe, $\mathrm{MeOH}$, r.t., 16 h, $100 \%$ v) BzCl, Pyr, DCM, $-80^{\circ} \mathrm{C}, 2 \mathrm{~h}, 50 \%$ vi) $\mathrm{Tf}_{2} \mathrm{O}, \mathrm{Ph}_{2} \mathrm{SO}$, TTBP, DCM, $-60^{\circ} \mathrm{C}, 1 \mathrm{~h}, 72 \%$ vii) ) $\mathrm{NaOMe}, \mathrm{MeOH} ; \mathrm{HF}$, pyridine; $\mathrm{Ac}_{2} \mathrm{O}$, pyridine, $63 \%$ viii) $\mathrm{NaOH}, \mathrm{MeOH}, 90 \%$

Building block 3,5-dihydroxybenzoic acid was used as the starting material for the synthesis of all four dendrimers (Figure 1). 2a and 2c was synthesized using previously reported procedures. ${ }^{28,29}$ Divalent dendrimer $\mathbf{2 b}$ was conveniently prepared by coupling methyl 3,5-bis(2aminoethoxy)benzoate to propargyl chloroformate and was obtained in $88 \%$ yield. Amide coupling of 2a to dodecane-1,12-diamine using BOP gave tetravalent dendrimer $\mathbf{2 d}$ in $60 \%$ yield. Dendrimers (2a, 2b, 2c, 2d) were conjugated to $\mathbf{1 d}$ by CuAAC in order to obtain final compounds 3, 4, 5 and 6 (Figure 2) in good yields. 


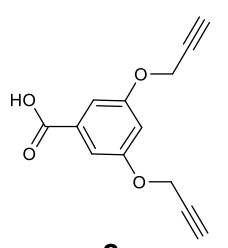

$2 a$

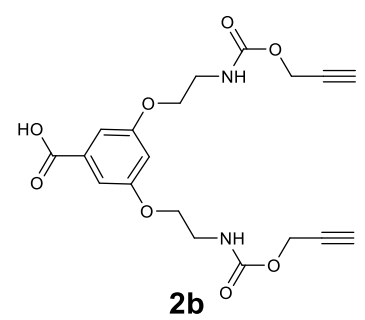

$2 b$

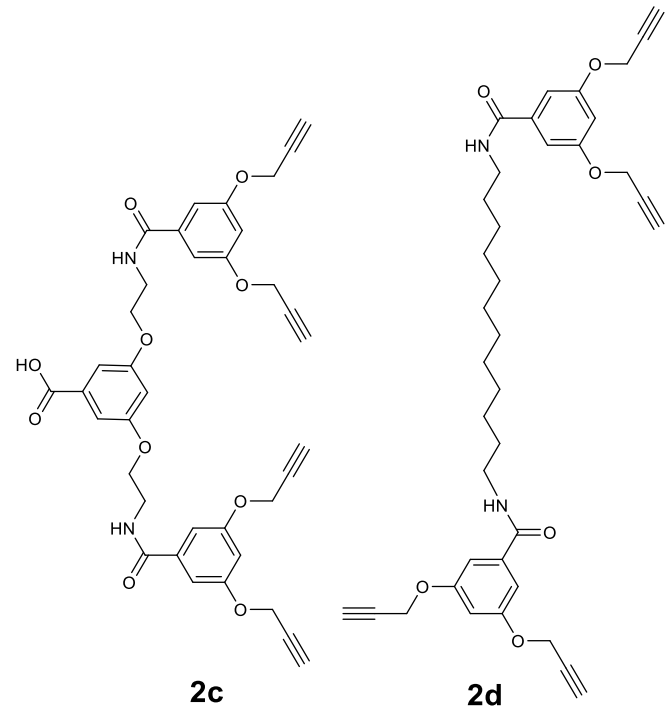

2d

Figure 1. Di- and Tetravalent Dendrimers.

Glycidol, a reactive hydroxy-epoxide was used as an $\mathrm{AB}_{2}$ monomer and polymerization was initiated using tris(hydroxymethyl)propane (TMP). TMP was partially deprotonated and used as an initiator for the anionic polymerization carried out by slow monomer addition and yielding hPG-OH of ca. 9.4 kDa with $125 \mathrm{OH}$ end groups, calculated using inverse-gated carbon and proton NMR. ${ }^{30}$ Azidation of the $\mathrm{hPG}$ was performed in two steps by first substituting the hydroxy groups of the hPG with the more reactive mesyl groups followed by azide substitution using sodium azide. ${ }^{31}$ Mesyl substitution of the hPG was calculated at 8\% (ca. 10 mesyl end groups per molecule) using proton NMR and complete substitution with azide groups was confirmed by the absence of the mesyl protons ( ${ }^{1} \mathrm{H}$ NMR) and the appearance of the azide stretching in the infrared spectra (IR) at $2110 \mathrm{~cm}^{-1}$. Propargylation of hPG was performed in a single step using propargyl bromide in $72 \%$ yield. 32 The polymer was calculated to be $16 \%$ functionalized, which means ca. 20 propargyl end groups per molecule based on proton NMR and the IR spectra further confirmed this via the $2110 \mathrm{~cm}^{-1}$ peak. 

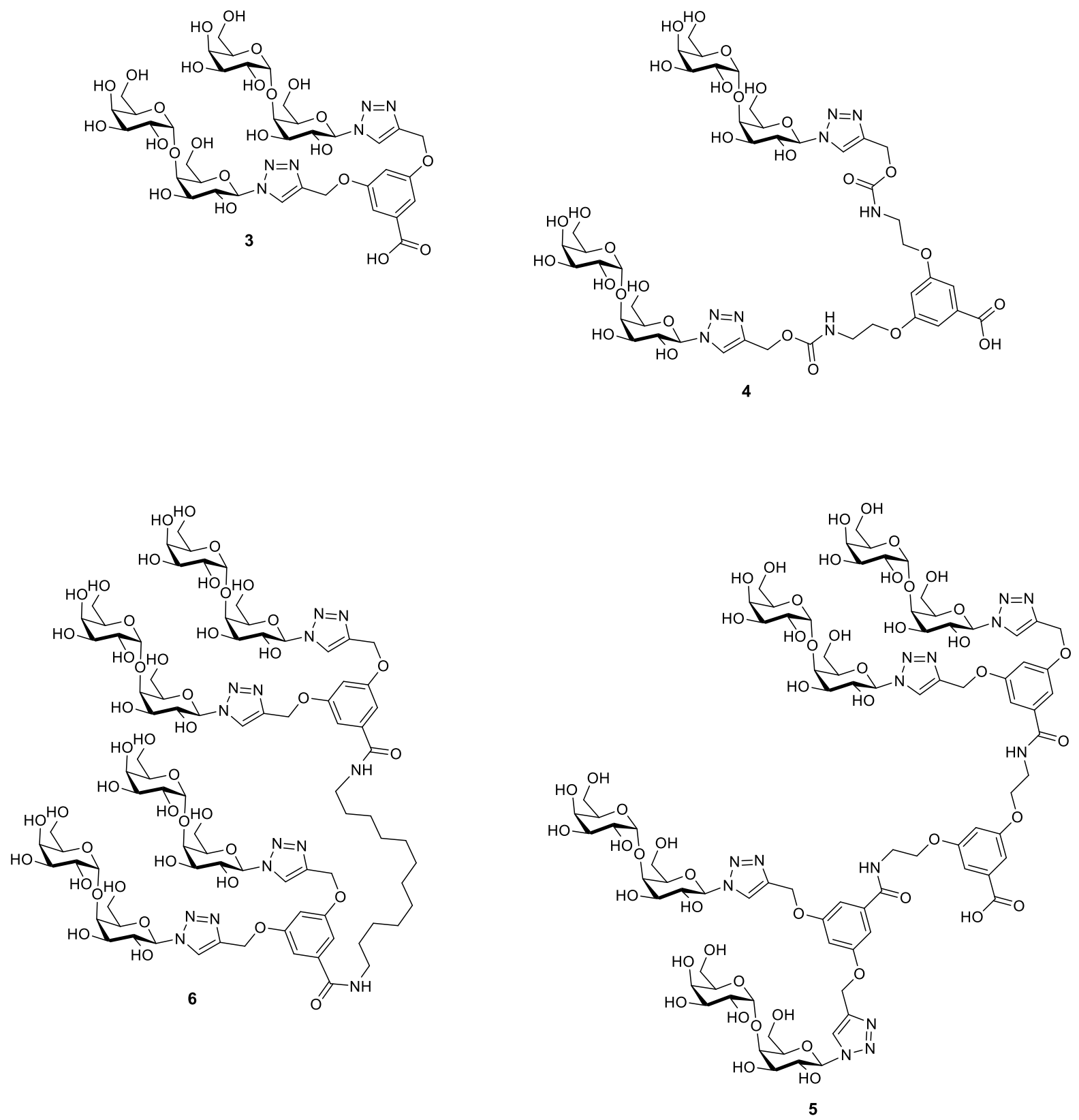

Figure 2. Dendrimer-Galabiose Conjugates 

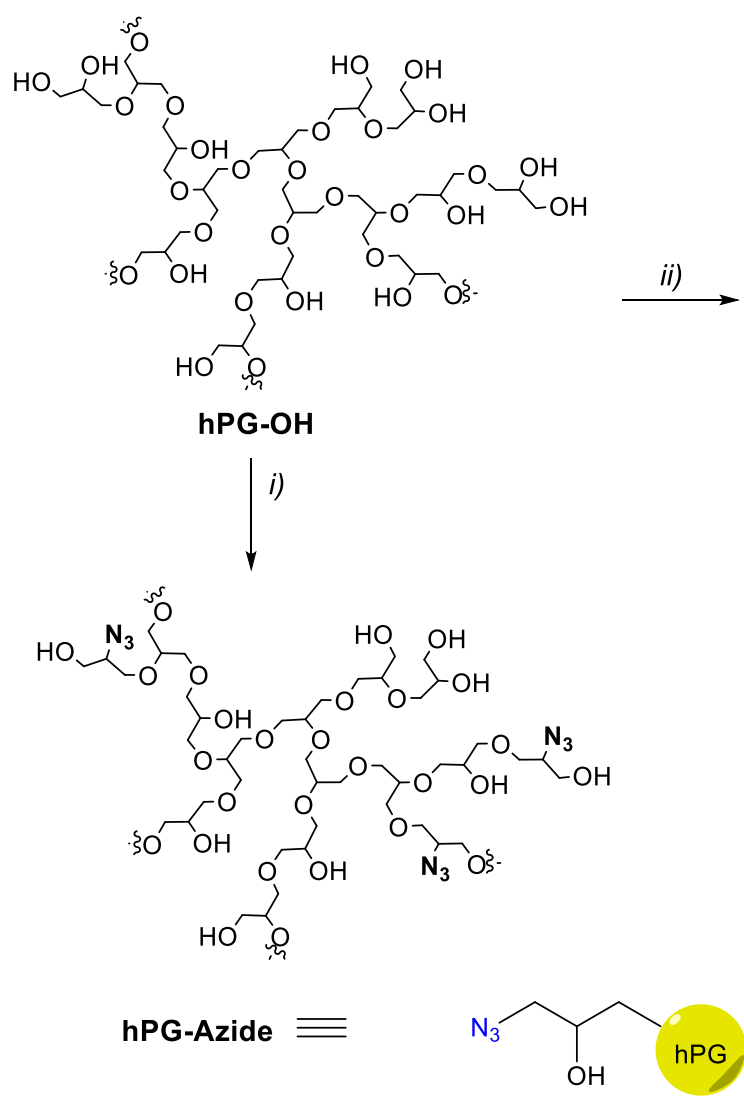
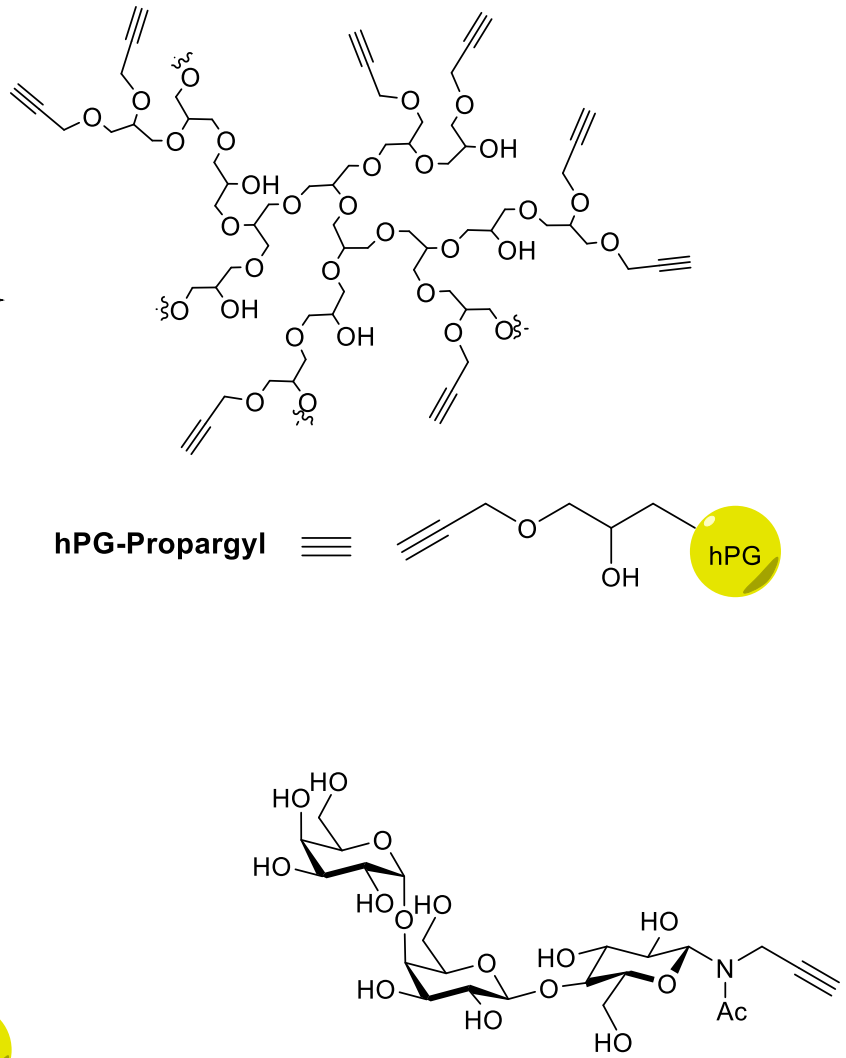

Globotriose-NAc-propargyl, 7

Scheme 2. Synthesis of Hyperbranched polymers ${ }^{a}$, aReagents and conditions: i) MsCl, TEA, DMF, $0^{\circ} \mathrm{C}$ - r.t., 16 h, $88 \%$; $\mathrm{NaN}_{3}, \mathrm{DMF}, 60^{\circ} \mathrm{C}$, quant. ii) $\mathrm{NaH}, \mathrm{KI}$, Propargyl bromide, DMF, $0^{\circ} \mathrm{C}$ - r.t., $72 \%$ hPG azide was conjugated by CuAAC to globotriose-NAc-propargyl (7), to obtain 8 in $80 \%$ yield (Scheme 2). Similarly, conjugation of 1d to hPG-propargyl following deprotection yielded final compound 9 in 75\% yield over two steps. Final polymers 8 and 9 were characterized by ${ }^{1} \mathrm{H}-\mathrm{NMR}$ and also by IR to check for the absence of the azide and alkyne stretching peaks respectively (Figure 2).
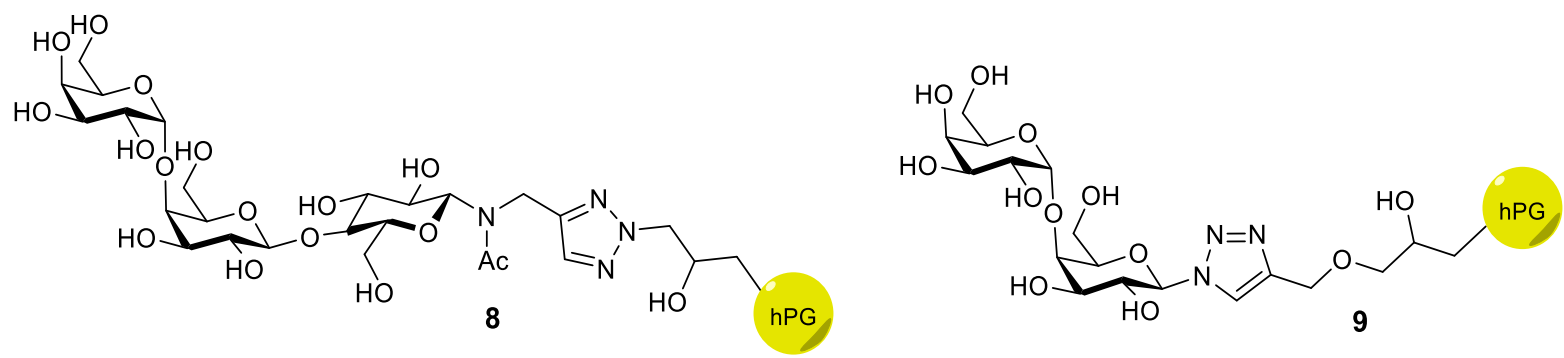

Figure 2. Polymer-Galabiose Conjugates 


\subsubsection{Shiga toxin inhibition}

Previously, inhibitors were tested for inhibition in ELISA assays using immobilization of the B subunit of Stx1 (Stx1B). ${ }^{24}$ Here a new assay was developed in which FSL-Gb3 was immobilized instead of the toxin, as this was deemed more realistic since in vivo the toxin is also free to move. FSL-GB3 is comprised of a functional component (F) which is GB3 conjugated via an $\mathrm{O}\left(\mathrm{CH}_{2}\right)_{3} \mathrm{NH}$ spacer (S) to an activated adipate derivative of dioleoylphosphatidylethanolamine (L) (Figure 3).

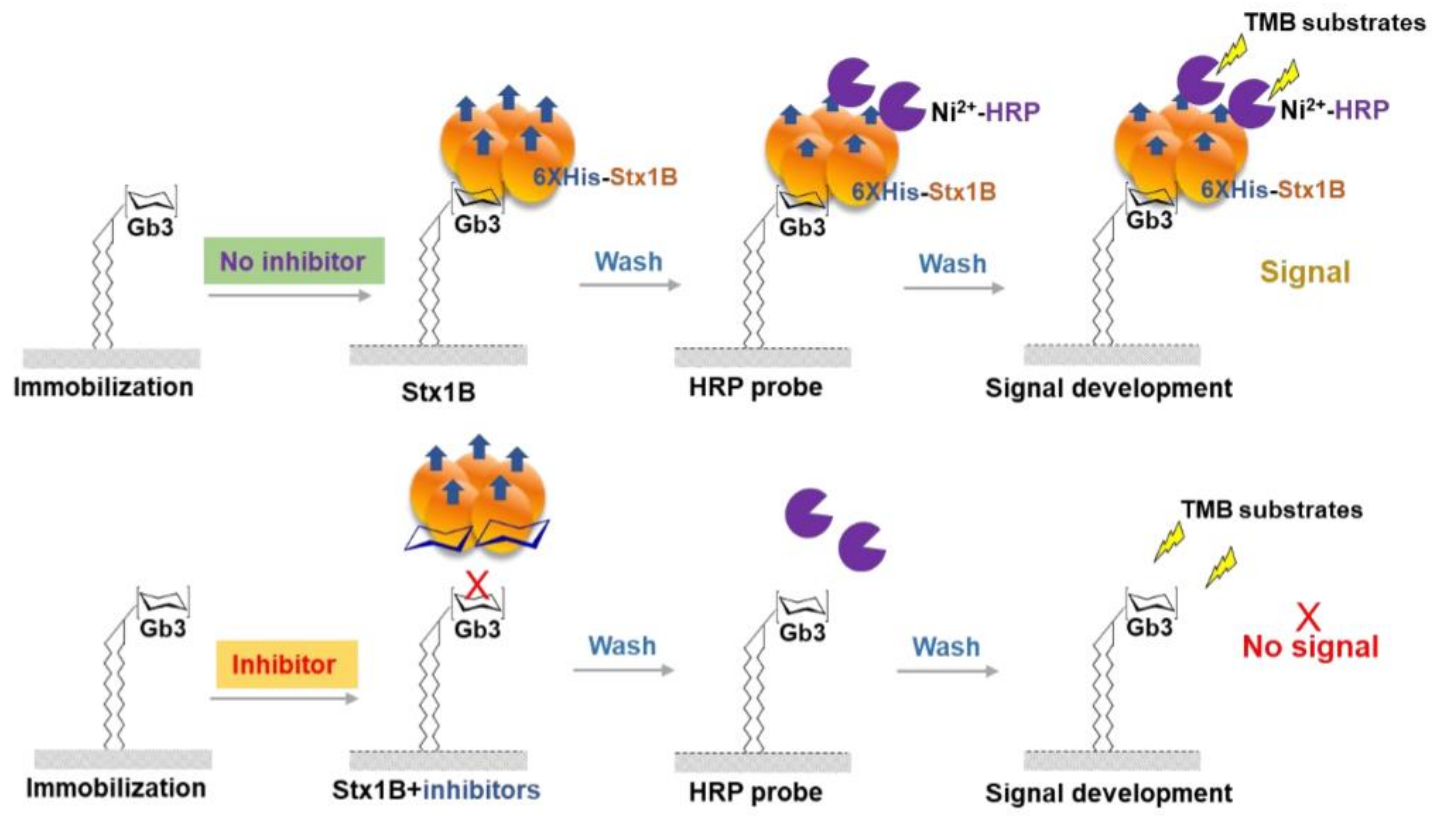

Figure 3. Cartoon explaining the Shiga toxin ELISA protocol.

1e was used as the monovalent reference in the ELISA and as expected showed millimolar inhibition of the toxin with an $\mathrm{IC}_{50}$ of approx. $5 \mathrm{mM}$. Divalent 3 and $\mathbf{4}$ also inhibited the toxin in the millimolar range (1 $\mathrm{mM}$ and $1.2 \mathrm{mM}$ respectively) (Table 1). Clearly, the small variation in spacer length between dendrimer $\mathbf{2 a}$ and $\mathbf{2} \mathbf{b}$ did not cause any significant variation in potency. It was anticipated that if the divalent ligands bridge between sites 1 and 2 on a single toxin subunit, ${ }^{6}$ which would be more easily possible with the longer spacer of 4 . A stronger enhancement of the inhibition was observed with the tetravalent compounds $\mathbf{5}$ and $\mathbf{6}$ as both showed micromolar inhibition ( $20 \mu \mathrm{M}$ and $13 \mu \mathrm{M}$ respectively). Here again, the toxin did not discriminate between the more flexible dendrimer 2d with respect to 2c (Figure 4). 


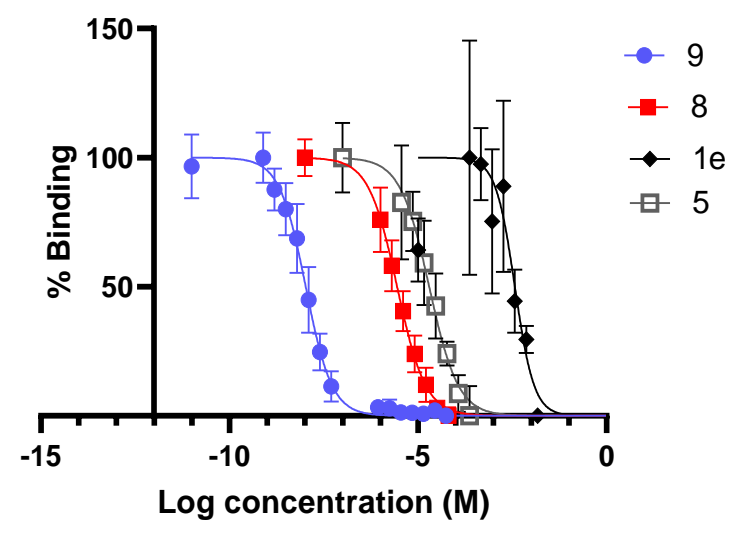

Figure 4. Inhibition curves of compounds from left to right, 9 (blue), 8 (red), 1e (white), 5 (black).

We expected both compounds to bridge between the strongest of the three binding sites per subunit, the so-called site 2,33 of the same pentamer separated by ca. $30 \AA^{6}{ }^{6}$ For the decavalent hPG-Gb3 polymeric inhibitor 8, low micromolar inhibition was seen $\left(\mathrm{IC}_{50}=3 \mu \mathrm{M}\right)$ (Figure 4). Indeed the compound was more potent than the tetravalent 5 and $\mathbf{6}$ but not by much and the inherently stronger trisaccharide ligand it contains, could easily be responsible for this difference. Gratifyingly, the more highly substituted hPG-galabiose conjugate $\mathbf{9}$ was much more potent with an $\mathrm{IC}_{50}$ of $8 \mathrm{nM}$ and a relative potency per sugar of ca. 30,000 (Table 1). These data make it the first nanomolar Stx inhibitor based on galabiose to the best of our knowledge.

Table 1. Results of inhibition in STx1B ELISA assay. ${ }^{a}$

\begin{tabular}{|c|c|c|c|c|c|}
\hline construct & ligand & $\begin{array}{c}\text { Valency (\% functionalization } \\
\text { of polymer) }\end{array}$ & $I C_{50}(\mu \mathrm{M})$ & rel.pot. ${ }^{b}$ & $\begin{array}{c}\text { rel. pot. } \\
\text { per sugarc }\end{array}$ \\
\hline $1 e$ & galabiose & 1 & $4968 \pm 1232$ & 4968 & 1 \\
\hline 3 & galabiose & 2 & $1070 \pm 283$ & 4.6 & 2.3 \\
\hline 4 & galabiose & 2 & $1245 \pm 169$ & 4 & 2 \\
\hline 5 & galabiose & 4 & $19.86 \pm 2.4$ & 250 & 62.5 \\
\hline 6 & galabiose & 4 & $13.53 \pm 2.6$ & 367 & 92 \\
\hline 8 & globotriose & $10(8 \%)$ & $2.8 \pm 0.17$ & 1,774 & 187 \\
\hline 9 & galabiose & $20(16 \%)$ & $0.0083 \pm 0.0006$ & 598,554 & 29,928 \\
\hline
\end{tabular}

adetermined in an ELISA-like assay with Stx1B $(0.7 \mathrm{ng} / \mathrm{mL})$ and wells coated with $\mathrm{Gb} 3,{ }^{b}$ relative to the potency of galabiose for $3,4,5,6$ and 9 crelative potency divided by the valency. 


\subsubsection{Evaluation of toxicity of glycopolymer 9}

In order to evaluate the potential toxicity of the most effective Stx inhibitor, polymer $\mathbf{9}$, toxicity tests were undertaken. Different concentrations of glycopolymer 9 (1, 10 and $100 \mathrm{nM})$ did not impair T84 cell viability after $24 \mathrm{~h}$ exposure as indicated by the MTT assay, while $10 \%$ ethanol (positive control) significantly reduced the cell viability (Figure 5a). Furthermore, as depicted in Figure 5b, 1, 10 and $100 \mathrm{nM}$ of glycopolymer 9 did not significantly alter the TEER values compared to untreated cells after $24 \mathrm{~h}$, whereas $10 \%$ ethanol strongly decreased the TEER values. TEER values (transepithelial electrical resistance) indicate the barrier integrity of epithelial cells.
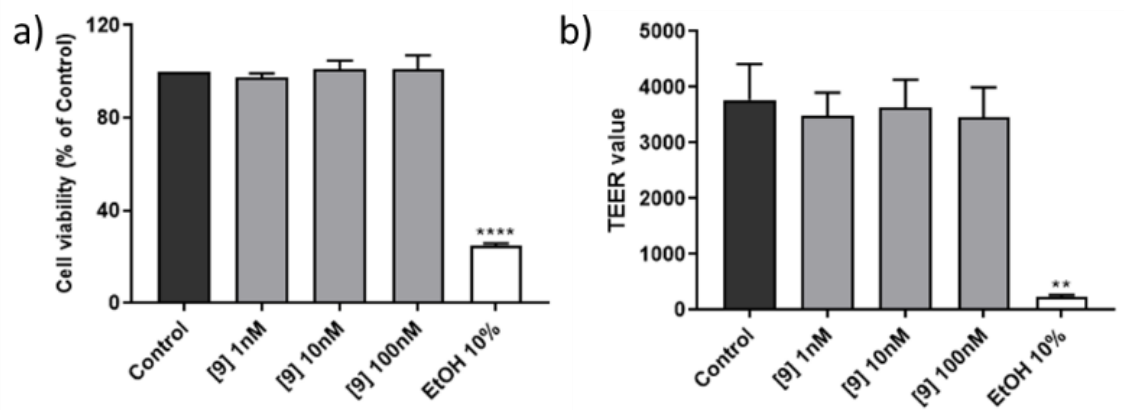

Figure 5. The effect of Glycopolymer $\mathbf{9}$ on intestinal cell viability and integrity. a) T84 cells grown on 96well plates were exposed to 1, 10 and $100 \mathrm{nM}$ glycopolymer 9 or $10 \%$ ethanol (positive control) for $24 \mathrm{~h}$, and cell viability was measured by a MTT reduction assay. The MTT values were presented as percentage MTT released by non-treated T84 cells as mean \pm SEM of three independent experiments each performed in triplicate. b) T84 cells grown on transwell inserts were exposed to 1,10 and $100 \mathrm{nM}$ glycopolymer 9 or $10 \%$ ethanol (positive control) for $24 \mathrm{~h}$ and TEER was measured as described in the experimental section. The TEER values were presented as mean $(\Omega \cdot \mathrm{cm} 2) \pm$ SEM of three independent experiments each performed in triplicate. ${ }^{* *}=\mathrm{P}<0.001$ compared to control. ${ }^{* * * *}=\mathrm{P}<0.0001$ compared to control)

\subsubsection{Commercial Oligosaccharides as Stx1B Inhibitors}

A number of natural or synthesized oligosaccharides were subsequently tested for activity at the maximal safe concentration of $2 \%$ (Figure 6 and Figure 7). ${ }^{34,35}$ Chitosan oligosaccharide (COS) is a cationic polymer obtained from crustaceans etc., composed of glucosamine repeating units and have shown several promising applications. ${ }^{36} \operatorname{COS}$ (degree of acetylation: $\geq 95 \%$ ) showed a $71 \%$ inhibition of the Stx1B with inhibitory effects seen as low as $0.25 \%$ (Figure 7). Alginate oligosaccharide (AOS), another naturally occurring polyuronic saccharide, is composed of $\beta$-Dmannuronic acid and $\alpha$-l-guluronic acid. ${ }^{37}$ AOS have been demonstrated as anti-tumor, antioxidative, immunoregulatory, anti-inflammatory among others. ${ }^{38}$ 

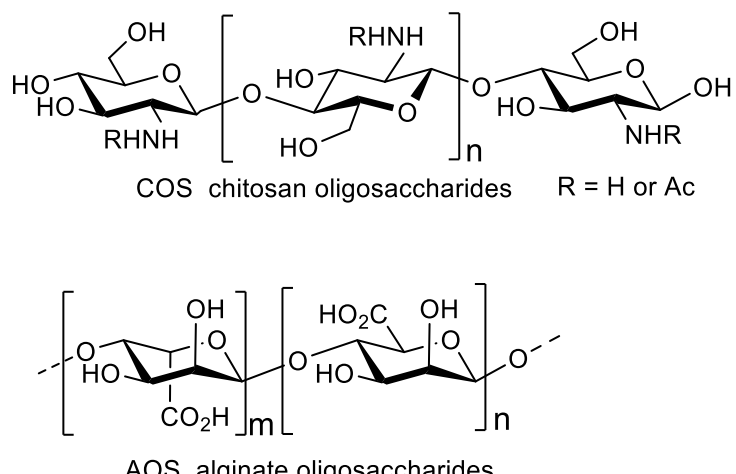

AOS alginate oligosaccharides
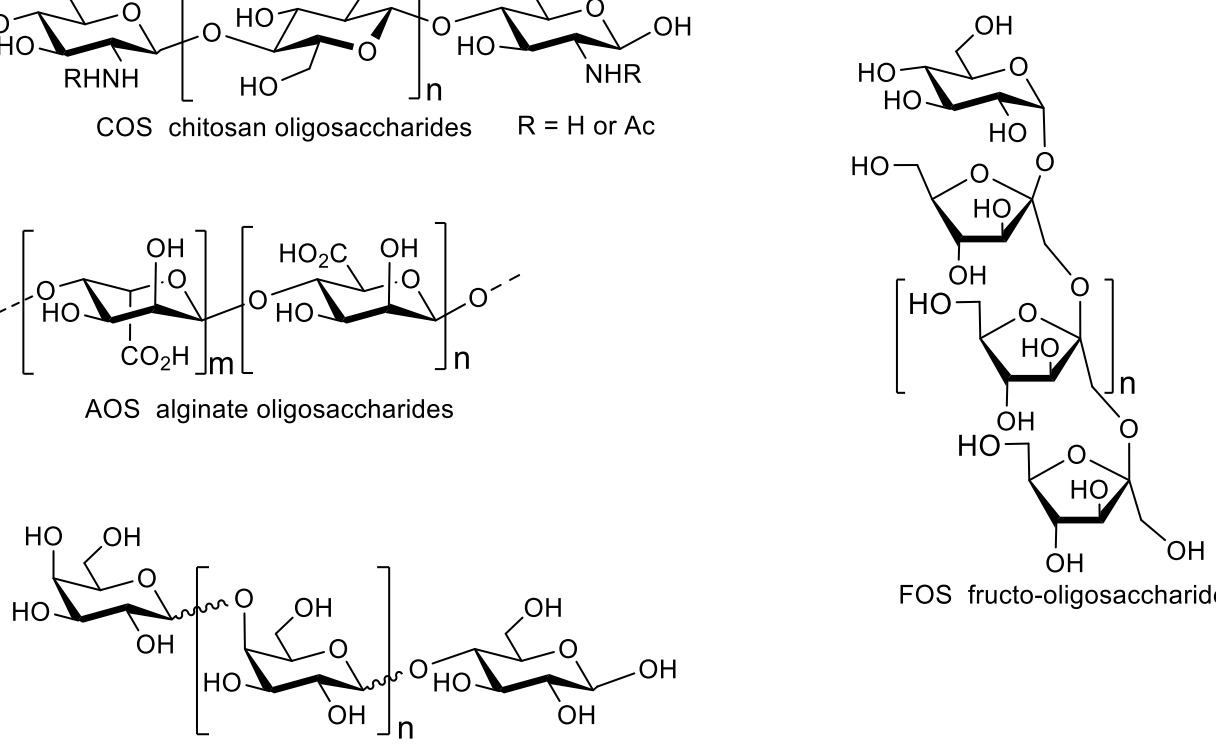

FOS fructo-oligosaccharides

GOS galacto-oligosaccharides

Figure 6 Structures of natural and synthetic inhibitors of Stx1B

AOS did show inhibition at a concentration of $0.5 \%$ resulting in $51 \%$ toxin inhibition. Curiously, higher AOS concentrations reduced the inhibition. Fructose and Galactose oligosaccharide (FOS and GOS) did not inhibit the toxin. Lactose was used as a negative control and did not show any activity.
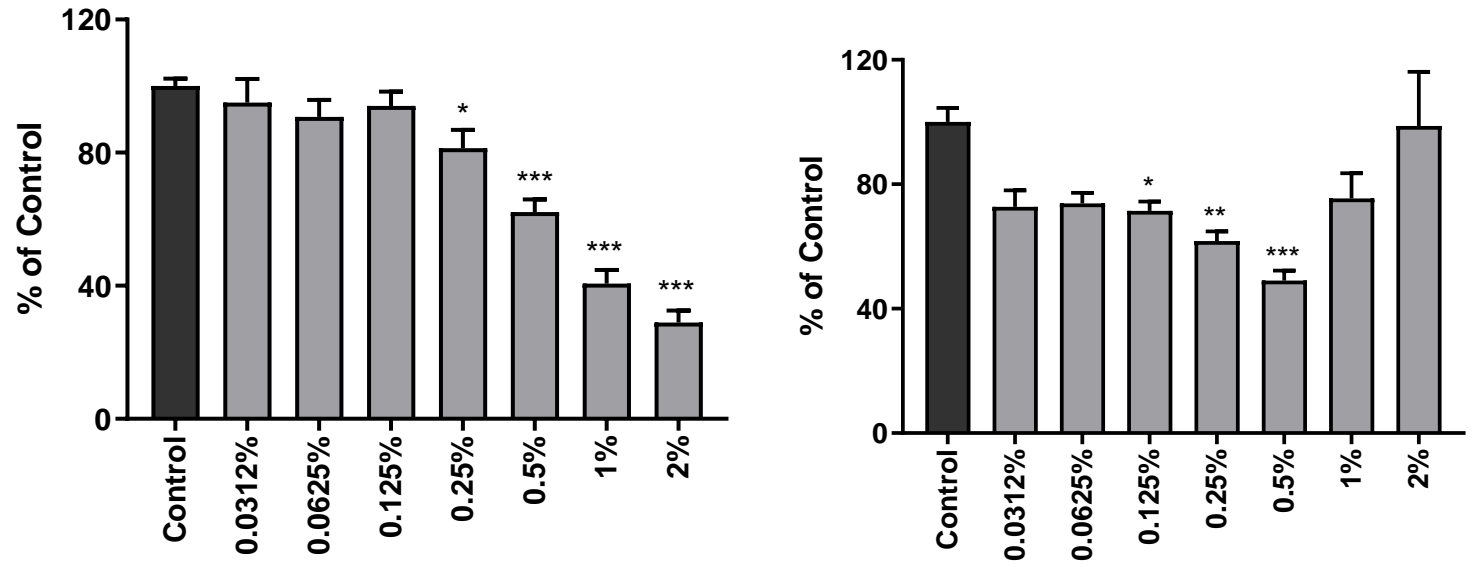

$\operatorname{COS}$ 


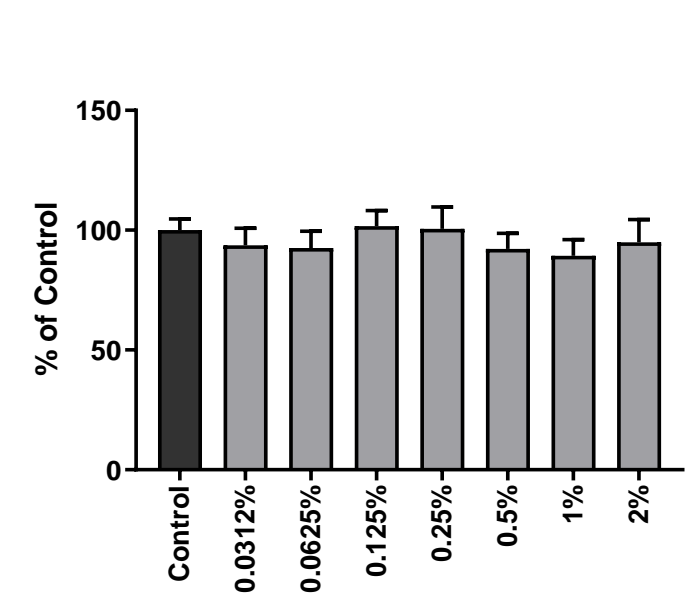

FOS

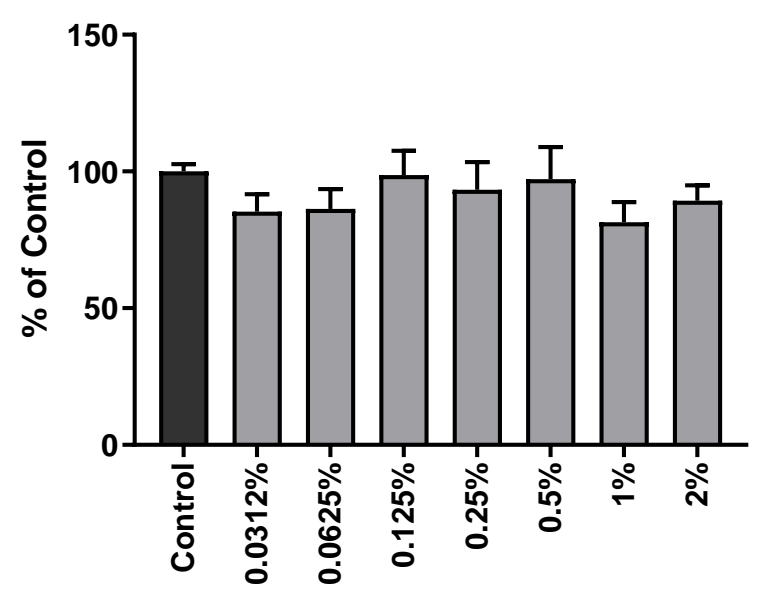

GOS

Figure 7. Activities of oligosaccharides in the Stx1B inhibition assay.

\subsubsection{Discussion and Conclusion}

A growing number of Shigella infections contain the deadly Shiga toxin and the related STEC is also still a major threat without a proper therapeutic approach. In this study we aimed for a simple and effective toxin inhibitor by comparing three classes of carbohydrate based inhibitors: glycodendrimers, glycopolymers and oligosaccharides. The glycodendrimers needed at least a tetravalent ligand to reach significant inhibition. One reason could be that it requires the bridging 39 of the two highest affinity sites (sites 2) of neighboring toxin subunits for a significant inhibitory effect. The smaller divalent compounds were too short to bridge the ca $30 \AA$ A It is likely that in addition to the chelation binding mode also aggregation of the toxin is taking place, as previously noted ${ }^{40}$ and also for the related cholera toxin. ${ }^{41}$ Of the two glycopolymers it was striking that the more highly functionalized 9 was much more potent than 8 , despite having the weaker galabiose ligand. Clearly the high density of binding sites helps the inhibition as we have seen for the related cholera toxin inhibition with similar polymers, 42,43 however with three binding sites per subunit, i.e 15 in total, the effects are more dramatic than for the cholera toxin with one binding site per subunit. Prior work, both theoretical and practical involving the Shigalike toxin has clearly indicated that avidity effects like seen here are caused by intrinsic inter and intramolecular recognition events, but that on top of that there is an important combinatorial factor that describes the probabilities of binding events. This factor is very important and favorable and was shown to increase rapidly for higher valency systems, provided that the 
geometry of the multivalent ligand is appropriate for the target. In the case at hand, the particle like nature of the polymer is particularly suitable for toxins in comparison with other polymers. ${ }^{42}$ Furthermore, the polymers were both ca. $10 \mathrm{kDa}$ but the ligand density is vastly different (valencies of 10 vs 20 for $\mathbf{8}$ and 9). Clearly the statistical possibilities for the higher ligand density 9 are far greater and can overcome the lower intrinsic binding potency of the disaccharide vs the trisaccharide ligand. 52

Shigella spp. are highly infective bacteria. Only 10-100 microbes are already enough to cause infection that could become fatal, especially when it produces the toxin, as is also the case for STEC. The initial diarrhea followed by the toxin moving into the circulation provides a challenge for therapy. It takes ca. 5-9 days between the initial gastroenteritis until HUS occurs. ${ }^{44}$ In this time window a GI-based agent e.g. a food grade polysaccharide such as COS can be beneficial. This is true also as a preventative in case of an outbreak as can happen with Shigella. In order to prevent the systemic diseases, i.e. HUS a soluble non-toxic multivalent glycan with sufficient potency will likely be helpful. As such a further optimized dendrimer or the glycopolymer 9 based on the hPG can be be prepared on a large scale in an economical manner and have also been used in circulation. ${ }^{45}$ The utility of hPG is also well established in terms of safety and biocompatibility. We have previously also used hPG backbone to target cholera toxin with good results. ${ }^{42,46}$ 


\subsection{Experimental Section}

\subsubsection{General information}

Chemicals were obtained from commercial sources and were used without further purification unless noted otherwise. The solvents were obtained as synthesis grade and stored on molecular sieves ( 4 Å). TLC was performed on Merck precoated Silica plates. Spots were visualized by UV light and $10 \% \mathrm{H}_{2} \mathrm{SO}_{4}$ in $\mathrm{MeOH}$. Microwave reactions were carried out in a Biotage microwave Initiator ( $300 \mathrm{~W}$, Uppsala, Sweden). The microwave power was limited by temperature control once the desired temperature was reached. Sealed vessels of 2-5 mL and 10-20 mL were used. ${ }^{1} \mathrm{H}$ NMR, HSQC, COSY (600 MHz) and ${ }^{13} \mathrm{C}(151 \mathrm{MHz})$ were performed on a Bruker 600 spectrometer. Infrared (IR) spectroscopy was performed using Universal Attenuated Total Reflectance (UATR) accessory of Perkin Elmer Spectrum Two FT-IR. High resolution mass spectrometry (HRMS) analysis was recorded using an Agilent 6560 Ion Mobility Q-TOF LC/MS instrument. Analytical HPLC and Preparative HPLC runs were performed on a Shimadzu 20A HPLC system. Analytical HPLC was performed using a Dr Maisch GmBh C18-AQ column (5 $\mu \mathrm{m})$ at a flow rate of 0.5 $\mathrm{mL} / \mathrm{min}$. The used buffers were $\mathrm{H}_{2} \mathrm{O}$ (Buffer $\mathrm{A}$ ) and $\mathrm{CH}_{3} \mathrm{CN}$ (Buffer B). Runs were performed using a standard protocol: 2 - $100 \%$ gradient buffer B in 35 min, UV-absorption was measured at 254 $\mathrm{nm}$. For Preparative HPLC, a Waters XBridge BEH Prep Amide column (5 $\mu \mathrm{m}, 250 \times 10 \mathrm{~mm}$ ) at a flow rate of $2.4 \mathrm{~mL} / \mathrm{min}$ was used. Runs were performed using a standard protocol: 95 - $50 \%$ gradient buffer B in $60 \mathrm{~min}$. UV-absorption was measured at $254 \mathrm{~nm}$ and $210 \mathrm{~nm}$.

Oligosaccharides: Fructo-oligosaccharides (FOS) isolated from chicory were obtained from Orafti (Wijchen, The Netherlands) (purity > 97 \%). Galacto-oligosaccharides (GOS) (Vivinal ${ }^{\circledR}$ GOS Powder, purity $>70 \%$ ) produced from lactose were provided by FrieslandCampina (Amersfoort, The Netherlands). Algi-nate Oligosaccharides (AOS) prepared by degradation of algin (purity > $85 \%$ ) and chitosan oligosaccharides (COS) derived from rich marine biological sources (shrimp \& crab shells) (purity > 90\%) were both purchased from BZ Oligo Biotech Co., Ltd. (Qingdao, Shandong, China). All oligosac-charide solutions were freshly prepared through dissolution in DMEM / F12 and their $\mathrm{pH}$ was adjusted to $\mathrm{pH}=7.2-7.4$.

Statistical analysis: Data were reported as mean values \pm SEM of three independent experiments $(n=3)$ routinely performed in triplicate ( 3 wells/condition). Results were analyzed using Prism 8.0 GraphPad Software (GraphPad, San Diego, CA, USA). Statistical significance was determined using one-way ANOVA followed by Bon-ferroni post-hoc test. Differences were considered statistical significant when $\mathrm{P}<0.05$. 
Note: Galabiose azide synthesis was performed by Torben Heise. Stx1B expression, purification and the Stx1B assay conditions were optimized by Jie Shi. TEER measurement and the MTT assay were performed by Mostafa Asadpoor.

\subsubsection{Plasmid construction, protein expression and protein purification}

The Stx1B expression plasmid was constructed by using the Gateway® recombinant cloning kit (ThermoFisher, Spain). Briefly, a synthetic DNA cassette (Invitrogen, Spain) that encodes residues 21-89 of Stx1B (GenBank: AAA98348.1) with c terminal 6×His tag was first inserted into an entry plasmid pENTR1A through restriction sites Dra I and Xho I. The resultant plasmid Stx1B-HispENTR1A together with a destination vector pDEST 14 was further subjected to the Gateway® LR Clonase cloning reaction to achieve the final protein expression construct Stx1B-His-pDEST14 following the manufacturer's instructions.

Protein expression was carried out using E. coli BL21 cells transformed with the plasmid Stx1BHis-pDEST14. The above E. coli cells were grown in LB broth media containing $100 \mathrm{mg} / \mathrm{ml}$ ampicillin at $37{ }^{\circ} \mathrm{C}$ until $\mathrm{OD}_{450}$ reached 0.6 and then IPTG was added to the culture at final concentration of $1 \mathrm{mM}$ to induce the expression of recombinant protein at room temperature for 16 hours. At the end of IPTG induction, E. coli cells were immediately lysed in the culture using BPER direct bacterial protein extraction Kit (ThermoFisher, Spain) with the supplement of protease inhibitor (EDTA free), DNase I and lysozyme following the manufacturer's instructions. After centrifugation $10 \mathrm{~min}$ at $12000 \mathrm{rpm}$ at $4{ }^{\circ} \mathrm{C}$, the supernatant was collected for further protein purification.

Protein purification was performed using a home-made column packed with HisPur ${ }^{\mathrm{TM}}$ Ni-NTA Resin (ThermoFisher, Spain) according to the manufacturer's instructions. After the column was washed with an equilibration buffer $(20 \mathrm{mM}$ sodium phosphate, $300 \mathrm{mM}$ sodium chloride, $10 \mathrm{mM}$ imidazole, $\mathrm{pH}$ 7.4), it was then loaded with the above supernatant containing $6 \times$ His tagged Stx1B at $4^{\circ} \mathrm{C}$ for $1 \mathrm{~h}$. Unbound proteins were removed from the column by using a washing buffer (20 $\mathrm{mM}$ sodium phosphate, $300 \mathrm{mM}$ sodium chloride, $20 \mathrm{mM}$ imidazole, $\mathrm{pH} 7.4$ ). Finally, $6 \times$ His tagged Stx1B was eluted from the column using an elution buffer $(20 \mathrm{mM}$ sodium phosphate, $500 \mathrm{mM}$ sodium chloride, $300 \mathrm{mM}$ imidazole, $\mathrm{pH}$ 7.4) and later confirmed by SDS-PAGE with staining free gel (Bio-Rad, Spain). Before applied for the later binding assay, imidazole residues in the eluted proteins were removed using a $10 \mathrm{kDa}$ molecular weight cut off protein concentrators (ThermoFisher, Spain) and a buffer containing $20 \mathrm{mM}$ sodium phosphate, $500 \mathrm{mM}$ sodium chloride. 

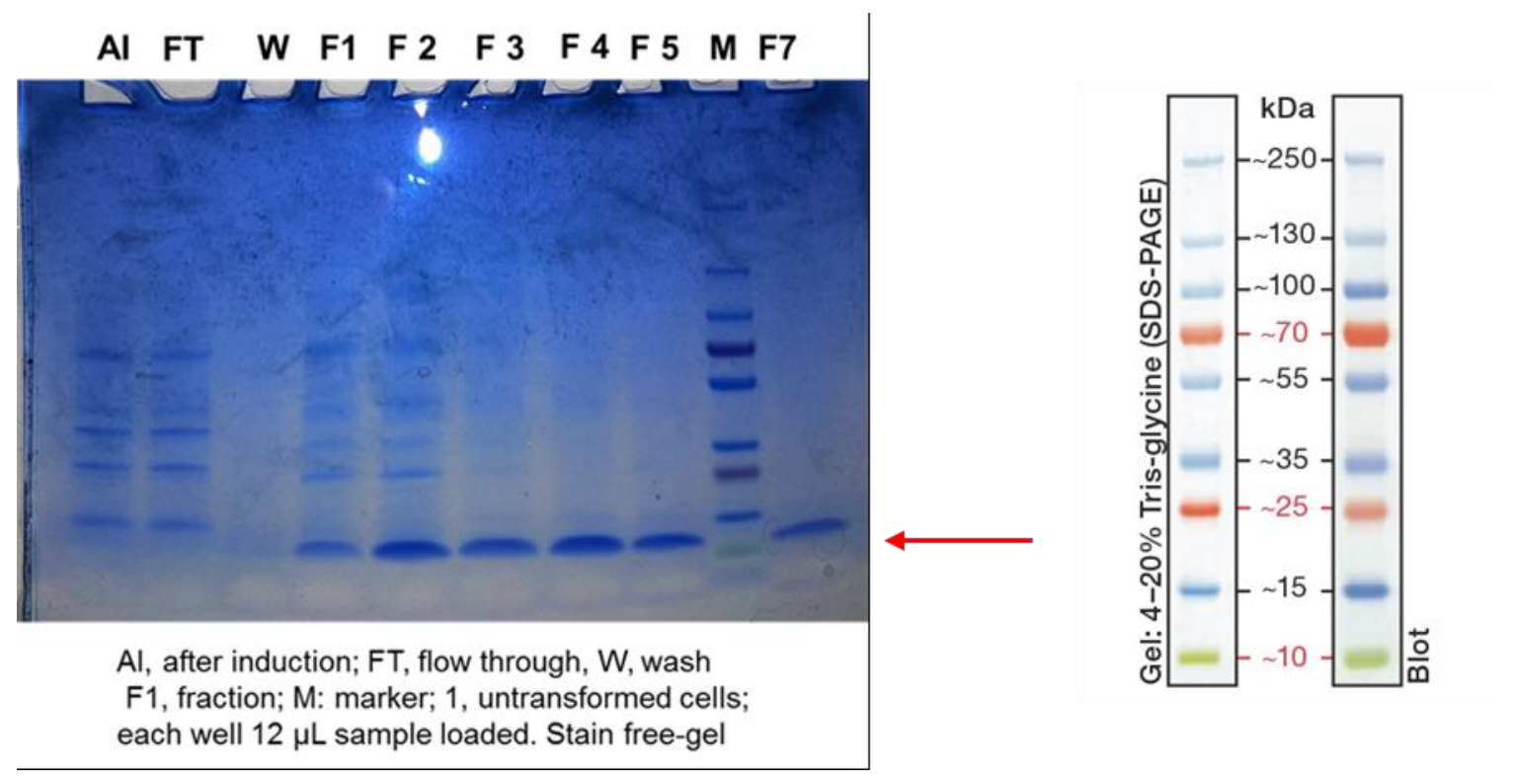

Figure 8. Purification of Stx 1B. All the protein samples were analyzed by SDS-PAGE with a stanning free gel. AI, proteins before loading to the column; FT, proteins flow through the column; $\mathrm{W}$, samples from the last column washing; F1-F7, fraction samples eluted from the column; $\mathrm{M}$, Marker. Stx 1B protein was indicated by the red arrow. Manufacturer markers were pasted on the right for comparison.

Purification of Stx 1B. All the protein samples were analyzed by SDS-PAGE with a stanning free gel. AI, proteins before loading to the column; FT, proteins flow through the column; W, samples from the last column washing; F1-F7, fraction samples eluted from the column; M, Marker. Stx 1B protein was indicated by the red arrow. Manufacturer markers were pasted on the right for comparison.

\subsubsection{Shiga toxin inhibition assay}

The assay conditions were optimized by varying the amount of toxin used which was varied between 16 and $100 \mathrm{ng} / \mathrm{mL}$ (i.e 1.6-100 ng/well, see figure below). For the assay $100 \mathrm{ng} / \mathrm{mL}$ (10 ng/well) was chosen as it was in the linear range and provided a good signal. 


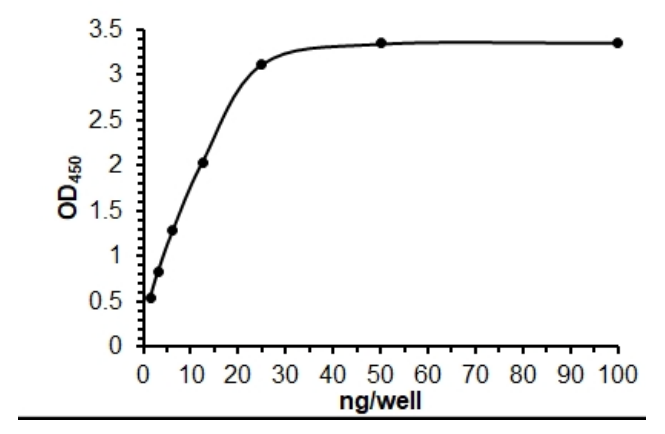

Figure 8. Optimization of Stx1B concentration used for the assay

A 96-well plate (Nunc PolySorp ${ }^{\mathrm{TM}}$ ) was coated with a solution of FSL-GB3 (50 $\mu \mathrm{L}, 2 \mu \mathrm{g} / \mathrm{mL}$ ) in phosphate buffered saline (PBS) for 3 hours at room temperature. Unattached GB3 was removed by washing with PBS $(0.2 \% \mathrm{BSA})$ and the remaining binding sites of the surface were blocked with BSA (1\%) for 1 hour, followed by washing with PBS (0.2\% BSA). Samples of Stx1B (50 $\mu \mathrm{L}, 0.1$ $\mu \mathrm{g} / \mathrm{mL}$ ) and inhibitor were transferred to the GB3-coated plate and incubated at room temperature for $1 \mathrm{~h}$ followed by washing with PBS (0.2\% BSA). HisProbe-HRP ( $4 \mathrm{mg} / \mathrm{mL}, 1: 2000$ dilution, $100 \mu \mathrm{L} /$ well) was incubated for $0.5 \mathrm{~h}$ followed by washing with PBS (0.2\% BSA). ${ }^{47} \mathrm{HRP}$ activity was measured by using 1 -Step ${ }^{\text {TM }}$ Ultra TMB-ELISA substrate solution (100 $\mu \mathrm{L} /$ well) for a maximum of $10 \mathrm{~min}$. After quenching with $\mathrm{H}_{2} \mathrm{SO}_{4}$, the absorbance in each well was measured at $450 \mathrm{~nm}$. Compounds $\mathbf{3 , 4 , 5 , 6 , 8}$ and $\mathbf{9}$ were tested at least twice in duplicate or triplicate whereas compound 1e was tested once. Inhibition data from the experiments were averaged and fitted in GraphPad Prism 8.3.0 with a non-fixed Hill-slope.

\subsubsection{Cell culture}

Human colonic epithelial T84 cells (ATCC® CCL-248 ${ }^{\mathrm{TM}}$ ) were cultured in Dulbecco's modified eagle's medium: Nutri-ent mixture F-12 (DMEM / F-12; Gibco, Invitrogen, Carls-bad, CA, USA) (1:1) supplemented with $10 \%$ fetal calf serum (FCS; Gibco), penicillin (100 U / mL) and streptomy-cin (100 g / mL) (Biocambrex) and maintained at $37^{\circ} \mathrm{C}$ in a humidified incubator with $5 \% \mathrm{CO} 2$. T84 cells were grown on plastic culture flasks $(75 \mathrm{~cm} 2)$ at a density of $3 * 106$ cells / ml. After 7 days, T84 cells were seeded on $0.3 \mathrm{~cm} 2$ high pore density polyethylene terephthalate membrane transwell inserts with $0.4 \mu$ m pores (Falcon, BD Biosciences, Franklin Lakes, NJ, USA) placed in a 24 -well plate ( density of $3 * 105$ cells/insert) or in 96-well microtiter plates (Costar 3614, Corning, NY, USA) at a density of $3 * 104$ cells/well. Cells were passaged by addition of trypsin ethylene diamine tetra-acetic acid (EDTA) at $100 \%$ confluency every week. The experiments were performed at passage number 51- 55 on fully confluent monolayers with transepithelial electrical resistance (TEER) values $>1000 \Omega \cdot \mathrm{cm} 2$. 


\subsubsection{Transepithelial electrical resistance (TEER) measurement.}

For evaluating the epithelial integrity of the T84 monolayer, TEER values were measured using a Millicell-ERS Volt-Ohm-meter (Millipore, Temecular, CA, USA). As described above, T84 cells were seeded at a density of $3 * 105$ cells/insert and cultured for 3 weeks. The inserts were placed in a 24-well plate with $300 \mu \mathrm{l}$ medium at the apical compartment and $700 \mu \mathrm{l}$ medium at the basolateral compartment. Different concentrations of the Glycopolymer 9 (1, 10 and $100 \mathrm{nM})$ were added to the apical compartment of the transwell inserts. Transwell inserts of T84 cells, treated with medium were considered as control group. The TEER values were measured before and $24 \mathrm{~h}$ after exposure to different concentrations of Glycopolymer 9 incubated at $37{ }^{\circ} \mathrm{C}$ in $5 \%$ C02. The tran-sepithelial electrical resistance was expressed as $\Omega \cdot \mathrm{cm} 2$.

\subsubsection{Viability - MTT Assay.}

Cell viability was measured by MTT [3-(4,5-dimethylthiazol-2-yl)-2,5-diphenyltetrazolium bromide] reduction assay (Sigma-Aldrich, St. Louis, Mo, USA). T84 cells were seeded on a flat bottomed 96-well plate at a density of $3 * 104$ cells/well and grown for 7 days until they reached $100 \%$ confluency. Thereafter, cells were exposed to three concentrations of glycopolymer 9 (1, 10 and $100 \mathrm{nM}$ ) and $10 \%$ ethanol was used as positive control. The wells with medium (no treatment) were considered as control group. After $24 \mathrm{~h}$ incuba-tion at $37^{\circ} \mathrm{C}$ in $5 \% \mathrm{CO} 2$, the medium was removed and $120 \mu \mathrm{l}$ of MTT working solution [20 $\mathrm{LL}$ MTT (5 mg/mL) and $100 \mu \mathrm{l}$ medium] was added to each well and incubated for $2 \mathrm{~h}$ under the same conditions. Finally, was added to lyse the cells and dissolve the purple blue sediment. After 5 min of mild shaking, the absorbance value of each well was meas-ured at $595 \mathrm{~nm}$ using a Glomax Discover microplate reader. The viability of the T84 cells was calculated based on the following equation: (mean absorbance of treatment cells / mean absorbance of control cells)*100. 


\subsubsection{Inhibition graphs}
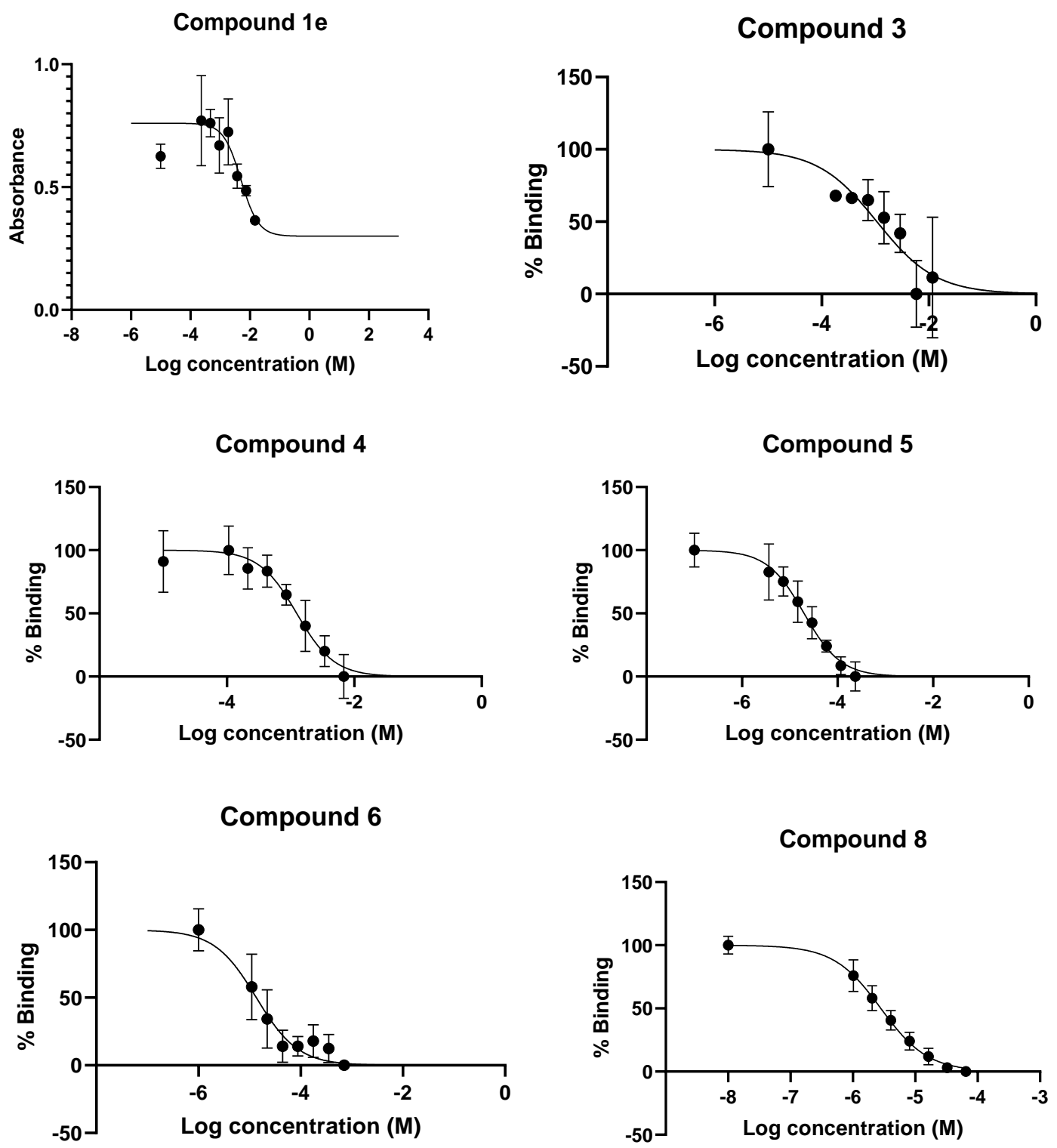

\section{Compound 9}

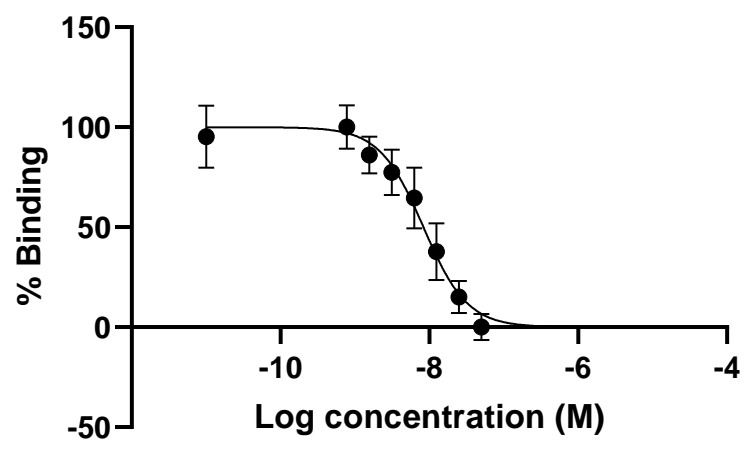




\subsubsection{Detailed synthesis}

\section{General procedure for the deacetylation reaction}

The peracetylated compound is dissolved in anhydrous methanol, followed by addition of a catalytic amount of aqueous $1 \mathrm{M} \mathrm{NaOH}$ solution and stirred at room temperature. The reaction is monitored by TLC. Upon the completion of the reaction, the reaction mixture is neutralized by the addition of Dowex marathon resin. The solvent is evaporated and the crude mixture is purified by preparative HPLC to get the pure product in $>80 \%$ yields (compounds $\mathbf{1 e}, \mathbf{3}, \mathbf{4}, \mathbf{5}, \mathbf{6}$ ).

Bis-alkyne $2 \mathbf{a}^{28}$ and Tetra-alkyne $2 \mathbf{c}^{29}$ was synthesized according to the reported procedures, with the spectral data in agreement with the reported values.

\section{General Procedure for CuAAC Conjugation for the Synthesis of Compounds 3, 4, 5, 6.}

All tested compounds were $>95 \%$ pure by HPLC. The alkyne (2a, 2b, 2c, 2d, 1 equiv.) is dissolved in DMF followed by the addition of the ligand $\mathbf{1 d}$ (1.2 equiv). Copper sulphate pentahydrate $(0.1$ equiv.) is dissolved in water separately and added to the reaction mixture. 0.3 equiv. of sodium ascorbate is also dissolved in water separately and added to the reaction mixture. The reaction is carried out at $80^{\circ} \mathrm{C}$ in the microwave for $60 \mathrm{~min}$. The reaction mixture was extracted using EtOAc and water, followed by column purification (6\% $\mathrm{MeOH}$ in $\mathrm{DCM})$ to get the purified compound which was further subjected to deacetylation as described below.

\subsubsection{Synthesis of intermediates}

\section{Azide 1c}

Compound 1a ( 2 g, 3.13 mmol, 1 equiv.), diphenyl sulfoxide (1.2 g, 6 mmol, 2.6 equiv.), and 2,4,6tris-tert-butylpyrimidine (2.232 g, 9 mmol, 3.0 equiv.) were dissolved in anhydrous DCM ( $45 \mathrm{~mL})$ under an atmosphere of argon. Activated molecular sieves ( $3 \AA$ ) were added. The solution was then cooled to $-40^{\circ} \mathrm{C}$ and trifluoromethanesulfonic anhydride (500 $\mu \mathrm{L}, 3 \mathrm{mmol}, 1.3$ equiv.) was added. The mixture was stirred for $10 \mathrm{~min}$ and galactose acceptor $\mathbf{1 b}(2.261 \mathrm{~g}, 4.373 \mathrm{mmol}, 1.4$ equiv.) was added as a solution in anhydrous DCM (40 mL). The reaction was stirred for ca $1.5 \mathrm{~h}$ at $-40{ }^{\circ} \mathrm{C}$ and then quenched by addition of triethylamine $(5 \mathrm{~mL}$, excess). The mixture was diluted with DCM $(100 \mathrm{~mL})$ and washed with $1 \mathrm{M} \mathrm{HCl}$ and saturated aqueous sodium bicarbonate. The organic layer was dried with $\mathrm{NaSO} 4$, filtrated and concentrated in vacuo. Purification was done by column chromatography (0-20\% EtOAc in petroleum ether) to yield the product $(1.655 \mathrm{~g}, 1.58$ mmol, 50\%). 
${ }^{1} \mathbf{H}$ NMR $\left(600 \mathrm{MHz}, \mathrm{CDCl}_{3}\right) \delta 8.09$ (dd, $J=8.1,1.4 \mathrm{~Hz}, 2 \mathrm{H}, 2 \mathrm{xCH} \mathrm{Bz}$ ortho), 8.04 (dd, $J=8.3,1.3 \mathrm{~Hz}$, 2H, 2xCH Bz ortho), 7.93 (dd, J = 8.2, 1.4 Hz, 2H, 2xCH Bz ortho), 7.62 - 7.56 (m, 1H, CH Bz para), 7.50 (dddd, $J=8.8,6.1,3.0,1.3 \mathrm{~Hz}, 2 \mathrm{H}, 2 \mathrm{xCH}$ Bz para), 7.46 (t, $J=7.8 \mathrm{~Hz}, 2 \mathrm{H}, 2 \mathrm{xCH}$ Bz meta), 7.36 (td, $J=7.8,3.7 \mathrm{~Hz}, 4 \mathrm{H}, 4 \mathrm{xCH} \mathrm{Bz} m e t a), 5.69$ (dd, $J=10.5,8.6 \mathrm{~Hz}, 1 \mathrm{H}, \mathrm{H}-2$ ) , 5.46 (dd, $J=10.5,2.4 \mathrm{~Hz}$, 1H, H-3), 5.02 (d, J = 3.1 Hz, 1H, H'-1), $4.83-4.76$ (m, 2H, H-1, H-6a), 4.68 (dd, J= 12.1, 7.3 Hz, 1H, H-6b), 4.41 (d, J = 2.5 Hz, 1H, H-4), 4.38 (d, J = 2.4 Hz, 1H, H'-4), $4.24-4.16$ (m, 3H, H'-2, H-5, H'6a), 4.12 - 4.07 (m, 2H, H'-3, H'-5) ) 4.05 (dd, J = 12.7, 1.9 Hz, 1H, H'-6b), 1.03 (s, 9H, $\operatorname{SiC}\left(\mathrm{CH}_{3}\right)_{3}$ ), $1.00\left(\mathrm{~s}, 9 \mathrm{H}, \mathrm{SiC}\left(\mathrm{CH}_{3}\right)_{3}\right), 0.97$ (s, 9H, $\left.\mathrm{SiC}\left(\mathrm{CH}_{3}\right)_{3}\right), 0.86\left(\mathrm{~s}, 9 \mathrm{H}, \mathrm{SiC}\left(\mathrm{CH}_{3}\right)_{3}\right), 0.19$ (s, 3H, $\left.\mathrm{SiCH}_{3}\right), 0.17$ (s, $\left.3 \mathrm{H}, \mathrm{SiCH}_{3}\right), 0.08\left(\mathrm{~s}, 3 \mathrm{H}, \mathrm{SiCH}_{3}\right), 0.04\left(\mathrm{~s}, 3 \mathrm{H}, \mathrm{SiCH}_{3}\right)$.

13C NMR (151 MHz, CDCl $) \delta 166.15$ (C=0, Bz), 165.82 (C=0, Bz), 165.12 (C=0, Bz), 133.60 (CH, Bz para), 133.36 (CH, Bz para), 133.21 (CH, Bz para), 130.01 (2xCH, Bz ortho), 129.83 (2xCH, Bz ortho), 129.80 (2xCH, Bz ortho), 129.78 (C Bz), 128.94 (C Bz), 128.67 (C Bz), 128.57 (2xCH, Bz meta), 128.43 (2xCH, Bz meta), 128.38 (2xCH, Bz meta), 101.45 (C'-1), 88.38 (C-1), 75.69 (C'-5), 75.05 (C'-4), 75.04 (C-4), 73.17 (C-3), 70.94 (C'-3), 70.04 (C'-2), 69.17 (C'-5), 68.68 (C-2), 67.02 (C'-6), 64.12 (C-6), $27.46\left(\mathrm{SiC}\left(\mathrm{CH}_{3}\right)_{3}\right), 27.36\left(\mathrm{SiC}\left(\mathrm{CH}_{3}\right)_{3}\right), 26.23\left(\mathrm{SiC}\left(\boldsymbol{C H}_{3}\right)_{3}\right), 26.21\left(\mathrm{SiC}\left(\mathrm{CH}_{3}\right)_{3}\right)$, $23.41\left(2 \times \mathrm{XiC}\left(\mathrm{CH}_{3}\right)_{3}\right), 18.36\left(\mathrm{SiC}\left(\mathrm{CH}_{3}\right)_{3}\right), 18.22\left(\mathrm{SiC}\left(\mathrm{CH}_{3}\right)_{3}\right),-3.91\left(\mathrm{SiCH}_{3}\right),-4.23\left(\mathrm{SiCH}_{3}\right),-4.35$ $\left(\mathrm{SiCH}_{3}\right),-4.66\left(\mathrm{SiCH}_{3}\right)$.

\section{Azide 1d}

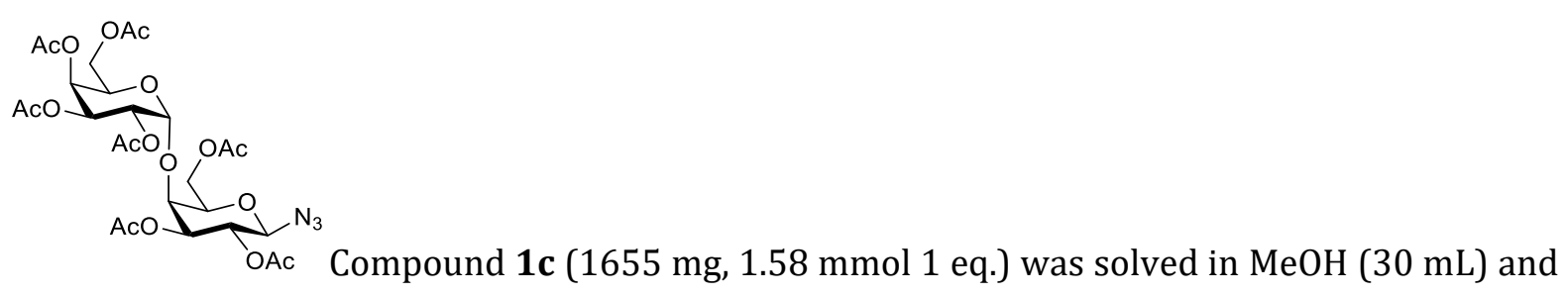
an excess of $\mathrm{K}_{2} \mathrm{CO}_{3}$ was added. The reaction was stirred at r.t. for $16 \mathrm{~h}$, then filtered and concentrated in vacuo. The crude product was dissolved in EtOAc and extracted with aqueous $\mathrm{NaHCO}_{3}$ and the organic layer was separated, dried with $\mathrm{NaSO}$, filtered and concentrated again in vacuo. The product was purified using column chromatography (10-50\% EtOAc in petroleum ether) to yield the product (1034 mg, $1.41 \mathrm{mmol}$, 89\%).The debenzoylated product (332 mg, $0.452 \mathrm{mmol}, 1$ eq.) was dissolved in DCM ( $5 \mathrm{~mL}$ ) and HF-Pyridine (70\%, $0.4 \mathrm{~mL})$ was added dropwise at r.t. under continuous argon flow. The reaction was stirred for $2 \mathrm{~h}$ and quenched by addition of solid $\mathrm{CaCl}_{2}$ (99 mg, 0.904 mmol, 2 eq.) Pyridine (10 mL, $124 \mathrm{mmol}, 272$ eq.), $\mathrm{Ac}_{2} \mathrm{O}$ (5 $\mathrm{ml}, 53 \mathrm{mmol}, 117$ eq.) and DMAP ( $3 \mathrm{mg}, 0.02 \mathrm{mmol}, 0.05$ eq.) were added. The reaction was stirred for $16 \mathrm{~h}$ at r.t. then diluted with EtOAc, and washed with saturated, aqueous $\mathrm{K}_{2} \mathrm{CO}_{3}$. The organic phase was dried with $\mathrm{NaSO}_{4}$, filtrated, and concentrated in vacuo. The product was purified using 
silica gel flash chromatography using a gradient of 40-100\% EtOAc in petroleum ether $154 \mathrm{mg}$, $0.232 \mathrm{mmol}, 51 \%$ (over 3 steps)). The spectral data was in accordance with the published data. ${ }^{48}$

1H NMR (600 MHz, $\left.\mathrm{CDCl}_{3}\right) \delta 5.53\left(\mathrm{dd}, J=3.4,1.3 \mathrm{~Hz}, 1 \mathrm{H}, \mathrm{H}^{\prime}-4\right), 5.33\left(\mathrm{dd}, J=11.0,3.4 \mathrm{~Hz}, 1 \mathrm{H}, \mathrm{H}^{\prime}-3\right.$ ), 5.16 (dd, $J=11.0,3.7 \mathrm{~Hz}, 1 \mathrm{H}, \mathrm{H}^{\prime}-2$ ), 5.12 (dd, $J=10.7,8.6 \mathrm{~Hz}, 1 \mathrm{H}, \mathrm{H}-2$ ) , 4.99 (d, $J=3.7 \mathrm{~Hz}, 1 \mathrm{H}, \mathrm{H}^{\prime}-$ 1), 4.83 (dd, $J=10.7,2.7 \mathrm{~Hz}, 1 \mathrm{H}, \mathrm{H}-3$ ), 4.63 (d, $J=8.6 \mathrm{~Hz}, 1 \mathrm{H}, \mathrm{H}-1$ ), 4.45 (ddd, $J=7.6,5.8,1.3 \mathrm{~Hz}$, 1H, H'-5), 4.40 (dd, J = 11.4, 6.9 Hz, 1H, H-6a), 4.12 (dd, J = 11.3, 6.1 Hz, 1H, H-6b), $4.10-4.04$ (m, 3H, H'6ab; H-4), 3.87 (t, J = 6.5 Hz, 1H, H-5), 2.09 (s, 3H, CH 3 Ac), 2.07 (s, 3H, CH3 Ac), 2.05 (s, 3H, $\mathrm{CH}_{3} \mathrm{Ac}$ ), 2.04 (s, 3H, CH $3 \mathrm{Ac}$ ), 2.04 (s, 3H, $\mathrm{CH}_{3} \mathrm{Ac}$ ), 2.00 (s, 3H, $\mathrm{CH}_{3} \mathrm{Ac}$ ), 1.95 (s, 3H, $\mathrm{CH}_{3} \mathrm{Ac}$ ).

${ }^{13} \mathrm{C}$ NMR (151 MHz, $\mathrm{CDCl}_{3}$ ) $\delta 170.45$ (C=0, Ac), 170.37 (C=0, Ac), 170.32 (C=0, Ac), 170.27 (C=0, Ac), 169.98 ( $C=0, A c), 169.66$ (C=0, Ac), 168.90 (C=0, Ac), 98.97 ( $\left.C^{\prime}-1\right), 88.11$ (C-1), 76.27 (C-4), 74.03 (C-5), 72.40 (C-3), 68.30 (C'-2), 67.88 (C-2), 67.67 (C'-4), 67.18 (C'-5), 67.07 (C'-3), 61.81 (C-6), 60.42 (C'-6), $20.76\left(\mathrm{CH}_{3}, \mathrm{Ac}\right), 20.62\left(\mathrm{CH}_{3}, \mathrm{Ac}\right), 20.58\left(\mathrm{CH}_{3}, \mathrm{Ac}\right), 20.54\left(\mathrm{CH}_{3}, \mathrm{Ac}\right), 20.51\left(\mathrm{CH}_{3}\right.$, Ac), $20.47\left(\mathrm{CH}_{3}, \mathrm{Ac}\right)$.

\section{Azide 1e}

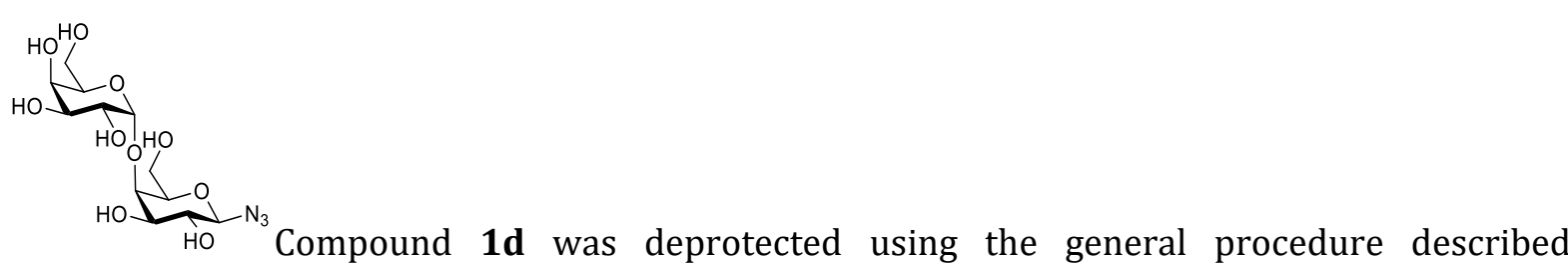
previously to obtain the final compound 1e in $90 \%$ yield. The spectral data was in accordance with the published data. ${ }^{49}$

${ }^{1}$ H NMR (600 MHz, MeOD) $\delta 4.94\left(\mathrm{~d}, J=3.7 \mathrm{~Hz}, 1 \mathrm{H}, \mathrm{H}^{\prime}-1\right), 4.52(\mathrm{~d}, J=8.4 \mathrm{~Hz}, 1 \mathrm{H}, \mathrm{H}-1), 4.18(\mathrm{t}, J=$ $6.2 \mathrm{~Hz}, 1 \mathrm{H}, \mathrm{H}-5), 3.99$ (d, J = 3.0 Hz, 1H, H-4), 3.88 (d, J = 3.2 Hz, 1H, H'-4), $3.85-3.71$ (m, 6H, H'2, H'-3, H'-5, H'-6ab, H-6a), 3.65 (dd, $J=11.2,5.1$ Hz, 1H, H-6b), 3.52 (dd, $J=10.0,2.9$ Hz, 1H, H-3), $3.41(\mathrm{dd}, J=10.3,1.9 \mathrm{~Hz}, 1 \mathrm{H}, \mathrm{H}-2)$.

13C NMR (151 MHz, MeOD) $\delta 101.43$ (C'-1), 91.39 (C-1), 78.37 (C-5), 76.70 (C-4), 73.43 (C-3), 71.62 (C'-5), 71.02 (C-2), 69.83 (C'-4), 69.66 (C'-2), 69.20 (C'-3), 61.30 (C-6), 59.70 (C'-6).

\section{Compound 2b}

Methyl 3,5-bis(2-(Boc-amino)ethoxy)benzoate (110 mg, $0.25 \mathrm{mmol}, 1$ equiv.) was prepared according to previously reported procedure ${ }^{29}$ and dissolved in 1:1 TFA:DCM and stirred at r.t. for $2 \mathrm{~h}$ before concentrating in vacuo. The residue was dissolved in DCM (10 ml) and TEA (139 $\mu \mathrm{L}, 1$ mmol, 4 equiv.) was added and the mixture was left stirring for 5 minutes at r.t. before cooling to $0^{\circ} \mathrm{C}$. Propargyl chloroformate ( $55 \mu \mathrm{L}, 0.55 \mathrm{mmol}, 2.2$ equiv.) was added dropwise and the reaction was allowed to slowly warm up to r.t. and was left stirring for $16 \mathrm{~h}$. The reaction was 
diluted with an excess of DCM and $1 \mathrm{M}$ aq. $\mathrm{HCl}$ and the organic layer was collected, dried with $\mathrm{NaSO}_{4}$, filtrated and concentrated in vacuo. The compound was purified by column chromatography using a gradient of $0-50 \%$ EtOAc in petroleum ether and with $1 \%$ TFA yielding the free acid ( $89 \mathrm{mg}, 0.22 \mathrm{mmol}, 88 \%$ ).

1 H NMR $\left(600 \mathrm{MHz}\right.$, Methanol- $\left.d_{4}\right) \delta 7.20(\mathrm{~d}, J=2.4 \mathrm{~Hz}, 2 \mathrm{H}, 2 \mathrm{xCH}$, ortho aromatic acid), $6.79(\mathrm{~d}, J=$ $2.5 \mathrm{~Hz}, 1 \mathrm{xCH}$, para aromatic acid), $4.68(\mathrm{~d}, J=2.4 \mathrm{~Hz}, 4 \mathrm{H}, 2 \mathrm{xCH}$, propargyl), $4.07(\mathrm{t}, J=5.5 \mathrm{~Hz}, 4 \mathrm{H}$, $\left.2 \mathrm{xOCH} \mathrm{C}_{2}\right), 3.41\left(\mathrm{t}, J=5.5 \mathrm{~Hz}, 4 \mathrm{H}, 2 \mathrm{xNCH}_{2}\right), 2.89(\mathrm{t}, J=2.5 \mathrm{~Hz}, 2 \mathrm{H}, 2 \mathrm{xC} \equiv \mathrm{CH})$.

13C NMR (151 MHz, Methanol- $d_{4}$ ) $\delta 169.61$ (C=0, acid), 161.30 (CO, aromatic), 158.13 (2xC=0, carbamate), 134.17 (C-COOH, aromatic acid), 109.32 (2xCH, ortho aromatic acid), 107.26 ( $\mathrm{CH}$, para aromatic acid $), 79.44(2 \times C \equiv \mathrm{CH}), 75.80(2 \mathrm{xC} \equiv \mathrm{CH}), 68.11\left(2 \mathrm{xOCH}_{2}\right), 53.20\left(2 \mathrm{xCH}_{2}\right.$, propargyl), $41.43\left(2 \mathrm{xNCH}_{2}\right)$. HR-ESI-TOF/MS (m/z): [M+Na]+ calcd. for $\mathrm{C}_{19} \mathrm{H}_{20} \mathrm{~N}_{2} \mathrm{O}_{8}, 427.1117$; found, 427.1116.

\section{Compound 2d}

To a solution of $2 \mathbf{a}(16.4 \mathrm{mg}, 82 \mu \mathrm{mol})$ in DCM $(1 \mathrm{~mL})$ was added $(\mathrm{COCl})_{2}(31 \mu \mathrm{L}, 246 \mu \mathrm{L}, 3$ eq.) and DMF $(10 \mu \mathrm{L})$. After stirring at rt for $1.5 \mathrm{hr}$, the mixture was concentrated. The resulting residue was azeotroped with $10 \mathrm{~mL}$ anhydrous toluene and then redissolved in DCM (1 mL), cooled to $0^{\circ} \mathrm{C}$. A solution of pyridine $(1 \mathrm{~mL})$, DCM $(1 \mathrm{mg})$ and dodecane-1,12-diamine $(10 \mathrm{mg})$ was added slowly to the reaction flask. The resulting mixture was stirred at rt overnight. Solvents were removed and the residue was partitioned between EtOAc and water. The organic layer was separated, washed with brine $(1 \mathrm{x})$, dried with anhydrous $\mathrm{MgSO}_{4}$, filtered, and concentrated. The residue was purified by silica gel flash chromatography and yielded product ( $20 \mathrm{mg}, 80 \%$ ).

1H NMR (600 MHz, Acetone- $d_{6}$ ) $\delta 7.57$ (t, J = $5.9 \mathrm{~Hz}, 2 \mathrm{H}, \mathrm{NH}$ ), 7.02 (s, 4H, 4xCH aromatic), 6.64 (s, $2 \mathrm{H}, 2 \mathrm{xCH}$ aromatic), $4.71-4.67\left(\mathrm{~m}, 8 \mathrm{H},\left(4 \mathrm{xOCH}_{2}\right), 3.24(\mathrm{q}, \mathrm{J}=6.7 \mathrm{~Hz}, 4 \mathrm{H}, 4 \mathrm{xCH}\right.$ propargyl), 2.97 (s, 4H, 2xNHCH ), $1.92\left(\mathrm{~s}, 4 \mathrm{H}, 2 \mathrm{x} \mathrm{CH}_{2}\right), 1.46\left(\mathrm{t}, \mathrm{J}=7.1 \mathrm{~Hz}, 4 \mathrm{H}, 2 \mathrm{x} \mathrm{CH}_{2}\right), 1.28-1.02\left(\mathrm{~m}, 12 \mathrm{H}, 6 \mathrm{x} \mathrm{CH}_{2}\right)$. ${ }^{13} \mathrm{C}$ NMR (151 MHz, Acetone- $d_{6}$ ) $\delta 165.64$ (2xC=0), 158.77 (4xCO, aromatic), 137.57 (2xC-CONH), $106.68(4 \mathrm{xCH}), 104.54(2 \mathrm{xCH}), 78.54$ (4xCCH, alkyne), $76.38\left(4 \mathrm{xCCH}\right.$, alkyne), $55.70\left(4 \mathrm{xOCH}_{2}\right)$, $39.64\left(2 \mathrm{xN}-\mathrm{CH}_{2}\right), 29.32\left(\mathrm{CH}_{2}\right), 29.30\left(\mathrm{CH}_{2}\right), 29.17\left(\mathrm{CH}_{2}\right), 29.15\left(\mathrm{CH}_{2}\right), 29.04\left(\mathrm{CH}_{2}\right), 29.01\left(\mathrm{CH}_{2}\right)$, $28.90\left(\mathrm{CH}_{2}\right), 28.77\left(\mathrm{CH}_{2}\right), 28.64\left(\mathrm{CH}_{2}\right)$. HR-ESI-TOF/MS (m/z): [M+H]+ calcd. for $\mathrm{C}_{38} \mathrm{H}_{44} \mathrm{~N}_{2} \mathrm{O}_{6}$, 625.3277; found, 625.3302 .

\subsubsection{Synthesis of dendrimer-galabiose conjugates}

\section{Compound 3}

${ }^{1} \mathrm{H}$ NMR (600 MHz, Deuterium Oxide) $\delta 8.23$ (s, 2H, triazole), 7.07 (dd, J = 2.3, $0.9 \mathrm{~Hz}, 2 \mathrm{H}, 2 \mathrm{x}$ CHarom-2,6),), 6.68 (td, J = 2.3, 0.8 Hz, 1H, 1x CHarom-4), 5.58 (dd, J = 9.0, 0.8 Hz, 2H, 2x H-1), 
$5.18\left(\mathrm{~s}, 4 \mathrm{H}, 2 \mathrm{x}\right.$ OCH2), $4.90\left(\mathrm{~d}, \mathrm{~J}=4.0 \mathrm{~Hz}, 2 \mathrm{H}, 2 \mathrm{x} \mathrm{H}^{\prime}-1\right), 4.29(\mathrm{t}, \mathrm{J}=6.4 \mathrm{~Hz}, 2 \mathrm{H}, 2 \mathrm{x} \mathrm{H}-5$ ), 4.20 (t, J = $9.5 \mathrm{~Hz}, 2 \mathrm{H}, 2 \mathrm{x} \mathrm{H}-2$ ), 4.07 (d, J = 3.2 Hz, 2H, 2x H'-5) ) $3.96-3.68$ (m, 14H, 2x H'-4, 2x H'-2, 2x H'-6, $2 \mathrm{x} \mathrm{H}^{-4}, 2 \mathrm{x} \mathrm{H}^{\prime}-3,2 \mathrm{x} \mathrm{H}-3$ ), $3.64-3.55$ (m, 4H, 2x H-6).

${ }^{13} \mathrm{C}$ NMR (151 MHz, Deuterium Oxide) $\delta 174.24$ (-COOH), 158.33 (2xCarom-3), 143.27 (2x-OCH2C), 139.24 (COOH-C), 125.28 (2x N-CH), 108.97 (2x CHarom-2,6), 105.72 (1x CHarom-4), 100.48 (2xC'-1), 88.10 (2xC-1), 78.28 (2xC'-5), 77.24 (2xC-4), 72.69 (2xC'-3), 70.90 (2xC-5), 69.61 (2xC-

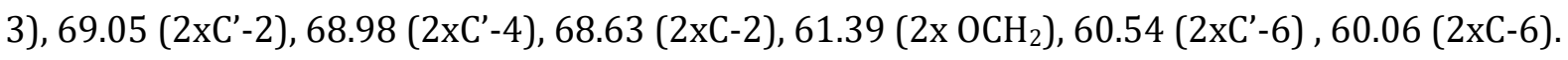
HR-ESI-TOF/MS (m/z): [M+Na] calcd. for $\mathrm{C}_{37} \mathrm{H}_{52} \mathrm{~N}_{6} \mathrm{O}_{24}, 987.2930$; found, 987.2934.

\section{Compound 4}

1H NMR (600 MHz, Deuterium Oxide) $\delta 8.23$ (s, 2H, triazole), 7.07 (s, 2H, 2x CHarom-2,6),), 6.66 (s, 1H, 1x CHarom-4), 5.66 (d, J = 9.0 Hz, 2H, 2x H-1), 5.20 (d, J = 2.4 Hz, 4H, 2xNH-CO-CH ), 5.03 (d, $J=4.0 \mathrm{~Hz}, 2 \mathrm{H}, 2 \mathrm{x} \mathrm{H}-1), 4.41(\mathrm{t}, J=6.5 \mathrm{~Hz}, 2 \mathrm{H}, 2 \mathrm{x} \mathrm{H}-5), 4.31$ (t, $J=9.6 \mathrm{~Hz}, 2 \mathrm{H} 2 \mathrm{x} \mathrm{H}-2), 4.20$ (d, $J$ $=3.0 \mathrm{~Hz}, 2 \mathrm{H}, 2 \mathrm{x} \mathrm{H}-3), 4.13\left(\mathrm{t}, J=5.1 \mathrm{~Hz}, 4 \mathrm{H}, 2 \mathrm{xCONH}-\mathrm{CH}_{2}-\mathrm{CH}_{2}\right), 4.07-3.84\left(\mathrm{~m}, 14 \mathrm{H}, 2 \mathrm{x} \mathrm{H}^{\prime}-4,2 \mathrm{x} \mathrm{H}^{\prime}-\right.$ 3, 2x H'-2, 2x H'-5, 2x H-4, 2x H-6), $3.78-3.68$ (m, 4H, 2x H'-6), 3.52 (t, J = 5.2 Hz, 4H, 2xCONH$\mathrm{CH}_{2}-\mathrm{CH}_{2}$ ).

${ }^{13} \mathrm{C}$ NMR (151 MHz, Deuterium Oxide) $\delta 157.89$ (2xCarom3,5), 125.11 (2x N-CH), 108.29 (2x

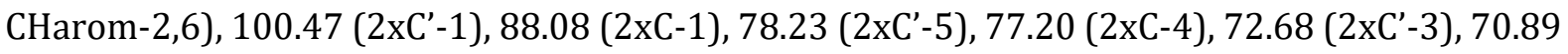
(2xC-5), 69.59 (2xC-3), 69.06 (2xC'-2), 68.97 (2xC'-4), 68.62 (2xC-2), 67.18 (2x OCH $), 60.53$ (2xC'-6), 60.00 (2xC-6), 57.63 ( $2 \mathrm{xNHCO}^{-0}-\mathrm{CH}_{2}$ ), 40.09 ( $2 \mathrm{x} \mathrm{OCH}_{2}-\mathrm{CH}_{2}$ ).

HR-ESI-TOF/MS (m/z): [M+Na] ${ }^{+}$calcd. for $\mathrm{C}_{43} \mathrm{H}_{62} \mathrm{~N}_{8} \mathrm{O}_{28}, 1161.3571$; found, 1161.3574 .

\section{Compound 5}

${ }^{1} \mathrm{H}$ NMR (600 MHz, Deuterium Oxide) $\delta 8.26$ (s, 4H, triazole), 7.06 (s, $J=1.9 \mathrm{~Hz}, 2 \mathrm{H}, 2 \mathrm{x}$ CHarom2,6), 6.70 (s, 1H, 1x CHarom-4), 6.62 (d, J = 2.2 Hz, 4H, 4x CHarom-2',6'), 6.44 (s, 2H, 2x CHarom4'), $5.64(\mathrm{~d}, J=9.0 \mathrm{~Hz}, 4 \mathrm{H}, 4 \mathrm{x} \mathrm{H}-1), 5.00$ (d, $J=4.0 \mathrm{~Hz}, 4 \mathrm{H}, 4 \mathrm{x} \mathrm{H}-1$ ), 4.95 (s, 8H, 4x triazole- $\mathrm{CH}_{2}-$ ), 4.35 (t, $J=6.4 \mathrm{~Hz}, 4 \mathrm{H}, 4 \mathrm{x} \mathrm{H}-5$ ), 4.29 (t, $J=9.6 \mathrm{~Hz}, 4 \mathrm{H}, 4 \mathrm{x} \mathrm{H}-2$ ), 4.17 (d, $J=3.2 \mathrm{~Hz}, 8 \mathrm{H}, 4 \mathrm{x} \mathrm{H}-4,2 \mathrm{x}$ CONH-CH $2_{2}-\mathrm{CH}_{2}-$ ), $4.00\left(\mathrm{t}, J=6.3 \mathrm{~Hz}, 4 \mathrm{H}, 4 \mathrm{x} \mathrm{H}^{\prime}-5\right), 3.97-3.88\left(\mathrm{~m}, 12 \mathrm{H}, 4 \mathrm{x} \mathrm{H}-3,4 \mathrm{x} \mathrm{H}^{\prime}-3,4 \mathrm{x} \mathrm{H}^{\prime} 4\right), 3.88$ - 3.78 (m, 12H, 4x H'-6, 4x H'-2), 3.68 (d, J = 6.4 Hz, 8H, 4x H-6), 3.64 (s, 4H, 2x CONH-CH${ }_{2}-\mathrm{CH}_{2}-$ ).

${ }^{13} \mathrm{C}$ NMR (151 MHz, Deuterium Oxide, extracted from HSQC) $\delta 125.03$ (triazole), 108.89 (2xCHarom-2,6, 104.45 1x CHarom-4), 106.57 (4xCHarom-2',6'), 105.32 (2x CHarom-4'), 88.11(C-1), 100.53 (C'-1), 61.07 (triazole- $\mathrm{CH}_{2}$-), 70.93 (C-5), 69.65 (C-2), 77.35, 66.73, 78.13 (C'5), 68.94, 72.72, 59.97, 68.70, 60.52 (C-6), 39.84 (CONH- $\mathrm{CH}_{2}-\mathrm{CH}_{2}$-). HR-ESI-TOF/MS (m/z): [M$\mathrm{H}]$ - calcd. for $\mathrm{C}_{85} \mathrm{H}_{116} \mathrm{~N}_{14} \mathrm{O}_{50}, 2132.6964$; found, 2132.6869 


\section{Compound 6.}

${ }^{1} \mathrm{H}$ NMR (600 MHz, Deuterium Oxide) $\delta 8.18$ (s, 4H, 4H, triazole), 6.92 (s, 4H, 4xCHarom-2',6'), 6.56 (s, 2H, 2xC CHarom-4'), 5.54 (s, 4H, 4x H-1), 4.98 (s, 6H, 4x H'-1), 4.76 (s, 8H, 4x triazole- $\mathrm{CH}_{2^{-}}$ ), 4.32 (s, 4H, 4x H-5), 4.25 (s, 4H, 4x H-2), 4.12 (s, 4H, 4x H-4), 4.01 - 3.49 (m, 32H, 4x H'-2, 4x H'-

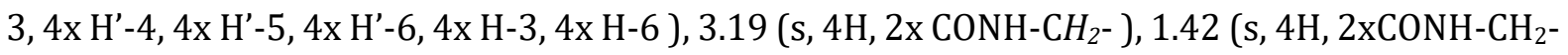
$\left.\mathrm{CH}_{2^{-}}\right), 1.05\left(\mathrm{~s}, 16 \mathrm{H}, \mathrm{CONH}-\left(\mathrm{CH}_{2}\right)_{12}\right)$.

HR-ESI-TOF/MS (m/z): [M-H]- calcd. for $\mathrm{C}_{86} \mathrm{H}_{128} \mathrm{~N}_{14} \mathrm{O}_{46}, 2092.8107$; found, 2092.8028

\subsubsection{Synthesis of polymers and polymer-galabiose conjugates}

\section{Hyperbranched Polyglycerol (hPG-OH)}

hPG-OH was synthesized using a reported procedure. ${ }^{30}$ The polymerization was carried out in a flask fitted with a mechanical stirrer and a syringe pump under argon atmosphere and heated to $100^{\circ} \mathrm{C} .1,1,1$-Tris(hydroxymethyl)propane $(0.134 \mathrm{~g}, 1 \mathrm{mmol}, 1$ equiv.) and added to the flask and melted at $60^{\circ} \mathrm{C}$. This was followed by addition of potassium hydroxide solution in methanol $(0.02$ g, $0.37 \mathrm{mmol}, 0.37$ equiv. of $\mathrm{KOH}$ ) and the resulting mixture was stirred for $1 \mathrm{~h}$. Excess methanol was evaporated under reduced pressure and the temperature of the reactor was increased to $100^{\circ} \mathrm{C}$. Glycidol monomer ( $10 \mathrm{~g}, 135 \mathrm{mmol}, 135$ equiv.) was added slowly to the reaction with the aid of a syringe pump $(0.5 \mathrm{~mL} / \mathrm{hr})$. Once all the glycidol was consumed, the reaction was quenched using methanol and neutralized with Amberlite IRC-150 resin. The resin was filtered off over 0.4 pore size filter and the crude compound was dissolved in water and dialyzed using a cellulosebased dialysis membrane (MWCO: $3.5 \mathrm{~K}$ ) to give a colorless viscous polymer (Yield $=50 \%$ ). The degree of branching (DB) was calculated using inverse gated (IG) ${ }^{13} \mathrm{C}$ NMR as reported in literature. ${ }^{50} \mathrm{Mn}$ was calculated using reported formula as described below. ${ }^{51}$

\begin{tabular}{|c|c|c|}
\hline Structural unit & NMR integration & Relative abundance (\%) \\
\hline Terminal (T) & 3.20 & 32.3 \\
\hline Linear 1,3 (L13) & 1.02 & 10.32 \\
\hline Linear 1,4 (L14) & 2.91 & 29.45 \\
\hline Dendritic (D) & 2.75 & 27.83 \\
\hline
\end{tabular}

$$
\begin{aligned}
\mathrm{DB} & =\frac{2 D}{2 D+L 13+L 14} \\
& =0.58
\end{aligned}
$$


$\mathrm{DP}_{\mathrm{n}}=$ degree of polymerization of $\mathbf{h P G}-\mathbf{O H}$; molecular weight of glycidol $\mathrm{M}_{\mathrm{G}}: 74.1 \mathrm{~g} / \mathrm{mol}$; molecular weight of the initiator TMP $\mathrm{M}_{\mathrm{I}}: 134.2 \mathrm{~g} / \mathrm{mol}$.

$\mathrm{A}_{\mathrm{PG}}=$ relative abundance of $\mathbf{h P G}-\mathbf{O H}$ backbone protons $=\frac{\text { integral of polymer backbone }}{5 \mathrm{H}}=\frac{206.17}{5}=41.23$

$\mathrm{A}_{\mathrm{I}}=$ relative abundance of initiator protons $=\frac{\text { integral of initiator methyl group }}{3 \mathrm{H}}=0.33$

$\mathrm{DP}_{\mathrm{n}}=\frac{\mathrm{APG}}{\mathrm{AI}}$

$\mathrm{DP}_{\mathrm{n}}=125$

$\mathrm{Mn}(\mathbf{h P G}-\mathbf{O H})=\mathrm{DP}_{\mathrm{n}} \cdot \mathrm{M}_{\mathrm{G}}+\mathrm{M}_{\mathrm{I}}=\left(\frac{\mathrm{APG}}{\mathrm{AI}} \cdot 74 \cdot 1+134.2\right) \mathrm{g} / \mathrm{mol}$

Mn (hPG-OH) $=9393.1 \mathrm{~g} / \mathrm{mol}$

\section{hPG-OMs (8\%)}

hPG-OMs was synthesized using a reported procedure. ${ }^{31} \mathbf{h P G}-\mathbf{O H}(0.52 \mathrm{~g}, 0.74 \mathrm{mmol}$ OH to be functionalized) was dissolved in dry DMF $(5 \mathrm{~mL})$, followed by addition of triethylamine $(0.2 \mathrm{~mL}$, $1.47 \mathrm{mmol}, 2.0$ equiv. with respect to $\mathrm{OH}$ group), and then cooled to $0{ }^{\circ} \mathrm{C}$. Methane sulphonyl chloride (103 $\mu \mathrm{L}, 1.33 \mathrm{mmol}, 1.8$ equiv. with respect to OH group) dissolved in dry DMF ( $2 \mathrm{~mL})$ was added dropwise at $0{ }^{\circ} \mathrm{C}$. The mixture was allowed to reach room temperature and was stirred for 16 hours. The dry DMF was removed in vacuo and the resulting mixture was dialyzed in $\mathrm{MeOH}$ using a benzoylated dialysis tubing ( MWCO: $2 \mathrm{~K}$ ) for 2-3 days to afford the pure compound with $\mathrm{DF}=0.08$ as a colorless polymer. The degree of mesylation was quantified by ${ }^{1} \mathrm{H}$ NMR. Yield $=88 \%$.

${ }^{1} \mathrm{H}$ NMR (600 MHz, MeOD): $\delta(\mathrm{ppm})=4.57-3.50$ (m, $\mathrm{CH}_{2}$ and $\mathrm{CH}, \mathrm{hPG}-\mathrm{OH}$ backbone); 3.28 (brs, $\mathrm{CH}_{3}$ mesyl).

Normalised integral of hPG backbone protons $=5$

Mesyl $\mathrm{CH}_{3}$ protons integral $=0.24$

Degree of functionalisation (DF) $=\frac{0.24}{3}=0.08$ or $8 \%$

Number of mesyl groups in hPG-OMs = Number of OH groups in $\mathrm{hPG}-\mathrm{OH} \times(8 \%)=10$ mesyl end groups

Molecular weight of hPG-OMs $=10494.4 \mathrm{~g} / \mathrm{mol}$

\section{hPG-Azide (8\%)}

hPG-azide was synthesized using a reported procedure. ${ }^{31} \mathrm{dPG}-\mathrm{OMs}, \mathrm{DF}=0.08(0.11 \mathrm{~g}, 0.105 \mathrm{mmol}$ OMs) was dissolved in dry DMF (5 mL) in a one-neck flask equipped with a refluxing condenser. 
Sodium azide ( $27.4 \mathrm{mg}, 0.25 \mathrm{mmol}, 4$ equiv. with respect to $0 \mathrm{Ms}$ group) was added to the reaction mixture and stirred at $60^{\circ} \mathrm{C}$ for 1 day. The resulting salts were filtered off and the solvent was evaporated using rotary evaporator. The crude mixture was dialyzed in $\mathrm{MeOH}$ using a benzoylated dialysis tubing (MWCO: $2 \mathrm{~K}$ ) for 2-3 days to afford the pure compound with a quantitative conversion (determined by ${ }^{1} \mathrm{H}$ NMR) as a colorless polymer. The IR spectra showed a visible $\mathrm{N}_{3}$ stretching peak around $2110 \mathrm{~cm}^{-1}$. Yield= quantitative

${ }^{1} \mathrm{H}$ NMR $\left(600 \mathrm{MHz}, \mathrm{D}_{2} \mathrm{O}\right): \delta(\mathrm{ppm})=4.05-3.23\left(\mathrm{~m}, \mathrm{CH}_{2}\right.$ and $\mathrm{CH}, \mathrm{hPG}-\mathrm{OH}$ backbone), $1.36\left(\mathrm{~s}, \mathrm{CH}_{2}\right.$ core), 0.87 (s, $\mathrm{CH}_{3}$ core).

Molecular weight of hPG-azide $=9813.3 \mathrm{~g} / \mathrm{mol}$

\section{hPG-Propargyl (16\%)}

To a solution of hPG-OH (186 mg, 0.26 mmol OH groups) in $5 \mathrm{ml}$ anhydrous DMF, NaH (13.9 mg, $0.57 \mathrm{mmol}, 2.2$ equiv., $60 \%$ dispersion in m.o.) was added. After stirring for $3 \mathrm{~h}$ at rt, potassium iodide ( $8.7 \mathrm{mg}, 0.052 \mathrm{mmol}, 0.2$ equiv. )was dissolved in minimum amount of DMF and added to the reaction mixture. After cooling the mixture to $0{ }^{\circ} \mathrm{C}$, propargyl bromide $(40 \mu \mathrm{L}, 0.44 \mathrm{mmol}$, 1.7 equiv.) was added and stirred overnight. The reaction mixture was extracted with EtOAc with ethyl acetate $(3 \times 60 \mathrm{ml})$, the combined organic layers were concentrated in vacuo and the crude product was purified by dialysis in chloroform $(48 \mathrm{~h})$ to obtain a light brown viscous oil. The IR spectra showed a visible $\mathrm{C} \equiv \mathrm{CH}$ stretching peak at $2112 \mathrm{~cm}^{-1}$. Yield $=72 \%$.

${ }^{1} \mathrm{H}$ NMR (600 MHz, Deuterium Oxide): $\delta(\mathrm{ppm})=4.46-4.19\left(\mathrm{OCH}_{2} \mathrm{C} \equiv \mathrm{CH}\right), 4.10-3.20\left(\mathrm{~m}, \mathrm{CH}_{2}\right.$ and CH, hPG-OH backbone), 2.96 ( $\mathrm{C} \equiv \mathrm{CH}$ ), 1.37 (s, $\mathrm{CH}_{2}$ core), 0.88 (s, $\mathrm{CH}_{3}$ core).

Normalised integral of hPG backbone protons $=5$

Propargyl $\mathrm{CH}$ protons integral $=0.16$

Degree of functionalisation (DF) $=\frac{0.16}{1}=0.16$ or $16 \%$

Number of propargyl groups in hPG-Propargyl $=$ Number of OH groups in hPG-OH $\times(16 \%)=20$ propargyl end groups

Molecular weight of hPG-Propargyl = $10494.2 \mathrm{~g} / \mathrm{mol}$

\section{Compound 8}

hPG-azide ( $2.5 \mathrm{mg}, 0.002 \mathrm{mmol}$ of azide groups)was dissolved in water followed by the addition of the ligand 7 ( $1.8 \mathrm{mg}, 0.0032 \mathrm{mmol}, 1.6$ equiv.). Copper sulphate pentahydrate ( 0.1 equiv )was dissolved in water separately and added to the reaction mixture. 0.3 equiv. of sodium ascorbate was also dissolved in water separately and added to the reaction mixture. The reaction was 
carried out at $100^{\circ} \mathrm{C}$ in the microwave for $60 \mathrm{~min}$. Cuprisorb ${ }^{\circledR}$ resin was added to the reaction mixture and stirred to adsorb excess copper. The solvent was evaporated and the crude reaction mixture was purified by dialysis using a cellulose based dialysis cassette (MWCO: $2 \mathrm{~K}$ ) against deionized water for 3-4 days and freeze dried to get 8 in $80 \%$ yield as an off-white solid. The disappearance of the azide stretching peak in the IR spectra of the final compound confirmed that all of the azido polymer was consumed.

${ }^{1} \mathrm{H}$ NMR (600 MHz, Deuterium Oxide) $\delta 8.03$ (s, triazole), $5.18-3.16\left(\mathrm{~m}, \mathrm{CH}_{2}\right.$ and $\mathrm{CH}, \mathrm{hPG}-\mathrm{OH}$ backbone; $\left.\mathrm{GB}_{3}\right), 2.31-2.18\left(\mathrm{~m}, \mathrm{~GB}_{3} ; \mathrm{CH}_{3}\right), 0.85$ ( $\mathrm{s}$, hPG core, $\mathrm{CH}_{2}$ ).

\section{Compound 9}

hPG-propargyl ( $5 \mathrm{mg}, 0.0095 \mathrm{mmol}$ of propargyl groups ) was dissolved in water followed by the addition of the ligand $\mathbf{1 d}(8.2 \mathrm{mg}, 0.012 \mathrm{mmol}, 1.3$ equiv.) which was dissolved in DMF. Copper sulphate pentahydrate ( 0.1 equiv )was dissolved in water separately and added to the reaction mixture. 0.3 equiv. of sodium ascorbate was also dissolved in water separately and added to the reaction mixture. The reaction was carried out at $80^{\circ} \mathrm{C}$ in the microwave for $60 \mathrm{~min}$. Cuprisorb ${ }^{\circledR}$ resin was added to the reaction mixture and stirred to adsorb excess copper. The crude mixture was extracted using ethyl acetate and water. The protected polymer conjugate was then subjected to deacetylation using the standard procedure described above. The solvent was evaporated and the crude reaction mixture was purified by dialysis using a cellulose based dialysis cassette (MWCO: $2 \mathrm{~K}$ ) against deionized water for 3-4 days and freeze dried. The final product 9 was obtained in $75 \%$ yield as a white solid. The disappearance of the $\mathrm{C} \equiv \mathrm{CH}$ stretching peak in the IR spectra of the final compound confirmed that all of the polymer was consumed. ${ }^{1} \mathrm{H}$ NMR (600 MHz, Deuterium Oxide) $\delta 8.30$ (s, triazole), 5.69 (d, $J=9.2 \mathrm{~Hz}$, galabiose; H-1), 5.00 (d, $J=3.9 \mathrm{~Hz}$, galabiose; $\mathrm{H}^{\prime}-1$ ), $4.51-3.30$ ( $\mathrm{m}, \mathrm{CH}_{2}$ and $\mathrm{CH}$, hPG-OH backbone; galabiose; $\mathrm{H}-2, \mathrm{H}-3$, H-4, H-5, H-6, H'-2, H'-3, H'-4, H'-5, H'-6), 1.25 (s, $\mathrm{CH}_{2}$ core), 0.84 (s, $\mathrm{CH}_{3}$ core). 


\subsubsection{NMR spectra}

1H NMR (600 MHz, MeOD) of hPG-OH

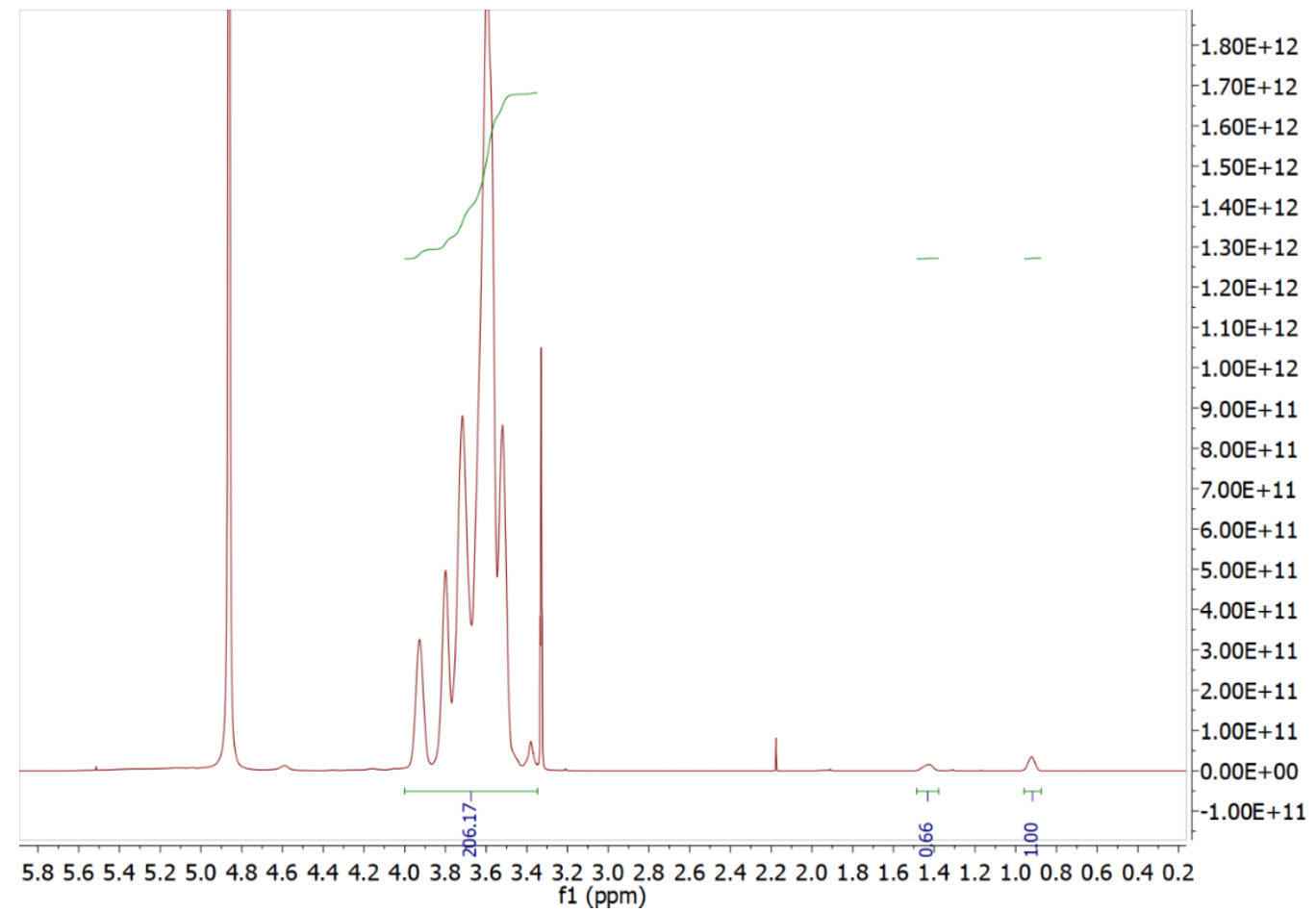

IG ${ }^{13}$ CNMR (151 MHz, D 20 ) of hPG-OH

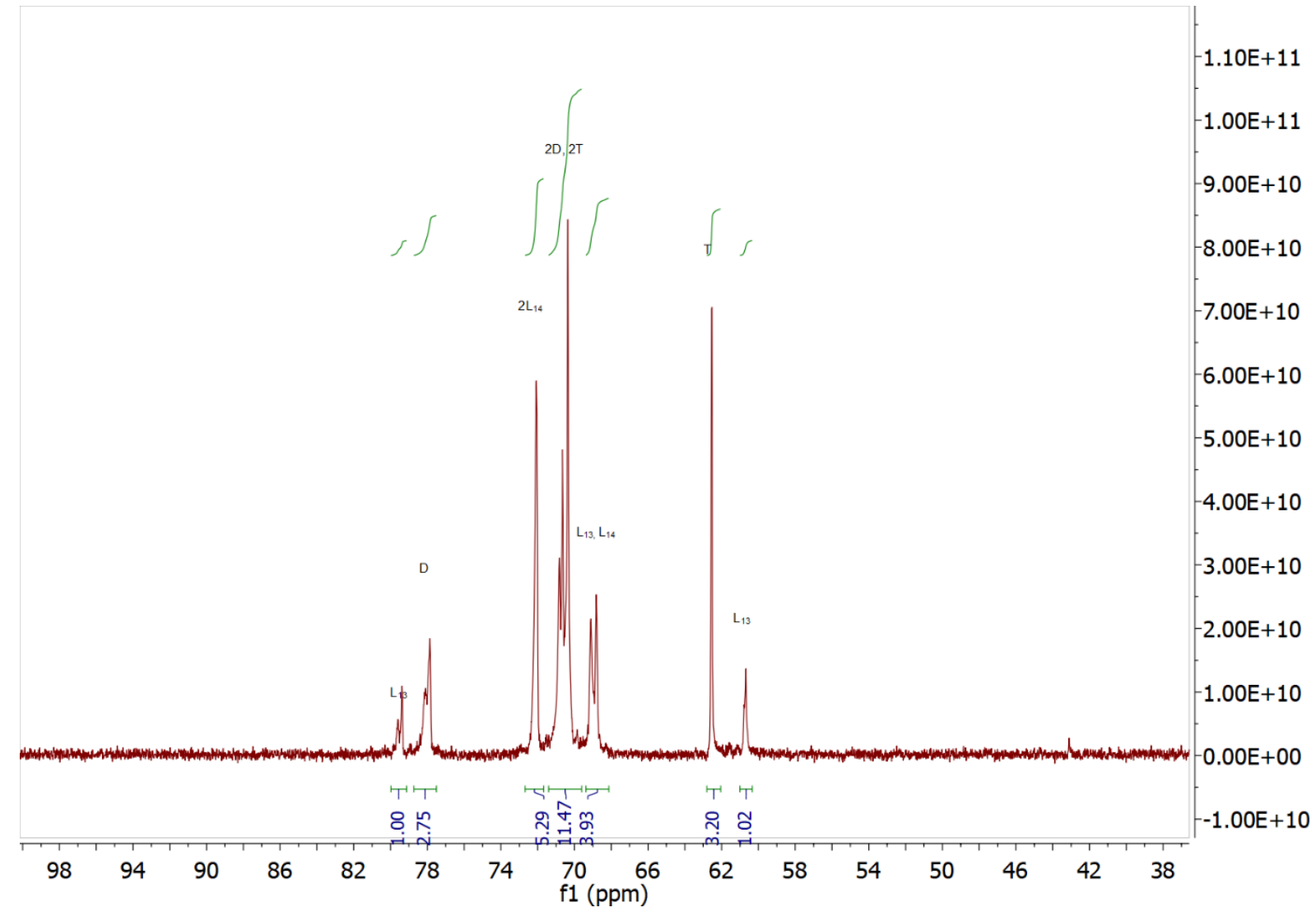


${ }^{1}$ H NMR (600 MHz, MeOD) of hPG-OMs 8\%

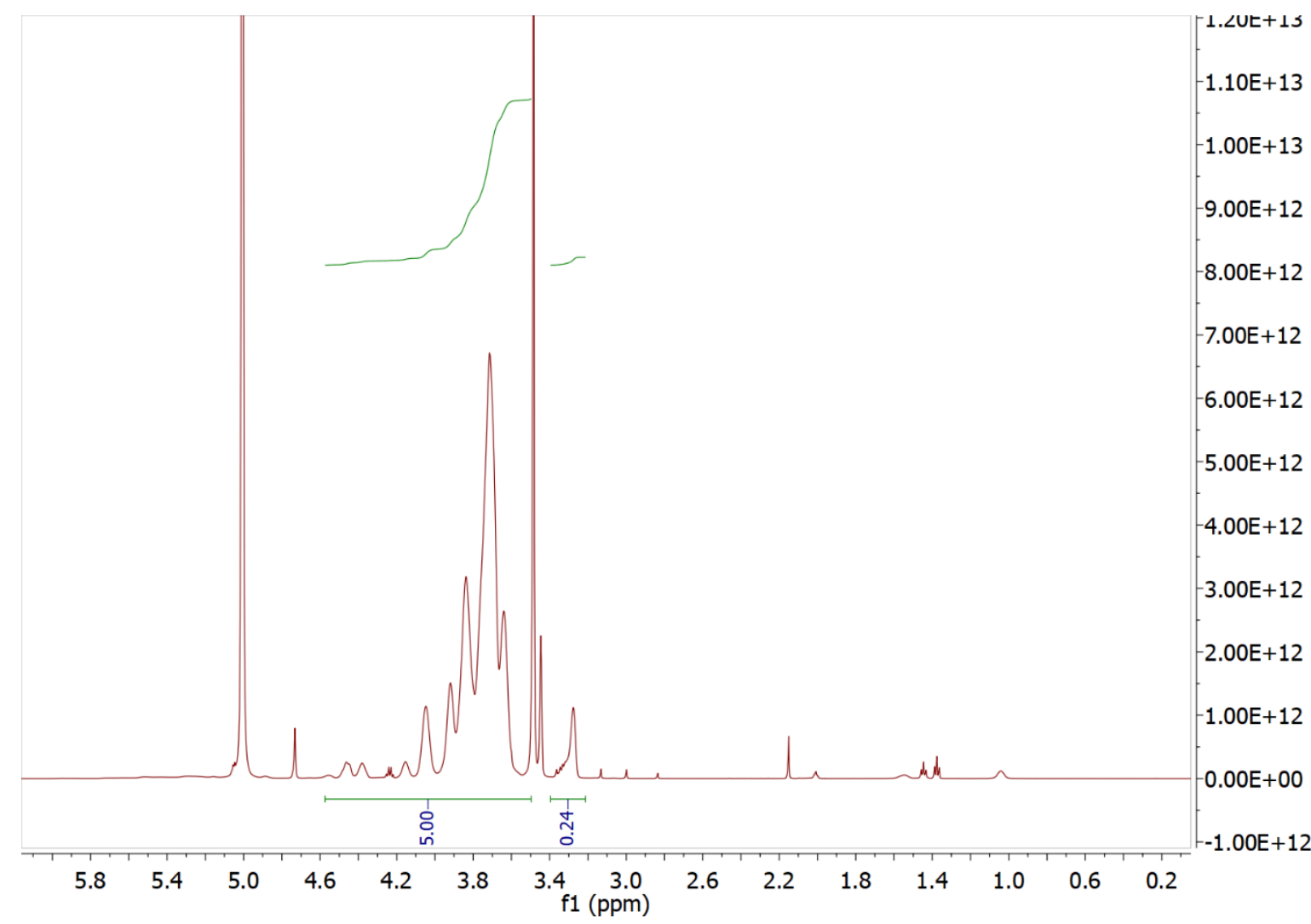

${ }^{1} \mathrm{H}$ NMR (600 MHz, D 20 ) of hPG-azide 8\%

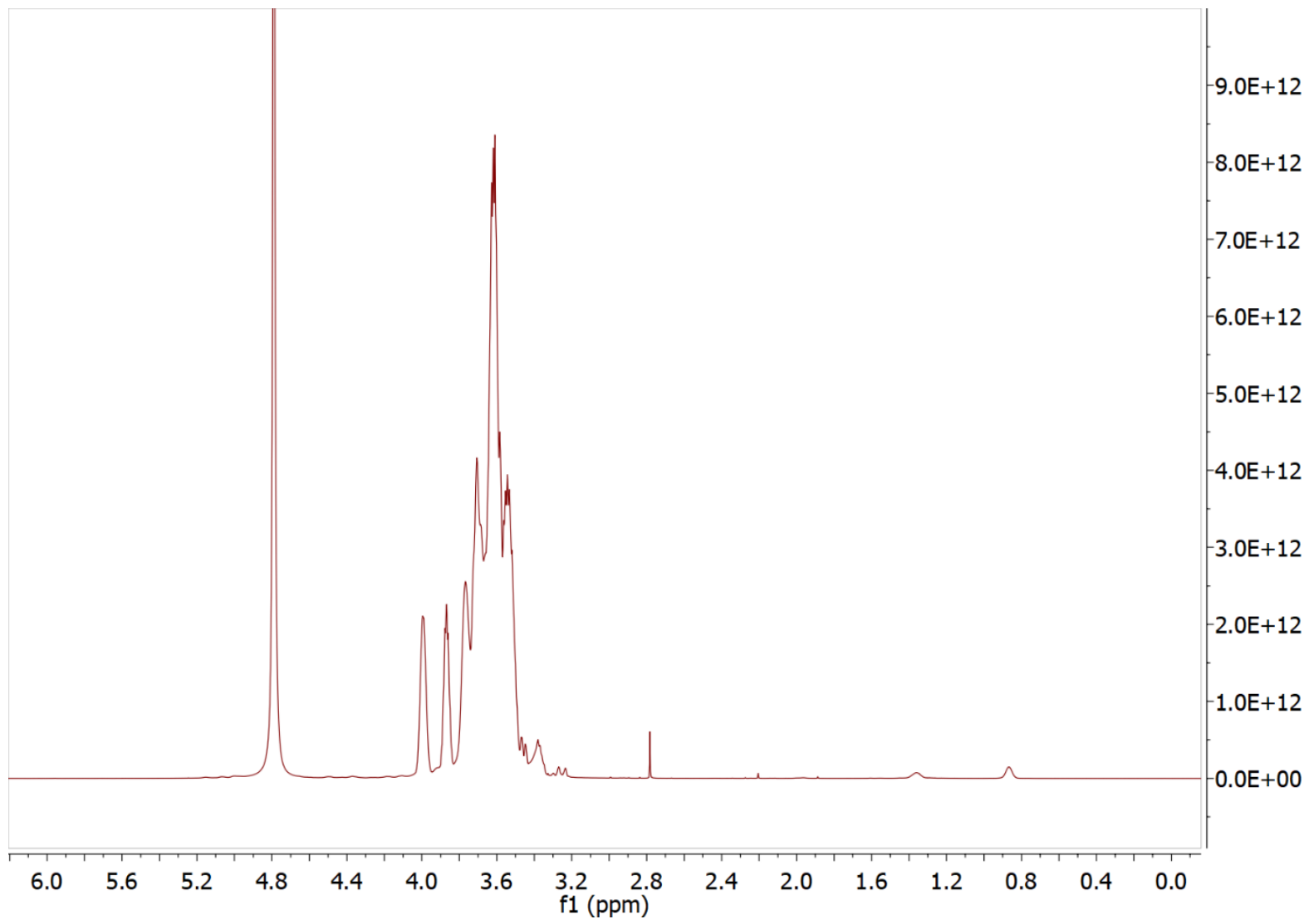


${ }^{1} \mathrm{H}$ NMR (600 MHz, $\mathrm{D}_{2} \mathrm{O}$ ) of hPG-Propargyl (16\%)

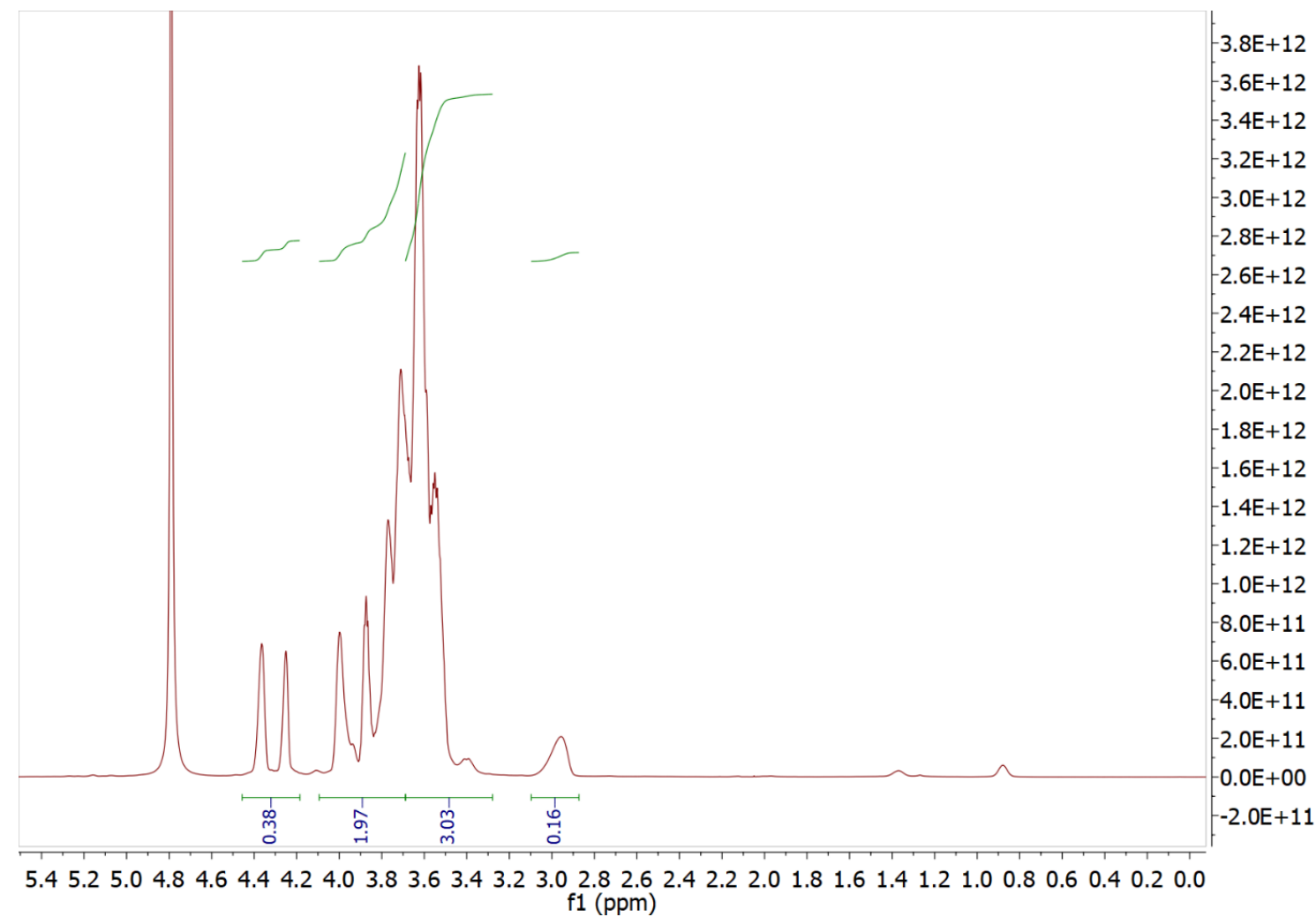

${ }^{1} \mathrm{H}$ NMR ( $600 \mathrm{MHz}, \mathrm{D}_{2} \mathrm{O}$ ) of Compound 9

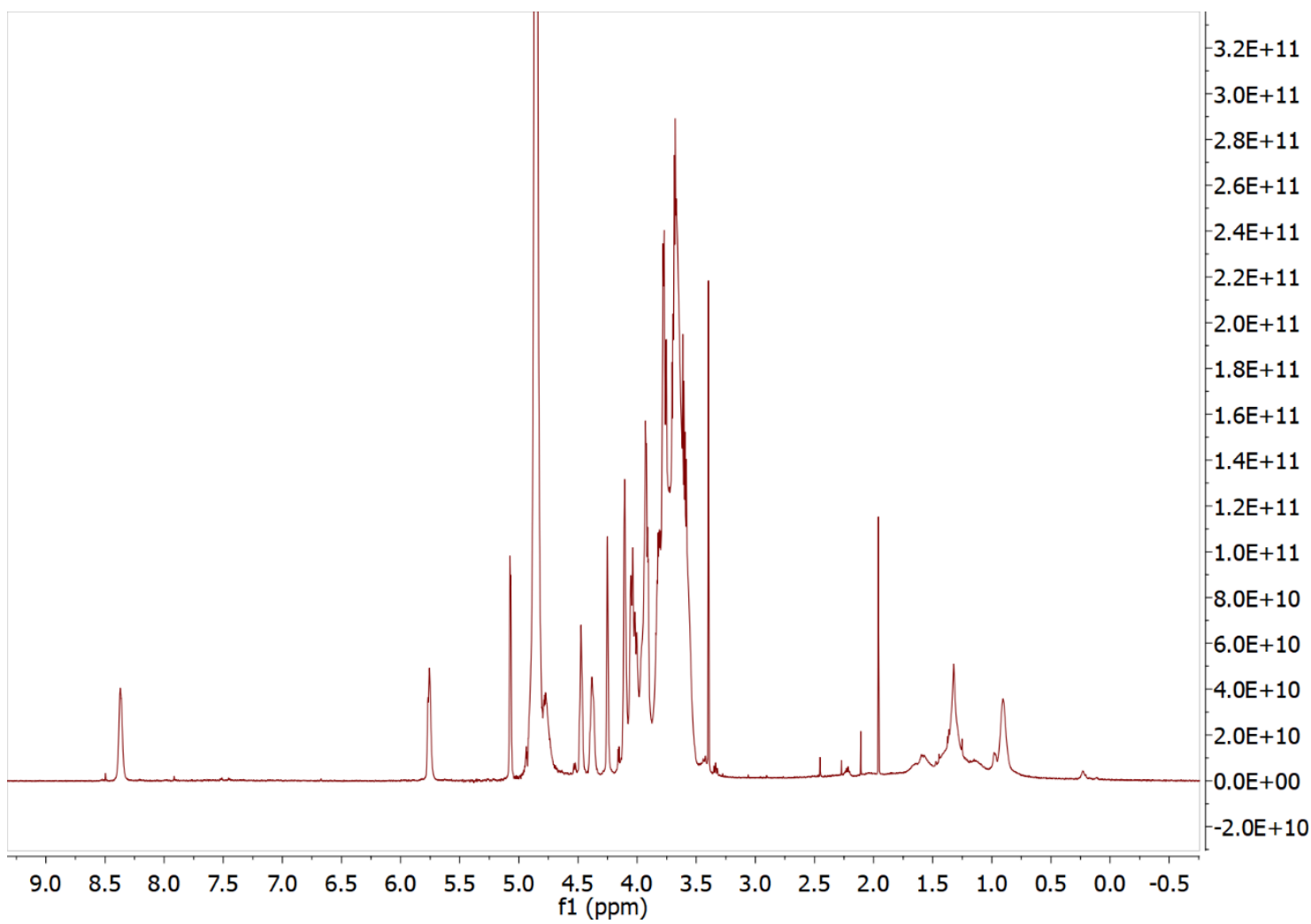




\subsubsection{IR spectra}

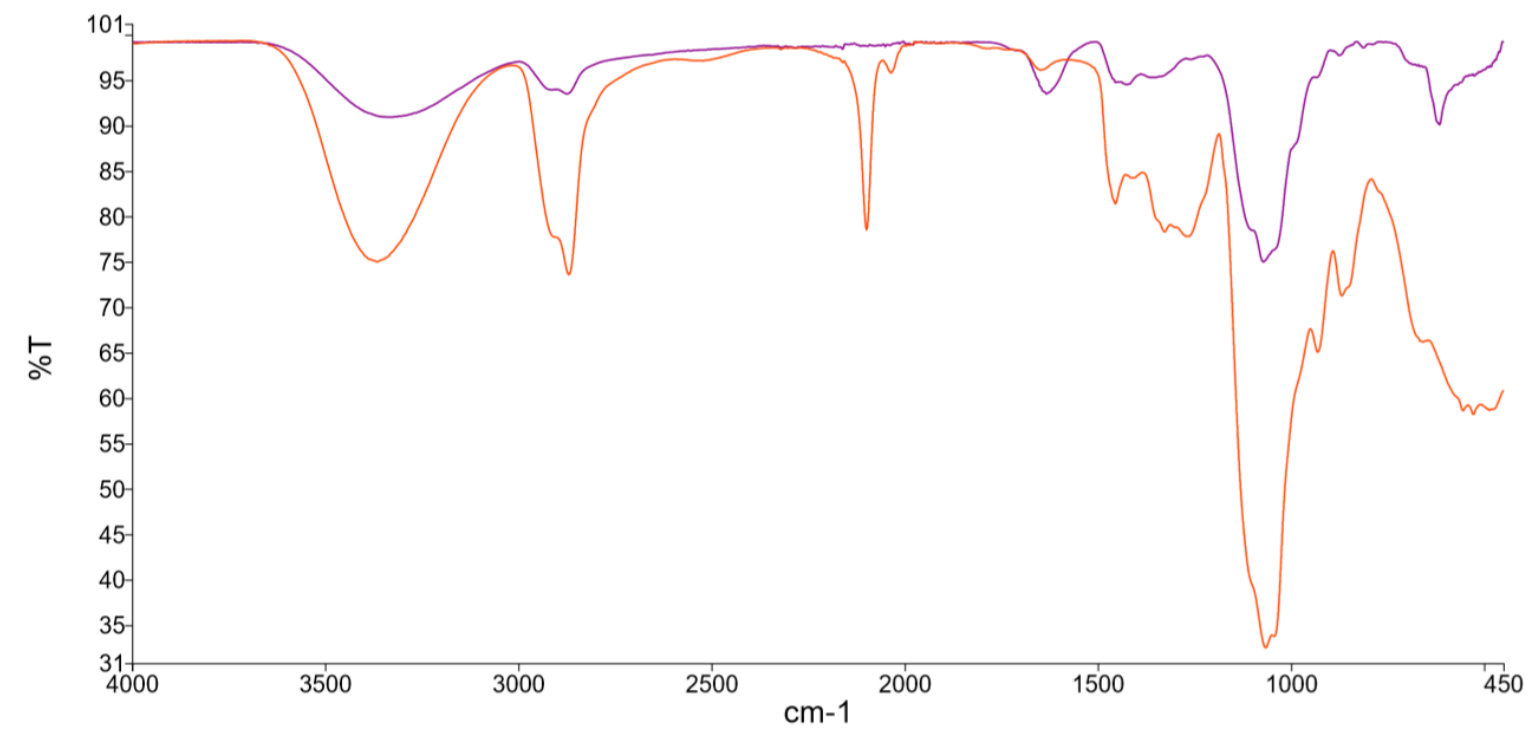

hPG-azide; Compound 8

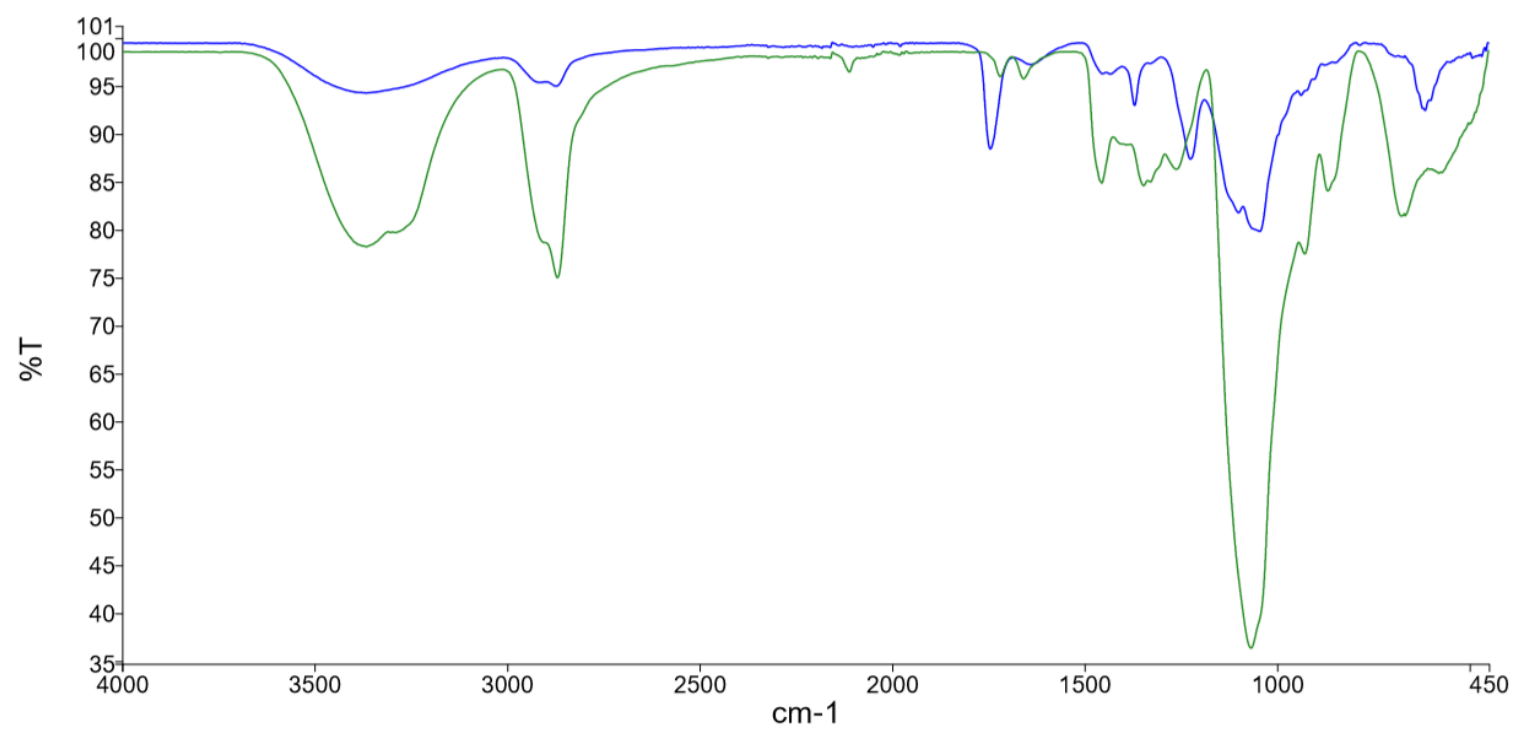

hPG-propargyl; Compound 9 


\subsection{References}

(1) Liu, J.; Platts-Mills, J. A.; Juma, J.; Kabir, F.; Nkeze, J.; Okoi, C.; Operario, D. J.; Uddin, J.; Ahmed, S.; Alonso, P. L.; Antonio, M.; Becker, S. M.; Blackwelder, W. C.; Breiman, R. F.; Faruque, A. S. G.; Fields, B.; Gratz, J.; Haque, R.; Hossain, A.; Hossain, M. J.; Jarju, S.; Qamar, F.; Iqbal, N. T.; Kwambana, B.; Mandomando, I.; McMurry, T. L.; Ochieng, C.; Ochieng, J. B.; Ochieng, M.; Onyango, C.;

Panchalingam, S.; Kalam, A.; Aziz, F.; Qureshi, S.; Ramamurthy, T.; Roberts, J. H.; Saha, D.; Sow, S. O.; Stroup, S. E.; Sur, D.; Tamboura, B.; Taniuchi, M.; Tennant, S. M.; Toema, D.; Wu, Y.; Zaidi, A.; Nataro, J. P.; Kotloff, K. L.; Levine, M. M.; Houpt, E. R. Use of Quantitative Molecular Diagnostic Methods to Identify Causes of Diarrhoea in Children: A Reanalysis of the GEMS Case-Control Study. Lancet 2016, 388 (10051), 1291-1301.

(2) Tesh, V. L.; Burris, J. A.; Owens, J. W.; Gordon, V. M.; Wadolkowski, E. A.; O’Brien, A. D.; Samuel, J. E. Comparison of the Relative Toxicities of Shiga-like Toxins Type I and Type II for Mice. Infect. Immun. 1993, 61 (8), 3392-3402.

(3) Muniesa, M.; Hammerl, J. A.; Hertwig, S.; Appel, B.; Brüssow, H. Shiga Toxin-Producing Escherichia Coli 0104:H4: A New Challenge for Microbiology. Appl. Environ. Microbiol. 2012, 78 (12), 40654073.

(4) Lee, M.-S.; Koo, S.; Jeong, D. G.; Tesh, V. L. Shiga Toxins as Multi-Functional Proteins: Induction of Host Cellular Stress Responses, Role in Pathogenesis and Therapeutic Applications. Toxins (Basel). 2016, 8 (3), 1-23.

(5) Bergan, J.; Dyve Lingelem, A. B.; Simm, R.; Skotland, T.; Sandvig, K. Shiga Toxins. Toxicon 2012, 60 (6), 1085-1107.

(6) Ling, H.; Boodhoo, A.; Hazes, B.; Cummings, M. D.; Armstrong, G. D.; Brunton, J. L.; Read, R. J. Structure of the Shiga-like Toxin I B-Pentamer Complexed with an Analogue of Its Receptor Gb3. Biochemistry 1998, 37 (7), 1777-1788.

(7) Lingwood, C. Verotoxin Receptor-Based Pathology and Therapies. Front. Cell. Infect. Microbiol. 2020, 10 (March), 1-10.

(8) Paletta, A. C. C.; Castro, V. S.; Conte-Junior, C. A. Shiga Toxin-Producing and Enteroaggregative Escherichia Coli in Animal, Foods, and Humans: Pathogenicity Mechanisms, Detection Methods, and Epidemiology. Current Microbiology. 2020, pp 612-620.

(9) Wong, C. S.; Jelacic, S.; Hareeb, R. L.; Watkins, S. L.; Tarr, P. I. The Risk Of The Hemolytic-Uremic Syndrome After Antibiotic Treatment Of Escherichia Coli 0157:H7 Infections. N. Engl. J. Med. 2000, 342, 1930-1936.

(10) Fogolari, M.; Mavian, C.; Angeletti, S.; Salemi, M.; Lampel, K. A.; Maurelli, A. T. Distribution and Characterization of Shiga Toxin Converting Temperate Phages Carried by Shigella Flexneri in Hispaniola. Infect. Genet. Evol. 2018, 65 (April), 321-328.

(11) Carter, C. C.; Fierer, J.; Chiu, W. W.; Looney, D. J.; Strain, M.; Mehta, S. R. A Novel Shiga Toxin 1aConverting Bacteriophage of Shigella Sonnei With Close Relationship to Shiga Toxin 2-Converting Pages of Escherichia Coli. Open Forum Infect. Dis. 2016, 3 (2), ofw079.

(12) Nyholm, O.; Lienemann, T.; Halkilahti, J.; Mero, S.; Rimhanen-Finne, R.; Lehtinen, V.; Salmenlinna, S.; Siitonen, A. Characterization of Shigella Sonnei Isolate Carrying Shiga Toxin 2-Producing Gene. Emerg. Infect. Dis. 2015, 21 (May), 891-892.

(13) Tóth, I.; Sváb, D.; Bálint, B.; Brown-Jaque, M.; Maróti, G. Comparative Analysis of the Shiga Toxin Converting Bacteriophage First Detected in Shigella Sonnei. Infect. Genet. Evol. 2016, 37 (2016), 150-157.

(14) Gray, M. D.; Lampel, K. A.; Strockbine, N. A.; Fernandez, R. E.; Melton-Celsa, A. R.; Maurelli, A. T. Clinical Isolates of Shiga Toxin 1a-Producing Shigella Flexneri with an Epidemiological Link to Recent Travel to Hispaniola. Emerg. Infect. Dis. 2014, 20 (10), 1669-1677.

(15) Gupta, S. K.; Strockbine, N.; Omondi, M.; Hise, K.; Fair, M. A.; Mintz, E. Short Report: Emergence of Shiga Toxin 1 Genes within Shigella Dysenteriae Type 4 Isolates from Travelers Returning from the Island of Hispa??Ola. Am. J. Trop. Med. Hyg. 2007, 76 (6), 1163-1165.

(16) Sváb, D.; Bálint, B.; Vásárhelyi, B.; Maróti, G.; Tóth, I. Comparative Genomic and Phylogenetic Analysis of a Shiga Toxin Producing Shigella Sonnei (STSS) Strain. Front. Cell. Infect. Microbiol. 2017, 7 (May), 1-10.

(17) Bekal, S.; Pilon, P. A.; Cloutier, N.; Doualla-bell, F.; Longtin, J. Identification of Shigella Flexneri Isolates Carrying the Shiga Toxin 1-Producing Gene in Quebec, Canada, Linked to Travel to Haiti. Can. J. Microbiol. 2015, 61 (September), 995-996.

(18) Beutin, L.; Strauch, E.; Fischer, I. Isolation of Shigella Sonnei l y s o g e n i c for a Bacteriophage 
Encoding Gene for Production of Shiga Toxin. Lancet 1999, 353, 1498.

(19) Lamba, K.; Nelson, J. A.; Kimura, A. C.; Poe, A.; Collins, J.; Kao, A. S.; Cruz, L.; Inami, G.; Vaishampayan, J.; Garza, A.; Chaturvedi, V.; Vugia, D. J. Shiga Toxin 1 - Producing Shigella Sonnei Infections, California, United States, 2014-2015. Emerg. Infect. Dis. 2016, 22, 679-686.

(20) Watanabe, M.; Igai, K.; Matsuoka, K.; Watanabe, T.; Yanoshita, R.; Terunuma, D.; Natori, Y.; Miyagawa, A.; Samejima, Y. Structural Analysis of the Interaction between Shiga Toxin B Subunits and Linear Polymers Bearing Clustered Globotriose Residues Structural Analysis of the Interaction between Shiga Toxin B Subunits and Linear Polymers Bearing Clustered Globotriose Residu. Infect. Immun. 2006, 74 (3), 1984-1988.

(21) Takeda, T.; Yoshino, K. I.; Adachi, E.; Sato, Y.; Yamagata, K. In Vitro Assessment of a Chemically Synthesized Shiga Toxin Receptor Analog Attached to Chromosorb P (Synsorb Pk) as a Specific Absorbing Agent of Shiga Toxin 1 and 2. Microbiol. Immunol. 1999, 43 (4), 331-337.

(22) Trachtman, H.; Cnaan, A.; Christen, E.; Gibbs, K.; Zhao, S.; DWK, A.; Weiss, R.; FJ, K.; Spitzer, A.; GH, H. Effect of an Oral Shiga Toxin-Binding Agent on Diarrhea-Associated Hemolytic Uremic Syndrome in Children: A Randomized Controlled Trial. JAMA J. Am. Med. Assoc. 2003, 290 (10), 1337-1344.

(23) Ganji, A.; Islami, M.; Ejtehadifar, M.; Zarei-Mehrvarz, E.; Darvish, M. Nanobody and Aptamer as Targeting Moiety against Bacterial Toxins: Therapeutic and Diagnostic Applications. Rev. Med. Microbiol. 2019, 30 (3), 183-190.

(24) Kitov, P. I.; Sadowska, J. M.; Mulvey, G.; Armstrong, G. D.; Ling, H.; Pannu, N. S.; Read, R. J.; Bundle, D. R. Shiga-like Toxins Are Neutralized by Tailored Multivalent Carbohydrate Ligands. Nature 2000, 403 (6770), 669-672.

(25) Mulvey, G. L.; Marcato, P.; Kitov, P. I.; Sadowska, J.; Bundle, D. R.; Armstrong, G. D. Assessment in Mice of the Therapeutic Potential of Tailored, Multivalent Shiga Toxin Carbohydrate Ligands. J. Infect. Dis. 2003, 187 (4), 640-649.

(26) Nishikawa, K.; Matsuoka, K.; Kita, E.; Okabe, N.; Mizuguchi, M.; Hino, K.; Miyazawa, S.; Yamasaki, C.; Aoki, J.; Takashima, S.; Yamakawa, Y.; Nishijima, M.; Terunuma, D.; Kuzuhara, H.; Natori, Y. A Therapeutic Agent with Oriented Carbohydrates for Treatment of Infections by Shiga ToxinProducing Escherichia Coli 0157:H7. Proc. Natl. Acad. Sci. U. S. A. 2002, 99 (11), 7669-7674.

(27) Calderón, M.; Quadir, M. A.; Sharma, S. K.; Haag, R. Dendritic Polyglycerols for Biomedical Applications. Advanced Materials. January 12, 2010, pp 190-218.

(28) Rijkers, D. T. S.; Van Esse, G. W.; Merkx, R.; Brouwer, A. J.; Jacobs, H. J. F.; Pieters, R. J.; Liskamp, R. M. J. Efficient Microwave-Assisted Synthesis of Multivalent Dendrimeric Peptides Using Cycloaddition Reaction (Click) Chemistry. Chem. Commun. 2005, No. 36, 4581-4583.

(29) Dijkgraaf, I.; Rijnders, A. Y.; Soede, A.; Dechesne, A. C.; Van Esse, G. W.; Brouwer, A. J.; Corstens, F. H. M.; Boerman, O. C.; Rijkers, D. T. S.; Liskamp, R. M. J. Synthesis of DOTA-Conjugated Multivalent Cyclic-RGD Peptide Dendrimers via 1,3-Dipolar Cycloaddition and Their Biological Evaluation: Implications for Tumor Targeting and Tumor Imaging Purposes. Org. Biomol. Chem. 2007, 5 (6), 935-944.

(30) Sunder, A.; Hanselmann, R.; Frey, H.; Mülhaupt, R. Controlled Synthesis of Hyperbranched Polyglycerols by Ring-Opening Multibranching Polymerization. Macromolecules 1999, 32 (13), 4240-4246.

(31) Bhatia, S.; Lauster, D.; Bardua, M.; Ludwig, K.; Angioletti-Uberti, S.; Popp, N.; Hoffmann, U.; Paulus, F.; Budt, M.; Stadtmüller, M.; Wolff, T.; Hamann, A.; Böttcher, C.; Herrmann, A.; Haag, R. Linear Polysialoside Outperforms Dendritic Analogs for Inhibition of Influenza Virus Infection in Vitro and in Vivo. Biomaterials 2017, 138, 22-34.

(32) Kurniasih, I. N.; Liang, H.; Möschwitzer, V. D.; Quadir, M. A.; Radowski, M.; Rabe, J. P.; Haag, R. Synthesis and Transport Properties of New Dendritic Core-Shell Architectures Based on Hyperbranched Polyglycerol with Biphenyl-PEG Shells. New J. Chem. 2012, 36 (2), 371-379.

(33) Shimizu, H.; Field, R. A.; Homans, S. W.; Donohue-Rolfe, A. Solution Structure of the Complex between the B-Subunit Homopentamer of Verotoxin VT-1 from Escherichia Coli and the Trisaccharide Moiety of Globotriaosylceramide. Biochemistry 1998, 37 (31), 11078-11082.

(34) Varasteh, S.; Braber, S.; Garssen, J.; Fink-Gremmels, J. Galacto-Oligosaccharides Exert a Protective Effect against Heat Stress in a Caco-2 Cell Model. J. Funct. Foods 2015, 16, 265-277.

(35) Akbari, P.; Braber, S.; Alizadeh, A.; Verheijden, K. A. T.; Schoterman, M. H. C.; Kraneveld, A. D.; Garssen, J.; Fink-Gremmels, J. Galacto-Oligosaccharides Protect the Intestinal Barrier by Maintaining the Tight Junction Network and Modulating the Inflammatory Responses after a Challenge with the Mycotoxin Deoxynivalenol in Human Caco-2 Cell Monolayers and B6C3F1 Mice. J. Nutr. 2015, 145 (7), 1604-1613. 
(36) Naveed, M.; Phil, L.; Sohail, M.; Hasnat, M.; Baig, M. M. F. A.; Ihsan, A. U.; Shumzaid, M.; Kakar, M. U.; Mehmood Khan, T.; Akabar, M. D.; Hussain, M. I.; Zhou, Q. G. Chitosan Oligosaccharide (COS): An Overview. International Journal of Biological Macromolecules. May 2019, pp 827-843.

(37) Liu, J.; Yang, S.; Li, X.; Yan, Q.; Reaney, M. J. T.; Jiang, Z. Alginate Oligosaccharides: Production, Biological Activities, and Potential Applications. Compr. Rev. Food Sci. Food Saf. 2019, 18 (6), 1859-1881.

(38) Xing, M.; Qi, C.; Yu, W.; Han, X.; Jiarui, Z.; Qing, Z.; Aiguo, J.; Shuliang, S. Advances in Research on the Bioactivity of Alginate Oligosaccharides. Mar. Drugs 2020, 18 (3).

(39) Wittmann, V.; Pieters, R. J. Bridging Lectin Binding Sites by Multivalent Carbohydrates. Chem. Soc. Rev. 2013, 42 (10), 4492.

(40) Hilaire, P. M. S.; Boyd, M. K.; Toone, E. J. Interaction of the Shiga-like Toxin Type 1 B-Subunit with Its Carbohydrate Receptor. Biochemistry 1994, 33 (48), 14452-14463.

(41) Fu, O.; Pukin, A. V.; van Ufford, H. C. Q.; Branson, T. R.; Thies-Weesie, D. M. E.; Turnbull, W. B.; Visser, G. M.; Pieters, R. J. Tetra- versus Pentavalent Inhibitors of Cholera Toxin. ChemistryOpen 2015, 4 (4), 471-477.

(42) Haksar, D.; de Poel, E.; van Ufford, L. Q.; Bhatia, S.; Haag, R.; Beekman, J.; Pieters, R. J. Strong Inhibition of Cholera Toxin B Subunit by Affordable, Polymer-Based Multivalent Inhibitors. Bioconjug. Chem. 2019, 30 (3), 785-792.

(43) Haksar, D.; Quarles Van Ufford, L.; Pieters, R. J. A Hybrid Polymer to Target Blood Group Dependence of Cholera Toxin. Org. Biomol. Chem. 2019, 18 (1), 52-55.

(44) Armstrong, G. D.; Rowe, P. C.; Goodyer, P.; Orrbine, E.; Terry, P.; Wells, G.; Mackenzie, A.; Lior, H.; Blanchard, C.; The, S.; Diseases, I.; Apr, N.; Armstrong, G. D.; Rowe, P. C.; Goodyer, P.; Orrbine, E.; Klassen, T. P.; Wells, G.; Mackenzie, A.; Lior, H.; Blanchard, C.; Auclair, F.; Thompson, B.; Rafter, D. J.; Mclaine, P. N. A Phase I Study of Chemically Synthesized Verotoxin ( Shiga-like Toxin ) PkTrisaccharide Receptors Attached to Chromosorb for Preventing Hemolytic-Uremic Syndrome Auclair , Brad Thompson, David J . Rafter and Peter N . McLaine Published by : Oxford Univ. J. Infect. Dis. 1995, 171, 1042-1045.

(45) Chapanian, R.; Constantinescu, I.; Brooks, D. E.; Scott, M. D.; Kizhakkedathu, J. N. In Vivo Circulation, Clearance, and Biodistribution of Polyglycerol Grafted Functional Red Blood Cells. Biomaterials 2012, 33 (10), 3047-3057.

(46) Lu, W.; Du, W.; Somovilla, V. J.; Yu, G.; Haksar, D.; De Vries, E.; Boons, G. J.; De Vries, R. P.; De Haan, C. A. M.; Pieters, R. J. Enhanced Inhibition of Influenza A Virus Adhesion by Di- and Trivalent Hemagglutinin Inhibitors. J. Med. Chem. 2019, 62 (13), 6398-6404.

(47) Shin, I. S.; Nishikawa, K.; Maruyama, H.; Ishii, S. Histidine-Tagged Shiga Toxin B Subunit Binding Assay: Simple and Specific Determination of Gb3 Content in Mammalian Cells. Chem. Pharm. Bull. 2006, 54 (4), 522-527.

(48) Novoa, A.; Eierhoff, T.; Topin, J.; Varrot, A.; Barluenga, S.; Imberty, A.; Römer, W.; Winssinger, N. A LecA Ligand Identified from a Galactoside-Conjugate Array Inhibits Host Cell Invasion by Pseudomonas Aeruginosa. Angew. Chemie - Int. Ed. 2014, 53 (34), 8885-8889.

(49) Ohlsson, J.; Larsson, A.; Haataja, S.; Alajääski, J.; Stenlund, P.; Pinkner, J. S.; Hultgren, S. J.; Jukka, F.; Kihlberg, J.; Nilsson, U. J. Structure-Activity Relationships of Galabioside Derivatives as Inhibitors of E. Coli and S. Suis Adhesins: Nanomolar Inhibitors of S. Suis Adhesins. Org. Biomol. Chem. 2005, 3 (5), 886-900.

(50) A. Sunder H. Frey R. Mülhaupt. Hyperbranched Polyglycerols by Ring-opening Multibranching Polymerization. 2000, 196, 187-196.

(51) Yang, Y. F.; Chung, L. W.; Zhang, X.; Houk, K. N.; Wu, Y. D. Ligand-Controlled Reactivity, Selectivity, and Mechanism of Cationic Ruthenium-Catalyzed Hydrosilylations of Alkynes, Ketones, and Nitriles: A Theoretical Study. J. Org. Chem. 2014, 79 (18), 8856-8864. 
Chapter 5

Summary \& Perspectives 



\subsection{Summary}

The thesis focuses on multivalent inhibitors based on carbohydrate ligands and polymeric multivalent scaffolds. This design has been used to tackle diseases caused by bacterial toxins namely $\mathrm{AB}_{5}$ toxins i.e. cholera toxin and shiga toxin.

Chapter 1 gives a brief general introduction to the role of carbohydrate-protein interactions. Mutivalency as a concept is relevant because carbohydrates bind weakly to their complementary proteins. Multivalency as a design principle can be beneficial in converting inhibitors with low affinity to ones with high avidity relative to a monovalent ligand. Furthermore, the topic of cholera toxin is introduced along with the most important mono- and di-valent inhibitors discovered/synthesized. Different scaffolds have been used to synthesize multivalent inhibitors of cholera toxin including but not limited to calix[5]arenes, corannulenes, dendrimers etc. Several polymer-based inhibitors are also included. Shiga toxin is the other $\mathrm{AB}_{5}$ toxin which is one of the major causes of mortality in children under 5 years of age. We describe the various non-polymeric and polymer-based inhibitors of shiga toxin.

Chapter 2 focuses on the successful facile synthesis of meta-nitrophenyl $\alpha$-galactoside (MNPG) and it's conjugation to various polymeric scaffolds. MNPG is an important inhibitor that was discovered by Minke et al. We describe the synthesis of the click-able version of MNPG and used it for conjugation to polyacrylamide, dextran and a hyperbranched polyglycerol (hPG). The idea was to synthesize molecules which are affordable yet potent. The molecules were assayed using a GM1 ELISA in addition to an intestinal organoid assay. Although all the polymer-MNPG conjugates were sufficiently potent, the hPG-MNPG conjugate emerged as the best molecule. This result can be attributed to a combination of the particle shape of suitable size and a relatively high functionalization.

Chapter 3 examines new science in the field of cholera toxin inhibition wherein in addition to the GM1 binding site, a second binding site on the cholera toxin has been identified. This secondary binding site has been shown to bind to fucosylated structures. Our goal was to synthesize a molecule that could inhibit both these sites. Therefore, we synthesized a hybrid inhibitor which utilized a polymeric dextran-based scaffold which was appended with MNPG and fucose. Additionally, an ELISA using PAA-fucose made it possible to test the fucose-based adhesion in a short span of time.

Chapter 4 focuses on the inhibition of shiga toxin by comparing three classes of carbohydratebased inhibitors: glycodendrimers, glycopolymers and oligosaccharides. Our aim was to synthesize a simple yet effective inhibitor of the toxin. Although, $\mathrm{Gb}_{3}$ is the natural ligand for shiga toxin, we chose to explore the potential of the disaccharide (Gal $\alpha 1-4 \mathrm{Gal} \beta$; galabiose) as a 
possible monovalent alternative to $\mathrm{Gb} 3$ based inhibitors. For the dendrimeric approach, we compared divalent molecules vs tetravalent one. We observed that at least a tetravalent ligand is required to reach significant inhibition. Furthermore, in the case of polymers, the polymeric inhibitor based on galabiose was the most potent in the series exhibiting nanomolar inhibition. Finally, we tested four oligosaccharides and found that alginate and chitosan oligosaccharides also inhibited shiga toxin and may be usable as a prophylactic during shigella outbreaks.

\subsection{Perspectives}

Cholera and shiga toxin belong to the $\mathrm{AB}_{5}$ class of bacterial toxins thereby sharing an $\mathrm{A}$ subunit which is responsible for the toxicity, surrounded by the pentameric B subunit. Cholera is an acute bacterial intestinal infection caused by Vibrio cholerae (toxigenic strains of O-group 1 or 0-group 139). Historically, cholera has claimed the lives of millions of people spanning seven pandemics with the earliest one recorded in 1817 in India. Cholera is still endemic in approximately 50 countries. Since 2016, there is an ongoing pandemic in the war-torn country of Yemen wherein more than 2,700 people have lost their lives of which a quarter are children.

Cholera affects a large number of people in the developing countries due to limited access to safe drinking water and adequate sanitation. It is characterized by watery diarrhea which can rapidly be fatal when left untreated. The annual burden of cholera has been estimated at 1.3 to 4.0 million cases and 21,000 to 143,000 deaths worldwide. ${ }^{1}$ Cholera is routinely treated using oral rehydration therapy and antibiotics. Although vaccines are available, they are not very effective for children under five years of age. ${ }^{2}$

The GM1 oligosaccharide which is a part of the natural cell-surface receptor of cholera toxin, has been used extensively as a potent ligand to inhibit the toxin in suitable bioassays. However, the structural complexity of GM1 and therefore the costs involved in preparing it do not make it an ideal candidate for development of an affordable therapeutic. Affordability is key, especially considering that the therapeutic needs to be repeatedly administered due to the natural flow of the intestinal tract, in order to maintain protection during epidemics. Keeping these considerations at the forefront of our experimental design, we focused on a simpler yet effective ligand that could be further strengthened when conjugated to a multivalent scaffold. Thus, we chose meta-nitrophenyl $\alpha$-galactoside (MNPG) as the main candidate for our monovalent compound, which was discovered by Minke et $a l^{3}$ The usage of easily available (i.e. 
polyacrylamide, dextran) and easy to synthesize polymers (i.e. hyperbranched polyglycerol or hPG) further helped us in realizing economical final compounds (Figure 1).
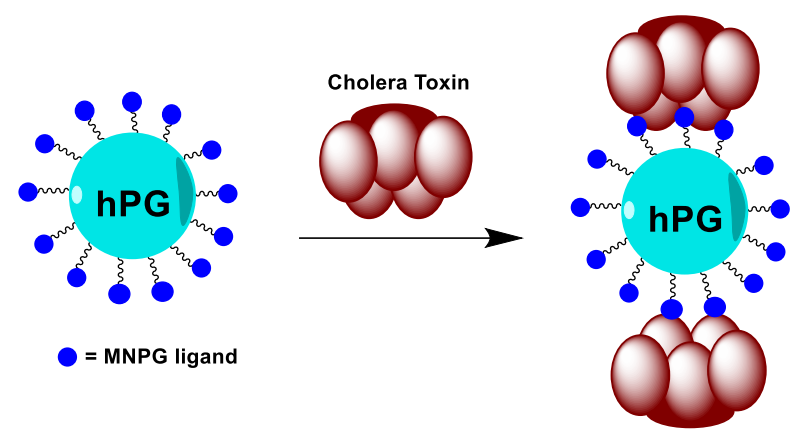

Figure 1. A representation of the hPG-MNPG conjugate binding to the $\mathrm{CTB}_{5}$

The most important measure for the potency enhancement imparted by the scaffold on which the ligands are presented is the potency per ligand. If a divalent ligand is twice as potent compared to the monovalent ligand it essentially provides no benefit, and the relative potency per ligand is 1. Of the various conjugates synthesized, the highest number that we observed was 594-fold for the MNPG-hPG conjugate. The hPG backbone was also the most effective when expressing its activity in terms of $\mu \mathrm{g} / \mathrm{mL}$ of the whole polymeric construct. The geometry of hPG is considered similar to that of a nanoparticle with a ca. 5-6 nm diameter. ${ }^{4}$ This fits the toxin diameter size of 6$7 \mathrm{~nm}$ quite well and has been shown to be favorable for strong inhibition. ${ }^{5}$ Ultimately, the cholera toxin inhibition that we were able to observe should be able to neutralize the up to micromolar quantities of the toxin B-subunits present in an active infection by repeated administration of the aforementioned prophylactic.

We explored the cholera toxin further by diving into the mounting evidence regarding the presence of a secondary binding site. GM1-deficient cell lines i.e. T84 and Colo205 were used to demonstrate that GM1 is not the sole receptor for CT. ${ }^{6}$ Additionally, it was also demonstrated that besides these cell lines, human intestinal epithelia also contain relatively little GM1.6,7 CTB binding to primary human jejunal epithelial cells was shown to correlate with the amount of displayed Lewis X (Lex) glycan. ${ }^{8}$ A direct binding interaction between CTB and the Le $^{\mathrm{Y}}$ tetrasaccharide was studied by ITC and revealed $\mathrm{K}_{\mathrm{d}}$ of $1-2 \mathrm{mM} .{ }^{9}$ Crystal structures and SPR studies further showed that Lex and also L-fucose bind exclusively to the secondary site with millimolar 
$\mathrm{K}_{\mathrm{d}}$ 's. ${ }^{7}$ All in all, although GM1 is the primary receptor in cell lines with both receptors, fucosylated glycoconjugates make a contribution to CTB binding and its internalization. ${ }^{10}$

To account for this secondary binding site, we envisioned a "hybrid" molecule that could block both GM1-based and fucose-based intoxication. This was done in anticipation of multivalency enhancements as we have seen for other multivalent platforms.11,12,13,14 For this purpose, we used a dextran based polymer to which fucose and a galactoside were conjugated. Meta-nitrophenyl $\alpha-$ galactoside (MNPG) was an ideal candidate as we had demonstrated that when conjugated to polymers, effective inhibition of cholera toxin could be achieved. ${ }^{15}$ To this end we synthesized the hybrid inhibitor for the cholera toxin that could potentially inhibit both the GM1 based adhesion of the primary binding site and the fucose-based adhesion of the secondary binding site (Figure 2). Additionally, we formulated an ELISA using PAA-fucose to test the fucose-based adhesion in a short span of time to circumvent the use of cells thereby enabling quick screening of the inhibitors. Although the hybrid was not as active as the homopolymers in either assay, the inhibition was still strong in the low micromolar range with large multivalency enhancements. The hybrid glycopolymer can be useful to account for both intoxication scenario's with a single agent. The agent was easy to synthesize, in a scalable synthesis whilst using dextran as a pharmaceutically benign dextran backbone. 16

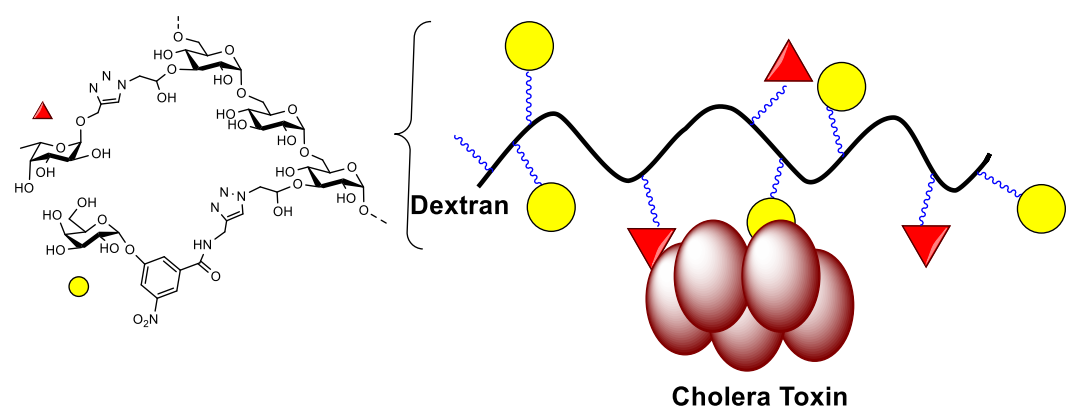

Figure 2. A representation of the hybrid polymer binding to the CTB5

Bacterial dysentery or shigellosis has been identified as one of the major causes of mortality in children under 5 years of age. ${ }^{17}$ Shigellosis is caused by gram negative bacterium of four species of Shigella: S. dysenteriae, S. flexneri, S. boydii, and S. sonnei through the fecal-oral route. The pathology can include bloody diarrhea (hemorraghic colitis) followed by the often fatal hemolytic uremic syndrome (HUS). HUS can occur if the pathogen is also producing the Shiga toxin. The toxin is produced by $S$. dysenteriae serotype 1 but closely related toxins Stx1 and Stx2 are also produced by Shiga toxin producing E. coli (STEC) or enterohemorrhagic E. coli (EHEC), where 
Stx2 has been reported to cause the more severe infections. ${ }^{18}$ STEC outbreaks are mostly foodborne with the largest ever reported in Germany (2011), linked to sprout consumption. ${ }^{19}$

The pentameric B subunit of shiga toxin binds to globotriaosylceramide (Gb3; Gal $\alpha 1-4 \mathrm{Gal} \beta 1$ 4Glc $\beta 1$-ceramide, also known as CD77 or the Pk blood group antigen). ${ }^{20}$ STEC infections are treated with antibiotics although their use is controversial with respect to their ability to increase the risk of HUS. ${ }^{21}$ The recent emergence of toxin producing strains of S. flexneri and S. sonnei points towards increased future morbidity and mortality. ${ }^{22,23}$ As an alternative to antibiotics, synthetic molecules based on Gb3 have been explored as potential prophylactic treatment for STEC. ${ }^{24}$ The most notable amongst these was Synsorb Pk, silicon dioxide coupled to synthetic Pk that showed promising results in preventing toxic effects on renal cells. ${ }^{25}$ The drug was withdrawn from clinical trials as it was not successful in diminishing diarrhea-associated HUS possibly due to late administration of the drug to the GI tract. 26

In order to find a simple yet effective toxin inhibitor we compared three classes of carbohydrate-based inhibitors: glycodendrimers (di- and tetravalent), glycopolymers (hPG-based) and oligosaccharides (chitosan, alginate, fructose and galactose). Keeping the theme of affordability in mind, we decided to use an attenuated ligand thereby opting for the disaccharide (Gal $\alpha 1-4 \mathrm{Gal} \beta$; galabiose). Our results suggested that the glycodendrimers needed at least a tetravalent ligand to reach significant inhibition. We postulate that this is because the bridging of the two highest affinity sites (sites 2) of neighboring toxin subunits is important for a significant inhibitory effect. ${ }^{27}$ The smaller divalent compounds were too short to bridge the ca $30 \AA \AA$. It is possible that in addition to the chelation binding mode also aggregation of the toxin is taking place, as previously noted, and also for the cholera toxin. ${ }^{28}$ The glycopolymers conjugated to galabiose emerged as the most potent of the series (Figure 3).

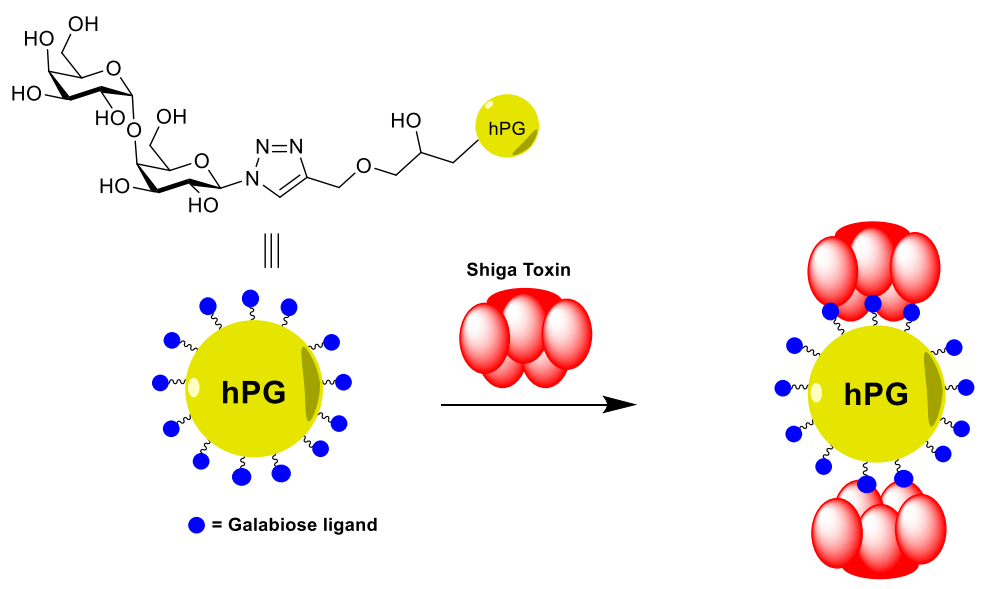

Figure 3. A representation of the hPG-galabiose conjugate binding to the Stx1B 
The high density of binding sites helps the inhibition as we have seen for the cholera toxin inhibition with hPG, however with three binding sites per subunit, i.e 15 in total, the effects are more dramatic than for the cholera toxin with one binding site per subunit. Prior work, both theoretical and practical involving the Shiga-like toxin has clearly indicated that avidity effects like seen here are caused by intrinsic inter- and intramolecular recognition events, but that on top of that there is an important combinatorial factor that describes the probabilities of binding events. This factor is very important and favorable and was shown to increase rapidly for higher valency systems, provided that the geometry of the multivalent ligand is appropriate for the target.

Shigella spp. are highly infective and infection could be fatal when it produces the toxin, as is also the case for STEC. The initial diarrhea followed by the toxin moving into the circulation provides a challenge for therapeutic intervention. It takes ca. 5-9 days between the initial gastroenteritis until HUS occurs. ${ }^{29}$ In order to prevent the systemic diseases, i.e. HUS a soluble non-toxic multivalent glycan with sufficient potency could be helpful.. As with cholera toxin inhibition, we achieved promising results against shiga toxin inhibition when hPG scaffold was used. This is encouraging as the utility of hPG is well established in terms of safety and biocompatibility.

Infectious diseases are a constant bane of the world we live in and we have taken the multivalent approach to target the problem of bacterial pathogenicity. The disease burden caused by bacterial toxins can be reduced significantly by adequate sanitation and availability of clean drinking water. However, unfortunately even in the $21^{\text {st }}$ century, large populations of our world do not have access to these basic amenities and therefore there is a requirement for therapeutics that can be useful and sustainable in such scenarios.

The results described in this thesis have further bolstered our confidence in multivalency as a potent alternative to current therapeutic approaches. Our initial objectives pertaining to the synthesis of potent inhibitors of the aforementioned AB5 toxins has been achieved. However, further optimization of the inhibitors with respect to the scaffolds used is a possibility to further fine-tune inhibition. Our experience shows that these potencies could be a result of the spatial arrangement of the ligands. Evidently, the work described in the present thesis could be a stepping stone for the design of potent and economical inhibitors against bacterial toxins.

\subsection{References}

(1) Ali, M.; Nelson, A. R.; Lopez, A. L.; Sack, D. a. Updated Global Burden of Cholera in Endemic Countries. PLoS Negl. Trop. Dis. 2015, 9, e0003832.

(2) Chowdhury, F. R.; Nur, Z.; Hassan, N.; von Seidlein, L.; Dunachie, S. Pandemics, Pathogenicity and 
Changing Molecular Epidemiology of Cholera in the Era of Global Warming. Ann. Clin. Microbiol. Antimicrob. 2017, 16 (1), 10.

(3) Minke, W. E.; Roach, C.; Hol, W. G. J.; Verlinde, C. L. M. J. Structure-Based Exploration of the Ganglioside GM1 Binding Sites of Escherichia Coli Heat-Labile Enterotoxin and Cholera Toxin for the Discovery of Receptor Antagonists †. Biochemistry 1999, 38 (18), 5684-5692.

(4) Sisson, A. L.; Steinhilber, D.; Rossow, T.; Welker, P.; Licha, K.; Haag, R. Biocompatible Functionalized Polyglycerol Microgels with Cell Penetrating Properties. Angew. Chemie Int. Ed. 2009, 48 (41), 7540-7545.

(5) Liese, S.; Netz, R. R. Quantitative Prediction of Multivalent Ligand-Receptor Binding Affinities for Influenza, Cholera, and Anthrax Inhibition. ACS Nano 2018, 12 (5), 4140-4147.

(6) Wands, A. M.; Fujita, A.; McCombs, J. E.; Cervin, J.; Dedic, B.; Rodriguez, A. C.; Nischan, N.; Bond, M. R.; Mettlen, M.; Trudgian, D. C.; Lemoff, A.; Quiding-Jarbrink, M.; Gustavsson, B.; Steentoft, C.; Clausen, H.; Mirzaei, H.; Teneberg, S.; Yrlid, U.; Kohler, J. J. Fucosylation and Protein Glycosylation Create Functional Receptors for Cholera Toxin. Elife 2015, 4, e09545.

(7) Breimer, M. E.; Hansson, G. C.; Karlsson, K.-A.; Larson, G.; Leffler, H. Glycosphingolipid Composition of Epithelial Cells Isolated along the Villus Axis of Small Intestine of a Single Human Individual. Glycobiology 2012, 22 (12), 1721-1730.

(8) Cervin, J.; Wands, A. M.; Casselbrant, A.; Wu, H.; Krishnamurthy, S.; Cvjetkovic, A.; Estelius, J.; Dedic, B.; Sethi, A.; Wallom, K. L.; Riise, R.; Bäckström, M.; Wallenius, V.; Platt, F. M.; Lebens, M.; Teneberg, S.; Fändriks, L.; Kohler, J. J.; Yrlid, U. GM1 Ganglioside-Independent Intoxication by Cholera Toxin. PLoS Pathog. 2018, 14 (2), e1006862.

(9) Wands, A. M.; Cervin, J.; Huang, H.; Zhang, Y.; Youn, G.; Brautigam, C. A.; Matson Dzebo, M.; Björklund, P.; Wallenius, V.; Bright, D. K.; Bennett, C. S.; Wittung-Stafshede, P.; Sampson, N. S.; Yrlid, U.; Kohler, J. J. Fucosylated Molecules Competitively Interfere with Cholera Toxin Binding to Host Cells. ACS Infect. Dis. 2018, 4 (5), 758-770.

(10) Sethi, A.; Wands, A. M.; Mettlen, M.; Krishnamurthy, S.; Wu, H.; Kohler, J. J. Cell Type and Receptor Identity Regulate Cholera Toxin Subunit B (CTB) Internalization. Interface Focus 2019, 9 (2), 20180076.

(11) Zhang, H.; Laaf, D.; Elling, L.; Pieters, R. J. Thiodigalactoside-Bovine Serum Albumin Conjugates as High-Potency Inhibitors of Galectin-3: An Outstanding Example of Multivalent Presentation of Small Molecule Inhibitors. Bioconjug. Chem. 2018, 29 (4), 1266-1275.

(12) Pera, N. P. N. P.; Kouki, A.; Haataja, S.; Branderhorst, H. M.; Liskamp, R. M. J.; Visser, G. M.; Finne, J.; Pieters, R. J. Detection of Pathogenic Streptococcus Suis Bacteria Using Magnetic Glycoparticles.

Org. Biomol. Chem. 2010, 8 (10), 2425-2429.

(13) Yu, G.; Vicini, A. C.; Pieters, R. J. Assembling of Divalent Ligands and Their Effect on Divalent Binding to Pseudomonas Aeruginosa Lectin LecA. J. Org. Chem. 2019, 84, 2470-2488.

(14) Ballell, L.; Scherpenzeel, M. Van; Buchalova, K.; Liskamp, R. M. J.; Pieters, R. J.; van Scherpenzeel, M. A New Chemical Probe for the Detection of the Cancer-Linked Galectin-3. Org. Biomol. Chem. 2006, 4 (23), 4387-4394.

(15) Haksar, D.; de Poel, E.; van Ufford, L. Q.; Bhatia, S.; Haag, R.; Beekman, J.; Pieters, R. J. Strong Inhibition of Cholera Toxin B Subunit by Affordable, Polymer-Based Multivalent Inhibitors. Bioconjug. Chem. 2019, 30 (3), 785-792.

(16) Kim, W.; Yang, Y.; Kim, D.; Jeong, S.; Yoo, J. W.; Yoon, J. H.; Jung, Y. Conjugation of Metronidazole with Dextran: A Potential Pharmaceutical Strategy to Control Colonic Distribution of the AntiAmebic Drug Susceptible to Metabolism by Colonic Microbes. Drug Des. Devel. Ther. 2017, 11, 419-429.

(17) Liu, J.; Platts-Mills, J. A.; Juma, J.; Kabir, F.; Nkeze, J.; Okoi, C.; Operario, D. J.; Uddin, J.; Ahmed, S.; Alonso, P. L.; Antonio, M.; Becker, S. M.; Blackwelder, W. C.; Breiman, R. F.; Faruque, A. S. G.; Fields, B.; Gratz, J.; Haque, R.; Hossain, A.; Hossain, M. J.; Jarju, S.; Qamar, F.; Iqbal, N. T.; Kwambana, B.; Mandomando, I.; McMurry, T. L.; Ochieng, C.; Ochieng, J. B.; Ochieng, M.; Onyango, C.;

Panchalingam, S.; Kalam, A.; Aziz, F.; Qureshi, S.; Ramamurthy, T.; Roberts, J. H.; Saha, D.; Sow, S. O.; Stroup, S. E.; Sur, D.; Tamboura, B.; Taniuchi, M.; Tennant, S. M.; Toema, D.; Wu, Y.; Zaidi, A.; Nataro, J. P.; Kotloff, K. L.; Levine, M. M.; Houpt, E. R. Use of Quantitative Molecular Diagnostic Methods to Identify Causes of Diarrhoea in Children: A Reanalysis of the GEMS Case-Control Study. Lancet 2016, 388 (10051), 1291-1301.

(18) Tesh, V. L.; Burris, J. A.; Owens, J. W.; Gordon, V. M.; Wadolkowski, E. A.; O’Brien, A. D.; Samuel, J. E. Comparison of the Relative Toxicities of Shiga-like Toxins Type I and Type II for Mice. Infect. Immun. 1993, 61 (8), 3392-3402. 
(19) Muniesa, M.; Hammerl, J. A.; Hertwig, S.; Appel, B.; Brüssow, H. Shiga Toxin-Producing Escherichia Coli 0104:H4: A New Challenge for Microbiology. Appl. Environ. Microbiol. 2012, 78 (12), 40654073.

(20) Lee, M. S.; Koo, S.; Jeong, D. G.; Tesh, V. L. Shiga Toxins as Multi-Functional Proteins: Induction of Host Cellular Stress Responses, Role in Pathogenesis and Therapeutic Applications. Toxins. 2016, pp 1-23.

(21) Wong, C. S.; Jelacic, S.; Hareeb, R. L.; Watkins, S. L.; Tarr, P. I. The Risk of the Hemolytic-Uremic Syndrome after Antibiotic Treatment of Escherichia Coli 0157:H7 Infections. N. Engl. J. Med. 2000, 342, 1930-1936.

(22) Fogolari, M.; Mavian, C.; Angeletti, S.; Salemi, M.; Lampel, K. A.; Maurelli, A. T. Distribution and Characterization of Shiga Toxin Converting Temperate Phages Carried by Shigella Flexneri in Hispaniola. Infect. Genet. Evol. 2018, 65 (April), 321-328.

(23) Carter, C. C.; Fierer, J.; Chiu, W. W.; Looney, D. J.; Strain, M.; Mehta, S. R. A Novel Shiga Toxin 1aConverting Bacteriophage of Shigella Sonnei With Close Relationship to Shiga Toxin 2-Converting Pages of Escherichia Coli. Open Forum Infect. Dis. 2016, 3 (2), ofw079.

(24) Watanabe, M.; Igai, K.; Matsuoka, K.; Watanabe, T.; Yanoshita, R.; Terunuma, D.; Natori, Y.; Miyagawa, A.; Samejima, Y. Structural Analysis of the Interaction between Shiga Toxin B Subunits and Linear Polymers Bearing Clustered Globotriose Residues Structural Analysis of the Interaction between Shiga Toxin B Subunits and Linear Polymers Bearing Clustered Globotriose Residu. Infect. Immun. 2006, 74 (3), 1984-1988.

(25) Takeda, T.; Yoshino, K. I.; Adachi, E.; Sato, Y.; Yamagata, K. In Vitro Assessment of a Chemically Synthesized Shiga Toxin Receptor Analog Attached to Chromosorb P (Synsorb Pk) as a Specific Absorbing Agent of Shiga Toxin 1 and 2. Microbiol. Immunol. 1999, 43 (4), 331-337.

(26) Trachtman, H.; Cnaan, A.; Christen, E.; Gibbs, K.; Zhao, S.; DWK, A.; Weiss, R.; FJ, K.; Spitzer, A.; GH, H. Effect of an Oral Shiga Toxin-Binding Agent on Diarrhea-Associated Hemolytic Uremic Syndrome in Children: A Randomized Controlled Trial. JAMA J. Am. Med. Assoc. 2003, 290 (10), $1337-1344$.

(27) Wittmann, V.; Pieters, R. J. Bridging Lectin Binding Sites by Multivalent Carbohydrates. Chem. Soc. Rev. 2013, 42 (10), 4492-4503.

(28) Fu, O.; Pukin, A. V.; van Ufford, H. C. Q.; Branson, T. R.; Thies-Weesie, D. M. E.; Turnbull, W. B.; Visser, G. M.; Pieters, R. J. Tetra- versus Pentavalent Inhibitors of Cholera Toxin. ChemistryOpen 2015, 4 (4), 471-477.

(29) Armstrong, G. D.; Rowe, P. C.; Goodyer, P.; Orrbine, E.; Terry, P.; Wells, G.; Mackenzie, A.; Lior, H.; Blanchard, C.; The, S.; Diseases, I.; Apr, N.; Armstrong, G. D.; Rowe, P. C.; Goodyer, P.; Orrbine, E.; Klassen, T. P.; Wells, G.; Mackenzie, A.; Lior, H.; Blanchard, C.; Auclair, F.; Thompson, B.; Rafter, D. J.; Mclaine, P. N. A Phase I Study of Chemically Synthesized Verotoxin ( Shiga-like Toxin ) PkTrisaccharide Receptors Attached to Chromosorb for Preventing Hemolytic-Uremic Syndrome Auclair , Brad Thompson, David J . Rafter and Peter N . McLaine Published by : Oxford Univ. J. Infect. Dis. 1995, 171, 1042-1045. 


\section{Appendices}

Nederlandse samenvatting

Publications

Curriculum vitae Acknowledgements 



\section{Nederlandse samenvatting}

Dit proefschrift concentreert zich op multivalente inhibitoren die gebaseerd zijn op koolhydraat liganden en polymere structuren. De ontwerpen zijn gebruikt om ziekten aan te pakken die veroorzaakt worden door bacteriële toxines van het $\mathrm{AB}_{5}$ type, namelijk het cholera toxine en het shiga toxine.

Hoofdstuk 1 geeft een korte algemene inleiding over de rol van koolhydraat-eiwit interacties. Multivalentie als concept is hierin relevant omdat koolhydraten normaliter zwak binden and hun complementaire eiwitten. Multivalentie kan helpen om van zwakke monovalente inhibitoren veel sterkere varianten te maken met hoge aviditeit. Verder wordt het onderwerp cholera toxine geïntroduceerd samen met de belangrijkste mono- en divalente inhibitoren die eerder beschreven zijn. Multivalente cholera toxine inhibitoren zijn gemaakt met o.a. calix[5]arenen, corannulenen, en dendrimeren als basisstructuren. Inhibitoren met een polymeer als basisstructuur worden ook besproken. Het shiga toxine is de andere besproken $\mathrm{AB}_{5}$ toxine die een van de grote veroorzakers is van sterfte van kinderen onder de vijf. Tenslotte worden verschillende shiga toxine inhibitoren beschreven gebaseerd op zowel polymeren en nietpolymeren.

Hoofdstuk 2 gaat over de succesvolle synthese van de verbinding meta-nitrophenyl $\alpha$ galactoside (MNPG) en de koppeling ervan aan verschillende polymeren. MNPG is een belangrijke inhibitor die was ontdekt door Minke et al. We beschrijven de synthese van een versie van MNPG die te koppelen is aan polyacrylamide, dextran en hypervertakt polyglycerol (hPG). Het idee achter de aanpak was dat we moleculen maken die krachtig werken maar ook betaalbaar zijn. Deze worden getest in an ELISA test gebaseerd op GM1 en ook in een test met organoïden. Hoewel alle polymere-MNPG combinaties voldoende krachtig bleken was de hPG-MNPG combinatie de beste. De reden hiervoor lijkt de grootte en de ronde vorm van het construct te zijn en het relatief grote aantal gekoppelde MNPG moleculen per hPG.

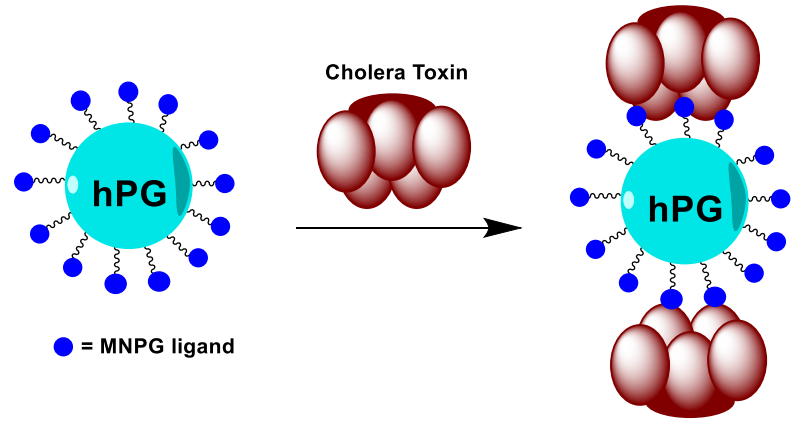

Hoofdstuk 3 onderzoekt nieuwe wetenschap in het cholera gebied die ontdekt heeft dat het cholera toxine niet alleen GM1 gebruikt om te infecteren maar een extra plek heeft die andere 
suikers gebruikt. Deze secundaire bindingsplaats bleek te binden aan gefucosyleerde structuren. Het werd ons doel om een molecuul te make dat beide plekken op het toxine kon blokkeren. Om deze reden werd een hybride construct gemaakt gebaseerd op dextraan waaraan zowel MNPG en fucose werden gekoppeld. Verder werd een ELISA test gebruikt met het fucose-bevattende PAAfucose die het mogelijk maakte om de snel de adhesie door de nieuwe bindingsplaats op het toxine te meten.

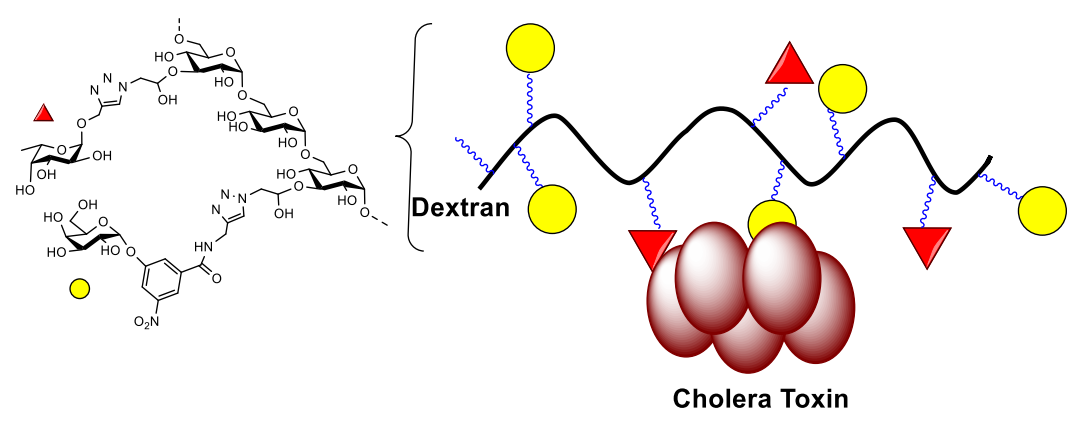

Hoofdstuk 4 concentreert zich op het blokkeren van het shiga toxine door drie klassen van koolhydraat derivaten te bekijken: glycodendrimeren, glycopolymeren en oligosaccharides. Het doel was om een eenvoudige maar wel effectieve blokker van dit toxine te ontwikkelen. Hoewel de $\mathrm{Gb}_{3}$ trisaccharide het natuurlijke ligand is voor de shiga toxine kozen wij ervoor de disaccharide galabiose (Gal $\alpha 1-4 \mathrm{Gal} \beta$ ) te onderzoeken als een mogelijk monovalent alternatief voor Gb3. Wat betreft de dendrimeren werden divalente en tetravalente moleculen vergeleken. Gevonden werd dat tenminste een tetravalente dendrimeer noodzakelijk is om het toxine significant te blokkeren. Wat betreft de polymeren bleek het galabiose conjugaat de beste en zelfs nanomolaire inhibitor. Tot slot, wat betreft de geteste polysacchariden werd gevonden dat zowel alginaat en chitosan in staat waren het toxine te blokkeren en kunnen wellicht nuttig zijn om preventief te werken tijdens een shigella uitbraak.

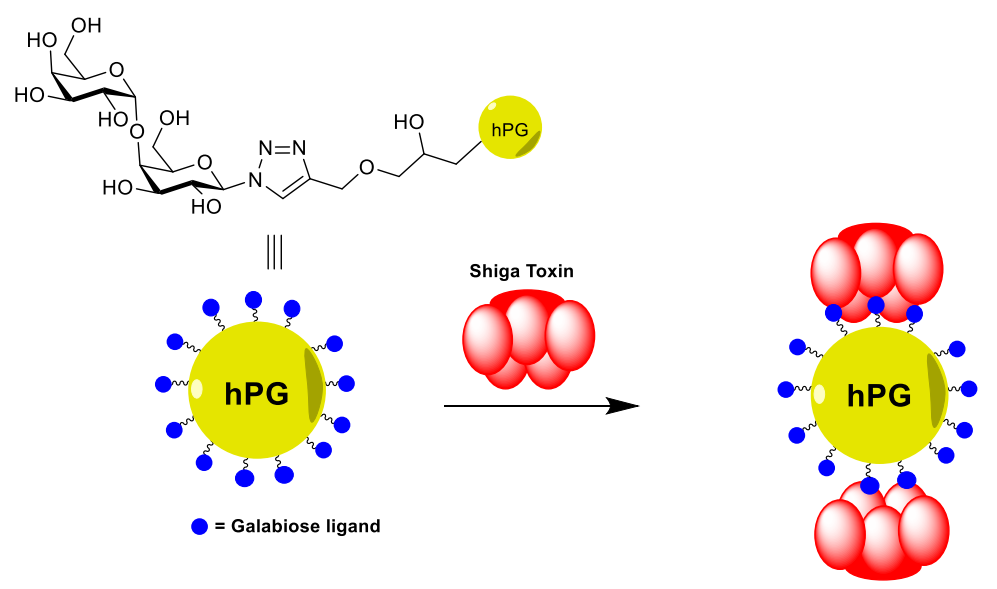


Publications (during PhD)

1. Haksar, D.; Asadpoor M.; Heise T.; Shi J.; Braber S.; Folkerts G.; Ballell L.; Rodrigues J.; Pieters, R. J. Fighting Shigella by blocking its disease-causing toxin. J. Med. Chem., 2021, 64, 6059-6069.

2. Haksar, D.; Quarles Van Ufford, L.; Pieters, R. J. A Hybrid Polymer to Target Blood Group Dependence of Cholera Toxin. Org. Biomol. Chem. 2019, 18 (1), 52-55.

3. Haksar, D.; de Poel, E.; van Ufford, L. Q.; Bhatia, S.; Haag, R.; Beekman, J.; Pieters, R. J. Strong Inhibition of Cholera Toxin B Subunit by Affordable, Polymer-Based Multivalent Inhibitors. Bioconjug. Chem. 2019, 30 (3), 785-792.

4. Lu, W.; Du, W.; Somovilla, V. J.; Yu, G.; Haksar, D.; De Vries, E.; Boons, G. J.; De Vries, R. P.; De Haan, C. A. M.; Pieters, R. J. Enhanced Inhibition of Influenza A Virus Adhesion by Diand Trivalent Hemagglutinin Inhibitors. J. Med. Chem. 2019, 62 (13), 6398-6404.

5. Mahon, C. S.; Wildsmith, G. C.; Haksar, D.; De Poel, E.; Beekman, J. M.; Pieters, R. J.; Webb, M. E.; Turnbull, W. B. A "catch-and-Release" Receptor for the Cholera Toxin. Faraday Discuss. 2019, 219 (0), 112-127.

Seminars given (during PhD)

1. COST ACTION CA18132, Caparica (Portugal), 18-20th Nov 2019; A Hybrid Polymer to Target Blood Group Dependence of Cholera Toxin.

2. CHAINS 2018, Veldhoven (Netherlands), 3-5th Dec. 2018; Strong Inhibition of Cholera Toxin B Subunit by Affordable, Polymer-Based Multivalent Inhibitors.

3. David de Wied colloquium, Utrecht Science Park, 6th Nov. 2018; Strong Inhibition of Cholera Toxin B Subunit by Affordable, Polymer-Based Multivalent Inhibitors. 



\section{Curriculum vitae}

Diksha Haksar was born on 15th March 1987 at Jammu, India. She did her primary schooling in Udhampur and Jammu followed by secondary school at Mumbai. She graduated with a degree in Pharmaceutical Sciences from University of Mumbai in the year 2008. She followed her Bachelor's degree with a Master's degree in Drug Discovery and Drug Development from Panjab University at Chandigarh in 2010. For her Master's thesis, she worked with Late Prof. Anil Kumar (Department of Medicinal Chemistry) and her thesis focused on the synthesis of aldose reductase inhibitors as antidiabetics. She went on to work in pharmaceutical manufacturing (SUN Pharmaceutical Ltd., Mohali) and drug regulatory affairs (Marksans Pharma, Mumbai) followed by two stints in teaching pharmaceutical undergraduates. She did her PhD research with Prof. Roland Pieters at Utrecht University (Chemical Biology and Drug Discovery) that involved the synthesis of multivalent inhibitors against bacterial toxins. Since 2020, she is a postdoctoral researcher at Westerdijk Fungal Biodiversity Institute with Dr. Jerome Collemare (Fungal Natural Products group) where she works on the discovery of novel antimicrobials from the fungal biodiversity.

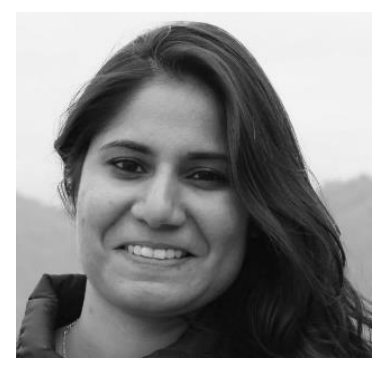





\section{Acknowledgements}

The work described in this thesis is the culmination of all the guidance and support that I received over the years, both within and outside the lab. This section is my attempt at acknowledging and thanking them.

I am grateful to Roland for the opportunity to work in his group. I am grateful for all the freedom that was given to me and it was a pleasure to be able to converse about any and everything. I have gained several valuable insights from our conversations about science and life. I will continue to drop by in the office unannounced...

I am especially grateful to Aliaksei as he gave me my first introduction to sugar chemistry and was willing to listen to and answer my often stupid questions! I cannot thank Aliaksei enough for his help for my first project which was unfortunately a flop and the beginnings of chapter 2 . In the same vein, Linda was my first contact in the biolab who helped me take baby steps in my long journey into bioassays. I am grateful for her generosity in sharing all her accumulated experience with bioassays. Performing experiments in the lab would not be possible without Arwin's help with accumulating glassware, reagents and special apparatus from time-to-time. Like every other chemist, NMR was an integral part of my work and I thank Justyna for her help with setting up new experiments as and when required. I thank Lies and Sjaak from Drug Delivery group for their help with polymer instrumentation and analysis. I could use the IR instrument within the catalysis group and I thank them for this, especially Alessio who showed me the instrument.

Chapter 4 contains significant contributions from Torben and Jie and I thank them for it.

The collaborators at FU, Berlin: Sumati Bhatia and Rainer Haag, collaborators at UMC Utrecht: Eyleen de Poel and Jeffrey Beekman, collaborators within Pharmacology: Adel and Gert Folkerts.

The sugar meetings were an opportunity to learn from my colleagues and hone my speaking skills. The past and present members of the sugar group are acknowledged for this: Cyril, Margherita, Xuan, Guangyun, Nishant, Dania, Suhela, Wenjing, Pouya, Elena, Gabri, Marjon, Nives, Ou, Barbara, Reshmi.

I spent most of my time in the East Lab and I thank my colleagues there for their help with experiments and the maintenance of the lab : Nathaniel and his group members, Minglong, Pieter, Yvette, Helena, Vito, Tim.

I have looked to a lot of people for their expertise and help with my experiments: Apoorva, Javier, Gerlof, Mehman, Lifeng, Lemeng, Xiufen, Frank, Yanyan, Jack, Xianke, Frederik, Hanna, Enrico, Gael, Roosmarijn.

Friday meetings at CBDD were an opportunity to look back at my work and get feedback from the members for which I am extremely grateful. CBDD members: Rob, Dirk, Seino, Geert-Jan, Tom, Bernd.

I am happy and grateful to have Olga and Yanfang as my "parafilms", for their endless support and good times together.

I am grateful to the entire FNP group and people at the Westerdijk for their support: Jerome, Xin, Caroline, Jorge, Trung, Dujuan, Xinxin. 
I thank the people who I got to know during my PhD outside the lab: Anil, Natalia, Lana, Arjan \& Annamieke (+3).

I thank my parents ( B. \& P. Haksar) for raising my B.P. from time to time.. for catering to all my whims when I visit them... my brother ( A. Haksar) for his appreciation of my taste in punjabi music. 
